\title{
Field and Laboratory Investigation of Asphalt Pavement Permeability
}

\author{
by \\ Moustafa Awadalla \\ B.Sc. American University of Sharjah
}

A thesis submitted to the Faculty of Graduate and Postdoctoral Affairs in partial fulfillment of the requirements for the degree of

\author{
Master of Applied Science \\ In \\ Civil Engineering
}

Ottawa-Carleton Institute of Civil and Environmental Engineering

Carleton University

Ottawa, Ontario

(C) 2015, Moustafa Awadalla 


\begin{abstract}
The long-term performance of road pavements is highly dependent upon the construction quality of the newly paved sections. The current assessment method used to evaluate the as-built quality of the newly finished roads utilizes relative density alone which may not necessarily reflect the actual properties that are required in the finished pavement. This research aims to perform comprehensive investigations concerning the hot mix asphalt (HMA) pavement permeability as a potential quality indicator of newly constructed roads. According to the conducted research, it is quite evident that considering the permeability along with relative density in the design mix procedure should provide a better indication and representation of the actual as-built physical condition of the newly constructed HMA road pavements.
\end{abstract}




\section{Acknowledgements}

Foremost, I would like to express all my gratitude to Allah for giving me the spiritual support and strength to accomplish this dissertation successfully.

I would also love to express my deepest and sincere gratitude to each of my dear thesis supervisors, Professor A. O. Abd El Halim and Professor Yasser Hassan, for providing me with all necessary support and guidance throughout my studying period. Their valuable feedback and constructive criticism to my thoughts were behind the success of this research. I would like to extend my honest thanks and appreciation to the examining committee, Professor John A. Goldak and Professor Shawn Kenny, for their comments and feedback on my thesis study.

My deepest appreciation goes to my parents, Samir and Samiah, for supporting me spiritually and financially through this journey. I cannot forget my dear siblings, Ahmed, Hala, Sara, and Mohammed, for all their encouragement and for remembering me in their prayers.

Special thanks go to my colleague Anandkumar Chelliah for providing me with all assistance in collecting the field and laboratory data. Last but not least, I would love to thank my dearest friend and brother, Mohammed Atef, for his support and sincere advice. The financial support provided by the Ministry of Transportation of Ontario (MTO) is highly appreciated and acknowledged. 


\section{Table of Contents}

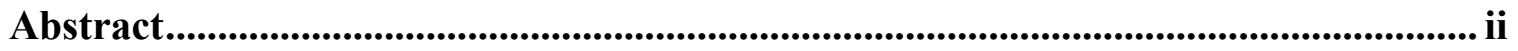

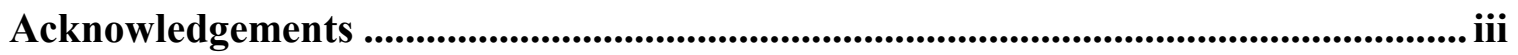

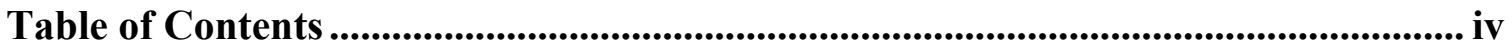

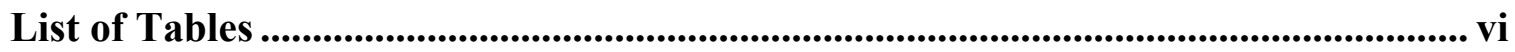

List of Figures............................................................................................................. viii

List of Appendices ................................................................................................................ xii

Chapter 1: Introduction................................................................................................................1

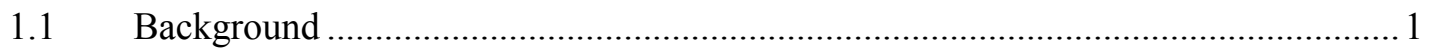

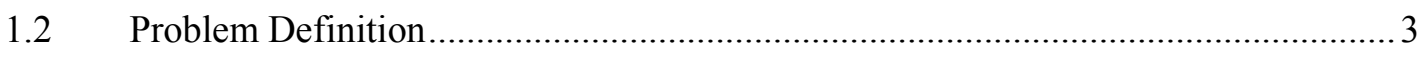

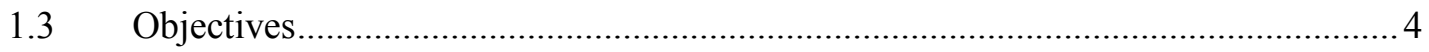

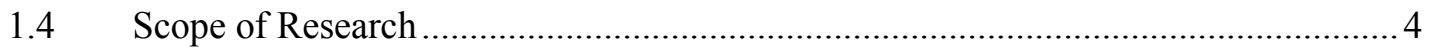

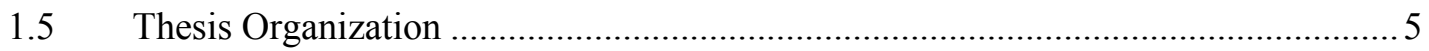

Chapter 2: Literature Review ...................................................................................................6

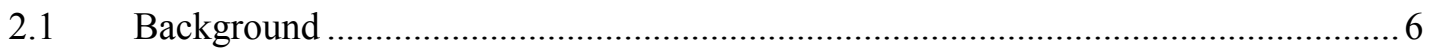

2.2 Theoretical Background of Asphalt Pavement Permeability .................................... 9

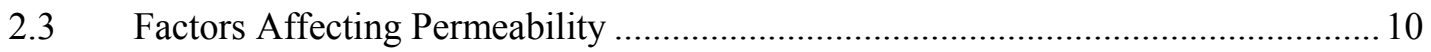

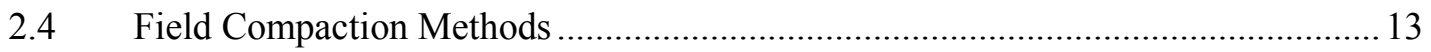

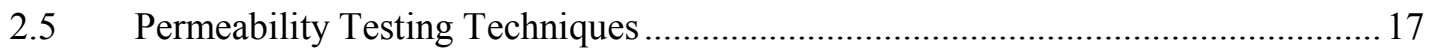

Chapter 3: Experimental Program ...........................................................................................................38

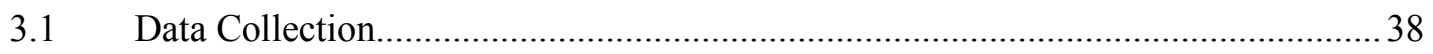

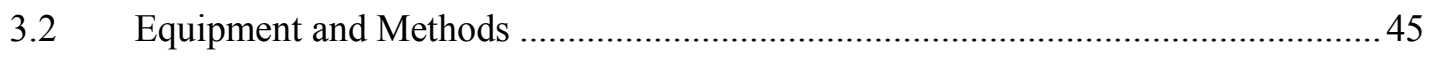

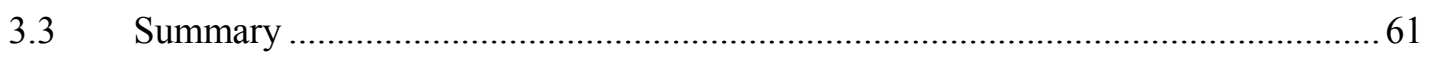

Chapter 4: Results of the Experimental Program ......................................................................62 


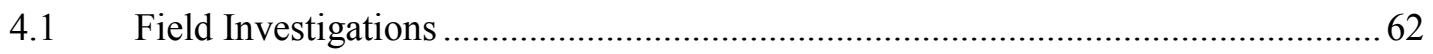

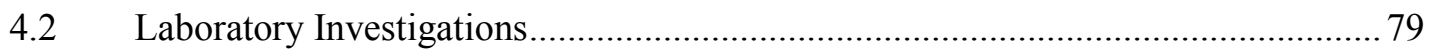

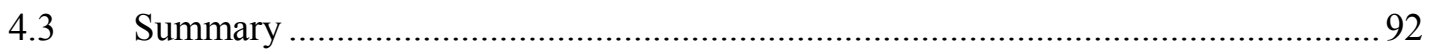

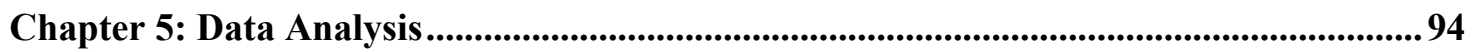

5.1 Physical and Mechanical Properties of Asphalt Pavement ..................................... 94

5.2 Correlations between the Physical and Mechanical Properties .............................. 114

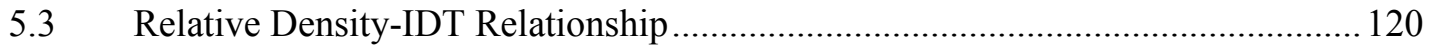

$5.4 \quad$ Relative Density-Permeability Relationship ..................................................... 128

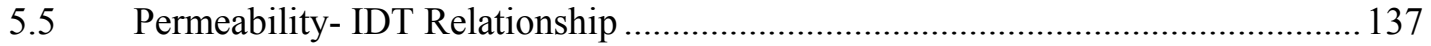

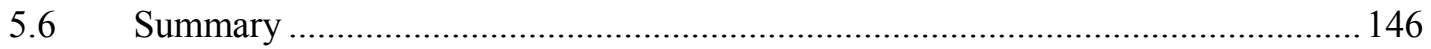

Chapter 6: Conclusions and Recommendations .........................................................149

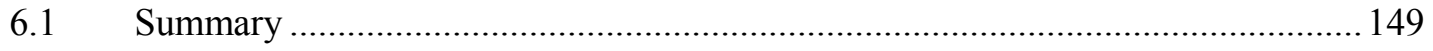

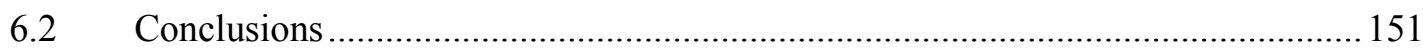

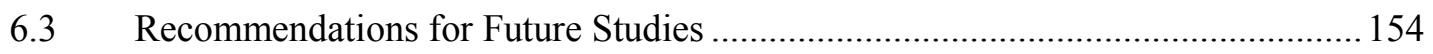

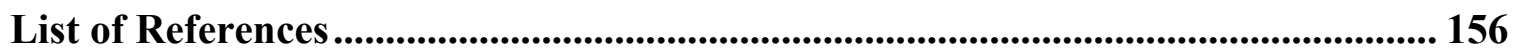

Appendices................................................................................................................................. 162 


\section{List of Tables}

Table 2.1: Pavement Compaction Requirements Based on Relative Density [MTO, 2002] ........... 8

Table 2.2: Comparison Matrix for All the Permeability Devices ............................................... 32

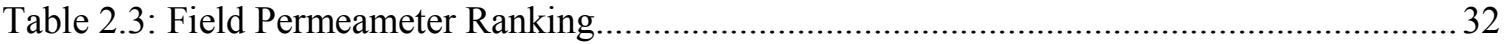

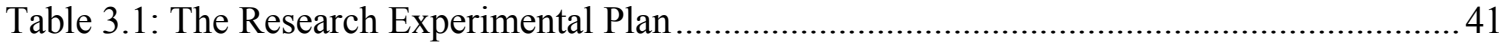

Table 3.2: Superpave Volumetric Mix Design and Properties of the Three Available Mixes.......57

Table 3.3: The Different Compaction Levels of SGC Specimens...............................................59

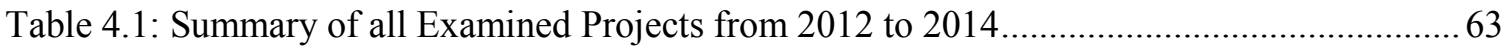

Table 4.2: The Laboratory Results on SGC Specimens for the Four Considered Mixtures ...........80

Table 5.1: Summary of the Relative Density Dataset...................................................................95

Table 5.2: Summary of the Three-Way ANOVA Test Hypotheses............................................... 97

Table 5.3: Summary of the Three-Way ANOVA Results for Relative Density ...........................98

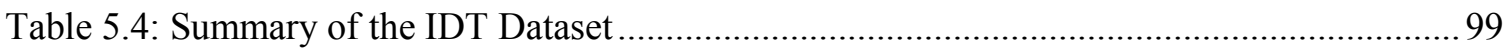

Table 5.5: Summary of the Three-Way ANOVA Results for IDT ............................................. 101

Table 5.6: Summary of One-Way ANOVA Results for Effect of Compaction Method on IDT.101

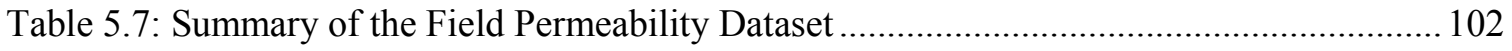

Table 5.8: Summary of the Three-Way ANOVA Results for Field Permeability ....................... 105

Table 5.9: Summary of One-Way ANOVA Results for Effect Compaction Method on Field

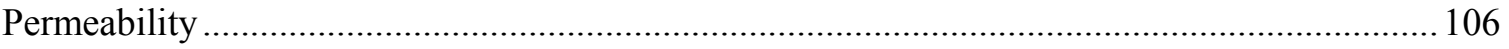

Table 5.10: Summary of the $t$-test Results for Effect of Age and Traffic on Field Permeability 107

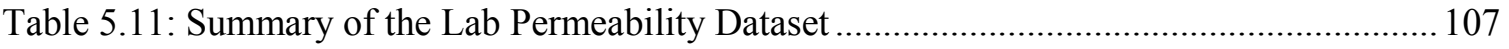

Table 5.12: Summary of the Three-Way ANOVA Results for Lab Permeability ....................... 110

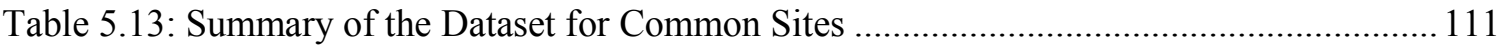

Table 5.14: Summary of the Null and Alternative Hypotheses for Common Sites ..................... 114

Table 5.15: Summary of the One-way ANOVA Results for the common sites ......................... 114 
Table 5.16: Summary of the Correlation Coefficients and $p$-values for SGC Samples.....

Table 5.17: Summary of the Correlation Coefficients and $p$-values for Conventional Method .116

Table 5.18: Summary of the Correlation Coefficients and $p$-values for Advanced Method........ 117

Table 5.19: $t$-test Results for Examining the Difference between the Field and Lab Permeability

Table 5.20: Summary of Linear Regression Model between Field and Lab Permeability 119

Table 5.21: Summary of the Regression Models between IDT and Relative Density (SCG

Specimens).

Table 5.22: Summary of the Regression Models between IDT and Relative Density (Field-

Recovered Cores)

Table 5.23: Summary of the Regression Models between Lab Permeability and Relative Density

(SCG Specimens) 131

Table 5.24: Summary of the Regression Models between Lab Permeability and Relative Density

(Field-Recovered Cores) 133

Table 5.25: Summary of the Regression Models between Field Permeability and Relative Density

Table 5.26: Summary of the Regression Models between Lab Permeability and IDT (SCG

Specimens)

Table 5.27: Summary of the Regression Models between Lab Permeability and IDT (Field-

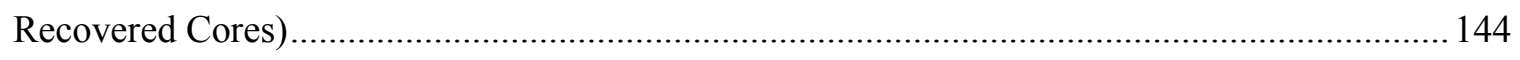

Table 5.28: Summary of the Regression Models between Field Permeability and IDT .............. 146

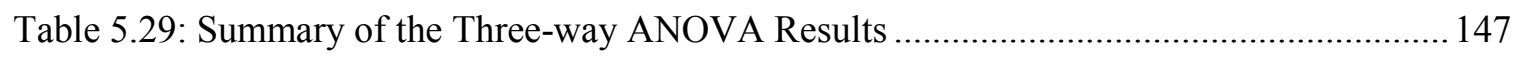




\section{List of Figures}

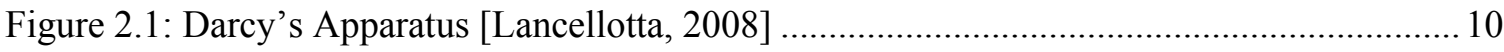

Figure 2.2: Schematic of the Conventional Steel Drum Rolling [Abd El Halim and Mostafa, 2006]

Figure 2.3: Schematic of the Advanced Rolling [Abd El Halim and Mostafa, 2006] 17

Figure 2.4: NCAT Field Permeability Permeameter [Williams, 2006]

Figure 2.5: Kuss Field Permeameter [Williams, 2006] 20

Figure 2.6: Typical Kuss Field Permeameter Data [Williams, 2006] ........................................22

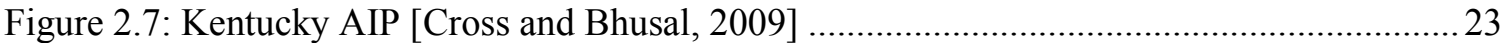

Figure 2.8: Kuss Vacuum Permeameter [Williams, 2006] …........................................................25

Figure 2.9: WPI Modified NCAT Permeameter [Mallick, et al., 2003] .......................................26

Figure 2.10: Marshall Mold Permeameter Paraffin Seal [Cooley, 1999] ......................................2 27

Figure 2.11: Marshall Mold Permeameter Silicon Seal [Cooley, 1999] .........................................28

Figure 2.12: Romus Air Permeameter [Russell, et al., 2005; Retzer, 2008] .................................29

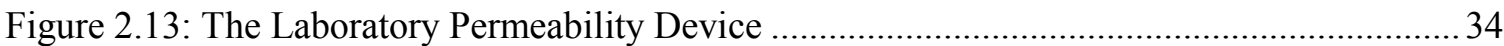

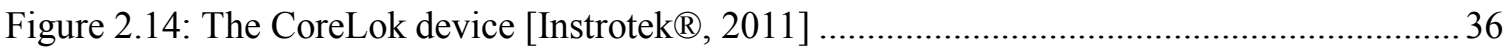

Figure 2.15: The Constant Head Permeameter [Maupin, 2000b] ................................................ 37

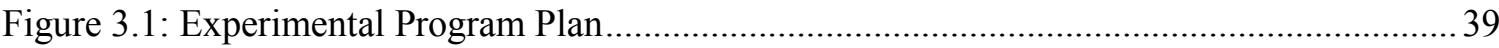

Figure 3.2: Location of Selected Sites in Ontario's Eastern Region [d-maps, 2015] ................... 40

Figure 3.3: In-Situ Permeability Testing Layout ........................................................................ 44

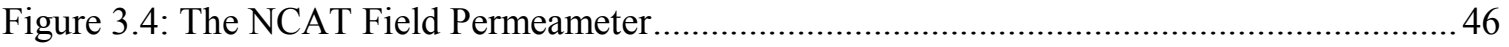

Figure 3.5: In-situ Permeability Test at Highway 16 Project...................................................... 47

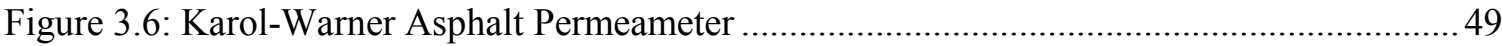

Figure 3.7: Schematic the Lab Permeability Apparatus (Not to Scale) [Florida Test Method, 2012] 


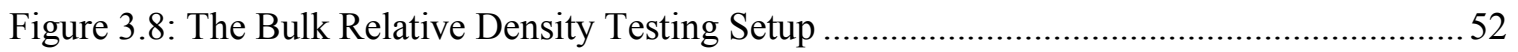

Figure 3.9: The IDT Test on One of the Field-Recovered Cores.................................................54

Figure 3.10: The Laboratory Apparatus Required for SGC Specimen Preparation.......................56

Figure 3.11: Seize Analysis Gradation for the Considered Mixtures ........................................57

Figure 4.1: Field Permeability Result of Tomlinson In-house Field Trial (2012) ........................ 64

Figure 4.2: Field Permeability Result of Thousand Islands Parkway (2012) ...............................64

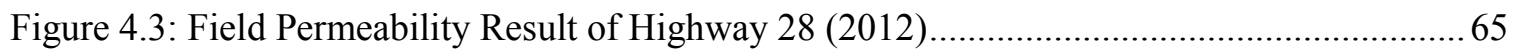

Figure 4.4: Field Permeability Result of Tomlinson In-house Field Trial (2013) ........................66

Figure 4.5: Field Permeability Result of Highway 16 (2013)................................................... 66

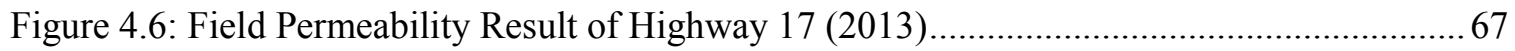

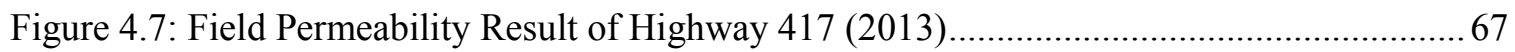

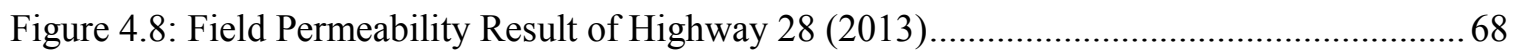

Figure 4.9: Field Permeability Result of Thousand Islands Parkway (2013) ................................. 68

Figure 4.10: Field Permeability Result of Highway 15 before Microsurfacing (2013) ................69

Figure 4.11: Field Permeability Result of Highway 15 after Microsurfacing (2013).................... 69

Figure 4.12: Field Permeability Result of Greenbelt Trial One (2014) ....................................... 70

Figure 4.13: Field Permeability Result of Highway 34 Bridge (2014) ...................................... 71

Figure 4.14: Summary of all 12 Investigated Projects Finished by the Conventional Method ..... 72

Figure 4.15: Field Permeability Result of Thousand Islands Parkway (2012) ............................. 73

Figure 4.16: Field Permeability Result of Tomlinson In-house Field Trial (2012) ...................... 74

Figure 4.17: Field Permeability Result of Highway 28 (2012)................................................. 74

Figure 4.18: Field Permeability Result of Thousand Islands Parkway (2013) ............................ 75

Figure 4.19: Field Permeability Result of Highway 28 (2013)................................................ 75

Figure 4.20: Field Permeability Result of Tomlinson In-house Field Trial (2013) ...................... 76

Figure 4.21: Field Permeability Result of Highway 34 Bridge (2014) ...................................... 77

Figure 4.22: Field Permeability Result of Greenbelt Trial One (2014) …................................... 77

ix 
Figure 4.23: Summary of Projects Compacted by the Advanced Method .78

Figure 4.24: The Average Relative Density Values corresponding to the Four Compaction Levels 81

Figure 4.25: The Average IDT Values corresponding to the Four Compaction Levels .81

Figure 4.26: The Average Permeability Values corresponding to the Four Compaction Levels .. 82

Figure 4.27: Field Coring For the Inner Edge Location at Highway 417 Project......................... 83

Figure 4.28: The Bulk Specific Gravity Results for year 2012 Projects...................................... 85

Figure 4.29: The IDT Results for year 2012 Projects ............................................................. 85

Figure 4.30: The Bulk Specific Gravity Results for year 2013 Projects...................................... 86

Figure 4.31: The Lab Permeability Results for year 2013 Projects ............................................. 87

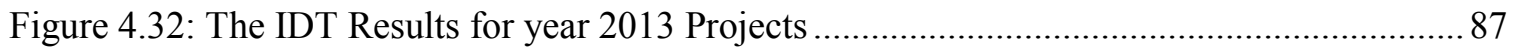

Figure 4.33: The Laboratory Results of The in-house Field Trial at Greenbelt............................. 88

Figure 4.34: The Bulk Specific Gravity Results for year 2012 Projects.................................... 89

Figure 4.35: The IDT Results for year 2012 Projects ............................................................. 90

Figure 4.36: The Bulk Specific Gravity Results for year 2014 Projects..................................... 91

Figure 4.37: The Lab Permeability Results for year 2013 Projects ............................................. 91

Figure 4.38: The IDT Results for year 2014 Projects .............................................................. 92

Figure 5.1: Relative Density vs. Testing Locations (Conventional Method) ..............................96

Figure 5.2: Relative Density vs. Testing Locations (Advanced Method) ....................................96

Figure 5.3: IDT vs. Testing Locations (Conventional Method)............................................... 99

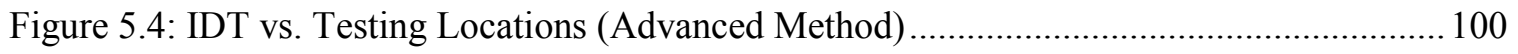

Figure 5.5: Field Permeability vs. Testing Locations (Conventional Method) ............................ 103

Figure 5.6: Field Permeability vs. Testing Locations (Advanced Method) ................................. 104

Figure 5.7: Lab Permeability vs. Testing Locations (Conventional Method)............................ 109

Figure 5.8: Lab Permeability vs. Testing Locations (Advanced Method) ................................. 109 
Figure 5.9: Comparison Between The Compaction Methods In Terms The Four Pavement

Properties 112

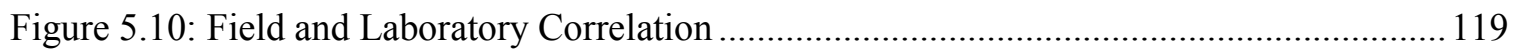

Figure 5.11: The Relative Density-IDT Relationship for SGC Specimens ............................... 121

Figure 5.12: The General Trend of the Relative Density-IDT Relationship for SGC ................ 122

Figure 5.13: The Relative Density-IDT Relationship for Field Cores...................................... 124

Figure 5.14: The Relative Density-IDT Relationship Categorized by Compaction Method....... 125

Figure 5.15: The Relative Density-IDT Relationship for Field Cores (Conventional Method) .. 126

Figure 5.16: The Relative Density- IDT Relationship for Field Cores (Advanced Method)....... 127

Figure 5.17: The Relative Density-Permeability Relationship for SGC Specimens.................... 129

Figure 5.18: The General Trend of the Relative Density-Permeability Relationship for SGC ... 130

Figure 5.19: The Relative Density-Permeability Relationship for Field Cores ........................... 132

Figure 5.21: The Correlation between Relative Density and Field Permeability ........................ 134

Figure 5.21: Field Permeability-Density Relationship Categorized by Compaction Method ..... 135

Figure 5.22: The Relative Density-Permeability Trend for Field Cores and Field Measurements

Figure 5.23: The Permeability- IDT Relationship for SGC Specimens.................................... 138

Figure 5.24: The General Trend of the Strength-Permeability Relationship for SGC................ 139

Figure 5.25: The Permeability- IDT Relationship for All Data Points ...................................... 141

Figure 5.26: The Permeability- IDT Relationship based on Compaction Method ...................... 142

Figure 5.27: The Permeability- IDT Relationship for Field Cores (Conventional Method)........ 142

Figure 5.28: The Permeability- IDT Relationship for Field Cores (Advanced Method) ............. 143

Figure 5.29: The Correlation between IDT and Field Permeability ....................................... 145 


\section{List of Appendices}

Appendix A: ANOVA and $t$-test Results................................... 162

A.1 Relative Density................................................. 162

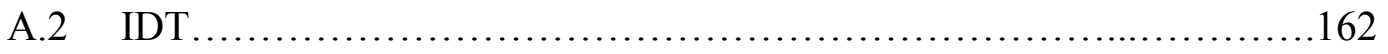

A.3 Field Permeability ........................................................

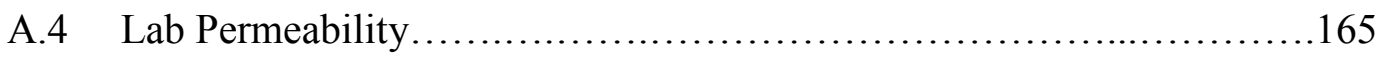

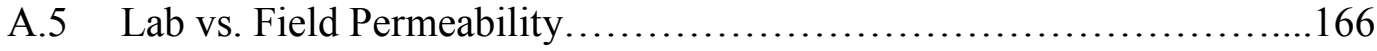

A.6 Comparison between the two compaction methods.......................168

Appendix B: Regression Analysis.................................................. 169

B.1 Relative Density ................................................... 169

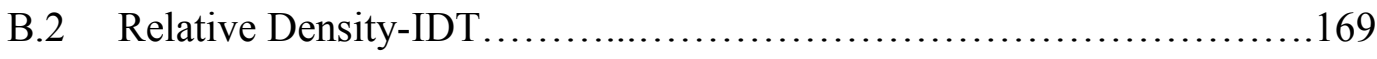

B.3 Relative Density-Permeability ........................................ 171

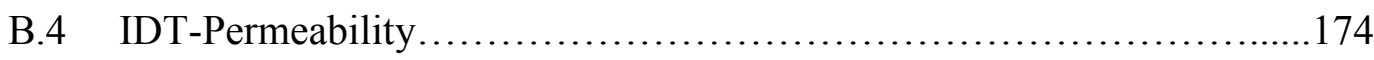




\section{CHAPTER 1: INTRODUCTION}

\subsection{Background}

The Canadian roadway system constitutes a considerable part of the total infrastructure network. There are nearly one million kilometers of both paved and unpaved roads in Canada, where Ontario alone has approximately 200,000 kilometers [Government of Canada, 2012; OHMPA Asphalt Fact Sheet, 2012]. The Canadian economy, environment, and public safety depend highly on how we maintain and monitor such a crucial asset. The design and construction of road pavements consider various factors including, but not limited to, pavement performance, traffic, environment, drainage, and so forth. In general, the newly paved roads are expected to perform for a particular period of time under various traffic loads and environmental conditions. However, it is common to observe failure in these roads after short duration [Rollings and Rollings, 1991]. A general dilemma faced by transportation jurisdictions is that fund dedicated for road rehabilitation and maintenance is inadequate for every deteriorated section. Therefore, it is vital to ensure that the newly built roads are properly designed, constructed, and met the quality assurance/control (QA/QC) specifications. This should in turn maximize the anticipated road service life as well as minimizing the overall rehabilitation cost and maintenance.

Pavement structure is classified in terms of structural characteristics into two main types, flexible and rigid pavement. On one hand, the flexible pavement is made of an asphalt (or bituminous) layer followed down by base, subbase, and subgrade layer. On the other hand, the rigid pavement has Portland cement concrete (PCC) surface course over the subbase and subgrade layers [Garber and Hoel, 2014]. The most common type of flexible 
pavements is the hot mix asphalt (HMA) which can be classified into three main categories; the dense-graded mix, stone matrix asphalt or stone mastic asphalt (SMA), and open-graded [Pavement Interactive, 2010]. The dense-graded mixes, which will be considered in this study, are usually designed under a primary assumption of being relatively impermeable to water and air.

The construction of road pavements incorporates several activities including mix preparation, transportation, placement, and finally compaction. All the aforementioned activities have crucial impacts on the overall long-term performance of road pavements. Among these activities, compaction is the most influential factor governing the long-term performance and durability of the newly constructed road sections [Geller, 1984]. In other words, inadequate compaction efforts are expected to lead to poor pavement performance even if all other essential variables (e.g. mixture design and favorable environmental conditions) were met and achieved. Compaction can be defined as the process by which the volume of air in an HMA mixture is reduced by using external forces [Roberts, et al., 1996]. This reduction in air voids results in increasing the achieved density to fall within an acceptable range set by transportation authorities. Evaluation of compaction quality varies from one road jurisdiction to another depending on the followed test method and its acceptance criteria. In general, the compaction quality can be quantified by two common techniques [Pavement Interactive, 2009]. The first one entails extracting some samples from the paved roadbed; these samples are termed fieldrecovered cores. These cores are then shipped to a materials testing laboratory for density determination. The other approach suggests measuring the in-place density using a nuclear gauge, which is an automated device that sends gamma radiation through 
pavement structure to estimate its density. It is worth mentioning that the second approach is nondestructive, easier, and faster, than the first approach. However, it lacks accuracy and consistency compared to the first approach [Williams, 2006].

\subsection{Problem Definition}

The current practice followed by road jurisdictions, specifically the Ministry of Transportation Ontario (MTO), considers only one pavement property, which is the relative density, to accept or reject the as-built condition of the newly paved roads [MTO, 2004]. The primary assumption of relaying on relative density as an indicator is that road sections with acceptable relative density are more durable and will have better long-term performance. In the as-built condition, acceptable levels of relative density may not be sufficient to represent other important physical properties related to moisture and water infiltration rates. In fact, various pavement failure modes including moisture-induced damage, thermal and fatigue cracking, and potholes were observed at road pavements that were considered accepted according to the current quality control specifications. Consequently, it is not very rational to depend solely on one pavement property to evaluate the newly built HMA road pavements. Alternatively, considering other pavement characteristics could be beneficial in evaluating these new constructed roads and should provide QA/QC engineers with sound understanding of the expected pavement performance in short and long terms. There is no reliable method currently used and adopted by road authorities to quantify the degree or quality of field compaction based on laboratory procedure. There is a need to address the issue of using other pavement properties when assessing the as-built pavement condition in order to ensure attaining the highest possible quality. This new quality indicator(s) should be reliable and 
representative of the actual as-built condition of newly paved roads. In addition, this indicator should be measurable at both environments; the field and laboratory.

\subsection{Objectives}

The main set of objectives of this thesis is broken into three main goals. First and most importantly, this research aims to study HMA asphalt pavement permeability, as an important physical pavement characteristic related more to moisture-induced damages, and compare/relate it to the relative density, the currently adopted quality indicator of newly constructed HMA roads. Additionally, this dissertation is intended to perform extensive field and laboratory investigations in an attempt to explore the possible correlations between important physical (permeability and relative density) and mechanical characteristics of HMA. The study also tries to examine the effect of different factors including testing location, project level, and compaction method on the overall performance of HMA roads in terms of particular physical and mechanical properties.

\subsection{Scope of Research}

The scope of this research is limited and oriented in certain directions to achieve the stated objectives. Firstly, the study considers only HMA road pavements that are newly constructed and other one year in-service roads. These newly paved sections serve the needs of this research by evaluating only the as-built conditions and the short-term performance. Secondly, the research investigates only one type of dense-graded HMA asphalt pavement in terms of the aggregate size, which is $12.5 \mathrm{~mm}$ as it is one of the most commonly used mix type in Ontario. As well, the field data were collected at sites located in Eastern Ontario to minimize the traveling distance needed for field investigations. From laboratory perspective, the study is also limited to four loose asphalt mixtures of 
the same aggregate size, $12.5 \mathrm{~mm}$, provided by the MTO to ensure that these mixtures are the same mixtures studied in the field.

\subsection{Thesis Organization}

This dissertation consists of six chapters. Chapter one introduces the conducted research as well as stating the objectives and research scope. Chapter two describes the topic of HMA permeability in addition to extensively reviewing the most current practices and methods used to measure the HMA permeability. Chapter three describes the adopted field and laboratory experimental program. Chapter four presents the results obtained by performing the field and laboratory investigations. Chapter five shows the conducted analysis along with discussing of obtained results. Chapter six summarizes the findings, conclusions, and recommendations for future research. 


\section{CHAPTER 2: LITERATURE REVIEW}

\subsection{Background}

The Superior Performing Asphalt Pavements (SuperPave) system is initiated in late 80s by the Strategic Highway Research Program (SHRP) to provide the engineers, technicians and highway jurisdictions with a robust philosophy of designing hot-mix asphalt (HMA) pavement. One of the fundamental objectives of such design is to deliver road pavements of high quality, maximum durability, and long term performance with minimum distress issues under different environmental challenges over the pavement lifespan [Pavement Interactive, 2009]. However, it is common to observe various pavement failures that could be attributed to several causes such as the poor mixture design, improper compaction effort, repeated traffic loads, and environmental effects [Neal, 2014]. One of the most serious distresses leading to asphalt pavement failures is the phenomenon known as the moisture induced damage, which is a distress that occurs due to the presence of water within the pavement system and results in destroying the bond within the asphalt mix [Howson, et al., 2009; Caro, et al., 2010].

The existence of trapped water within the pavement structures has led to negative consequences by shortening the designed road service life or increasing the pavement maintenance and rehabilitation costs. Road pavements that have been poorly designed, compacted and/or constructed have higher chances of experiencing moisture related damage which adversely affects the asphalt strength and durability. The possible results of distress problems are moisture-induced cohesive and adhesive damage, fatigue cracking, freeze-thaw failure and/or permanent deformation [Umiliaco and Benedetto, 2013]. These concerns have been well investigated by numerous researchers to quantify 
the adverse effects of different distress problems [Chen, et al., 2004; Pang, 2012; YongRak, et al., 2004]. The pavement structure can also experience raveling, stripping, potholing, and rutting.

The QA/QC are crucial tools for all highway jurisdictions and contractors in order to ensure that the delivered asphalt pavements meet the end-result specifications. While the current $\mathrm{QA} / \mathrm{QC}$ practice in the province of Ontario resulted in improving the overall performance of the Ontario roads, the in-service highway sections are still suffering from distress problems after a relatively short period of time. This means that the as-built pavement conditions were overestimated according to the conventional QA/QC methods for HMA.

Subsequently, there is a need to establish an alternative approach that can objectively assess the as-built pavement conditions and thus ensures that it will meet its projected design life. According to the "Ontario Provincial Standards for Roads \& Public Works Archives: Construction Specification for Hot Mix Asphalt", the pavement compaction effort is measured by the maximum relative density of pavement structure [MTO, 2002]. Table 2.1 shows the accepted and rejected densities in order to evaluate the pavement compaction end results. Relying on the density alone in assessing the pavement quality could be a misleading practice. Several researchers showed that meeting minimum measured densities of finished asphalt pavement projects is not enough as a criterion to guarantee meeting the design service life. Meeting relative densities or specified compaction values of newly constructed asphalt mixes may not reflect the actual defects that exist in the finished pavement [Mostafa, 2005; Abd El Halim and Mostafa, 2006; Abd El Halim, et al., 2009; Brown, et al., 2004; Abd El Halim, et al., 2012; Hammoud, 
2010a; Hammoud, 2010b]. For example, defects such as construction-induced cracks resulting from the use of the current compaction method can lead to high permeability values of the finished surface while achieving the minimum compaction requirements given in Table 2.1.

Table 2.1: Pavement Compaction Requirements Based on Relative Density [MTO, 2002]

\begin{tabular}{cccc}
\hline Mix & Acceptable $\%$ & Borderline $\%$ & Rejectable \% \\
\hline HDBC & 91.0 to 96.5 & 96.6 to 97.5 & $\begin{array}{c}<1.0 \\
>97.5\end{array}$ \\
\hline DFC & 92.0 to 97.5 & 97.6 to 98.5 & $\begin{array}{c}<92.0 \\
>98.5\end{array}$ \\
\hline All Other Mixes & 92.0 to 96.5 & 96.6 to 97.5 & $\begin{array}{c}<92.0 \\
>97.5\end{array}$ \\
\hline HDBC: Heavy Duty Binder Course, DFC: Dense Friction Course
\end{tabular}

Clearly, a new assessment tool that is simple, effective and reliable should be established to be part of the QA/QC tools used by engineers and practitioners. This assessment method should be capable of indicating the expected pavement performance in short and long terms. Permeability was found to be better indicator of pavement durability as opposed to density [McLaughlin and Goetz, 1955]. In recent years, numerous research work has been performed in a number of states such as Georgia, Virginia, Florida, Iowa, and Oklahoma in an attempt to establish testing methods for measuring the initial permeability as a quality indicator of newly paved highways and develop acceptance criteria limits [Tarefder and Ahmed, 2014; Mogawer, et al., 2002; Maupin, 2000a] [Choubane, 1998; Owusu-Ababio and Schmitt, 2009]. Studies have shown that the coefficient of permeability is an important pavement property that can be used as an indicator for the pavement's performance over time [James, et al., 2004; Maupin, 2000a; Cooley, et al., 2001]. 


\subsection{Theoretical Background of Asphalt Pavement Permeability}

The permeability (hydraulic conductivity) is the property that describes how water flows through particular porous medium. Usually, the permeability is represented by the coefficient of permeability $(k)$ which is the constant of proportionality of the relationship between the flow velocity and hydraulic gradient between two points in a particular porous medium [Garber and Hoel, 2014]. The permeability of any porous medium can be explained by the early work done by the French engineer Henry Darcy in 1856. Darcy's Law explains the term hydraulic conductivity in an experimental framework as shown in Figure 2.1. Darcy's law was an attempt to develop a water purification system using the sand as the medium [Darcy, 1856]. Darcy's Law statement is that the discharge velocity of the fluid is directly proportional to the hydraulic gradient. Equation 2.1 represents Darcy's Law as follows:

$$
Q=K\left(\frac{\Delta h}{L}\right) A
$$

where:

$K=$ proportional factor called hydraulic conductivity or permeability coefficient, $Q=$ rate of flow (volume of water per unit time), $A=$ cross-sectional area perpendicular to the flow direction, $\Delta h=$ change in the hydraulic head, and $L=$ length of flow. 


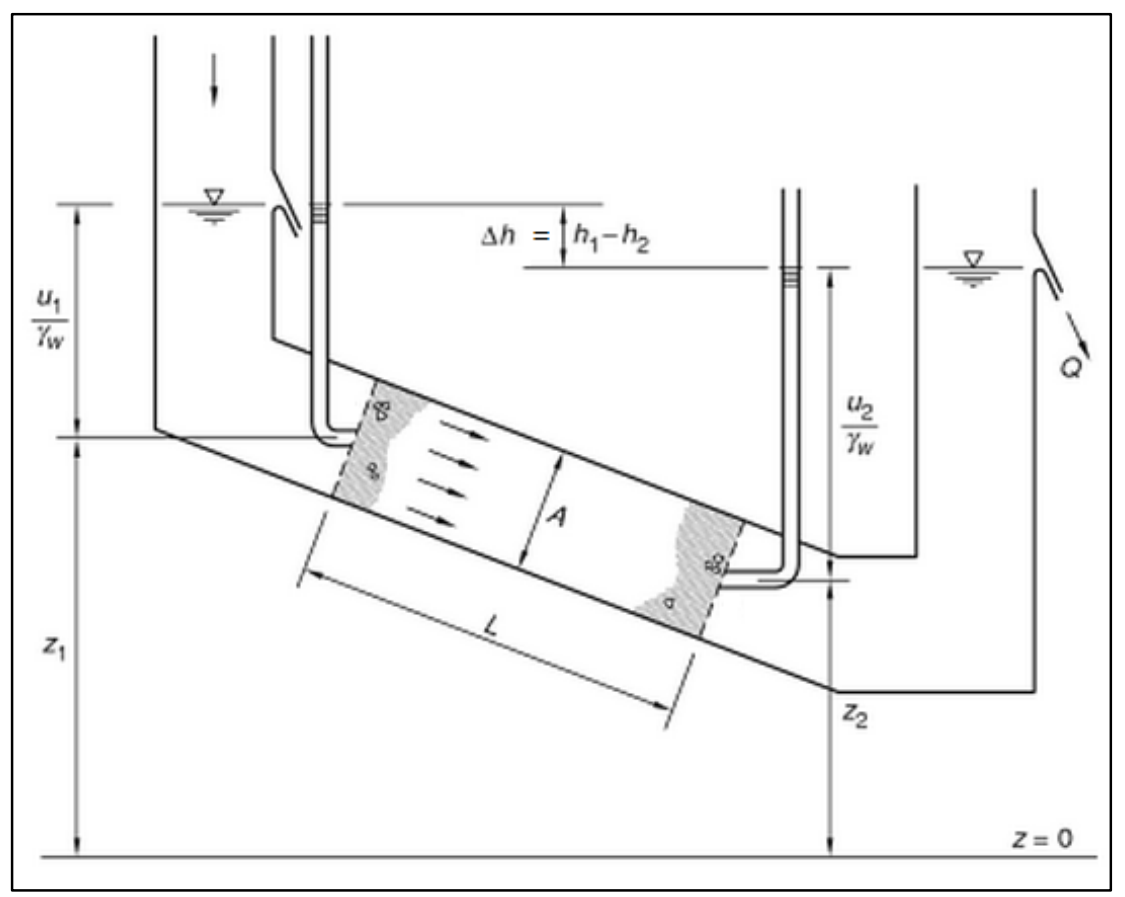

Figure 2.1: Darcy's Apparatus [Lancellotta, 2008]

By deploying Darcy's Law, the permeability coefficient can be estimated using two different testing techniques; the falling head and the constant head. In the literature, it has been found that the constant head test is more applicable to the more permeable media such as sand where the hydraulic conductivity is greater than $10^{-2} \mathrm{~mm} / \mathrm{sec}$. However, the falling head test is more appropriate for less permeable materials such as asphalt layers of a given pavement structure where the hydraulic conductivity is between $10^{-2} \mathrm{~mm} / \mathrm{sec}$ and $10^{-5} \mathrm{~mm} / \mathrm{sec}$ [Russell, et al., 2005].

\subsection{Factors Affecting Permeability}

\subsubsection{Density/Interconnected Air Voids}

In the literature, it has been found that the most prominent factor that influences the permeability coefficient is the content of interconnected air voids [McLaughlin and Goetz, 1955; Zube, 1962; Rajib, et al., 2003; Brown et al., 2004]. The air voids content and density are inversely related in a way that as the air voids content increases, the 
density decreases and vice versa. Unlike the interconnected air voids, the isolated voids do not really correlate with high permeability coefficient as there are no flow channels where the water can penetrate through. In other words, a pavement structure has the potential to be impervious even when having some air voids within it.

While Zube suggested that the dense-graded asphalt pavement experiences an excessively high permeability rates at air voids more than $8 \%$, or a relative density value less than $92 \%$ of the theoretical maximum density [Zube, 1962], others concluded that high permeability coefficient exists even when providing acceptable air voids in field (5\% to 7\%) [Brown, et al., 2004]. Other researchers showed that the as-built density for densegraded asphalt mixtures should not be more than $97 \%$ and not less than $92 \%$ of the theoretical maximum density [Roberts, et al., 1996]. Evidences suggested that very high as-built density, which can be caused by improper mix design, contributes to rutting and shoving. Alternatively, low as-built density, which is the result of poor surface compaction, allows more water and air to infiltrate through the pavement structure. This excessive infiltration is considered to be a major contribution to the raveling, cracking, moisture damages, and oxidation [Brown, et al., 2004].

In contrast, the coarse-graded asphalt mixtures behaved differently when it was investigated by the Florida Department of Transportation to identify the air voids percentage at which the pavement structure becomes excessively permeable. It was found that sometimes the coarse-graded mixes experience high permeability rates even when the air voids are below 8 percent [Choubane, et al., 1998]. This means, the coarse-graded mixes would have higher permeability coefficients than the dense-graded mixes for a particular air void content [Brown, et al., 2004]. This is likely the result of the different 
contents of interconnected air voids in both types of mixes where coarse-graded mixes will likely have more interconnected air voids than dense-graded mixes.

\subsubsection{Nominal Maximum Aggregate Size and Lift Thickness}

Several attempts were carried out to relate the permeability to both the nominal maximum aggregate size (NMAS) and the lift thickness. In a study conducted by Cooley et al. on two coarse-graded mixtures with different NMAS and possessing the same air void percentage had different permeability values [Cooley, et al., 2002]. Similar conclusion was reported by the National Center for Asphalt Technology (NCAT) [Mallick, et al., 2003]. The ratio between the lift thickness and the NMAS influences particular mixes; however, this ratio does not correlate with permeability values [Vardanega, 2014]. Mohammad et al. observed a trend where permeability decreases with the increase of lift thickness for lifts greater than $60 \mathrm{~mm}$ [Mohammad, et al., 2003] Brown et al. concluded that low air voids content in the pavement structure can be achieved when the ratio between lift thickness to the NMAS (t/NMAS) is high [Brown, et al., 2004].

\subsubsection{Surface Texture}

Few researchers have studied the relationship between air voids, permeability and surface texture on Portland cement concrete pavement, however; there is lack of research concerning the relationship between the permeability and its surface texture in asphalt pavement area. The conclusions of previous studies suggest that low air voids content can be correlated to a smoother surface and thus less permeable pavement structure [Vardanega, 2014]. However, due to the fact that the texture of different asphalt roads is 
currently achieved using the same compaction technology, a scientific assessment of this factor is not currently possible.

\subsection{Field Compaction Methods}

In the literature, compaction is defined as the process by which the volume of air in an HMA mixture is reduced by using external forces to reorient the constituent aggregate particles into a more closely spaced arrangement [Roberts, et al., 1996]. Reducing the air voids will in turn result in increasing the HMA density level. This dissertation studied two field compaction equipment that are designed and operated based on different principles. In this research, the term "conventional" refers to the current compaction methods, while the term "advanced" refers to a recent developed compaction technology.

\subsubsection{Conventional Compaction Methods}

The currently common practice followed by HMA community to compact new roadways is carried out using three basic pieces of self-propelled equipment of different functions. These equipment are, the steel static wheeled roller, pneumatic tire roller, and vibratory static wheeled roller. First, a paver screed places the HMA over the road base course. Then, the steel wheeled roller passes over the placed mix to apply the required compressive forces and achieve the desired relative density. In general, the steel roller (static or vibratory) has a roller diameter that ranges between 20 and 60 inches, while the roller width ranges from 35 to 85 inches [Pavement Interactive, 2009; Abd El Halim, et al., 2013]

\subsubsection{A Static Steel Wheel Roller}

The static roller is either two or three-wheel of variety of shapes and weights. The threewheel roller weighs $13600 \mathrm{~kg}$ and has two rear wheels of the same diameter and width, 
while the front wheels have different diameter and width compared to the two rear wheels [Geller, 1984]. These types of rollers have the potential to apply high pressure because of the large rear wheels. Since there is a difference in both the diameter and width between the front and wheels, this will possibly cause inconsistency and variability in compaction progression [Huerne, 2004]. On the other hand, the two-wheel roller has similar width and diameter in the front and rear wheels. It had been suggested that the actual compactive effort is dependent upon the contact pressure between the roller and the compacted asphalt layer [Roberts, et. al., 1996]. Also, the contact pressure depends upon the penetration depth in a way that as the penetration depth increases, the contact area increases, and in turns the contact pressure decreases.

\subsubsection{B Vibratory Steel Wheel Roller}

Unlike the static rollers, the vibratory rollers are produced in two-wheel design and can be used in static or vibratory mode depending on the need. The roller vibrating frequency ranges between 15 and $20 \mathrm{~Hz}$ [Maher, et al., 1999]. Compared to the static rollers, the vibratory ones are much more effective since it requires less number of passes to achieve the desired relative density. It is believed that the relative density increases as the vibration reduces the internal and mechanical friction in the mineral mix [BOMAG Fayat Group, 2009]. This reduction yields to an increase in the mechanical interlock later on [Roberts, et al., 1996]. However, the vibratory rollers require high skilled operator to avoid poor compaction. In particular, improper selection of the dynamic force level (represented by the amplitude and frequency), compaction speed, number of passes, or combination of them can considerably affect the end-results of the paved section. This attributed to the fact that applying heavy and dynamic load on a soft material (asphalt 
mix) will likely cause shearing of the material if improper compaction efforts is achieved [Huerne, 2004].

\subsubsection{Pneumatic-Tired Rollers}

The pneumatic tires roller is used in the intermediate phase between the vibratory/static roller and the static finish roller. These rollers are designed in such a way that the steering/oscillating axle is located at the front and while a rigid drive axle is located at the rear [BOMAG Fayat Group, 2009]. Typically, the roller can have 4, 5, 6, or 7 tires in front while having 3, 4, 5, or 6 at the rear. In general, pneumatic roller is intended to increase the relative density which cannot be achieved in many situations by the steel roller alone, remove the possible checking caused by the steel roller, and provide higher degree of uniformity in terms of compaction [Huerne, 2004].

\subsubsection{Advanced Compaction Technology/ Asphalt Multi-Integrated Roller II (AMIR-II):}

The mismatching in rigidities between the compacted structural systems (soft asphalt mistrial) and the compacting equipment of high stiffness (steel roller) during field compaction were suggested by Abd El Halim to be the main deficiency in the current compaction methods [Abdel Halim, 1986][ Abdel Halim, 1985]. This deficiency has contributed to produce what is known as the construction induced cracks or hairline cracks. These are surface cracks that are perpendicular to the rolling direction. In an attempt to minimize the mismatch in rigidities, the Asphalt Multi-Integrated Roller II (AMIR-II) prototype was introduced and designed by Carleton University and the National Research Council of Canada in 1989 [Abd El Halim, et al., 2013]. AMIR is a self-propelled roller that has two drums connected with a multilayered belt made of 
specialized rubber to create one flat surface of approximately $3 \mathrm{~m}^{2}$. This large contact area as well as the flexibility of the rubber belt minimize the mismatch in rigidity to the asphalt surface. Although the large contact area yields less applied pressure at $41.6 \mathrm{KPa}$ compared to the conventional compaction methods of $1.38 \mathrm{MPa}$, the load duration for AMIR roller is 30 longer than steel roller at the same rolling speed. The longer contact duration in addition to the larger contact area provides uniformity in terms of load distribution over the asphalt mat. This in turns minimize the horizontal forces while increasing the degree of confinement during field compaction. In addition, the uniform load distribution allows visco-plastic flow of asphalt which ensures proper expulsion of the possible entrained air. These aforementioned mechanisms have eliminated the hairline cracks, achieved tighter asphalt surface of low permeability, and increases pavement strength and resistance to fatigue damage [Abd El Halim, et al., 2013]. Figure 2.2 and Figure 2.3.illustrate the two compaction methods; the conventional and advanced respectively.

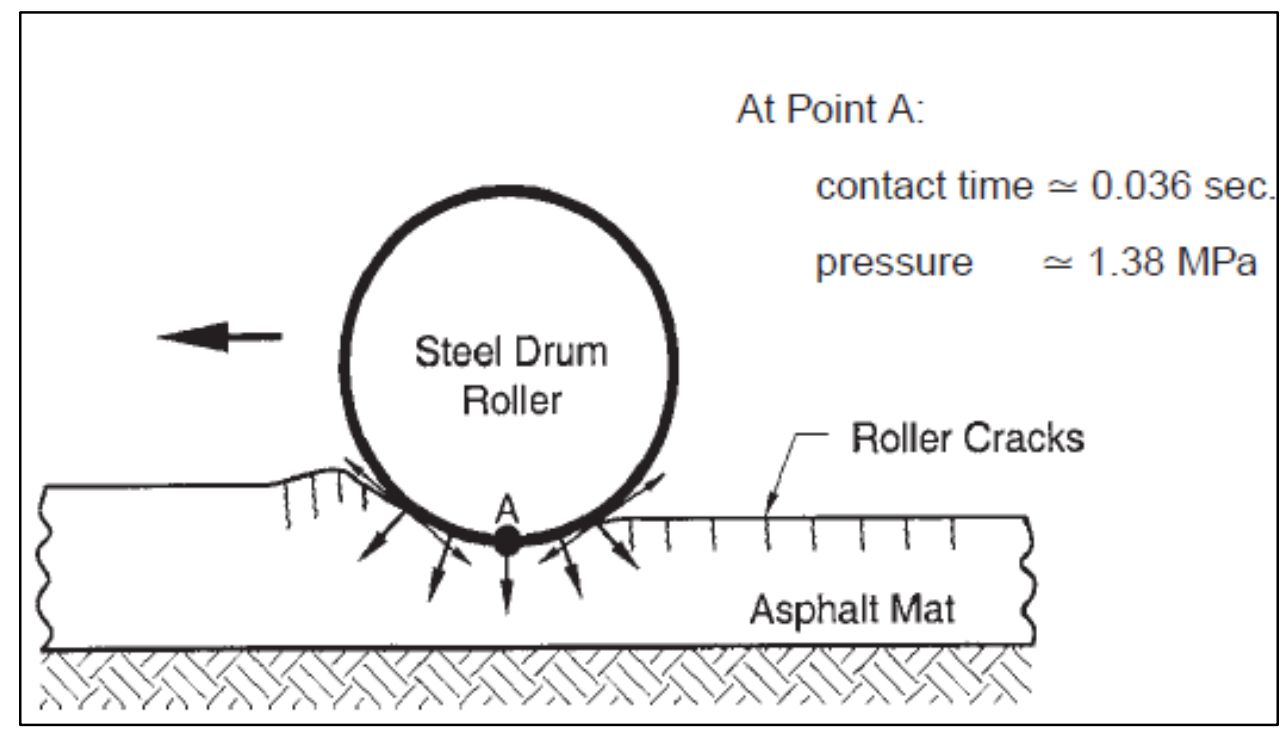

Figure 2.2: Schematic of the Conventional Steel Drum Rolling [Abd El Halim and Mostafa, 2006], used with permission. 


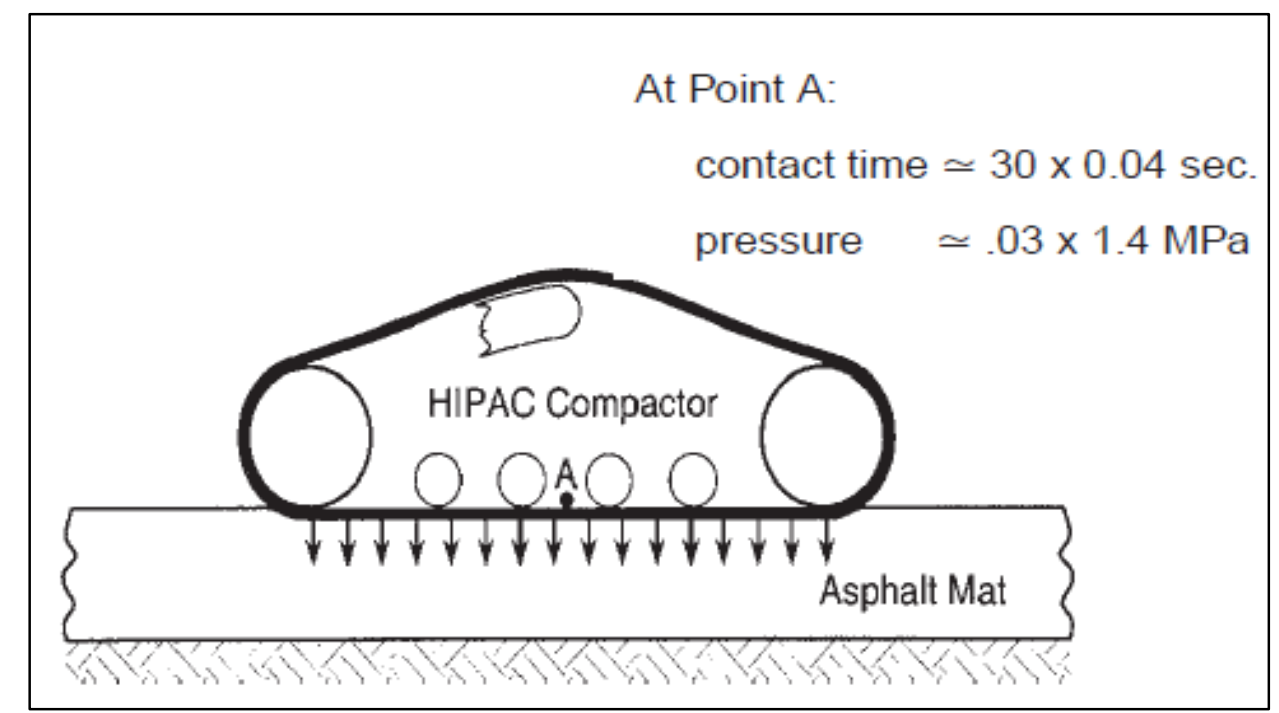

Figure 2.3: Schematic of the Advanced Rolling [Abd EI Halim and Mostafa, 2006], used with

permission

\subsection{Permeability Testing Techniques}

A number of devices and mechanisms are available in the literature for researchers and practitioners to determine the pavement hydraulic conductivity (permeability). Some apparatuses utilize the water as the fluid that will go through the pavement medium such as the NCAT permeameter, others uses the air as the penetrating fluid such as the Kentucky Air Induced permeameter [Allen, et al., 2003]. The techniques which some devices are based on could also differ; the NCAT for example is based on the falling head concept while the Kuss permeameter follows the constant head technique [Williams, 2006; Zaniewski and Yan, 2013; Hall, 2004]. This section of the literature is intended to present the most common techniques to measure the pavement permeability to date. Also, an evaluation and ranking of different field permeability testing methods will be carried out in order to prioritize devices in terms of their practicality. 


\subsubsection{Field Devices}

\subsubsection{A NCAT Field Permeameter}

In late 1990s, the NCAT developed a simple apparatus to measure the hydraulic conductivity of the pavement. The falling head principle is applied through the three tiers of the NCAT Permeameter. Although this approach of finding the permeability is not well standardized, it has been utilized to evaluate the pervious asphalt and thin layers of open graded asphalt on impermeable pavements [Li, et al., 2013]. Conceptually, this method follows Darcy's Law to measure the water flow rate seeping through the pavement structure. The apparatus consists of four standpipes of different inside diameters designed in such a way that the largest is at the bottom and the smallest is at the top as shown in Figure 2.4. The hierarchical arrangement of the apparatus is intended to provide the user with different levels of measuring the permeability. Generally, the high-permeable pavement will be determined through the bottom tier and vice versa [Williams, 2006].

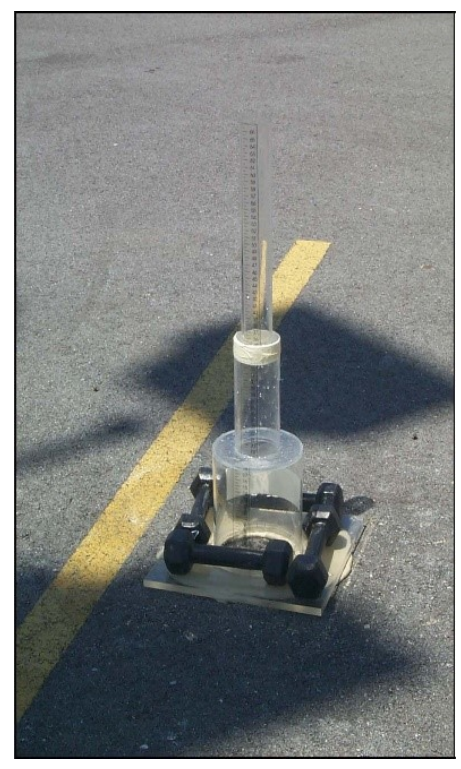

Figure 2.4: NCAT Field Permeability Permeameter [Williams, 2006], used with permission 
The area of the testing spot, which is one square foot, needs to be swept to ensure a clean surface with no debris or dust particles. This will enhance the sealing between the bottom of the device and the pavement surface. After placing the apparatus on ground, equal weights are added on the square base to avoid the escape of water outside the tested point.

The standpipe is filled with water till the top. The water starts to gradually drop down depending on the permeability of the pavement layer. If the speed of the water drop is fast, that indicates that the asphalt layer has a relatively high coefficient of permeability and vice versa. The time taken for the water to drop between two marked graduations within a particular tier should be recorded. Then, the coefficient of permeability is calculated using Equation 2.2 as follows:

$$
K=\frac{a L}{A t} \ln \left(\frac{h_{1}}{h_{2}}\right) t_{c}
$$

Equation 2.2

where:

$K=$ coefficient of permeability $(\mathrm{mm} / \mathrm{sec})$,

$a=$ inside cross-sectional area of standpipe $\left(\mathrm{mm}^{2}\right)$,

$L=$ thickness of the asphalt layer (mm),

$A=$ cross-sectional area in contact with water during the test $\left(\mathrm{mm}^{2}\right)$,

$\mathrm{hl}=$ initial head $(\mathrm{mm})$,

$h_{2}=$ final head $(\mathrm{mm})$, and

$t_{c}=$ temperature correction for viscosity of water $\left(20^{\circ} \mathrm{C}\right.$ is used as the standard $)$.

\subsubsection{B The Kuss Constant Head Field Permeameter}

The Kuss Constant Head Field permeameter or The University of Arkansas (UAF) device was developed in 2003 by the researcher Mark Kuss at The University of Arkansas 
[Williams, 2006; Zaniewski and Yan, 2013; Hall, 2004]. Unlike the NCAT field permeameter, the Kuss permeameter is designed based on the constant head method. In order to perform the test, the device is sealed with the pavement surface, and then the water is added to the standpipe to penetrate into the pavement surface by approximately half an inch $(12.5 \mathrm{~mm})$. The water level in the standpipe drops gradually as the water infiltrates into the pavement structure. The device has a water-level sensor linked to a flow meter valve as shown in the schematic of the device in Figure 2.5.

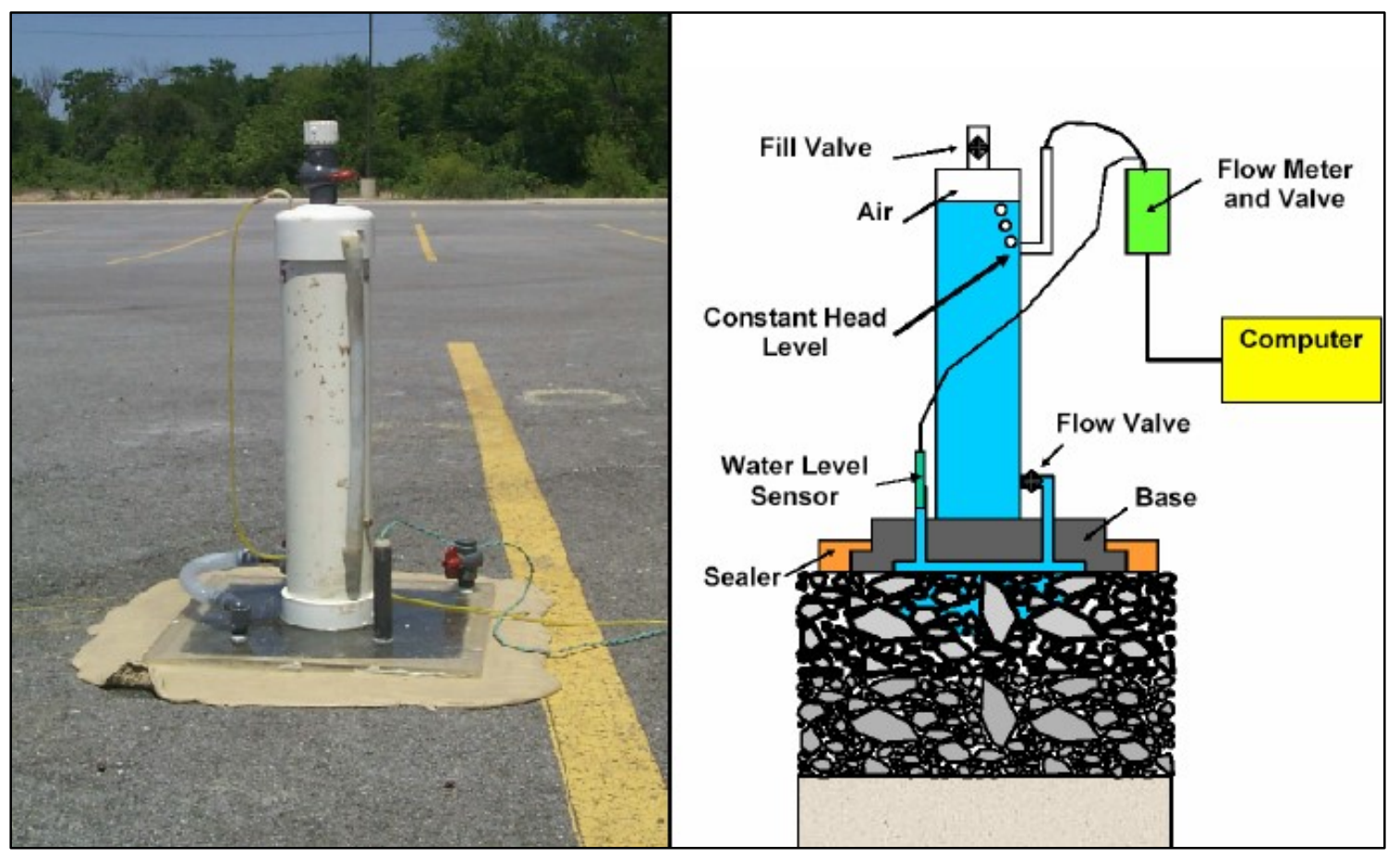

Figure 2.5: Kuss Field Permeameter [Williams, 2006], used with permission

The flow meter valve allows a metered volume of air to enter the standpipe of the device. By assuming that the metered amount of air is equivalent to the volume of water flowing into the pavement, a constant head pressure can be attained throughout the test. The permeability could be calculated by the following general equation:

$$
k=\frac{\text { flow rate }}{\left(\frac{\text { constant head height }}{\text { pavement thickness }}\right) \times \text { area }}
$$


The water flow rate which is measured over time by a data acquisition system in the device, the pavement cross-sectional area, and the pavement thickness are the needed parameters to calculate permeability as presented in Equation 2.4.

$$
k=\frac{Q}{60 \times \frac{25.4+L}{L} \times A}
$$

where:

$K=$ coefficient of permeability $(\mathrm{mm} / \mathrm{s})$,

$Q=$ flow rate $\left(\mathrm{mm}^{3} / \mathrm{min}\right)$

$A=$ area of base plate $\left(126450 \mathrm{~mm}^{2}\right)$,

$L=$ pavement thickness $(\mathrm{mm})$,

$60=$ conversion factor from minutes to seconds, and

$25.4=$ conversion factor from inch to millimeter.

Since the device is connected to a computer, the results of the flow rate could be generated automatically after conducting the test. A typical result is shown is Figure 2.6. Normally, the steady-state flow condition will be achieved after a time period ranging from 15 to 30 minutes. 


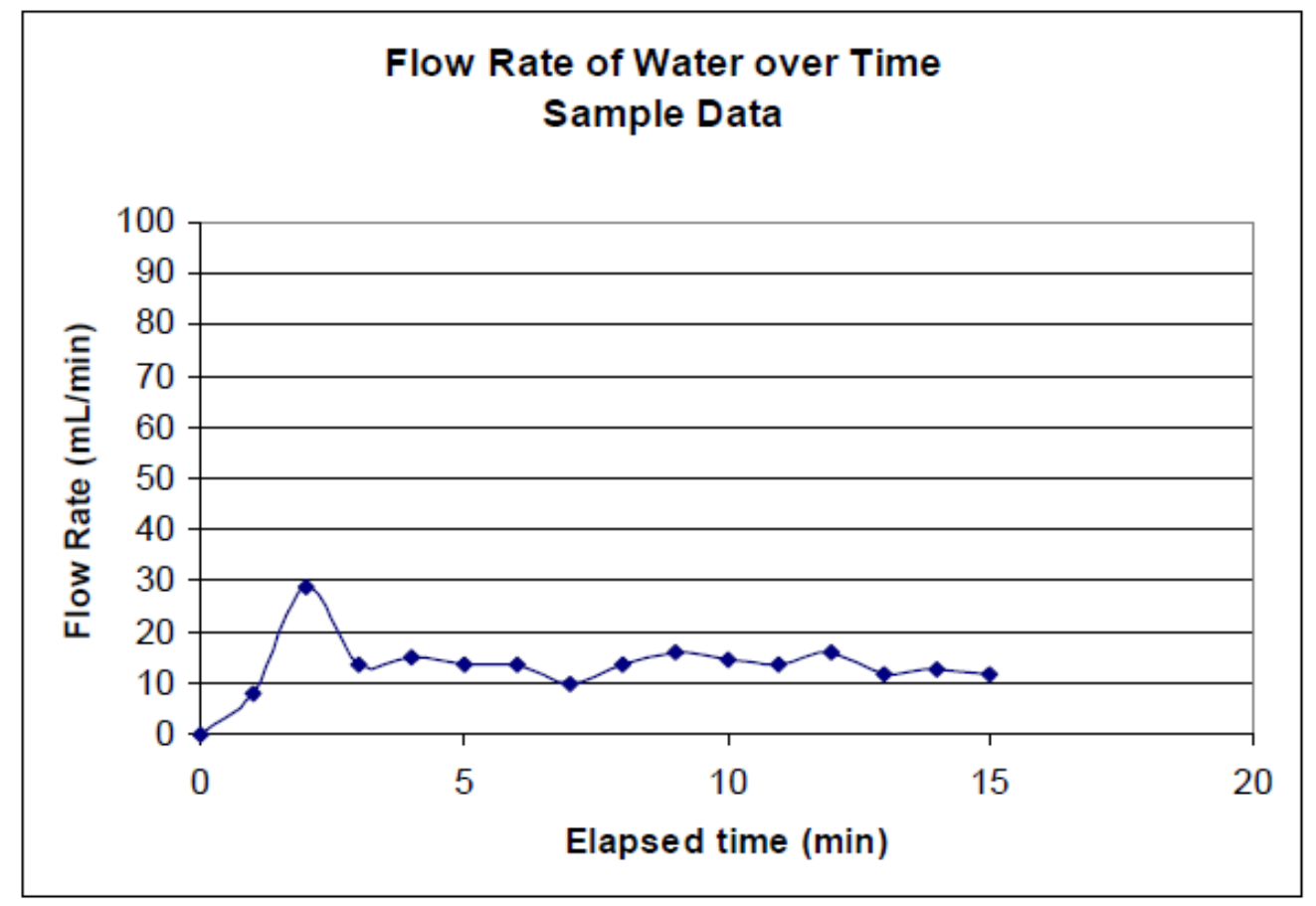

Figure 2.6: Typical Kuss Field Permeameter Data [Williams, 2006], used with permission

\subsubsection{Kentucky Air Induced Permeameter (AIP)}

The Kentucky Transportation Center developed the Kentucky Air Induced permeameter

Figure 2.7) to measure the pavement permeability. The device has been developed and calibrated based on both field and laboratory studies on construction projects in Kentucky [Allen, et al., 2003]. Kentucky Method 64-449-05 described the components, their functions, and the steps to determine the pavement permeability using the AIP. The AIP has the following parts: vacuum chamber, sealing ring, multi-venturi vacuum cube, digital gage, Air compressor, caulking gun, and caulk [Kentucky-Method-64-449-05, 2004]. The testing area under the AIP is around $50 \mathrm{in}^{2}$. The recommended sealing material is silicone-rubber, and the width of the sealing ring is 3 inches to prevent air leakage. The advantage of the AIP lies in its self-sealing mechanism that could be achieved by using a vacuum. A constant pressure of $68 \pm 3$ psi can be reached by the 
multi-venturi vacuum cube along with the air compressor [Zaniewski, et al., 2013]. The permeability of the pavement could be measured by drawing the air through the pavement under the testing area. The following formula is used to calculate the permeability [Allen, et al., 2003]:

$$
\mathrm{k}=25,757.53 \times \mathrm{V}^{-1.556}
$$

where:

$K=$ permeability (ft /day), and

$V=$ vacuum reading $(\mathrm{mmHg})$.

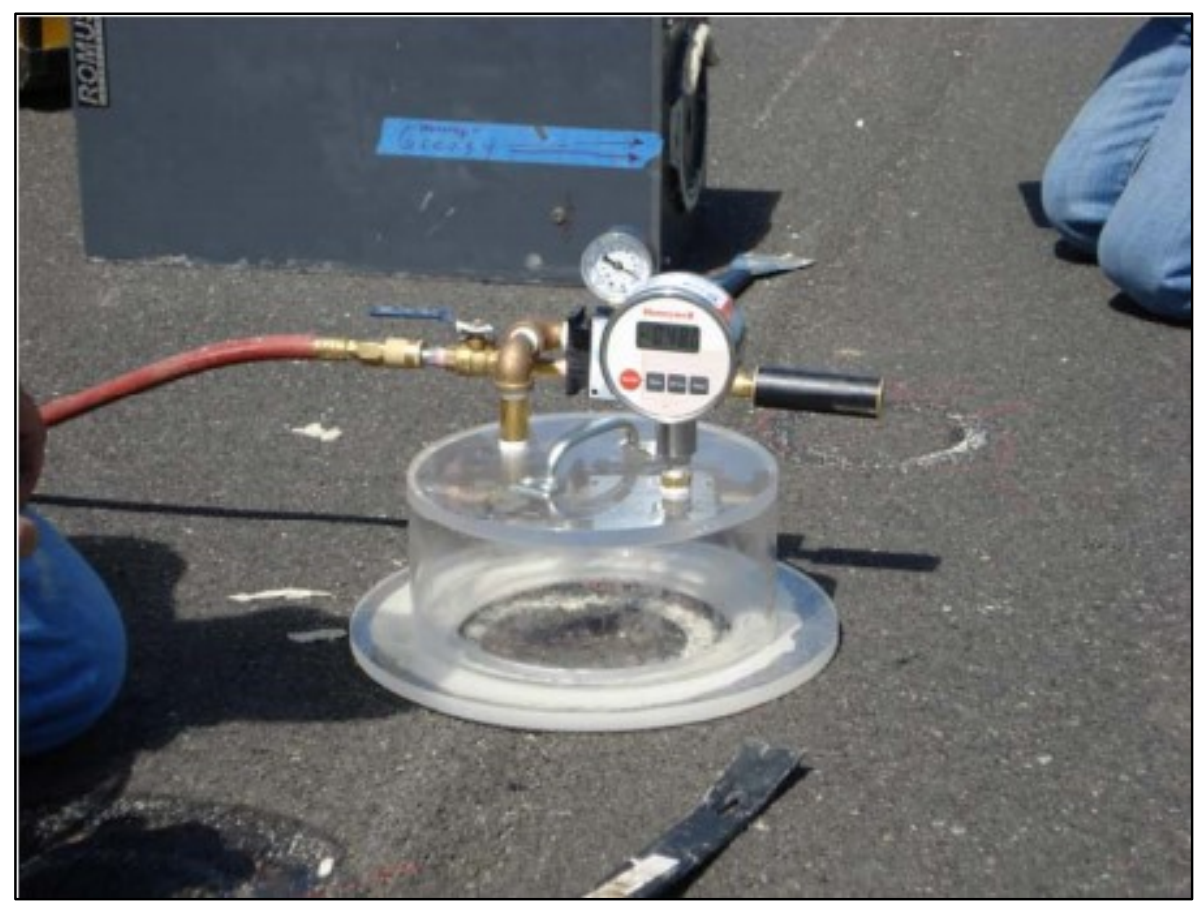

Figure 2.7: Kentucky AIP [Cross and Bhusal, 2009], used with permission

Another potential advantage of the AIP is the ability of performing the permeability test in relatively short time as it takes 15 seconds to record the vacuum reading. Beyond the 15 seconds, the pavement may experience delamination or humping. It is worth mentioning that the AIP permeability equation produces its results based on the NCAT permeability approach. In other words, the vacuum pressure measured by the AIP is 
correlated to NCAT permeability. Another drawback of the method is the fact that the AIP equation does not consider a temperature correction factor for viscosity of water as the NCAT equation does. The testing procedures require a gasoline operated air compressor or an electrical generator to be available in the field throughout the test which might add some difficulties for test performance [Cross and Bhusal, 2009].

\subsubsection{Kuss Vacuum Permeameter}

The Kuss Vacuum permeameter that is shown in Figure 2.8 uses different approach to measure the permeability; it utilizes the air vacuum to indicate the locations of the voids across the given testing area. The two main components of the device are the encasement and the vacuum machine. The encasement dimensions are 23 in. $\times 23$ in. $\times 3.5$ in. The testing procedures can be summarized as follow:

1) Select the testing area of the pavement,

2) Saturate the testing area with plane water,

3) Center the encasement over the testing area,

4) Apply the vacuum while recording a video tape for the testing area,

5) Study and analyze the recorded tape with regard to the size and location of the air bubbles, and

6) Make a judgment about the percentage of the air bubble. 


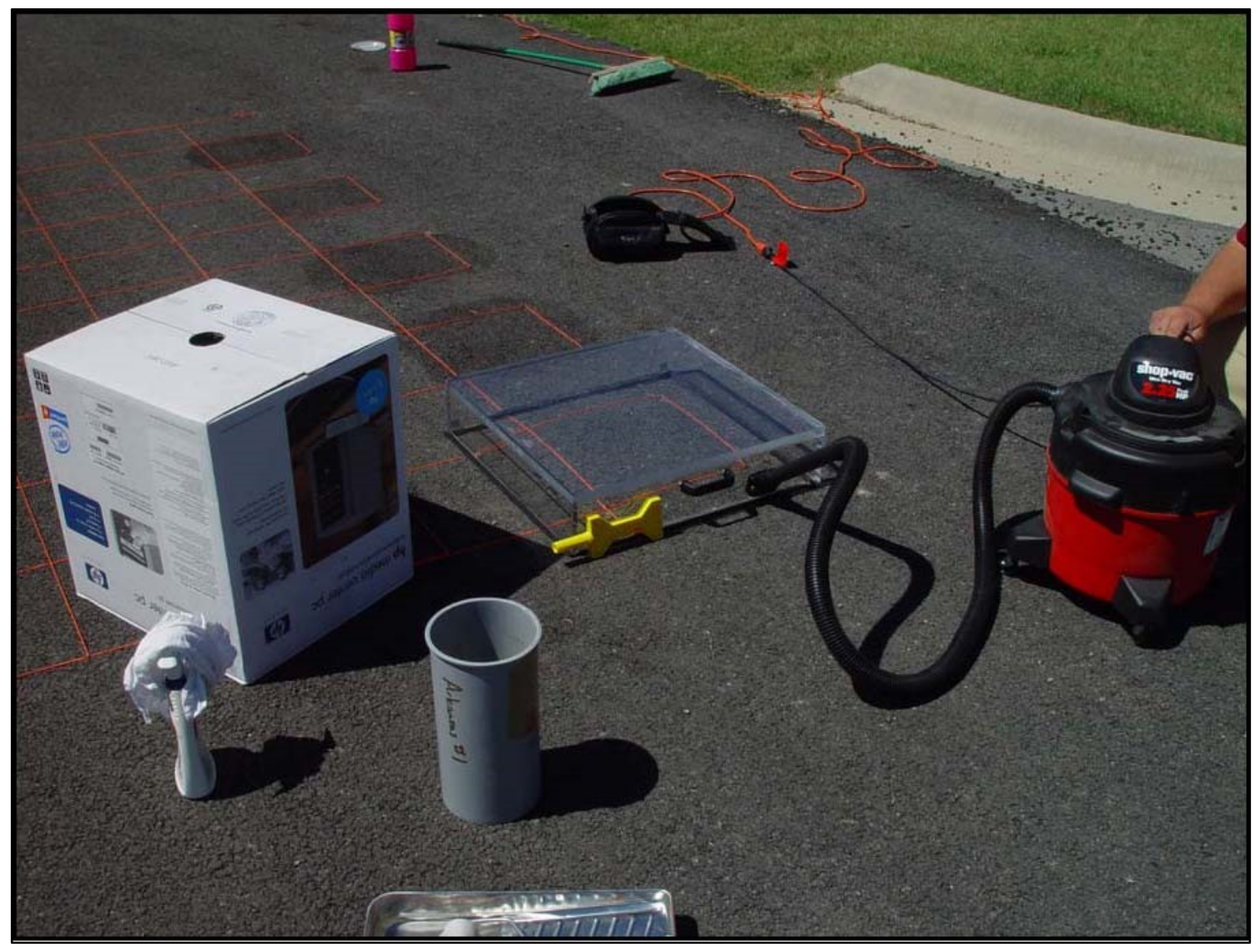

Figure 2.8: Kuss Vacuum Permeameter [Williams, 2006], used with permission

This method does not give the results of the permeability in the common forms but rather reports it as a percentage (e.g. 24\% air permeability) [Williams, 2006].

\subsubsection{E WPI Modified NCAT Permeameter}

Due to few shortcomings of the NCAT Permeameter, the Worcester Polytechnic Institute (WPI) developed a modified version of the NCAT [Harris, 2007]. The WIP enhanced the sealing mechanism and minimized the leakage issues associated with the NCAT especially on rough pavement textures. The WIP has three tiers, a flexible base, and five donut shaped weights that are $47 \mathrm{~kg}$ in total $(110 \mathrm{lb})$ as Figure 2.9 shows. These added weights help in preventing the water from leaking. The advantage of this sealing technique is that it allows cores to be taken at the exact same spot where testing is 
performed since the testing spot is not distorted by any marks or residuals of a sealant materials. To read the initial and final head, a scale is attached to the top two tiers. In order to establish a better sealing mechanism, the developer selected a flexible closed-cell sponge rubber to be used at the base of the device. This rubber has two advantages; first its non-absorptive nature, second its ability to prevent flow of water through the macrostructure of the pavement surface [Mallick, et al., 2003].

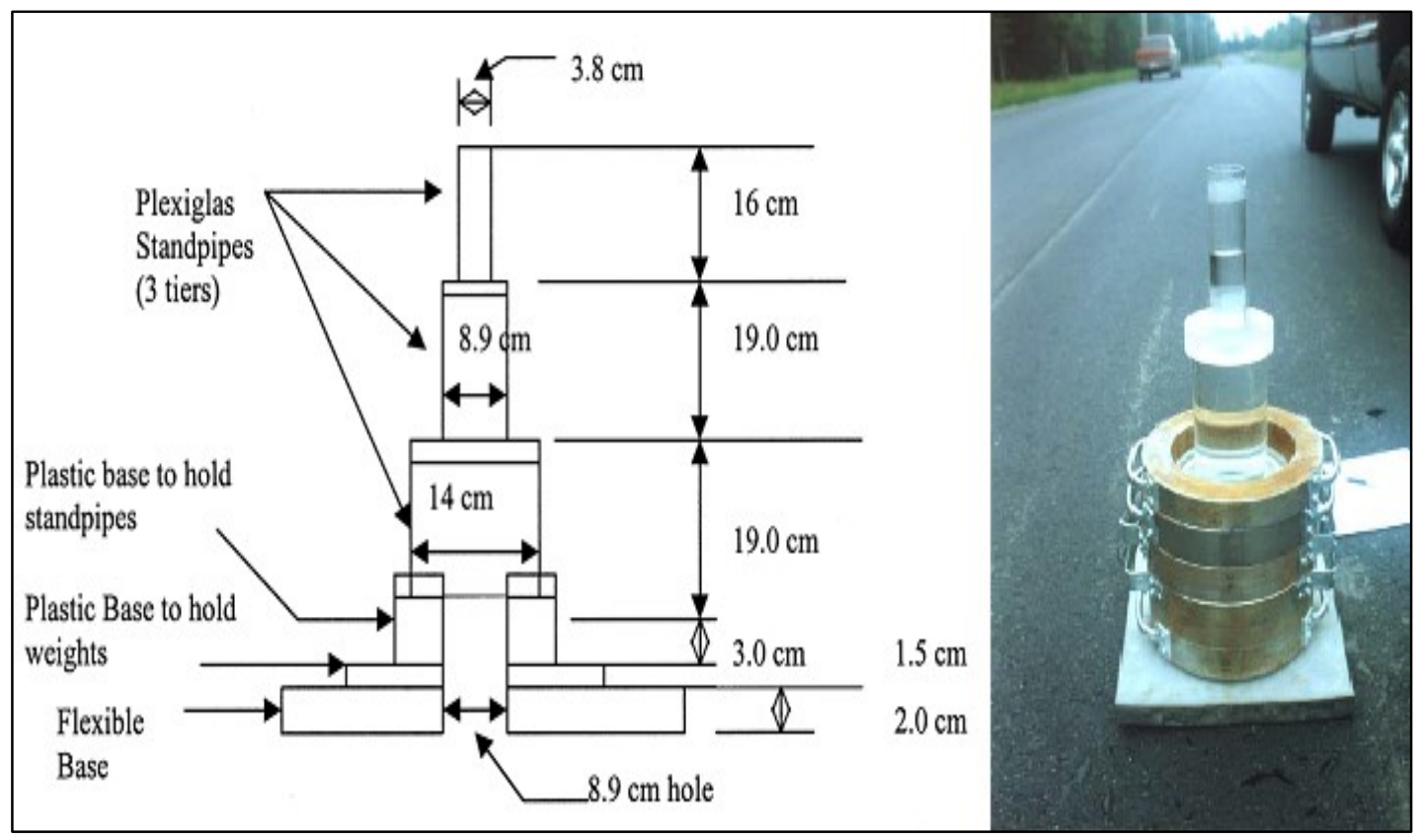

Figure 2.9: WPI Modified NCAT Permeameter [Mallick, et al., 2003], used with permission

\subsubsection{F Marshall Mold Permeameter - Paraffin Seal}

The Marshall Mold permeameter with paraffin seal is a simple device that is supplied by a commercial supplier. As shown in Figure 2.10, the main components of the apparatus are the six-inch diameter of the Marshall mold along with an attached plastic cap over the mold. At the middle of the plastic cap, there is a signal standpipe to measure the drop in water head. The last element is a ring that is $50 \mathrm{~mm}$ larger than the diameter of the Marshall mold. This ring helps in establishing the sealing mechanism between the device 
and the pavement surface. The unique sealing mechanism of this device embodied in using the paraffin to prevent the water leakage. The paraffin has been selected because of its physical nature that has two main advantages. The paraffin physical state shifts from liquid to solid in a relatively short time. In the liquid stage, the paraffin will fill all the voids and the pores between the pavement and the device [Cooley, 1999].

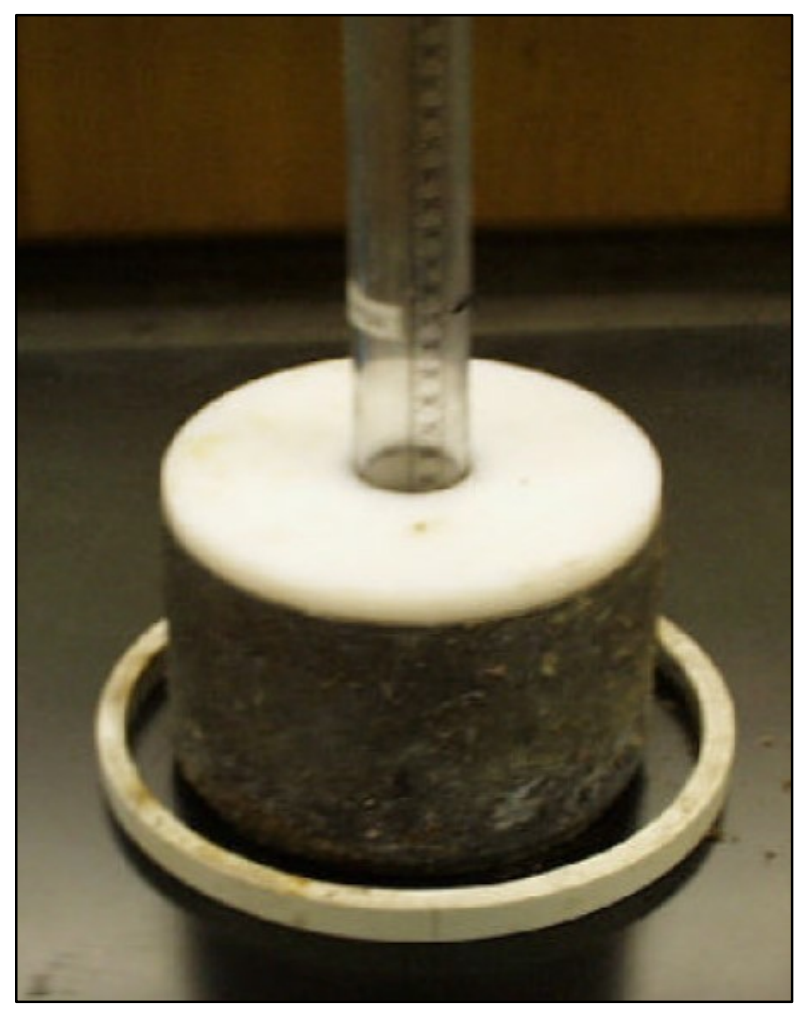

Figure 2.10: Marshall Mold Permeameter Paraffin Seal [Cooley, 1999], used with permission This method requires a well-trained user to perform the test. Heating and cooling down of the paraffin to the desirable degree of hardening is a challenging task. If the paraffin did not cool properly before the pouring stage, it would flow under the edges of the device and clog the flow paths. On the other hand, if the paraffin overly cooled, it would get stiffer fast and would not provide a good sealing [Williams, 2006; Harris, 2007]. 


\subsubsection{G Marshall Mold Permeameter - Silicon Seal}

Different sealing material was introduced for the Marshall Mold permeameter to overcome the aforementioned difficulties of the paraffin as sealing technique. As clearly shown in Figure 2.11, the bottom of the device has no base plate. Therefore, adding the sealant material around the base using a silicone-rubber caulk must be carefully performed to ensure its tightness. It has been observed that the permeameter produces better results if the sealing is added along both the inside and outside of the device's base. However, it is important to note that a reduction in the effective area of the testing spot can be experienced because of the inside sealing [Harris, 2007; Cooley and Brown, 2007].

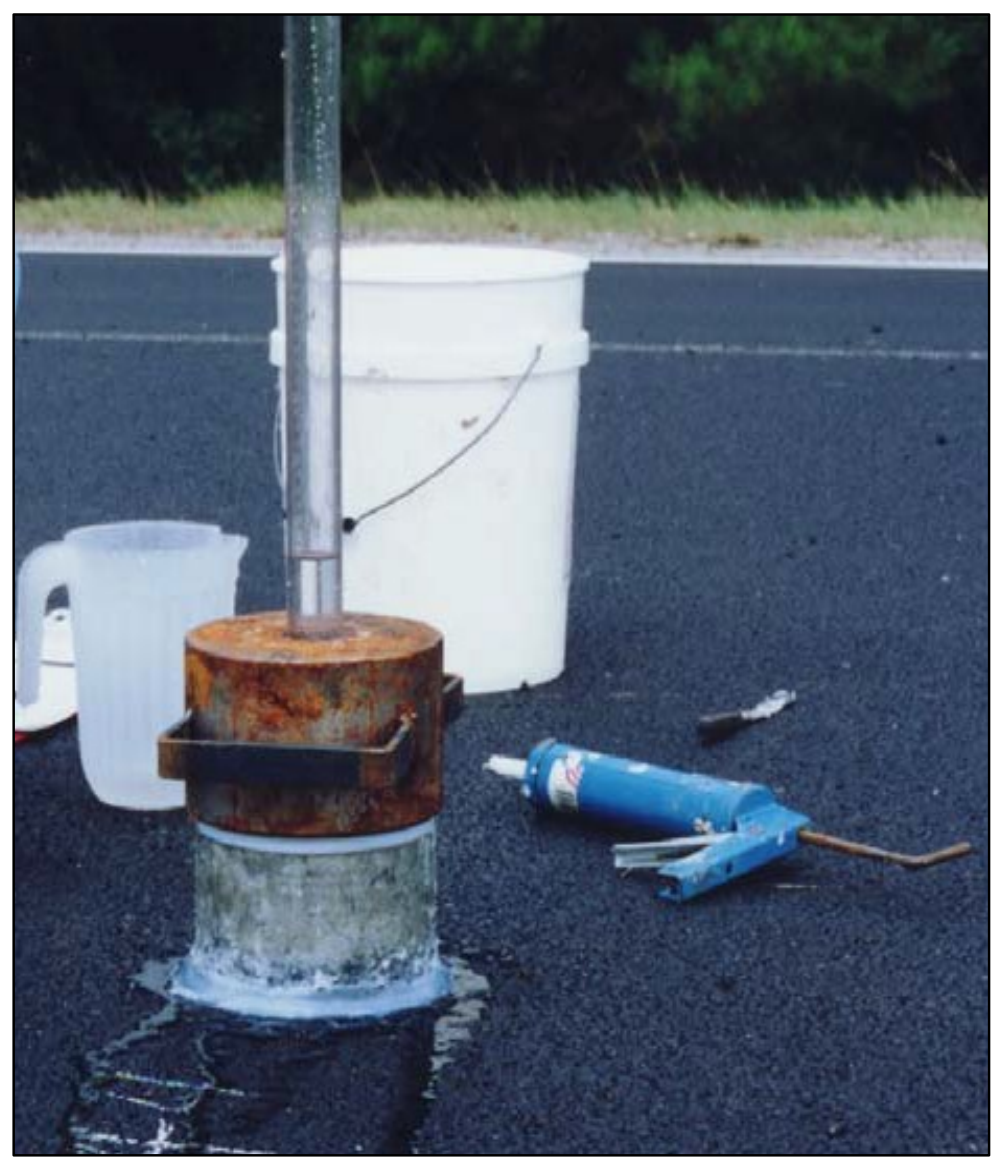

Figure 2.11: Marshall Mold Permeameter Silicon Seal [Cooley, 1999], used with permission 


\subsubsection{H Romus Air Permeameter}

The Romus Air Permeameter (RAP) was developed by Romus Inc. to determine the asphalt permeability using the falling-head principle. The device consists of several components as depicted in Figure 2.12. The device has a vacuum chamber that is intended for two purposes. The vacuum chamber draws air out of the pavement structure as well as improves the sealing condition between the bottom of the device and the asphalt road surface.

The sealing mechanism in the RAP uses the grease to prevent leaking. The grease is applied using a grease gun around a ring located at the bottom of the device as shown in Figure 2.12. The grease should spread around the ring to establish an airtight seal between the bottom of the RAP and the asphalt surface. It is worth mentioning that the testing spot of the RAP device duplicates the area of the lowest tier in the NCAT device [Russell, et al., 2005].

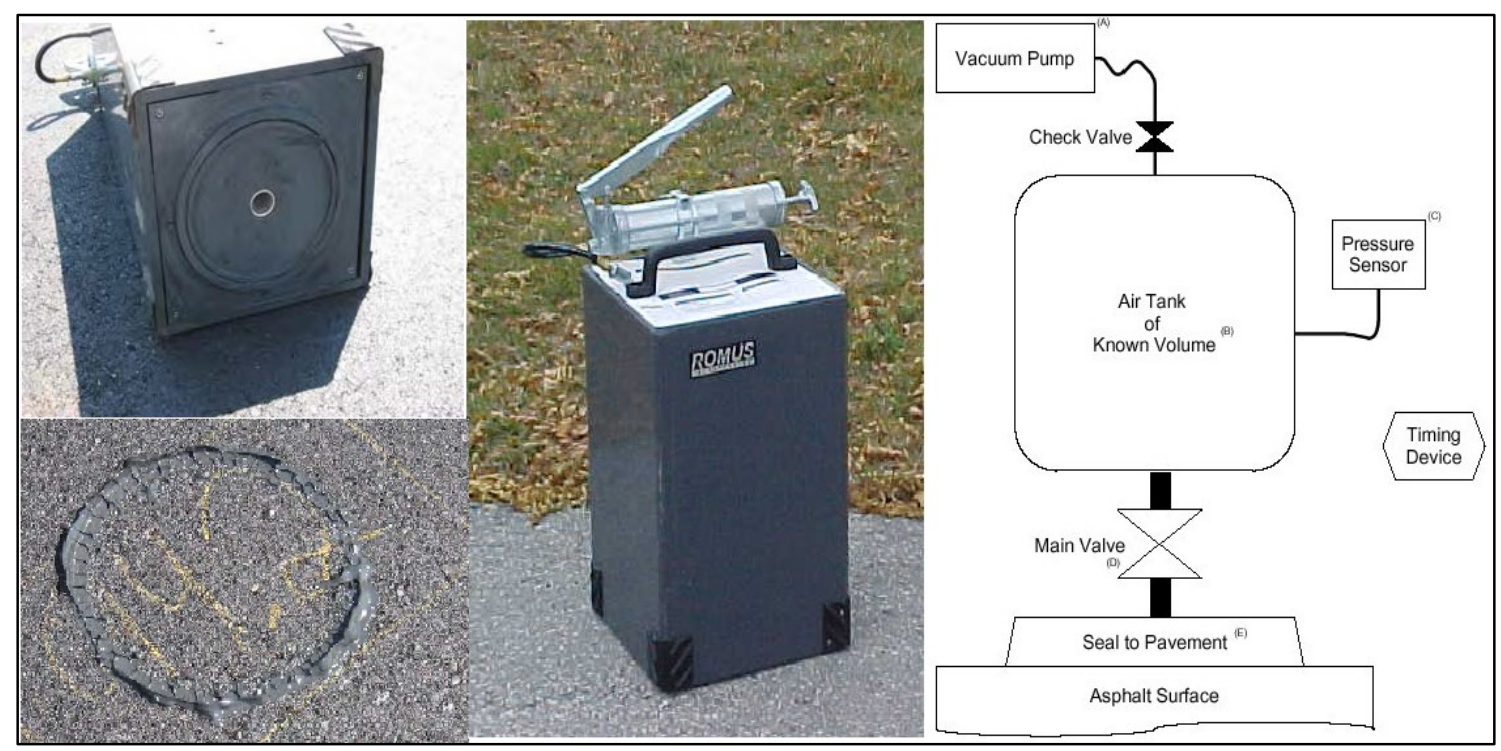

Figure 2.12: Romus Air Permeameter [Retzer, 2008], used with permission 
At the beginning of the test, the device should be sealed properly at the targeted location. Prior to starting the test, if the pressure of the device is not appropriately set, the air tank is pressurized to a head of 24 inches. The test begins once the "Start" button of the device is pressed. Subsequently, a fully automated system is activated where a pressure sensor monitors the pressure in the tank while the air is drawn through the pavement. The only output of the device is the time of head drop which is recorded for each 4 inches of pressure drop. Researchers at Marquette University have found out that the RAP produces consistent results for different testing locations [Russell, et al., 2005]. By using the time, thickness of the pavement layer, and other constant parameters, one can use Equation 2.6 to find the pavement permeability:

$$
k_{w}=\left[\frac{L V \mu \rho_{w} g}{T A P_{a} \mu_{w}}\right] \times \ln \left[\frac{P_{1}}{P_{2}}\right]
$$

where:

$K w=$ hydraulic permeability $(\mathrm{L} / \mathrm{T})$,

$L=$ pavement layer thickness $(\mathrm{L})$,

$V=$ volume of vacuum chamber $\left(\mathrm{L}^{3}\right)$,

$\mu=$ kinematic viscosity of air (M/LT),

$\rho w=$ density of water $\left(\mathrm{M} / \mathrm{L}^{3}\right)$,

$g=$ gravitational acceleration $\left(\mathrm{L} / \mathrm{T}^{2}\right)$,

$T=$ time of head drop (T),

$A=$ area of being tested $\left(\mathrm{L}^{2}\right)$,

$P a=$ pressure (atmospheric) $\left(\mathrm{F} / \mathrm{L}^{2}\right)$,

$\mu w=$ kinematic viscosity of water $(\mathrm{M} / \mathrm{LT})$,

$p_{1}=$ initial pressure $(\mathrm{L})$, and

$p_{2}=$ final pressure $(\mathrm{L})$. 


\subsubsection{Ranking and Evaluation of Field Test:}

As presented in the previous section, there are numerous techniques that are used to measure the permeability in the literature; these methods differ in their mechanism, reliability, and outcomes. This section is indented to evaluate and rank all the common permeability techniques based on some criteria which are device usability, testing speed, consistency, laboratory correlation, and purchasing cost. Each criterion will be given a weight based on its importance as follows:

- $\mathrm{A}=5$ (Very important)

- $\quad \mathrm{B}=4$ (Important)

- $\mathrm{C}=3$ (Moderate)

- $\quad \mathrm{D}=2$ (Less important)

- $\quad \mathrm{E}=1$ (Not important)

Each device will be assessed a score ranging from 0 (lowest score) to 10 (highest score) for each corresponding criterion. The formula that will be used to calculate the performance index for each device is

Performance Index $=\frac{\sum(\text { Criterion Weight }) \times(\text { Device Score })}{\sum \text { Criteria Weight }} \quad$ Equation 2.7

The Marshall Mold permeameter with paraffin seal is excluded from the evaluation and ranking processes because the device was found to be extremely difficult to be operated in the field as concluded by Cooley [Cooley, 1999]. Table 2.2 shows the seven considered devices for evaluation and their corresponding score for each criterion. These scores were given to each device based on the review of the literature. On the basis of the results of Table 2.2, it is shown that the most suitable and practical permeameter to be 
used by the QA/QC practitioners is the NCAT permeameter. The ranking for all devices is presented in Table 2.3.

Table 2.2: Comparison Matrix for All the Permeability Devices

\begin{tabular}{lcccccc}
\hline \multicolumn{1}{c}{ Criterion Name } & $\begin{array}{c}\text { Ease of } \\
\text { Use }\end{array}$ & $\begin{array}{c}\text { Test } \\
\text { Speed }\end{array}$ & $\begin{array}{c}\text { Consistency } \\
\text { In Results }\end{array}$ & $\begin{array}{c}\text { Correlation } \\
\text { With The } \\
\text { Lab Results }\end{array}$ & Cost & $\begin{array}{c}\text { Overall } \\
\text { Score }\end{array}$ \\
\cline { 3 - 7 } Device Name & Moderate & Important & $\begin{array}{c}\text { Very } \\
\text { Important }\end{array}$ & $\begin{array}{c}\text { Important } \\
\text { Less }\end{array}$ & \\
\hline The Kuss Permeameter & 7 & 5 & 8 & 8 & N/A & 7.06 \\
\hline Kentucky Permeameter (AIP) & 8 & 8 & 7 & 5 & N/A & 6.94 \\
\hline NCAT Permeameter & 7 & 8 & 6 & 8 & 8 & 7.28 \\
\hline Kuss Vacuum Permeameter & 5 & 4 & 8 & N/A & N/A & 5.92 \\
\hline WPI modified NCAT & 7 & 7 & 4 & N/A & N/A & 5.75 \\
\hline Romus Air Permeameter & 4 & 8 & 4 & 5 & 3 & 5.00 \\
\hline Marshall Mold (Silicon Seal) & 6 & 7 & 6 & 8 & N/A & 6.75 \\
\hline (N/A): No score was given as no conclusions were found in the literature & & & & \\
\hline
\end{tabular}

Table 2.3: Field Permeameter Ranking

\begin{tabular}{lc}
\hline \multicolumn{1}{c}{ Device } & Overall Score \\
\hline NCAT Permeameter & 7.28 \\
\hline The Kuss Permeameter & 7.06 \\
\hline Kentucky Permeameter (AIP) & 6.94 \\
\hline Marshall Mold (Silicon Seal) & 6.75 \\
\hline Kuss Vacuum Permeameter & 5.92 \\
\hline WPI modified NCAT & 5.75 \\
\hline Romus Air Permeameter & 5.00 \\
\hline
\end{tabular}

As previously stated, it has been found that the most common device for performing the hydraulic conductivity test in the field is the NCAT apparatus. This is due to its ease of use, short time of the test, and nondestructive nature. However, there are few drawbacks of this method that should be mentioned based on field observations. It is almost a 
challenging task to create a tight sealant between the pavement surface and the bottom of the NCAT device especially when the pavement surface is not smooth. Generally, rough pavement surface will promote more water leakage. This is due to the fact that the sealed material (putty) gets wet with time and allows the water to leak through its rough surface. A recent study proposed a new sealing material to be used to overcome the leaking issue.

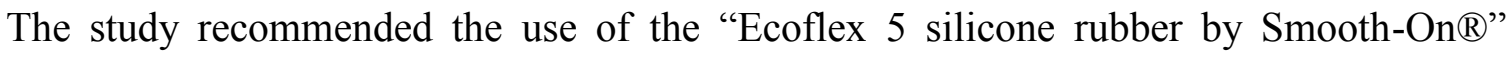
along with the caulking gun [Li, et al., 2013]. Also, the NCAT manual instructs the user to add some weights to the base of the device to have a better sealing. However, there is no defined standard weight that will guarantee a solution to leakage problem.

\subsubsection{Laboratory Devices}

\subsubsection{A Karol-Warner Asphalt Permeameter}

The common laboratory method that is adopted to measure the coefficient of permeability for HMA cores or laboratory prepared specimens was developed by the Florida Department of Transportation (FDOT) in 1996 [James, et al., 2004] This test method (Figure 2.13) has been selected as the standard lab test for measuring permeability and the procedure is outlined in ASTM PS 129-01, Permeability of Bituminous Materials [Zaniewski and Yan, 2013]. The method follows the falling head principle to measure the coefficient of permeability. Water is allowed to drop in the graduated cylinder passing through a saturated asphalt sample. The initial water head, the final water head, and the time interval between the two heads are recorded and used for permeability calculations based on Darcy's law [Florida Test Method, 1997] The testing producer was then slightly modified by recommending an epoxy resin to seal the sidewalls of the core when using the flexible latex membrane [Mallick, et al., 2003]. To represent a better simulation of the 
in-situ permeability, the ASTM subcommittee D.423 modified the testing apparatus by adding a rising tail element that acts as an outlet pipe for the penetrated water through the specimen.

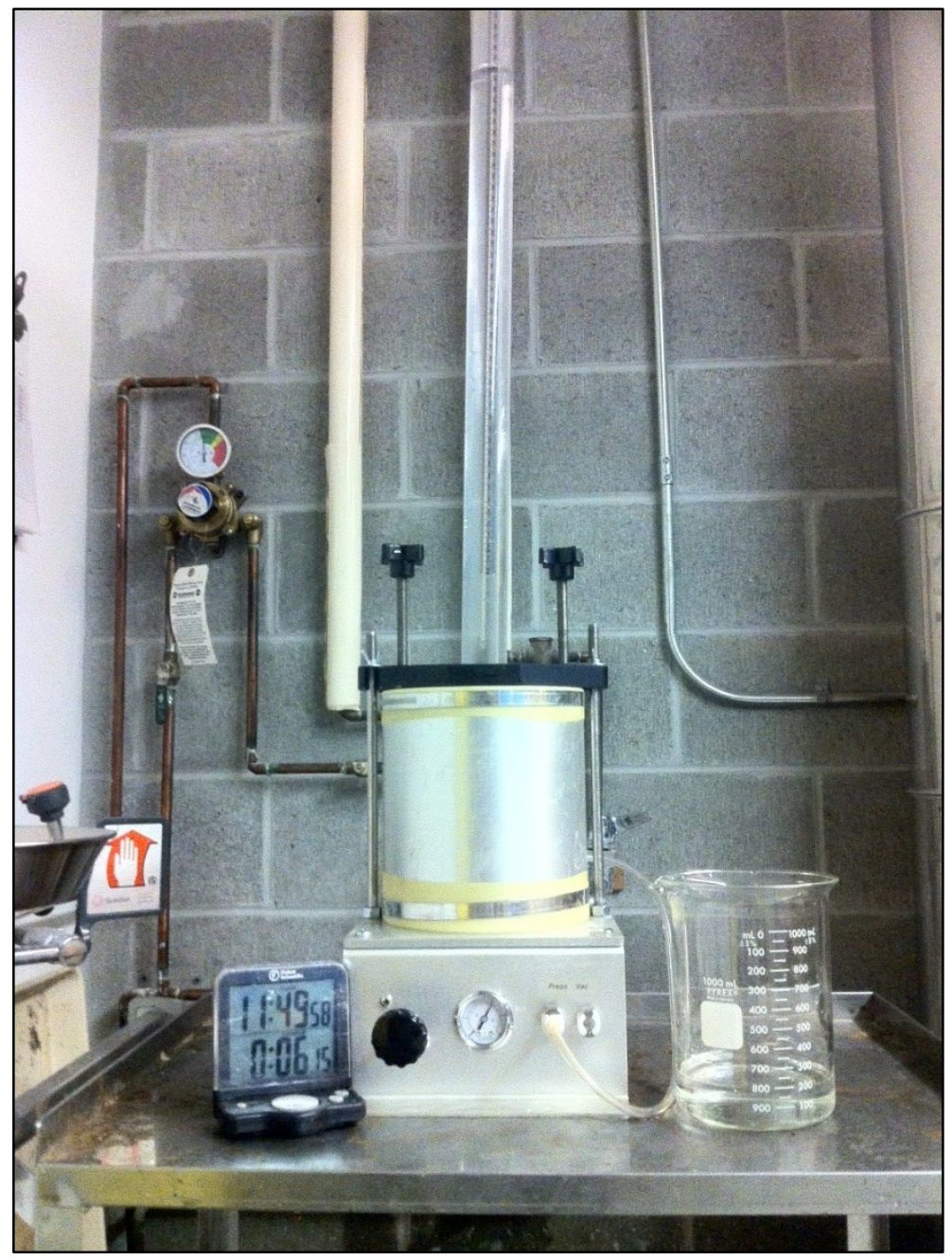

Figure 2.13: The Laboratory Permeability Device

This test is applicable for both field cores along with laboratory prepared specimens [Zaniewski and Yan, 2013]. The testing permeameter consists of a vertical standpipe, two expandable sealing rings, a six inch aluminum containment cylinder, a latex membrane, a water release valve, and a manual air pump with a pressure gauge. The testing specimen is placed on the chamber. Then the latex membrane is pressurized to prevent water passing through the sides of the sample. The specimen should reach a saturation 
condition by allowing a $500 \mathrm{ml}$ of water to pass through it twice. The difference in the water flow rate should not be more than $4 \%$ to assure the saturation condition. The standpipe is then filled with water and the valve is released. The time is then recorded for the water level to move from the initial head value to the final head value [Florida Test Method, 1997]. More details about his test will be presented later at Section 3.2.2.

\subsubsection{B Corelok Device}

The coefficient of permeability for HMA specimens can be determined through quantifying the percentage of porosity for a particular asphalt sample. The CoreLok device (Figure 2.14) can be used to measure the porosity for HMA samples which can be used to find the permeability value. One finding suggests that this method is better for determining permeability because two samples with the same percent porosity will have almost the same permeability value [Harris, 2007]. In general, for a coarse-graded mixture, measuring the porosity is much more representative rather than the air voids. In contrast, the air voids for dense-graded or fine mixtures is relatively sufficient to indicate the sample condition for quality control and QA purposes. The porosity accounts for the air voids content, size, and interconnectedness within a given sample [Vivar and Haddocl, 2006]. Generally, it has been concluded that the permeability is a good indicator of voids that are exposed to water, while porosity is good at indicating all voids whether they are accessible by water or not [Çelik, 2005].

The procedures that are required to find the porosity value begin by placing the sample in a vacuum-sealed bag to determine its density " $\rho_{1}$ ". Then, the sample should be covered and placed under water, then the bag covering the sample should be opened while maintaining the submerged condition; this is necessary to quantify its underwater density 
" $\rho_{2}$ ". These two density measurements are used to calculate the percentage of porosity as shown in Equation 2.8 [Instrotek $\left.{ }^{\circledR}, 2011\right]$.

$$
\operatorname{Porosity}(\%)=\left[\frac{\rho_{2}-\rho_{1}}{\rho_{2}}\right] \times 100
$$

Equation 2.8

where:

$\rho_{1}=$ the CoreLok vacuum sealed density of compacted sample, and

$\rho_{2}=$ density of the vacuum sealed sample after opening under water.

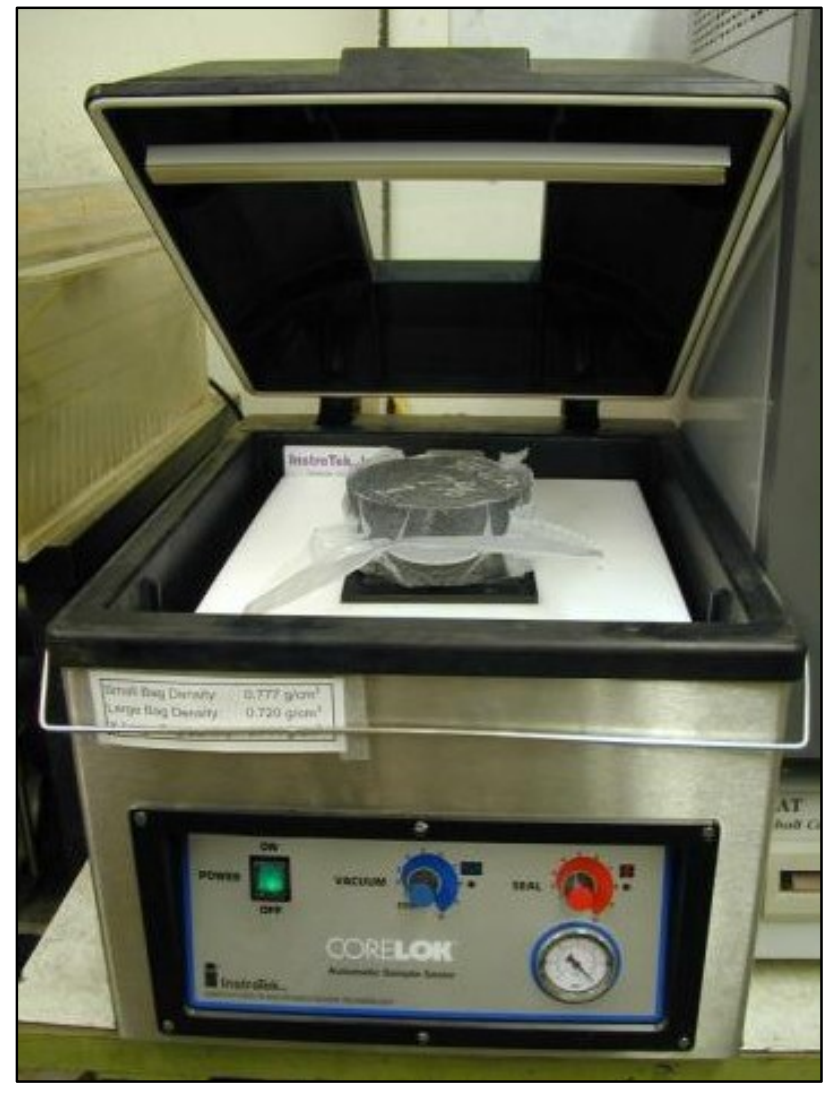

Figure 2.14: The CoreLok device [Cooley, et al., 2002], used with permission

\subsubsection{The Constant Permeameter}

In the literature, the constant head technique has been used in the laboratory environment to test the permeability coefficient of the HMA pavement cores. The soil testing system (Figure 2.15) that measures the soil permeability can be utilized for the asphalt cores 
testing as well. The 6 inch diameter asphalt sample should be placed in the testing cell where it is enclosed with a flexible rubber membrane along with placing some porous stones at its bottom and top faces. In this testing configuration, the water will be used to apply a confining pressure using an inlet pressure and outlet pressures. In order to ensure that the water flow is laminar (i.e. not turbulent), the difference in the applied pressures should not be high [Zaniewski and Yan, 2013] [Maupin, 2000b]. Equation 2.9 is used to calculate the coefficient of permeability.

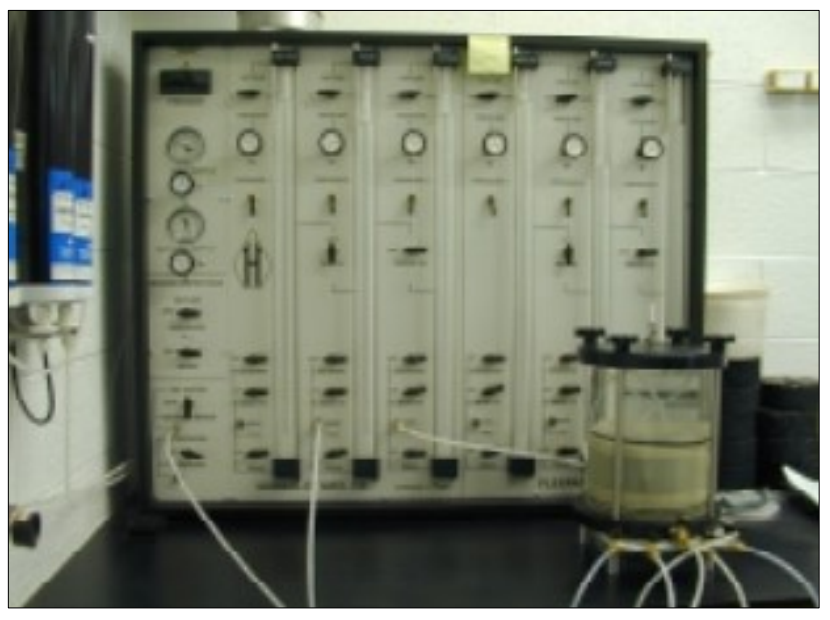

Figure 2.15: The Constant Head Permeameter [Maupin, 2000b]

$$
k=\frac{Q L}{\mathrm{Ath}}
$$

Equation 2.9

where:

$k=$ permeability coefficient $(\mathrm{mm} / \mathrm{s})$,

$Q=$ quantity of flow $\left(\mathrm{mm}^{3}\right)$,

$L=$ specimen length $(\mathrm{mm})$,

$A=$ specimen cross-sectional area $\left(\mathrm{mm}^{2}\right)$,

$t=$ interval of time over which flow Q occurs (s), and

$h=$ difference in hydraulic head across the specimen $(\mathrm{mm})$. 


\section{CHAPTER 3: EXPERIMENTAL PROGRAM}

The planned and implemented experimental program in this study consisted of two major phases. The first phase dealt with the measurements of in-situ permeability of newly constructed asphalt pavement surfaces and in-service roads. The term "in-service" refers to sites that were compacted and tested in a previous year. In addition, field cores were recovered from each test location for performing a major portion of the second phase. The second phase is mainly based on laboratory investigations including preparing laboratory specimens using loose mixtures provided by the MTO along with performing different laboratory tests. In particular, the laboratory experimental program involved measuring the relative density, IDT, and laboratory permeability of the field-recovered cores as well as laboratory prepared specimens. Figure 3.1 illustrates the major components of the experimental investigation carried out in this research.

\subsection{Data Collection}

Several sites (highway projects and in-house field trials) in Ontario's Eastern Region were selected for inspection and sampling immediately after the paving and the compaction stages are completed. The term "in-house" is used in this research to refer to non-highway field projects performed at controlled locations/sections under the supervision of the construction firm R.W.Tomlinson Limited. Other in-service highway sections were also investigated to evaluate the effect of age and traffic on the permeability of the road surface. The testing program included sites finished by two different compaction methods including the advanced and the conventional compaction techniques to examine the effect of compaction on the mechanical and physical properties of asphalt pavement. 


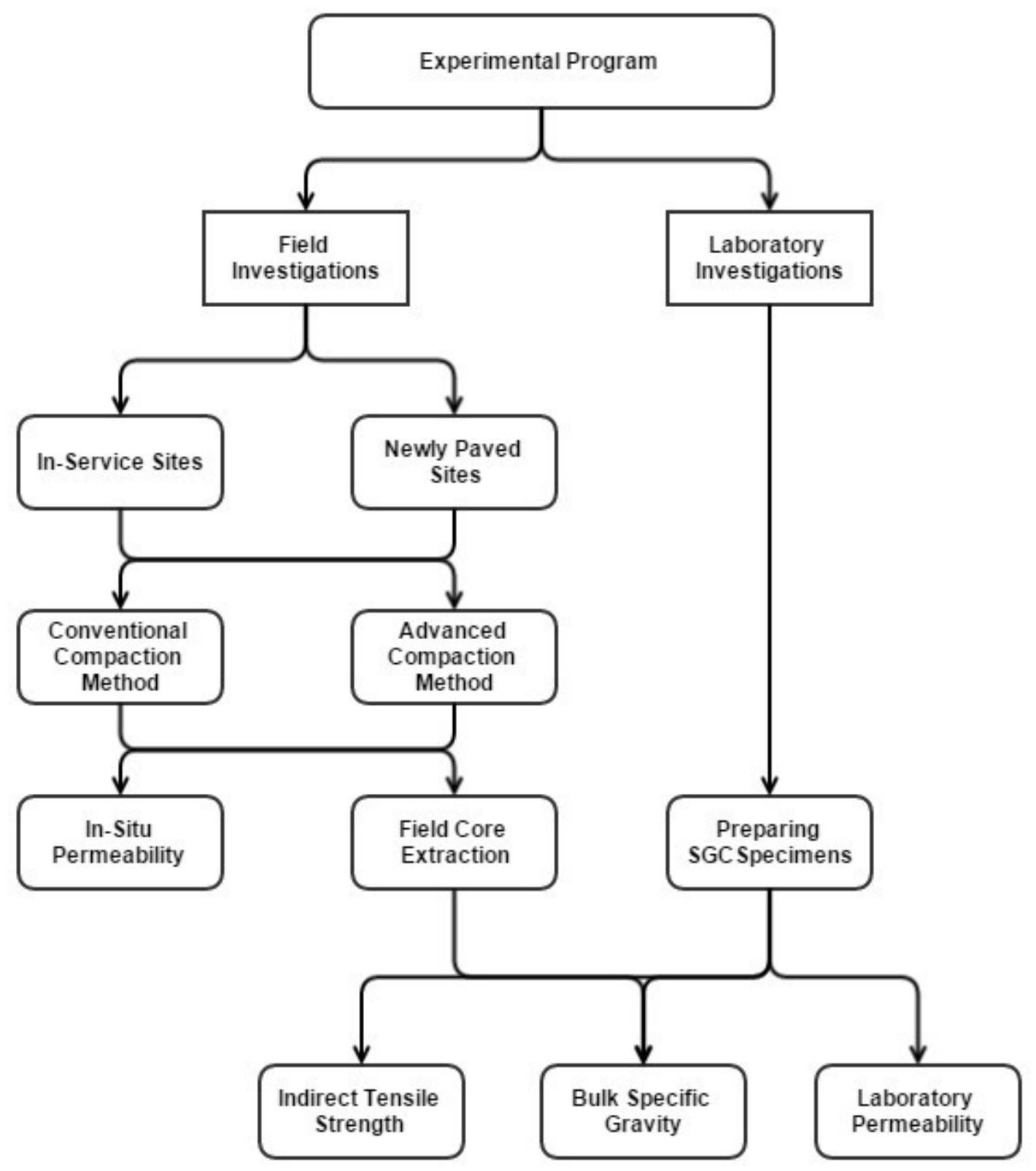

Figure 3.1: Experimental Program Plan

Figure 3.2 illustrates the location of each HMA highway project or in-house field trial included in this study. The selected sites represent different asphalt design mixtures that are approved and adopted by The MTO in order to ensure the diversity and generalities in the collected data. 


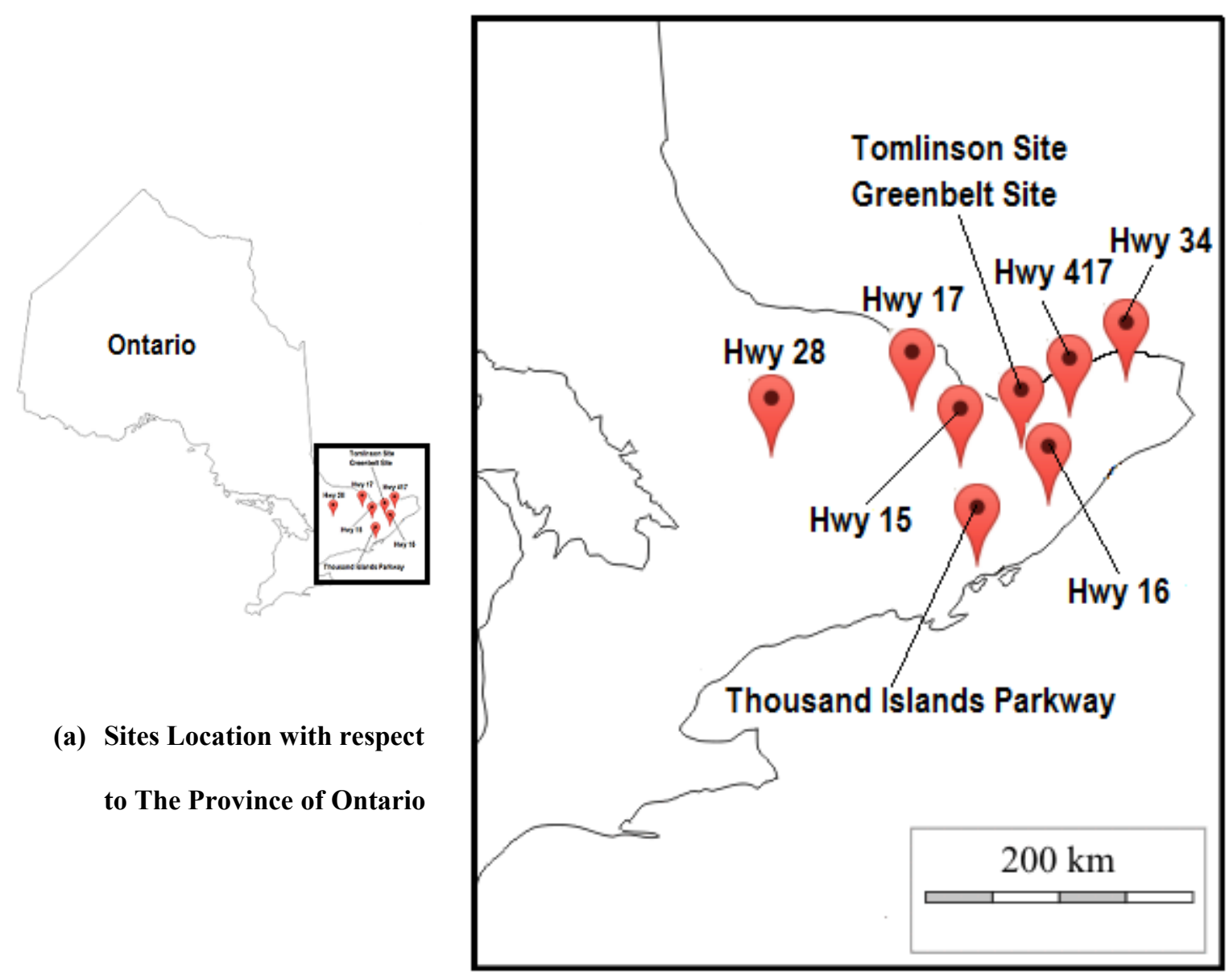

(a) Sites Location with Respect to Eastern Ontario

Figure 3.2: Location of Selected Sites in Ontario's Eastern Region [d-maps, 2015]

The full study plan implemented in this research, including Phase One and Two, is shown in Table 3.1. For each site, the table describes the used compaction method, the field testing date, and the mix type. In addition, the table summarizes Phase One testing by showing the total number of field measurements taken at each site along with the number of the field-recovered cores. 
Table 3.1: The Research Experimental Plan

\begin{tabular}{|c|c|c|c|c|c|c|c|c|c|c|}
\hline \multicolumn{5}{|c|}{ Site Specifications } & \multicolumn{2}{|c|}{ First Experimental Phase } & \multicolumn{4}{|c|}{ Second Experimental Phase } \\
\hline Name & Date & Year & $\begin{array}{l}\text { Compaction } \\
\text { Method }\end{array}$ & Mix Type & $\begin{array}{c}\text { Field } \\
\text { Permeability }\end{array}$ & $\begin{array}{l}\text { Field } \\
\text { Cores }\end{array}$ & $\begin{array}{c}\text { SGC } \\
\text { Samples }\end{array}$ & $\begin{array}{l}\text { Relative } \\
\text { Density }\end{array}$ & $\begin{array}{c}\text { Lab } \\
\text { Permeability }\end{array}$ & IDT \\
\hline Tomlinson In-house & Nov 10th & 2012 & Conventional & SP12.5 RAP & 7 & 10 & N/A & $\checkmark$ & $x$ & $\checkmark$ \\
\hline Thousand Islands Parkway & Oct 26th & 2012 & Conventional & SP 12.5 & 7 & 5 & $\mathrm{~N} / \mathrm{A}$ & $\checkmark$ & $x$ & $\checkmark$ \\
\hline Highway 28 & Sep 21st & 2012 & Conventional & SP 12.5 & 10 & 10 & $\mathrm{~N} / \mathrm{A}$ & $\checkmark$ & $x$ & $\checkmark$ \\
\hline Tomlinson In-house & Nov 10th & 2012 & Advanced & SP12.5 RAP & 7 & 10 & $\mathrm{~N} / \mathrm{A}$ & $\checkmark$ & $x$ & $\checkmark$ \\
\hline Thousand Islands Parkway & Oct 26th & 2012 & Advanced & SP 12.5 & 7 & 5 & $\mathrm{~N} / \mathrm{A}$ & $\checkmark$ & $x$ & $\checkmark$ \\
\hline Highway 28 & Sep 21st & 2012 & Advanced & SP 12.5 & 10 & 10 & N/A & $\checkmark$ & $x$ & $\checkmark$ \\
\hline Tomlinson In-house & Nov 21st & 2013 & Conventional & SP12.5 RAP & 8 & 0 & N/A & $x$ & $x$ & $x$ \\
\hline Thousand Islands Parkway & Sep 19th & 2013 & Conventional & SP 12.5 & 9 & 0 & N/A & $x$ & $x$ & $x$ \\
\hline Highway 28 & May 30th & 2013 & Conventional & SP 12.5 & 14 & 0 & $\mathrm{~N} / \mathrm{A}$ & $x$ & $x$ & $x$ \\
\hline Highway 16 & Sep 27th & 2013 & Conventional & 12.5 FC2 RAP & 15 & 15 & 7 & $\checkmark$ & $\checkmark$ & $\checkmark$ \\
\hline Highway 17 & Sep 25 th & 2013 & Conventional & SP 12.5 Cat C & 15 & 15 & 7 & $\checkmark$ & $\checkmark$ & $\checkmark$ \\
\hline Highway 417 & Sep 29th & 2013 & Conventional & $12.5 \mathrm{FC} 2$ & 15 & 15 & 12 & $\checkmark$ & $\checkmark$ & $\checkmark$ \\
\hline Highway 15 (i) & Oct 2 nd & 2013 & Conventional & $\mathrm{N} / \mathrm{A}$ & 10 & 0 & 7 & $\checkmark$ & $\checkmark$ & $\checkmark$ \\
\hline Highway 15 (ii) & Oct 29th & 2013 & Conventional & $\mathrm{N} / \mathrm{A}$ & 10 & 0 & $\mathrm{~N} / \mathrm{A}$ & $x$ & $x$ & $x$ \\
\hline Tomlinson In-house & Nov 21st & 2013 & Advanced & SP12.5 RAP & 7 & 0 & N/A & $x$ & $x$ & $x$ \\
\hline Thousand Islands Parkway & Sep 19th & 2013 & Advanced & SP 12.5 & 10 & 0 & N/A & $x$ & $x$ & $x$ \\
\hline Highway 28 & May 30th & 2013 & Advanced & SP 12.5 & 16 & 0 & N/A & $x$ & $x$ & $x$ \\
\hline Greenbelt (i) & Oct 15 th & 2014 & Conventional & $12.5 \mathrm{FC} 2$ & 3 & 8 & N/A & $\checkmark$ & $\checkmark$ & $\checkmark$ \\
\hline Highway 34 Bridge & Nov 27th & 2014 & Conventional & $12.5 \mathrm{FC} 2$ & 7 & 0 & N/A & $x$ & $x$ & $x$ \\
\hline Greenbelt (i) & Oct 15 th & 2014 & Advanced & $12.5 \mathrm{FC} 2$ & 4 & 10 & N/A & $\checkmark$ & $\checkmark$ & $\checkmark$ \\
\hline Greenbelt (ii) & Oct 30th & 2014 & Advanced & $12.5 \mathrm{FC} 2$ & 0 & 14 & $\mathrm{~N} / \mathrm{A}$ & $\checkmark$ & $\checkmark$ & $\checkmark$ \\
\hline Highway 34 Bridge & Nov 27th & 2014 & Advanced & $12.5 \mathrm{FC} 2$ & 6 & 10 & N/A & $\checkmark$ & $\checkmark$ & $\checkmark$ \\
\hline
\end{tabular}


It can been seen that all included sites in this research have common nominal maximum aggregate size (NMAS) of $12.5 \mathrm{~mm}$. Table 3.1 summarizes also the second experimental phase by showing the incorporated laboratory tests on the field-recovered cores as well as the SGC specimens of each site. It is important to mention that in some cases the number of the field-recovered cores might not be the same as the number of the field measurements. The time limitations of the road closure provided by the traffic control technicians, the time restriction/availability of the core drilling operator, or performing the field test and field coring in different days were behind not having the same number of field measurements and field-recovered cores. However, having shortage or surplus in the number of field cores with respect to the field measurements does not violate the fact that the field cores were extracted from the same in-situ tested location.

The field testing involved performing the in-situ permeability measurements at specific locations along and across the road sections. In addition, asphalt cores were extracted from the same locations where the in-situ measurements were taken. The testing program used the same field testing device at all sites. In particular, the in-situ permeability testing protocol was performed using the NCAT permeameter at each of the selected sites. As explained earlier in Chapter 2, this was the method recommended in this research based on the evaluation of available field permeability measurement techniques in the literature. At each investigated site a total of three to five testing spots were selected along the cross-section of a lane on each selected site to examine the variability in permeability with the change of lateral location of the testing location. For each testing spot (diameter $=150 \mathrm{~mm}$ ), a pavement core was then recovered and transported to the Civil Engineering 
Laboratory at Carleton University for further experimental investigations as explained earlier.

Figure 3.3 illustrates the testing locations incorporated in this research and their corresponding distances from the centerline of the paved lane. Relative to the centerline of the selected site lane:

- The first testing location was at $200 \mathrm{~mm}$ and termed "Inner Edge",

- The second was at $850 \mathrm{~mm}$ and termed "Inner Middle",

- The third was at $1900 \mathrm{~mm}$ and termed "Middle",

- The fourth was at $2750 \mathrm{~mm}$ and termed "Outer Middle" and

- The fifth was at $3400 \mathrm{~mm}$ and termed "Outer".

In certain sites and due to limitations of time and safety considerations of the research team, the in-situ permeability measurements were limited to three testing locations; the outer, middle and inner. In other sites where more testing time was allowed by the traffic control workers, all five locations were covered. As stated previously, the main reason of performing the permeability test at different locations was to ensure covering as wide area of the paved lane as possible and to assess the possible variability in density, permeability and strength values. 


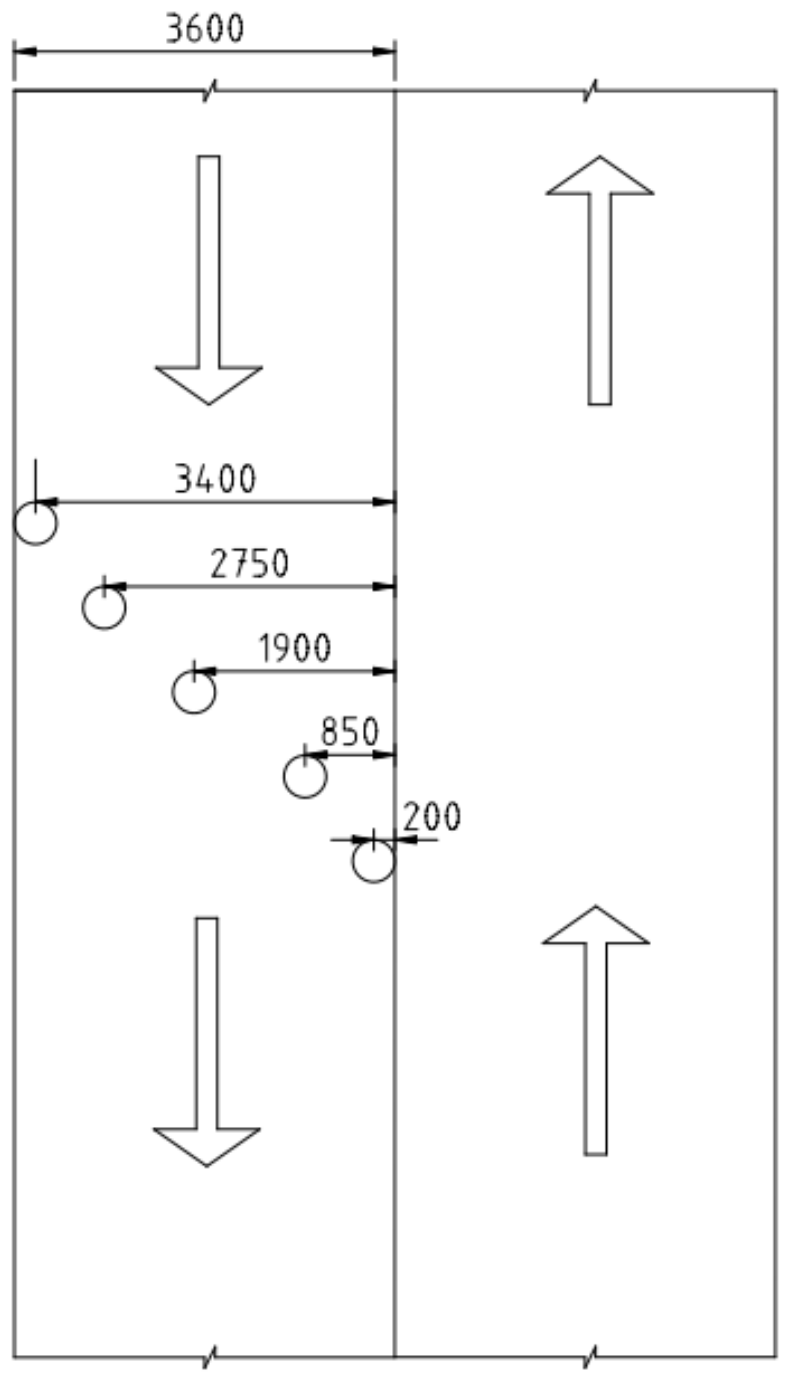

All Dimensions Are In Millimeter

Figure 3.3: In-Situ Permeability Testing Layout

The second phase of the experimental investigation included the use of the Superpave gyratory compactor (SGC) at Carleton University's J.A. Civil Engineering lab to prepare laboratory specimens corresponding to the same loose mixture of some of the selected sites for field inspection. This step was necessary to ensure that the collected field cores and the prepared laboratory specimens share the same material properties. The main objective of the prepared laboratory specimens is to compare the permeability of these 
laboratory specimens with the field-recovered cores and examine the existence of any possible relationship between the density and permeability of laboratory and field core samples. More details on the laboratory sample preparation using the Gyratory compactor will be presented later in this Chapter.

\subsection{Equipment and Methods}

\subsubsection{Field Permeability Testing}

To evaluate the in-situ permeability of the selected HMA pavement sites, the NCAT field permeameter was used. The testing mechanism of this device was explained earlier in Chapter two of the thesis. The following steps describe the procedure followed to measure the in-situ permeability:

1) A tape measure was used to mark the location of the testing spot to laterally cover one highway lane of $3.6 \mathrm{~m}$ width as previously explained,

2) The testing spot was cleaned to ensure proper application of the test procedure,

3) The sealant material (plumbing putty) was placed carefully around the bottom of the NCAT device,

4) The device was placed over the targeted testing spot,

5) Gentle pressures were applied to the square base of the device base to assure appropriate placement of the device,

6) Four equal loads (each weighted around $1 \mathrm{~kg}$ ) were added to the edges of the device base as presented in Figure 3.4 to resist the uplift pressure exerted by the water, 


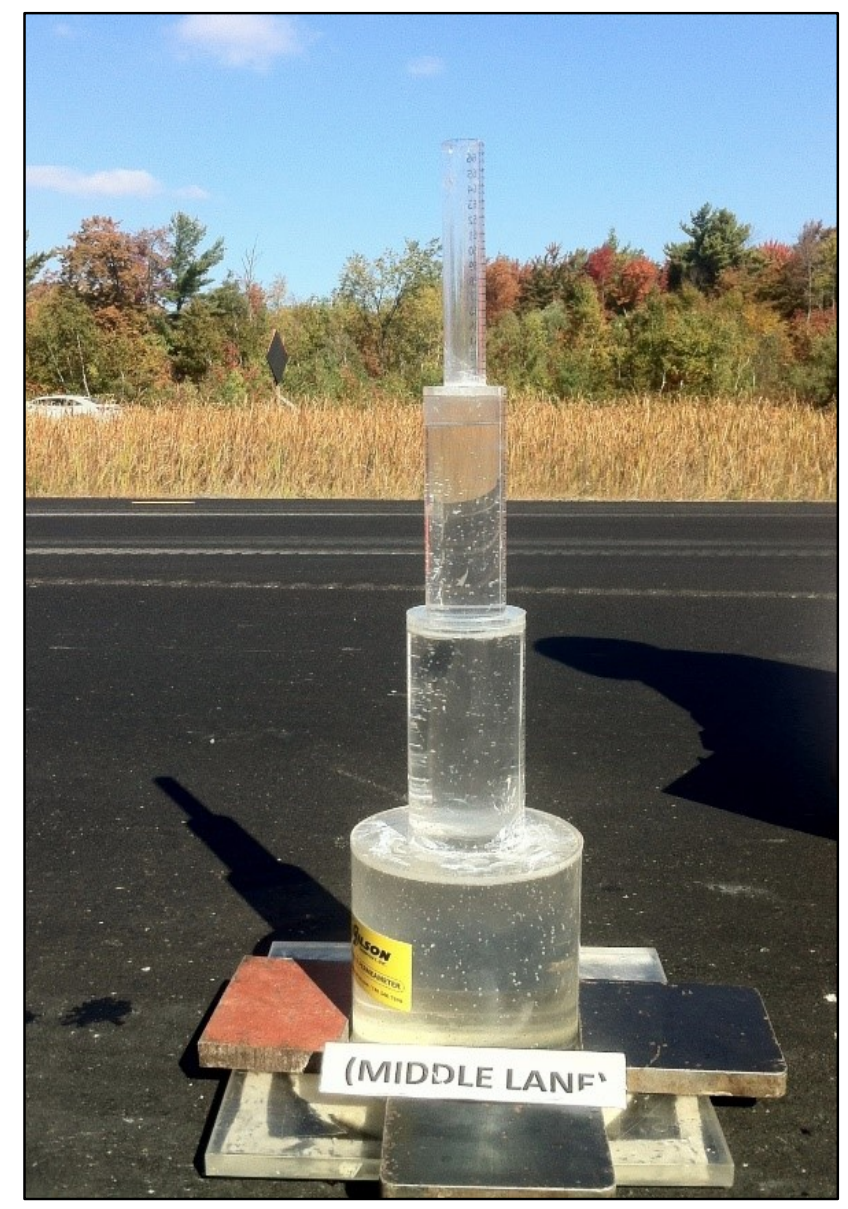

Figure 3.4: The NCAT Field Permeameter

7) The water temperature was checked using thermometer. This is essential to apply proper temperature correction for viscosity of water $\left(t_{c}\right)$ as shown in Equation 3.1,

8) Water was added using a hose attached to an elevated water tank as shown in Figure 3.5 , and 


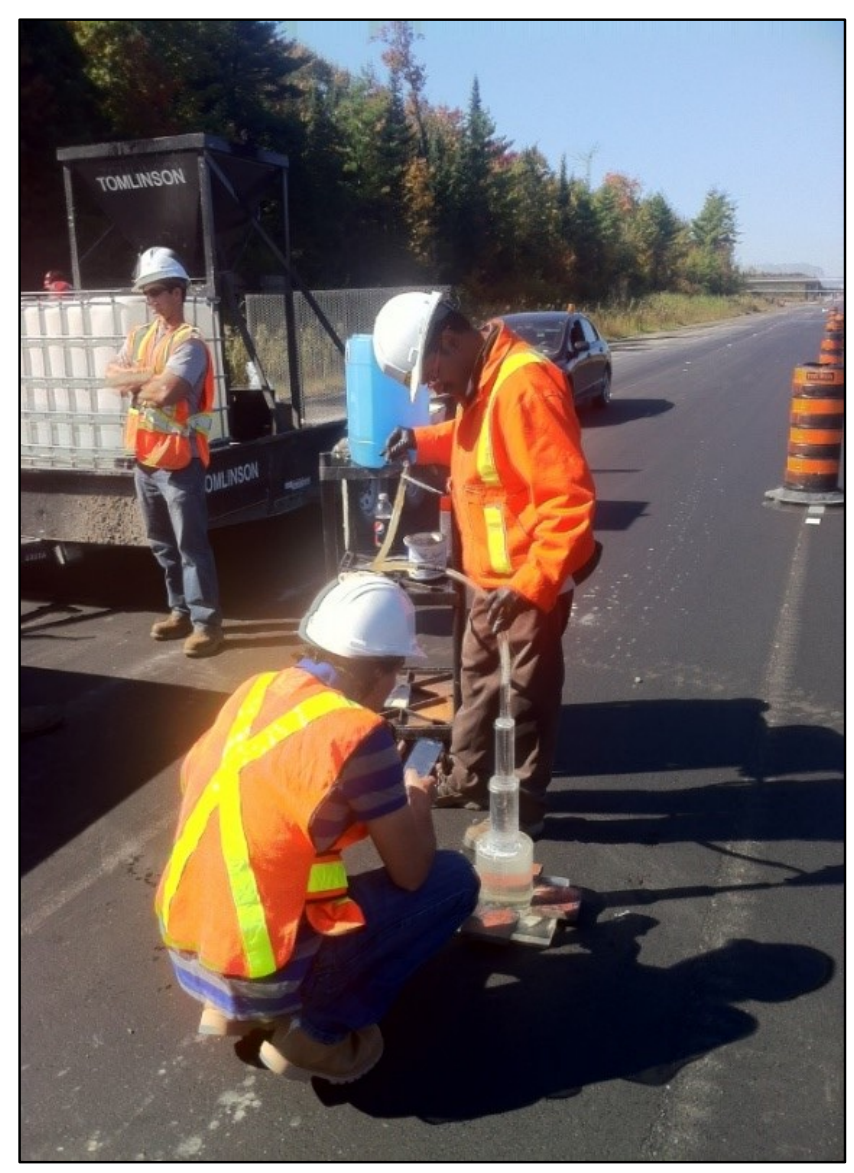

Figure 3.5: In-situ Permeability Test at Highway 16 Project

9) The time required for the water to drop from the top graduation mark (660 mm) of the tier with the smallest diameter to the bottom mark $(520 \mathrm{~mm})$ of the same tier was recorded.

In some cases where testing locations experienced relatively excessive permeability, causing water to drop fast in the first tier, the next tier was used. During the field investigations, any testing location that exhibited any water leakage signs was discarded and repeated elsewhere. Core extraction was performed on the exact location where the field permeability test was conducted. The coefficient of permeability was calculated using Equation 3.1. In all sites, the thickness of the asphalt layer $(L)$ was estimated by measuring the thickness of the field-recovered cores. 
$k=\frac{a L}{\mathrm{At}} \ln \left(\frac{h_{1}}{h_{2}}\right) t_{c}$

Equation 3.1

where:

$K=$ coefficient of permeability $(\mathrm{mm} / \mathrm{sec})$,

$a=$ inside cross-section area of standpipe $\left(\mathrm{mm}^{2}\right)$,

$L=$ thickness of the asphalt layer (mm),

$A=$ circular cross-sectional area of tested pavement $\left(\mathrm{mm}^{2}\right)$,

$h_{l}=$ initial head $(\mathrm{mm})$,

$h_{2}=$ final head $(\mathrm{mm})$,

$t=$ elapsed time between $h_{1}$ and $h_{2}(\mathrm{sec})$, and

$t_{c}=$ temperature correction for viscosity of water $\left(20^{\circ} \mathrm{C}\right.$ is used as the standard $)$.

\subsubsection{Laboratory Permeability Testing}

The laboratory permeability (hydraulic conductivity) of the test specimen was estimated using the Karol-Warner Asphalt permeameter that is shown in Figure 3.6. In this study, the Florida Test Method (FM 5-565) was followed to determine the laboratory permeability values [Florida Test Method, 2012]. Similar to the NCAT mechanism, the testing is based on the falling head principle to estimate the water flow rate through the pavement specimen. The required time for the water to drop from an initial level to a final level in the graduated cylinder is recorded and used to determine the sample's hydraulic conductivity. The testing assumptions to determine the laboratory permeability entail having a one dimensional flow of water while maintaining a laminar flow condition, applying the test to homogenous saturated samples, using incompressible fluid, and reaching a steady state flow condition [Cooley, 1999]. By assuming that Darcy's law 
is valid and applicable for pavement cores, the hydraulic conductivity can be estimated using Equation 3.1 that is previously presented.

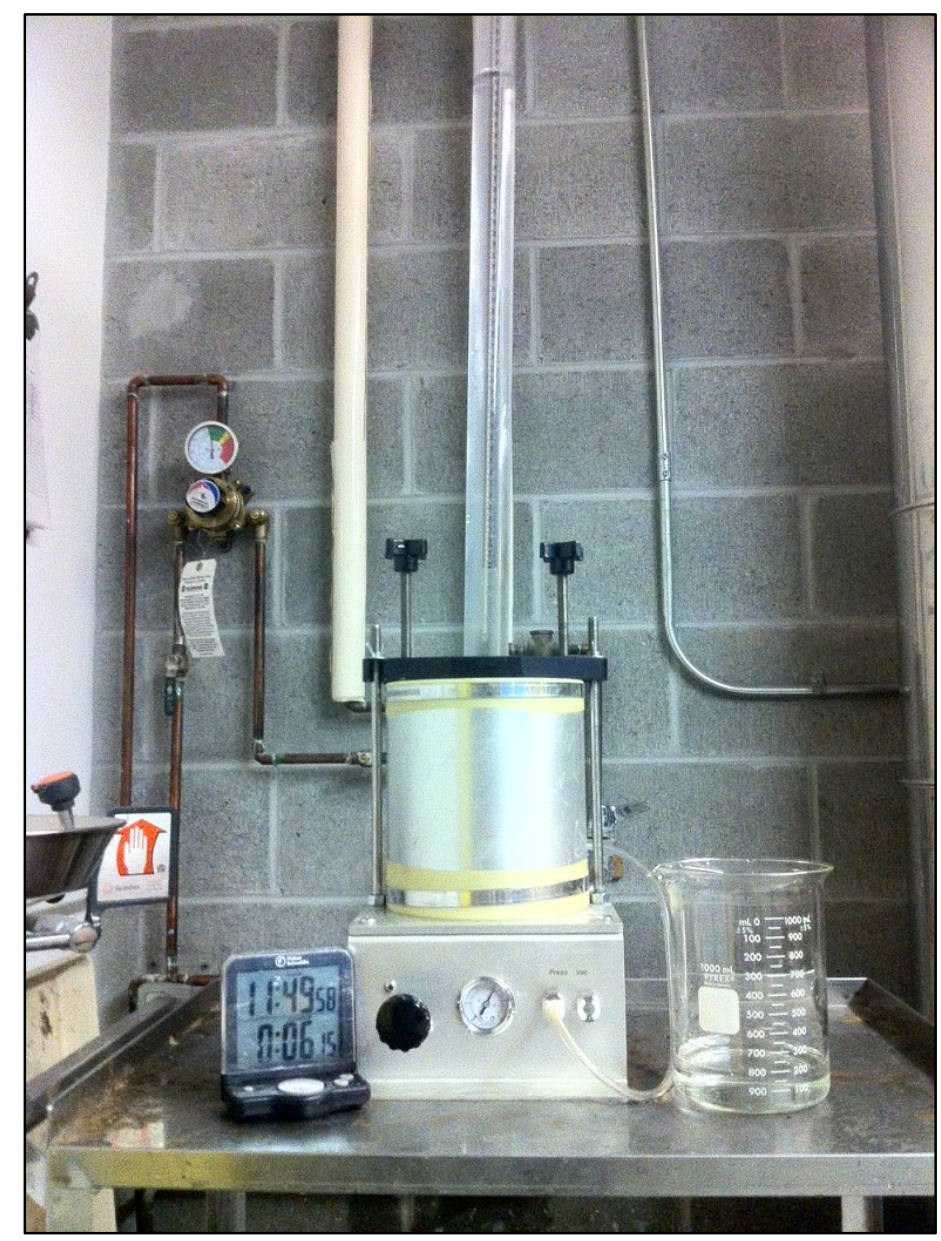

Figure 3.6: Karol-Warner Asphalt Permeameter

The Karol-Warner apparatus consists of several components (Figure 3.7); a metal cylinder that is opened from its top and bottom, a flexible membrane that wraps up the inside circumferential surface of the metal cylinder, two pedestal plates (top and bottom) to seal the metal cylinder, a graduated cylinder that is placed at the top pedestal plate, an air pump capable of applying $103 \mathrm{kPa}$ pressure in addition to evacuating the air from the flexible membrane, an O-rings used for preserving a seal against the pressurized flexible membrane, a pressure gauge ranging from 0 to $103 \mathrm{kPa}$, and an outlet pipe. 


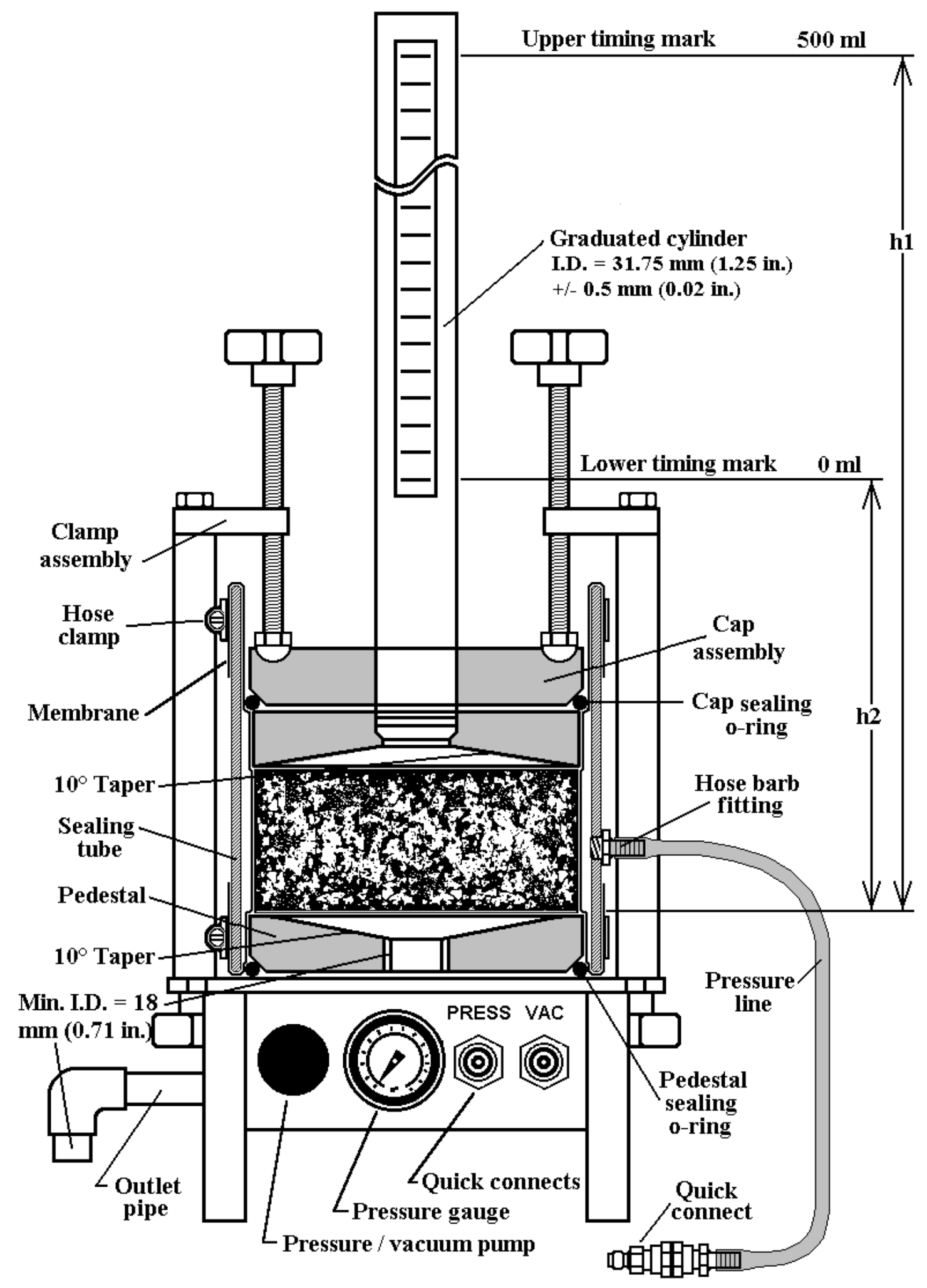

Figure 3.7: Schematic the Lab Permeability Apparatus (Not to Scale) [Florida Test Method, 2012] 
In this research, the following steps were undertaken to estimate the laboratory permeability:

1) Wrap the inside circumferential surface of the metal cylinder with the flexible membrane,

2) Use the air pump to evacuate any existing air from the flexible membrane,

3) Place and center the test specimen at the lower pedestal plates,

4) Place the metal cylinder over the lower pedestal plate to cover the test specimen,

5) Insert the upper pedestal plate over the test specimen,

6) Install and tighten evenly the two clamp assemblies onto the apparatus frame,

7) Use the air pump to pressurize the flexible membrane to $68.9 \pm 3.4 \mathrm{kPa}$ and ensure that this pressure is kept constant throughout the experiment,

8) Measure the water temperature used in the experiment,

9) Add the water to the graduated cylinder till the lower meniscus of the water reaches the upper timing mark $\left(h_{1}\right)$, and

10) Record the time required for the water to reach the lower timing mark $\left(h_{2}\right)$.

\subsubsection{Bulk Specific Gravity Testing}

The testing protocol followed in this study to measure the bulk specific gravity $\left(G_{m b}\right)$ or the bulk relative density (BRD) of a compacted HMA samples is the saturated surface dry (SSD) method outlined in the ASTM D2726/D2726M-14 [ASTM, 2014]. The SSD method is the most common technique of finding the $G_{m b}$ of asphalt specimen [Borden, et al., 2003; Pavement Interactive, 2011]. As shown in Figure 3.8, the needed tools to conduct the test are balance (scale), water bath, and towel. 


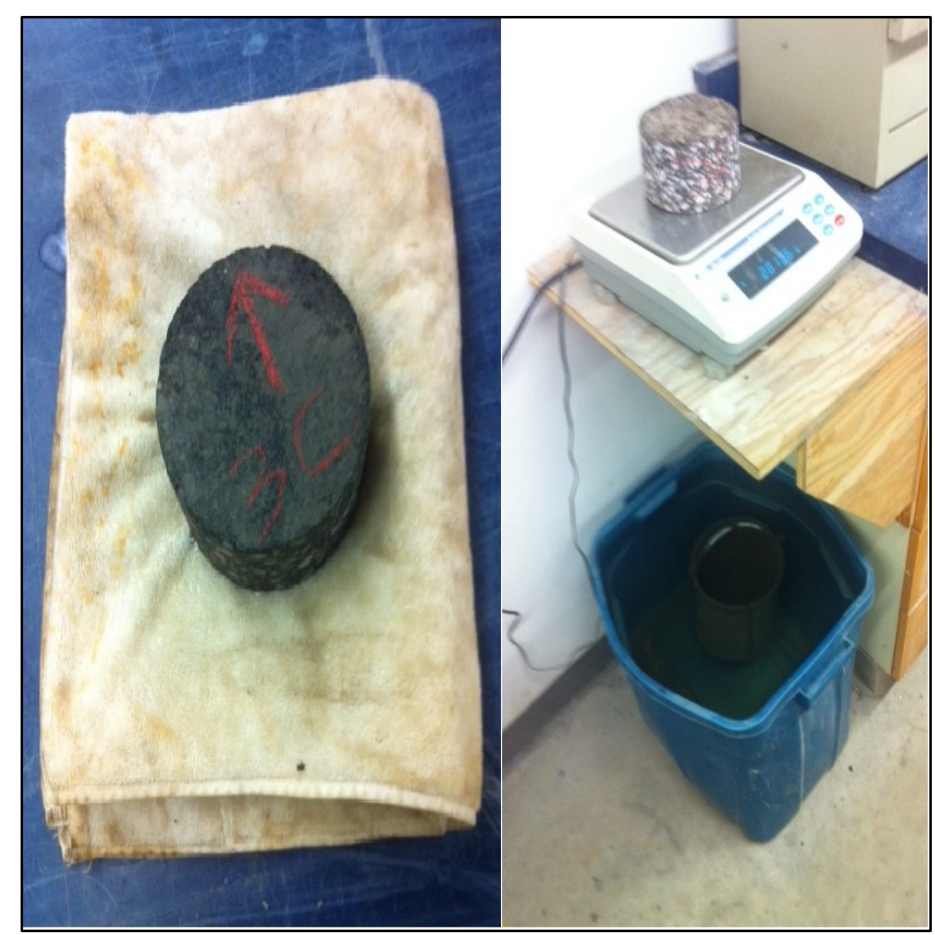

Figure 3.8: The Bulk Relative Density Testing Setup

The following steps describe the required procedure for estimating the bulk specific gravity of either laboratory prepared specimens or field-recovered cores:

1) Record the dry weight of the asphalt specimen by placing it over the scale,

2) Record the specimen weight after immersing it in a water bath for 4 to 5 minutes

3) Remove the specimen out of the water bath.

4) Damp-dry the wet specimen through rolling it one full roll on its side in addition to drying the sample's faces using damp towel; this creates a saturated surface dry condition,

5) Record the specimen weight during the saturated surface dry condition, and

6) Use Equation 3.2 to calculate the bulk specific gravity.

$G_{m b}=\frac{A}{B-C}$

Equation 3.2

where: 
$G_{m b}=$ bulk specific gravity,

$A=$ weight of specimen in air $(\mathrm{g})$,

$B=$ weight of surface dry specimen in air $(\mathrm{g})$, and

$C=$ weight of specimen in water $(\mathrm{g})$.

The ASTM D2726/D2726M-14 testing method implies that this test is only valid for samples that absorb maximum $2 \%$ of water by volume. As well, the specimen should not have open or interconnected voids. According to the same test method, the previously defined variables of Equation 3.3 can be re-arranged to quantify the amount of water absorbed by an asphalt sample as presented in.

percentage of water absorbed by volume $=\frac{B-A}{B-C} \times 100$

Equation 3.3

All calculated absorption percentages for the cores tested in the experimental program were less than $2 \%$ which indicates that the followed testing method to determine the $G_{m b}$ is valid as stated by the ASTM D2726/D2726M-14.

\subsubsection{IDT Testing}

The quality of the pavement mixtures can be evaluated by deploying the IDT on both the collected field cores and the SGC specimens as presented in Figure 3.9. The simplicity of carrying out the IDT test makes it a powerful technique that is considered by many researchers to assess one of the most fundamental pavement properties which is tensile strength. By correlating the mechanical or structural properties (strength) to the physical properties (permeability and density) of the pavement samples, one can have a better understanding of the main properties which may govern the long-term performance of different asphalt mixtures under service conditions. Also, the two physical properties can 
point out to some of the common asphalt shortcomings as the potential for rutting or cracking along with moisture-induced damage.

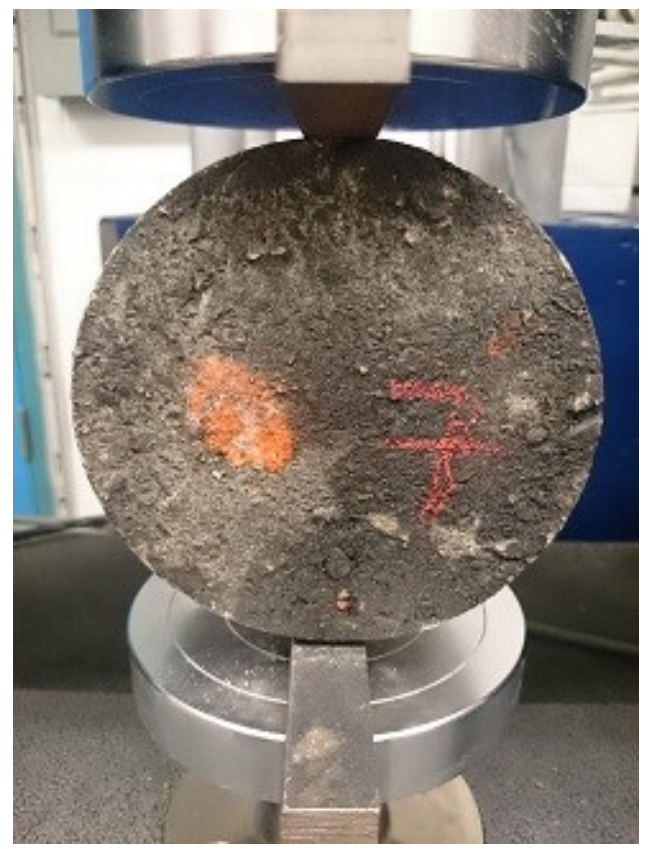

(a) Test Sample Before the IDT Test

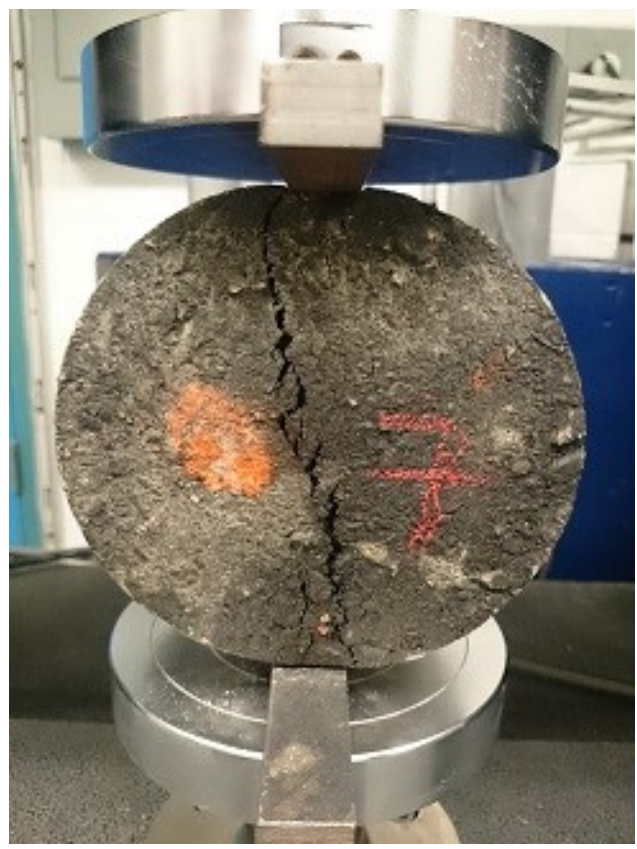

(b) Test Sample After the IDT Test

Figure 3.9: The IDT Test on One of the Field-Recovered Cores

Unlike the direct tensile test that is more applicable in evaluating the strength of large asphalt slabs, the IDT test method quantifies the strength of cylindrical specimens. In this research, the IDT test was conducted on both field cores and laboratory prepared specimens at Carleton's laboratory using an INSTRON series 5583 loading frame at a room temperature of $25^{\circ} \mathrm{C}$. The testing mechanism of the IDT entails a compressive loading to be applied across the diameter of a test specimen. This compressive load produces tensile stresses in the test specimen in a direction perpendicular to the vertical applied load. According to ASTM standard test method for IDT of bituminous mixtures D6931 [ASTM, 2012], the testing procedures are as follow:

1) Measure the specimen height or thickness $(t)$ and its diameter $(D)$, 
2) Place and center the specimen between the two steel strips,

3) Use the INSTRON to apply a compressive load at a rate of $50.8 \mathrm{~mm} / \mathrm{min}$,

4) Record the peak load $(P)$ which produces a failure condition, and

5) Use Equation 3.4 to calculate the IDT of the test specimen.

$S_{t}=\frac{2000 \times P}{\pi \times t \times D}$

Equation 3.4

where:

$S_{t}=$ IDT strength $(\mathrm{kPa})$,

$P=\operatorname{maximum} \operatorname{load}(\mathrm{N})$,

$t=$ specimen height immediately before test $(\mathrm{mm})$, and

$D=$ specimen diameter $(\mathrm{mm})$.

\subsubsection{The Superpave Gyratory Compactor}

The Gyratory compactor was utilized to compact the laboratory loose mix, provided by the MTO, at different compaction levels to simulate different field densities. Before the compaction stage using the SGC, four parameters were considered and calibrated including the specimen height, consolidation pressure, RAM travel speed, and turntable RPM. The calibration process was done according to the manual of operation and instruction supplied with the SGC. Figure 3.10 shows the laboratory apparatus employed in this research to prepare SGC specimens. 


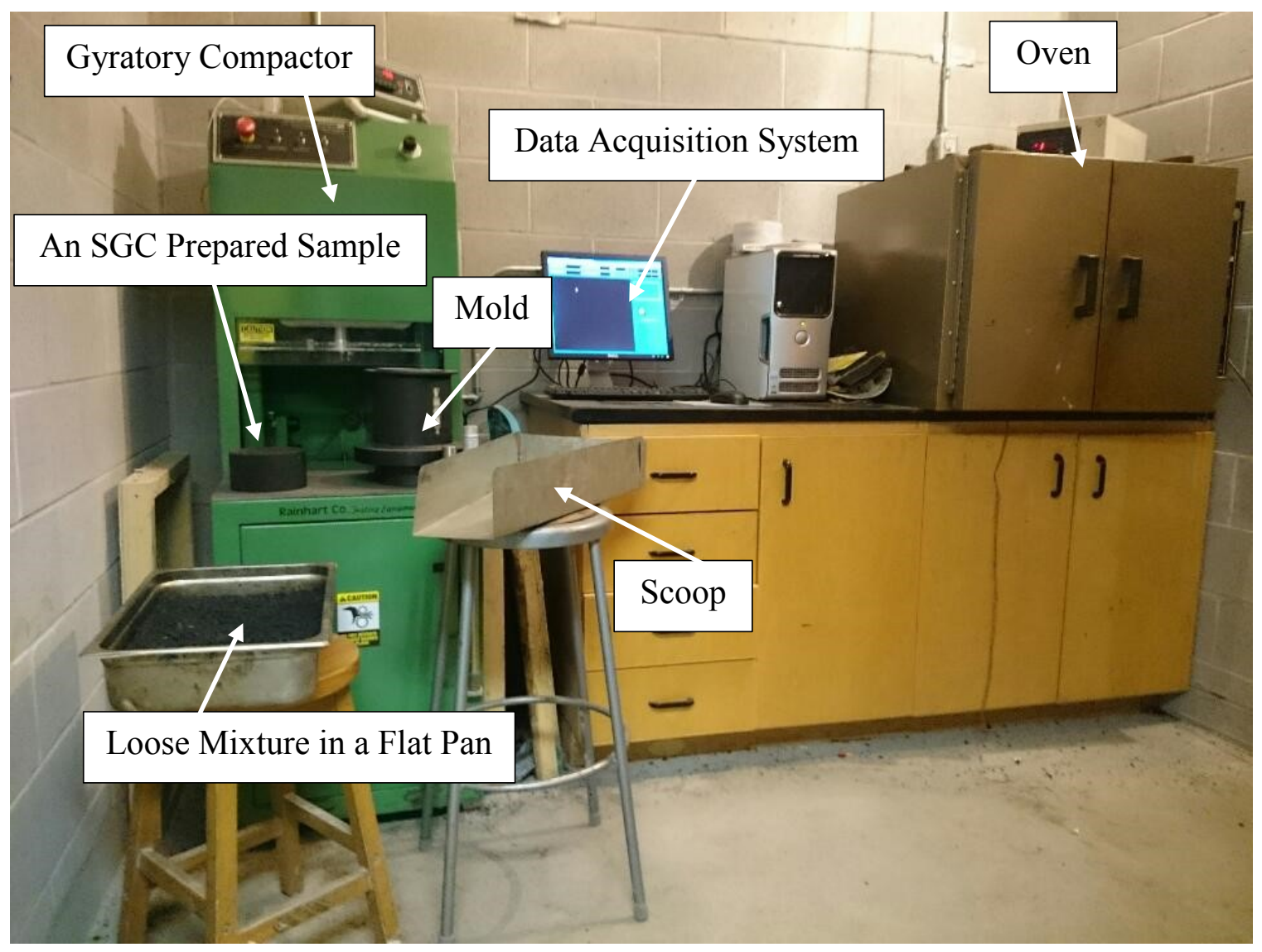

Figure 3.10: The Laboratory Apparatus Required for SGC Specimen Preparation

In this research, four different asphalt mixtures that are commonly adopted in Ontario highways were used to prepare several laboratory asphalt specimens of varied densities using the Gyratory compactor. The research scope was limited to only asphalt mixtures of 4 highway projects (Highway 15, 16, 17, and 417) and there was no loose mixture available for any of the in-house sites. Data related to the Superpave volumetric mix design were available for all mixes except for Highway 15 mix as it was not provided. The gradations of the three available mixture types are shown in Figure 3.11. The mix design specifications and the sieve analysis gradation for each mix are shown in Table 3.2 


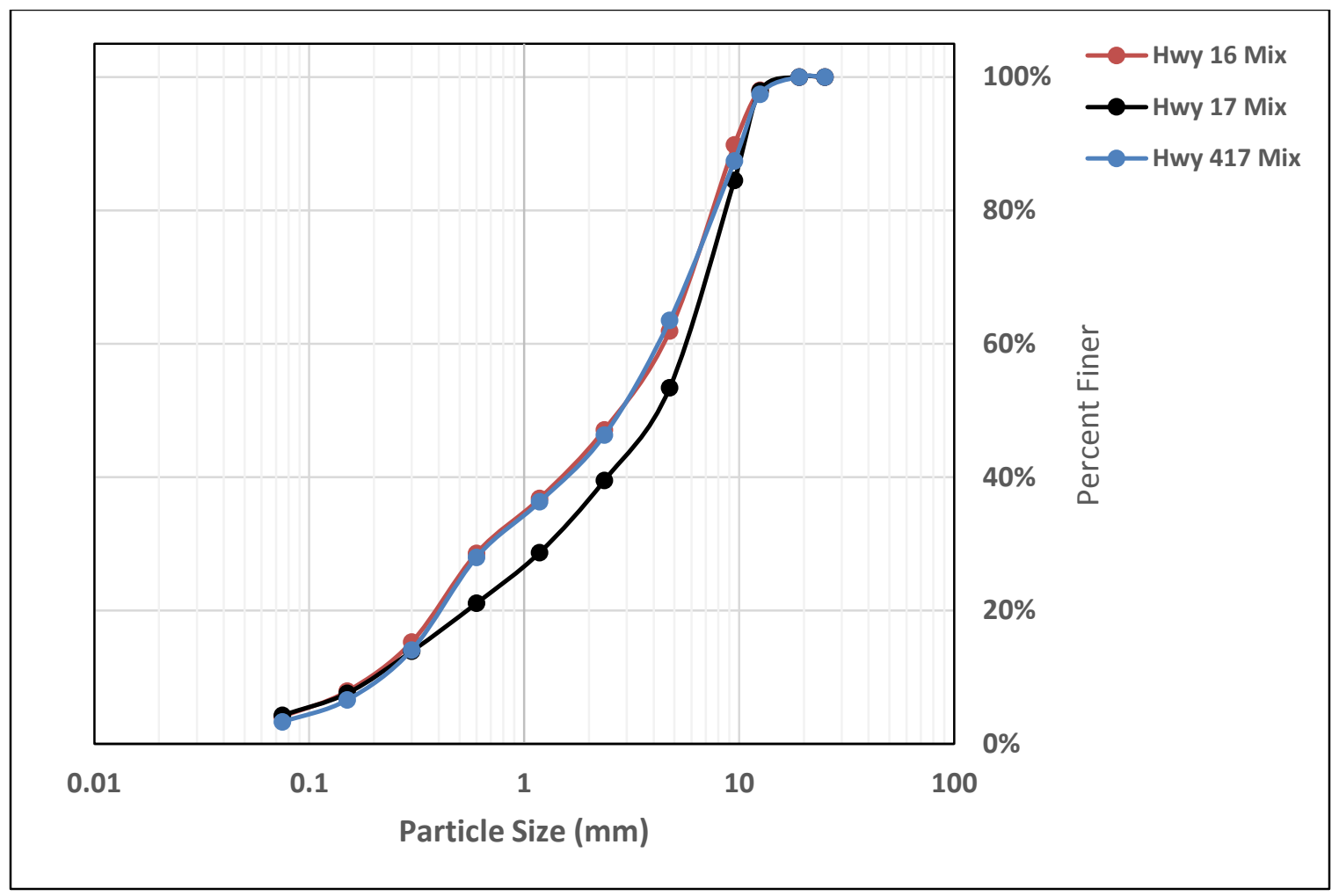

Figure 3.11: Seize Analysis Gradation for the Considered Mixtures

Table 3.2: Superpave Volumetric Mix Design and Properties of the Three Available Mixes

\begin{tabular}{cccc}
\hline Site Name & Highway $\mathbf{1 7}$ & Highway 417 & Highway 16 \\
\hline Number of Prepared Specimens & 7 & 12 & 7 \\
\hline NMAS & $12.5 \mathrm{~mm}$ & $12.5 \mathrm{~mm}$ & $12.5 \mathrm{~mm}$ \\
\hline Asphalt Binder Content & $5 \%$ & $4.8 \%$ & $4.8 \%$ \\
\hline Hot Mix Type & SP 12.5 Cat C & $12.5 \mathrm{FC} 2$ & $12.5 \mathrm{FC} 2 \mathrm{RAP}$ \\
\hline Traffic Category & $\mathrm{C}$ & $\mathrm{E}$ & $\mathrm{E}$ \\
\hline Sieve Size (mm) & \multicolumn{3}{c}{ Percentage Passing (\%) } \\
\hline 25 & 100 & 100 & 100 \\
\hline 19 & 100 & 100 & 100 \\
\hline 12.5 & 97.9 & 97.4 & 98 \\
\hline 9.5 & 84.5 & 87.4 & 69.8 \\
\hline 4.75 & 53.4 & 63.5 & 47.1 \\
\hline 2.36 & 39.5 & 46.3 & 36.8 \\
\hline 1.18 & 28.7 & 36.3 & 28.6 \\
\hline 0.6 & 21.1 & 28.0 & 15.3 \\
\hline 0.3 & 13.9 & 14.1 & 4.9 \\
\hline 0.15 & 7.6 & 6.6 & \\
\hline 0.075 & 4.3 & 3.3 & \\
\hline & & & \\
\hline
\end{tabular}


The MTO uses the term "Percent Compaction" to accept/reject field achieved densities [MTO, 2004]. The term "Percent Compaction" is equivalent to the common term "Relative density" which is defined as the ratio between the density achieved in the field and the theoretical maximum density measured in the laboratory. To simulate different compaction efforts achieved in the field, four levels of relative density were targeted and achieved using the Gyratory compactor. Several trials or iterations were performed in order to quantify the amount of loose mixture required to produce the targeted compaction levels. After producing an SGC specimen of anticipated compaction level (say level C), the relative density of that specimen was checked. If the measured relative density does not fall within the level specification range, the specimen was re-compacted and the amount of loose mixture was increased or decreased depending on the case. This iterative process was performed until the desirable amount of loose mixtures is determined. The four compaction levels were:

- Level D (unacceptable compaction),

- Level C (fair compaction),

- Level B (excellent compaction) and

- Level A (maximum theoretical compaction).

In order to prepare an asphalt laboratory specimen using the Gyratory compactor, one of two main inputs must be set. These two inputs are the specimen height or the number of gyrations. Table 3.3 gives details of the proposed four relative density levels. For the last three compaction levels (B, C, and D), the weight of loose mix as well as the specimen height was entered while not specifying the number of gyrations. This means that the 
number of gyrations for the compaction levels B, C, and D were varied and the Gyratory compactor selected the appropriate number of gyrations needed for each level. However, for the compaction level $\mathrm{A}$, the number of gyrations was set to the maximum number which is 998 gyrations and subsequently the specimen height was not defined as an input. The final specimen height ranged from 103 to $110 \mathrm{~mm}$ depending on the mixture type. It is important to note that due to the limited quantities of loose asphalt mixture of Highways 15, 16 and 17, only seven specimens were produced at different compaction levels while twelve specimens were prepared using Highway 417 mix.

Table 3.3: The Different Compaction Levels of SGC Specimens.

\begin{tabular}{|c|c|c|c|c|c|c|c|}
\hline \multirow[b]{2}{*}{$\begin{array}{c}\text { Compaction } \\
\text { Level }\end{array}$} & \multirow[b]{2}{*}{$\begin{array}{c}\text { Total No. } \\
\text { of } \\
\text { Specimens }\end{array}$} & \multicolumn{2}{|c|}{ Input Variables } & \multirow[b]{2}{*}{$\begin{array}{c}\text { Relative } \\
\text { Density } \\
\text { Range (\%) }\end{array}$} & \multirow{2}{*}{$\begin{array}{c}\text { Loose } \\
\text { Mix } \\
\text { Weight } \\
\text { (g) }\end{array}$} & \multirow[b]{2}{*}{$\begin{array}{c}\text { Compaction } \\
\text { Temperature } \\
\left({ }^{\circ} \mathrm{C}\right)\end{array}$} & \multirow[b]{2}{*}{$\begin{array}{c}\text { Final } \\
\text { Height } \\
(\mathbf{m m})\end{array}$} \\
\hline & & $\begin{array}{l}\text { Height } \\
\text { (mm) }\end{array}$ & $\begin{array}{c}\text { No. of } \\
\text { Gyrations }\end{array}$ & & & & \\
\hline $\mathbf{A}$ & 6 & - & 998 & $97<\mathrm{A}$ & 4602 & 145 & $103-110$ \\
\hline B & 9 & 90 & - & $93<\mathrm{B}<97$ & 3260 & 145 & 78 \\
\hline $\mathrm{C}$ & 9 & 90 & - & $89<\mathrm{C}<93$ & 3081 & 145 & 78 \\
\hline D & 9 & 80 & - & $\mathrm{D}<89$ & 2320 & 145 & 63 \\
\hline
\end{tabular}

The following procedure summarizes the required steps for preparing an SGC specimen:

1) Determine the desired compaction level and subsequently the required loose mix weight according to Table 3.3,

2) Place the weighted loose mixture in a flat pan,

3) Place the flat pan (with the loose mix) inside the oven until the compaction temperature of $145^{\circ} \mathrm{C}$ is reached, 
4) Place the compaction mold, the bottom and top base plate inside the oven 30 to 45 minutes prior to the compaction process at temperature close to the compaction temperature $\left(150{ }^{\circ} \mathrm{C}\right.$ was used in this research). This is necessary to prevent heat loss due to the possible difference in temperatures between the mold and the heated mix.

5) Carefully remove the pre-heated mold and plates from the oven,

6) Place bottom base plate and a paper disc at the mold's bottom,

7) Use a scoop to carefully place the heated mixture into the mold,

8) Level the mixture evenly,

9) Add another paper disc and the top base plate on the leveled surface of the mixture,

10) Place the mold inside the Gyratory compactor and center it under the loading ram,

11) Define the input parameter (the targeted height or the number of gyrations),

12) Input the consolidation pressure as $600 \mathrm{kPa}$, the angular velocity as 30 gyrations/min, and the gyratory angle as $1.25^{\circ}$ into the connected data acquisition system,

13) Start the compaction process, and

14) Remove the SGC sample from the Gyratory compactor and let it cool at the room temperature $\left(25^{\circ} \mathrm{C}\right)$. 
For each prepared specimen of each mixture, the density, laboratory permeability, and IDT were determined using the laboratory test methods discussed earlier. Firstly, the bulk relative density test was performed for all prepared samples followed by the laboratory measurement of their permeability, and finally the determination of the IDT.

\subsection{Summary}

In summary, this chapter presented the experimental program followed to accomplish the research objectives. The testing program included field and laboratory investigations of newly and in-service roads finished by two distinctly different compaction methods. The next chapter will present the results of the field and laboratory carried investigations. 


\section{CHAPTER 4: RESULTS OF THE}

\section{EXPERIMENTAL PROGRAM}

The previous chapter explained the testing program including explanations of the conducted experiments in two different settings; the field and laboratory. This chapter presents the results obtained from both the field and laboratory investigations. The chapter consists of two main sections. The first section provides results of the measured permeability values in the field, the second section deals with presenting the laboratory investigations incorporating both the measurements and results of the SGC specimens as well as the results of the laboratory testing on the collected field cores.

\subsection{Field Investigations}

This section of the chapter is devoted to display the field investigation test results of nine inspected sites, which included seven highway projects and two in-house asphalt pavement projects in Ontario. The in-situ field investigations were initiated during the summer of 2012 and continued until the late fall of 2014.

Table 4.1 summarizes all sites examined in this study, the compaction method used at each site, and the implemented type of investigation. In total, five (out of the total of nine) sites are common projects where the two compaction techniques were used. The field results obtained by the two different compaction techniques are present in this section. Firstly, the field results of various sites paved and compacted by the conventional vibratory steel drum and pneumatic train rollers are illustrated. Secondly, the results of field investigations on sites compacted by the AMIR-II roller are presented for the purpose of comparison. 
Table 4.1: Summary of all Examined Projects from 2012 to 2014

\begin{tabular}{ccc}
\hline Year & Site Name & Compaction Technique \\
\hline \multirow{2}{*}{2012} & Highway 28 & Conventional and Advanced \\
\cline { 2 - 3 } & Tomlinson Field Trial & Conventional and Advanced \\
\cline { 2 - 3 } & Thousand Islands Parkway & Conventional and Advanced \\
\hline & Highway 15 (i) & Conventional Only \\
\cline { 2 - 3 } & Highway 15 (ii) & Conventional Only \\
\cline { 2 - 3 } & Highway 16 & Conventional Only \\
\cline { 2 - 3 } & Highway 17 & Conventional Only \\
\cline { 2 - 3 } & Highway 417 & Conventional Only \\
\cline { 2 - 3 } & Highway 28 & Conventional and Advanced \\
\cline { 2 - 3 } & Thousand Islands Parkway & Conventional and Advanced \\
\hline \multirow{2014}{*}{ Highway 34 Bridge } & Conventional and Advanced \\
\cline { 2 - 3 } & Greenbelt Trial One & Conventional and Advanced \\
\cline { 2 - 3 } & Greenbelt Trial Two & Conventional and Advanced \\
\hline
\end{tabular}

\subsubsection{Conventional Compaction Methods}

This subsection of the chapter summarizes the results obtained for three different years of field permeability measurements covering new and in-service sites finished by the conventional compaction techniques.

\subsubsection{A Field Results of Year 2012}

The in-situ permeability was measured using the NCAT device for all sites considered in this study. In 2012, three sites were inspected right after completing the compaction phase. Two of them were Ontario highway projects (Highway 28 and Thousand Islands 
Parkway) while the other one was an in-house field trial carried out at Power Road Tomlinson site. The results of in-situ permeability and testing locations are shown in Figure 4.1 through Figure 4.3. The testing locations at Highway 28 project in 2012 were not available due to incomplete data.

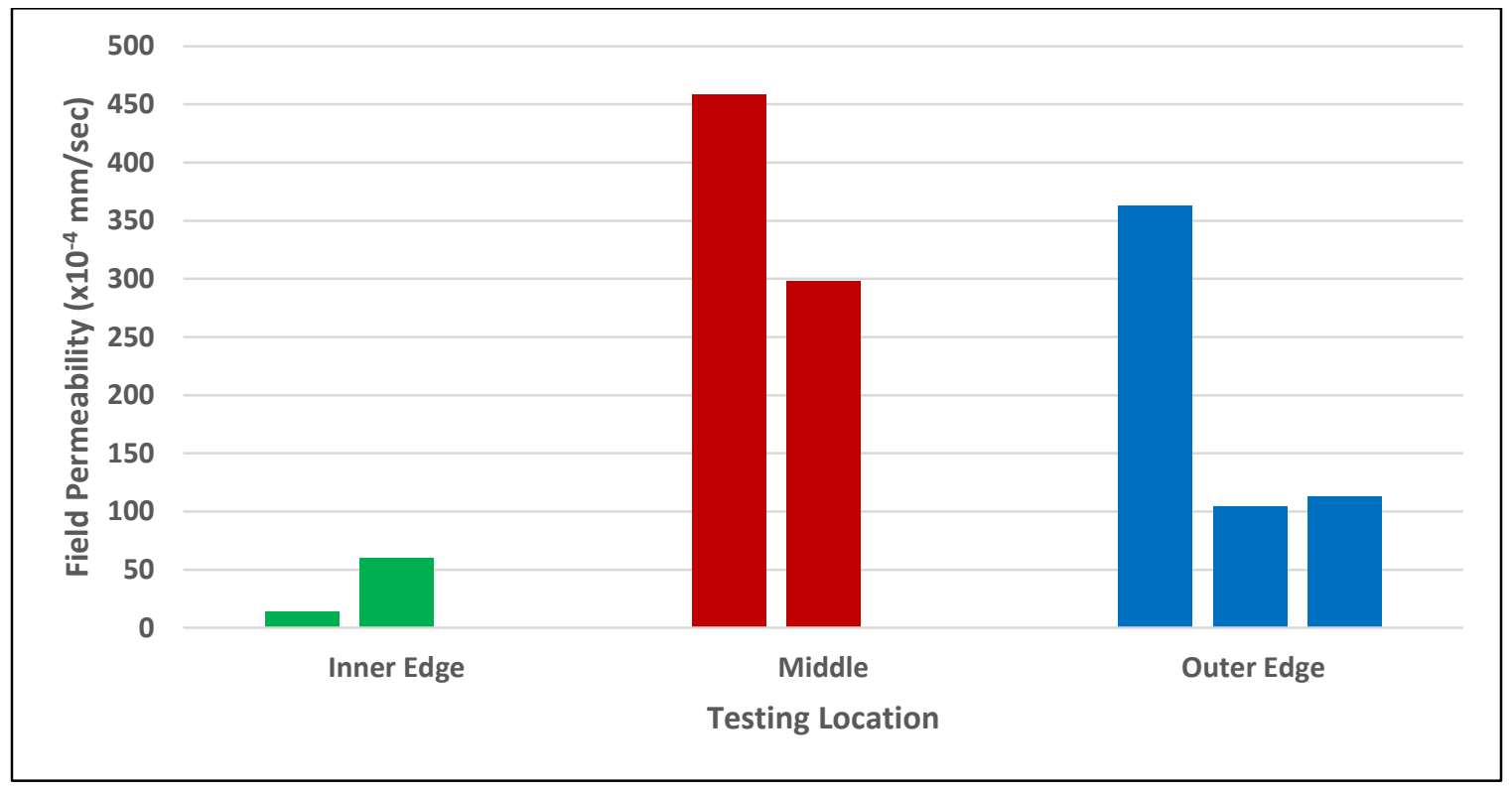

Figure 4.1: Field Permeability Result of Tomlinson In-house Field Trial (2012)

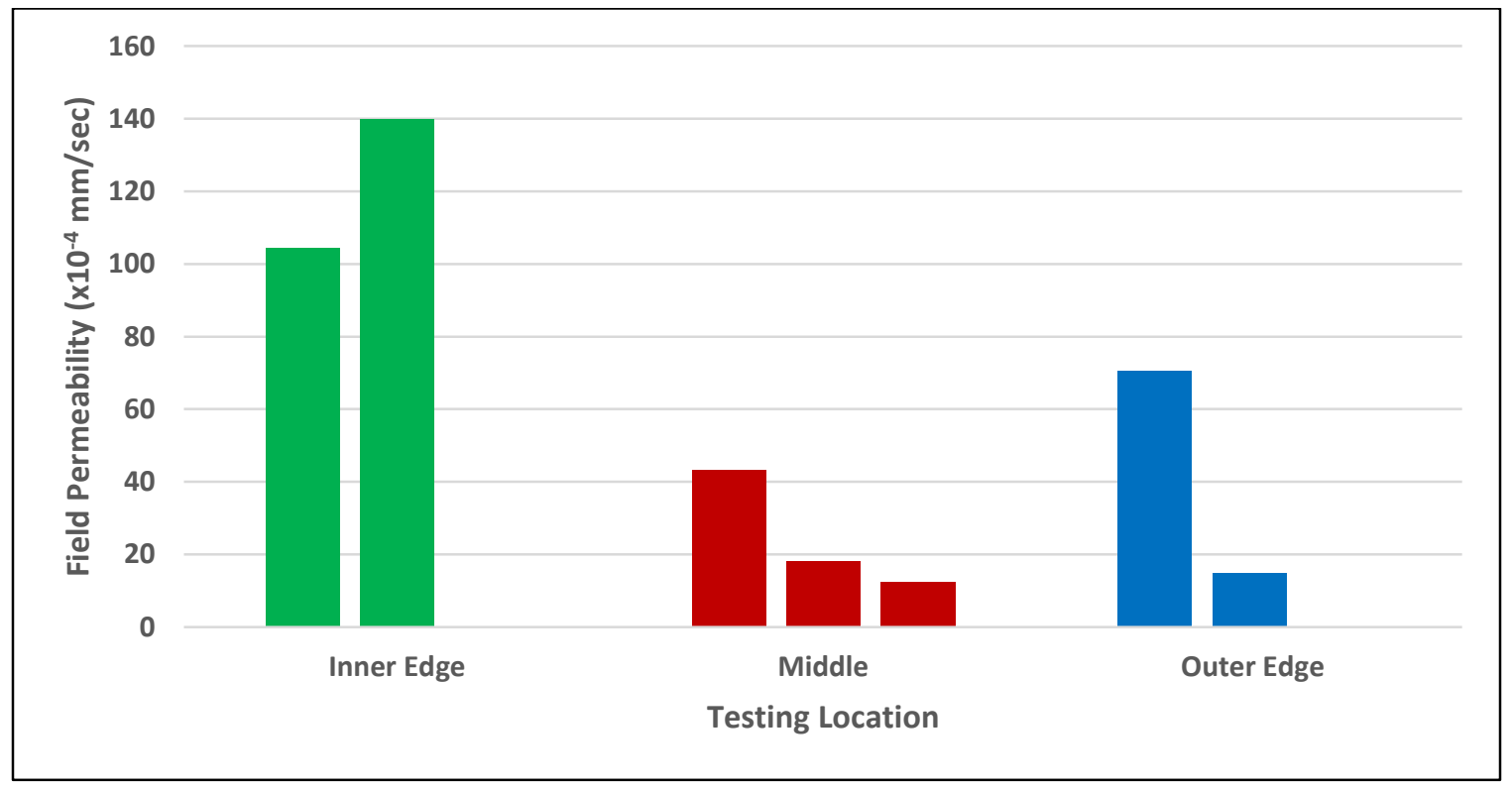

Figure 4.2: Field Permeability Result of Thousand Islands Parkway (2012) 


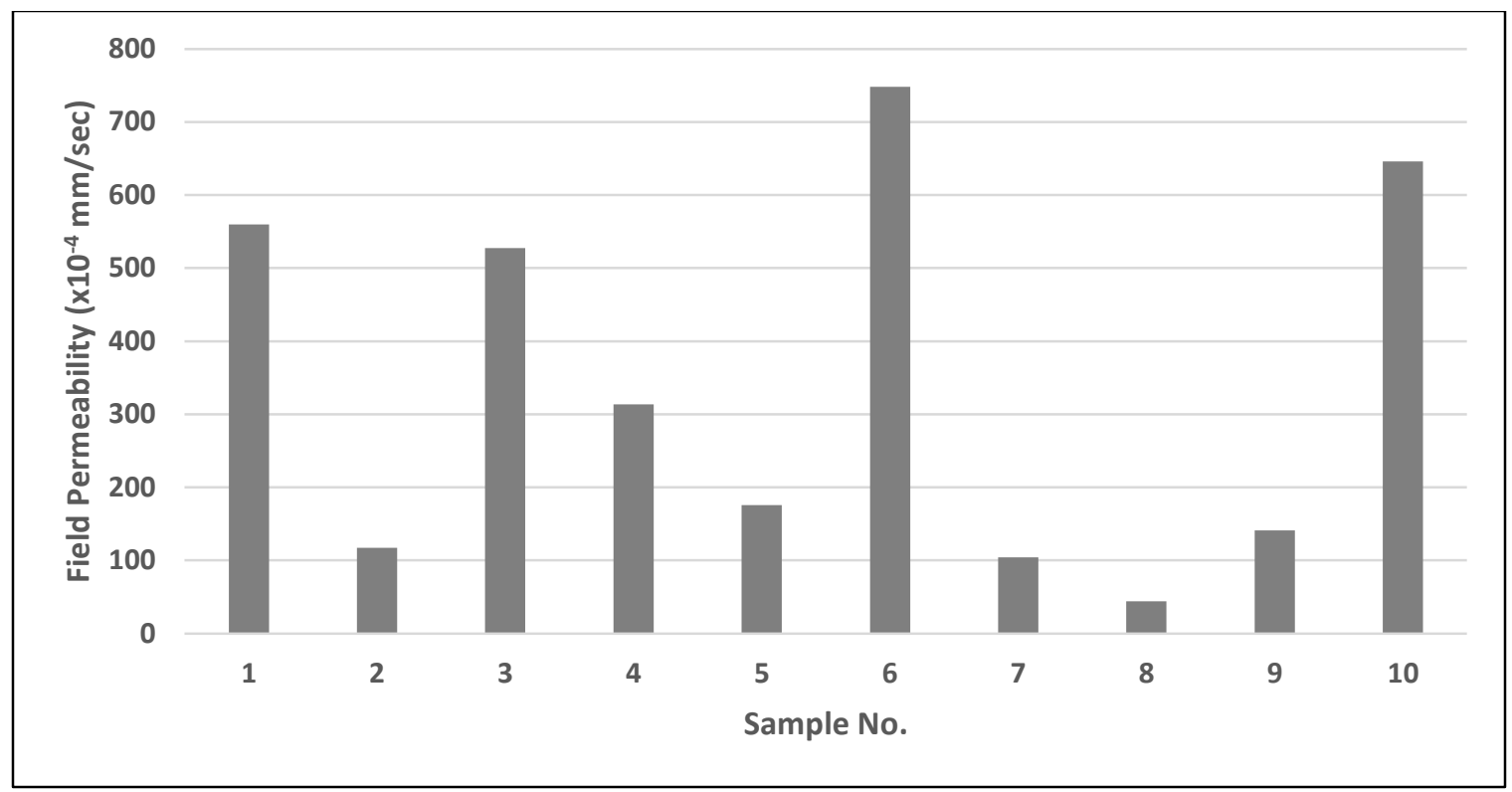

Figure 4.3: Field Permeability Result of Highway 28 (2012)

\subsubsection{B Field Results of Year 2013}

Majority of the field permeability measurements were conducted in 2013 as seven highway projects were selected in consultation with engineers from MTO for the in-situ permeability testing investigation in addition to an in-house controlled section performed on one of Tomlinson sites in Ottawa. For Highway 28 and Thousand Islands Parkway sites, the focus was to perform the permeability test at three testing locations; the lane inner edge, middle and lane outer edge as stated earlier. For the remaining five sites, two more lateral locations were added. The bar charts shown in Figure 4.4 through Figure 4.11 present the field permeability measurements and the testing locations for the seven sites. 


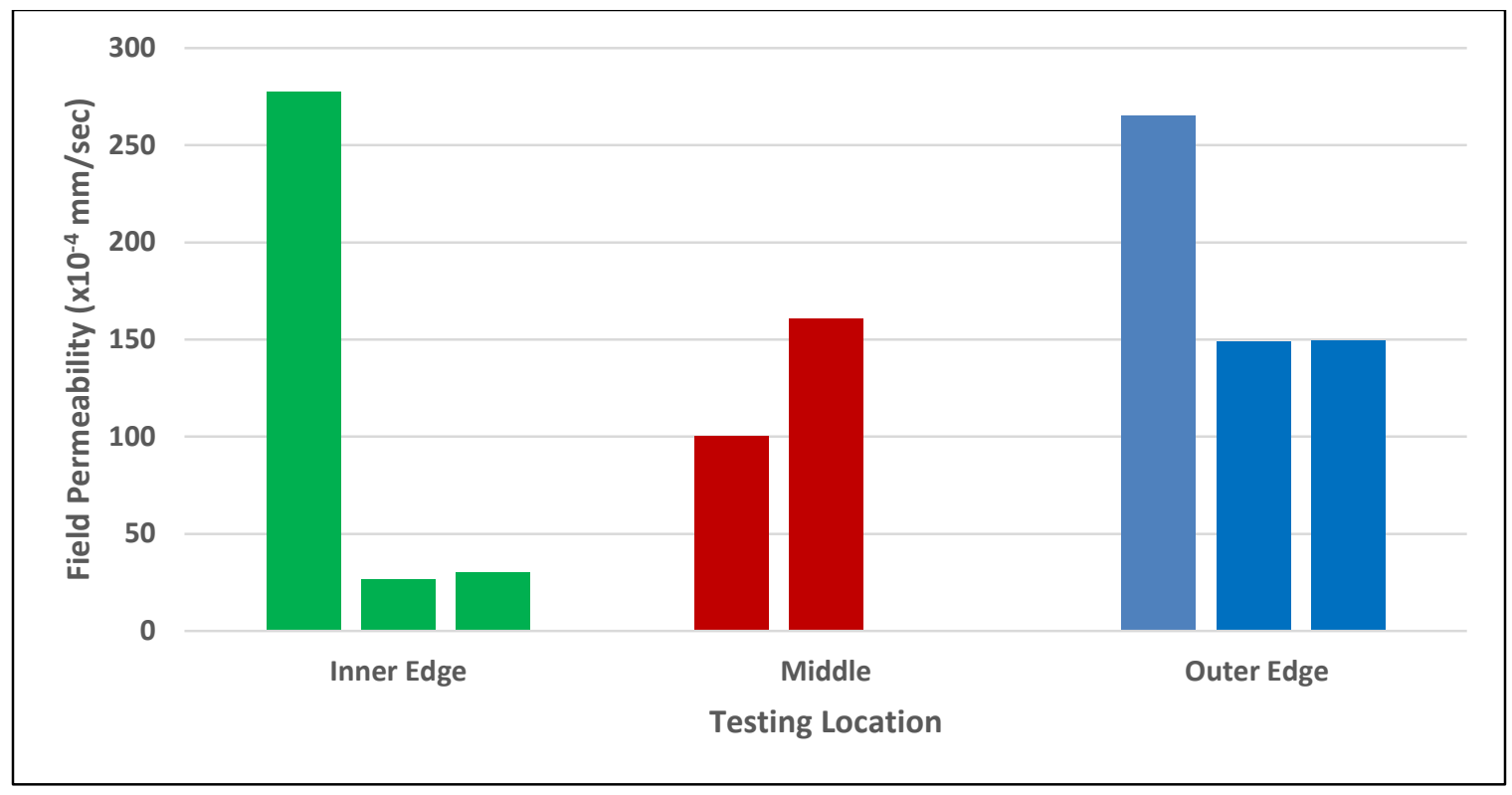

Figure 4.4: Field Permeability Result of Tomlinson In-house Field Trial (2013)

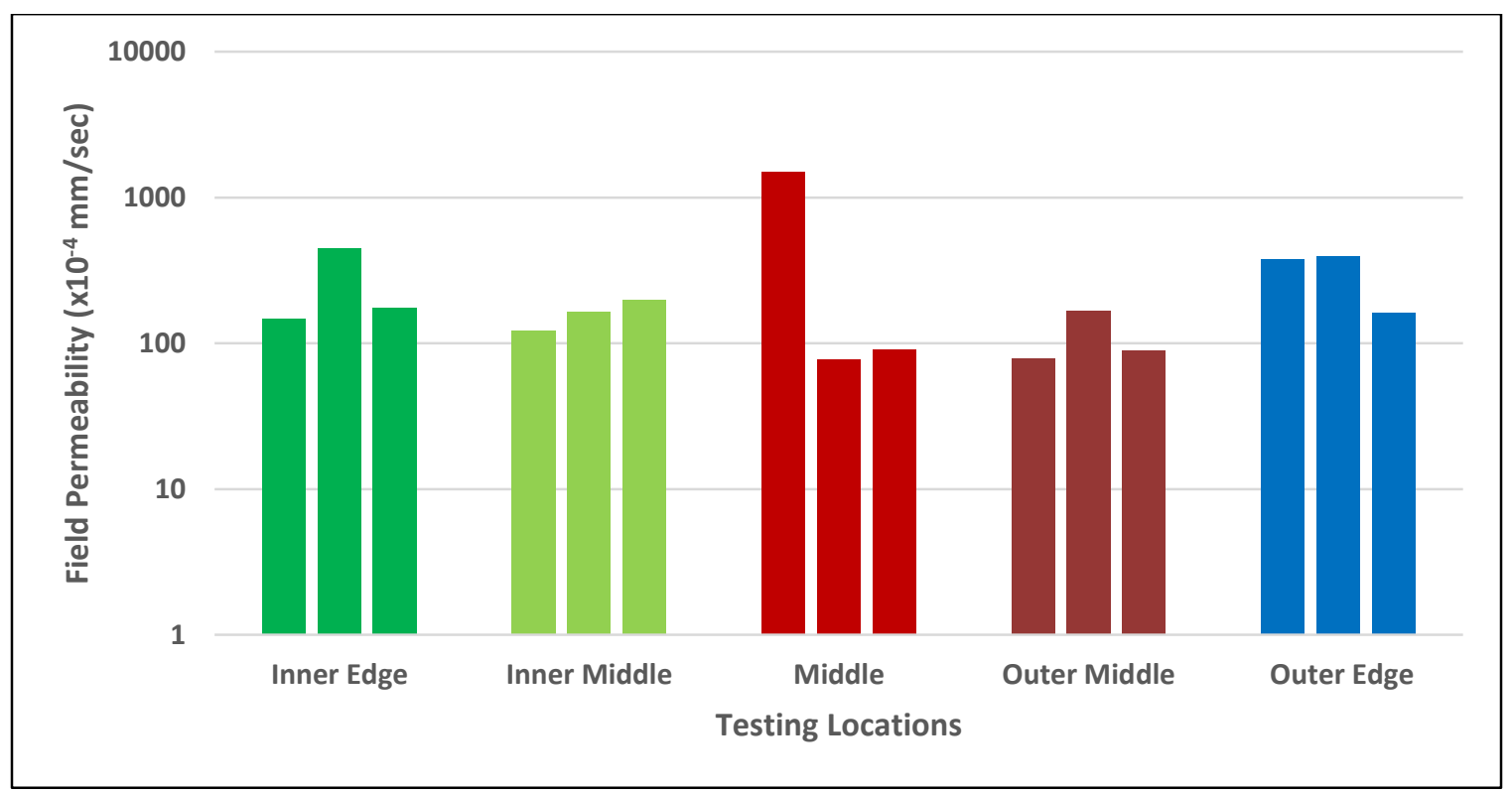

Figure 4.5: Field Permeability Result of Highway 16 (2013) 


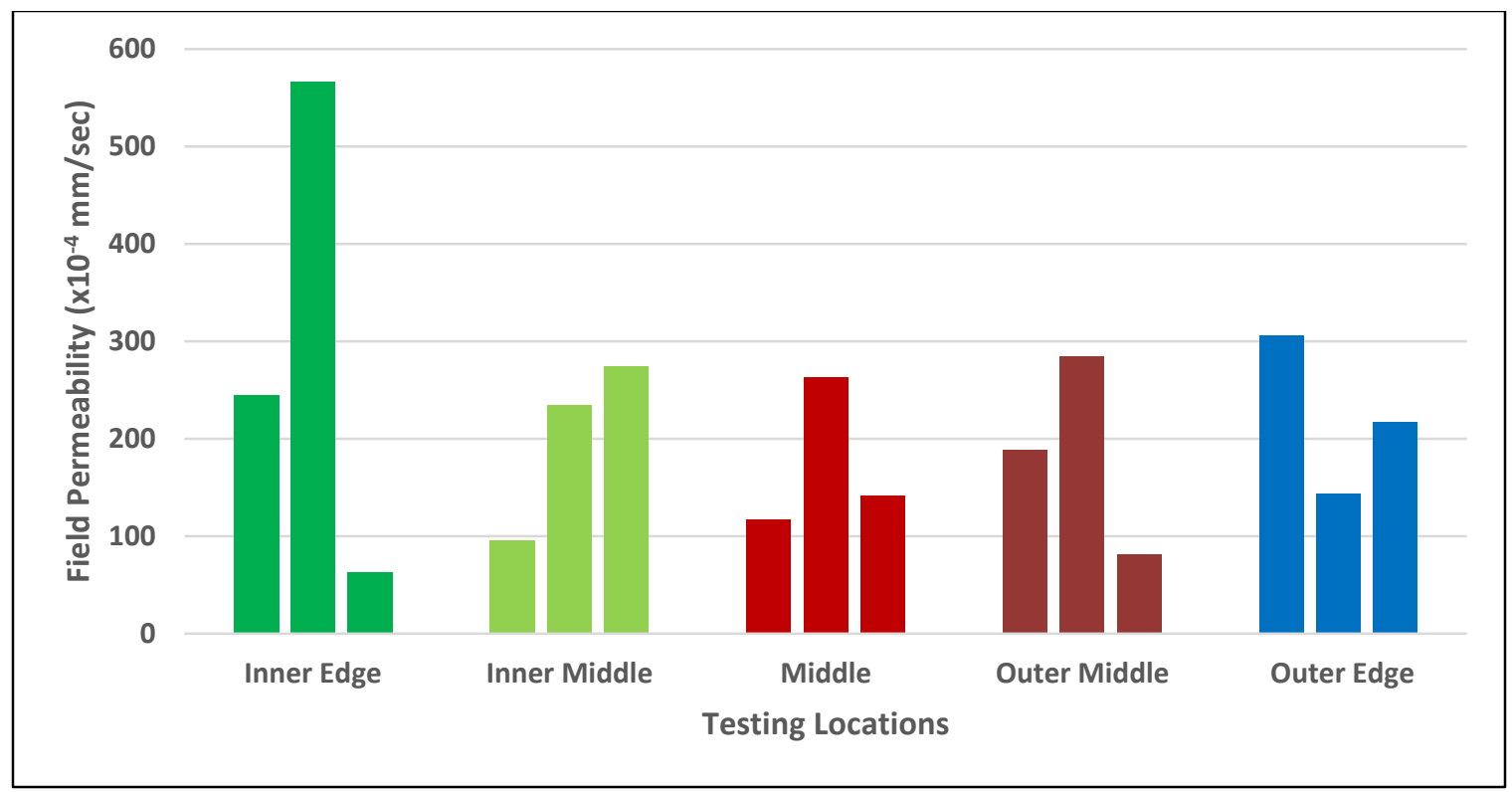

Figure 4.6: Field Permeability Result of Highway 17 (2013)

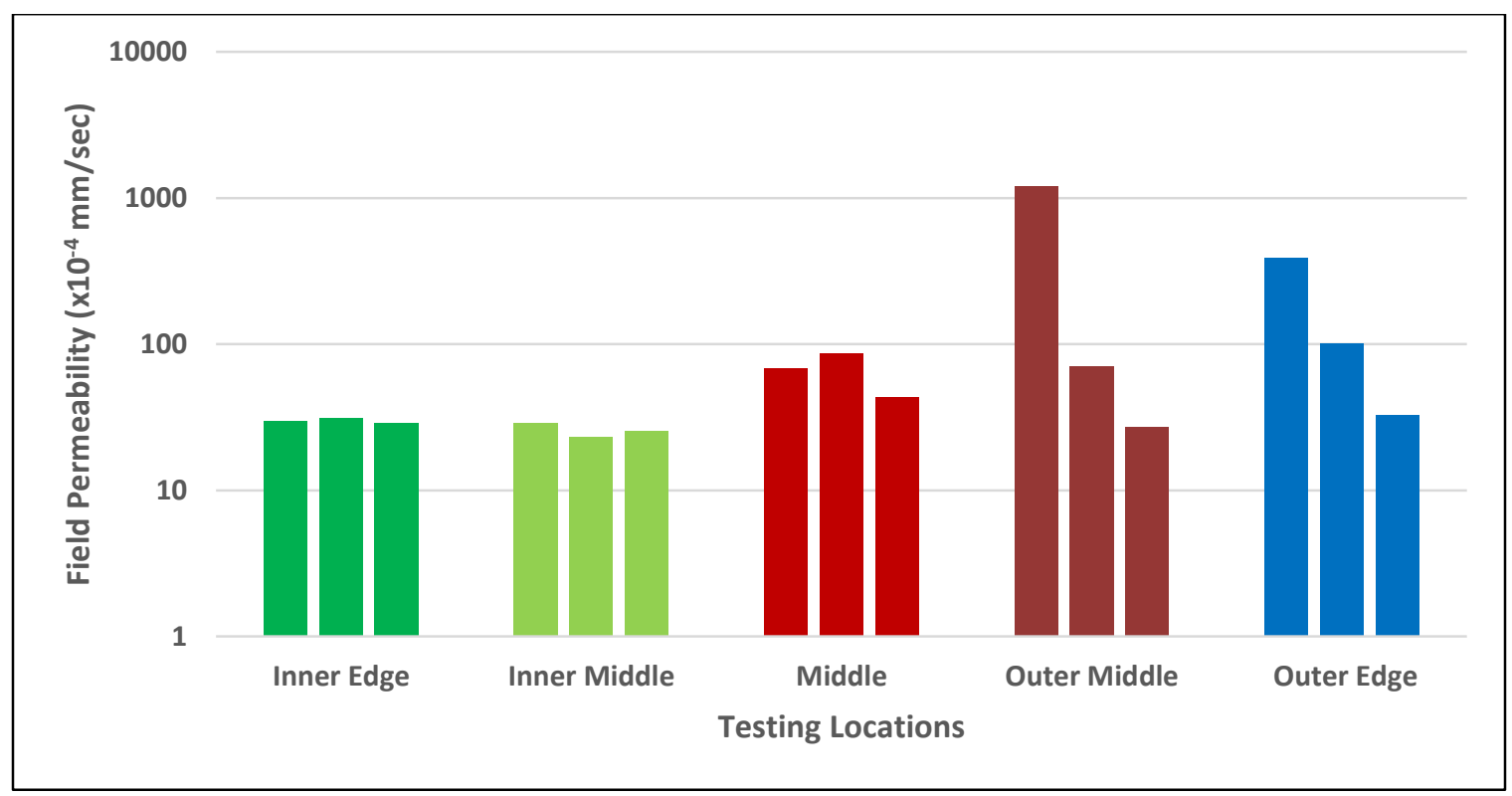

Figure 4.7: Field Permeability Result of Highway 417 (2013) 


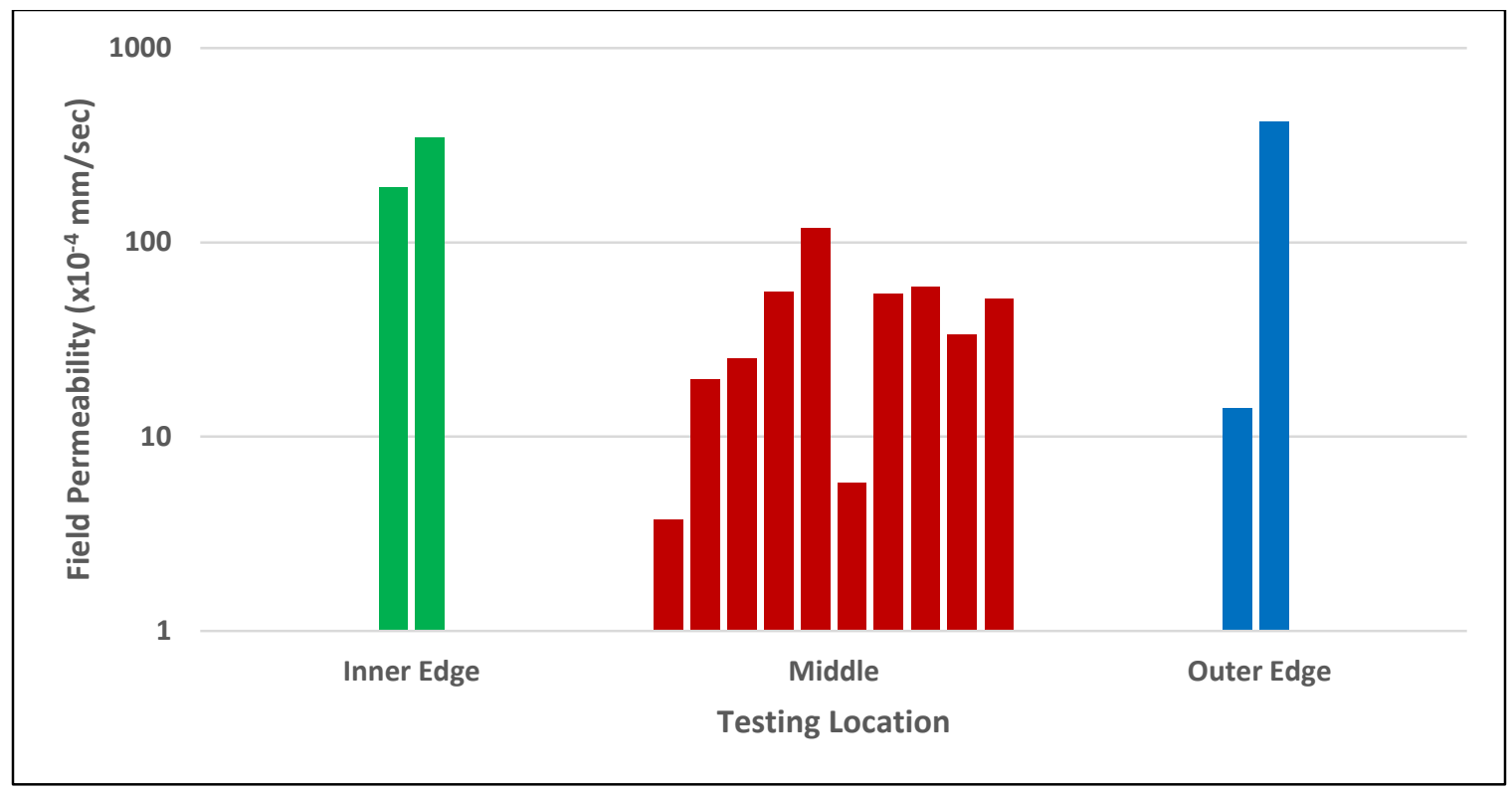

Figure 4.8: Field Permeability Result of Highway 28 (2013)

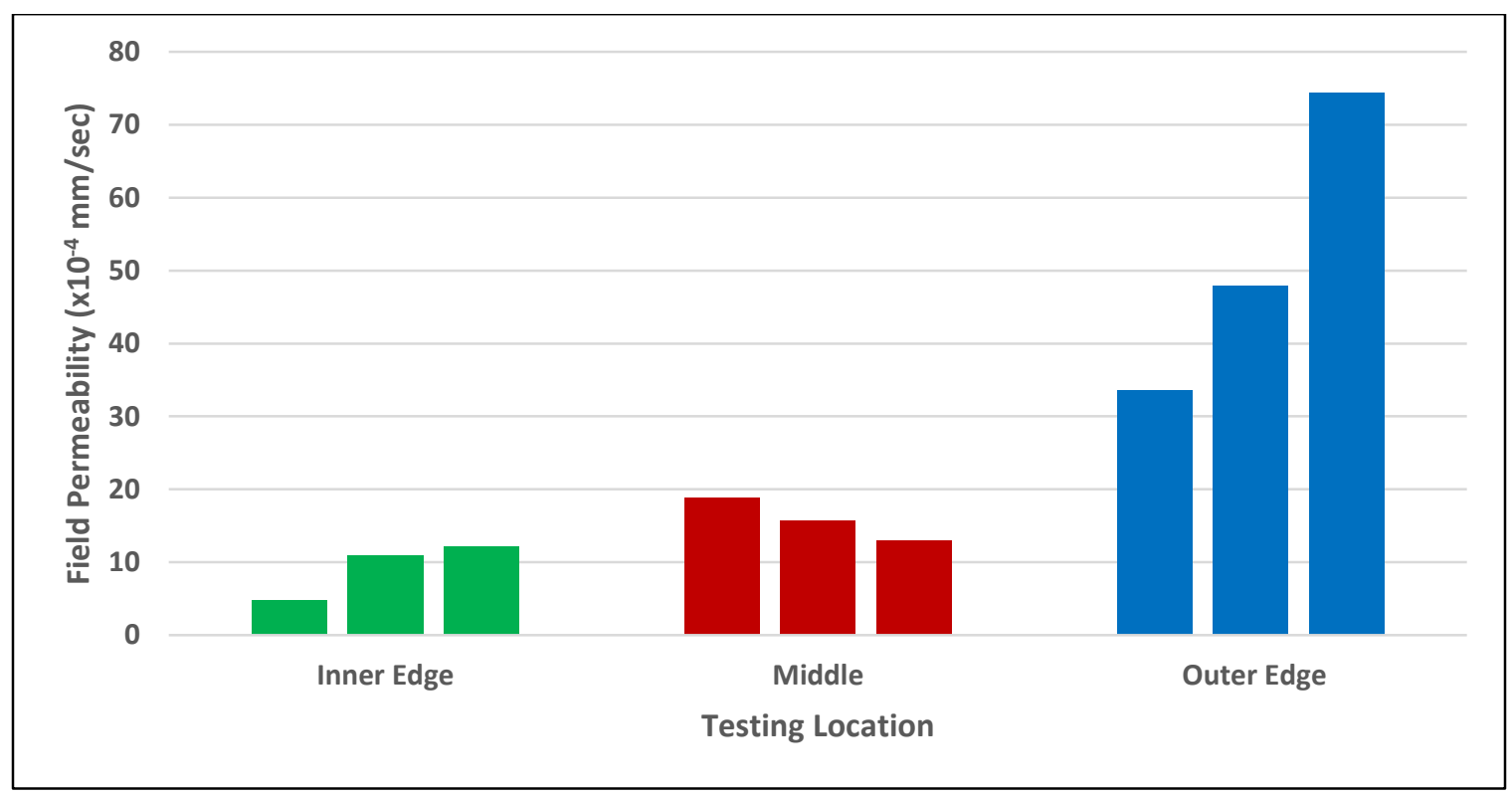

Figure 4.9: Field Permeability Result of Thousand Islands Parkway (2013)

The Microsurfacing application in Eastern Region was applied to several highways such as Highways 7, 15, 28, 62 and 416 [MTO, 2004]. In this study, Highway 15 site was inspected twice to perform the field permeability test; before and after the Microsurfacing 
application. The permeability results of before and after Microsurfacing with their testing locations are shown in Figure 4.10 and Figure 4.11, respectively.

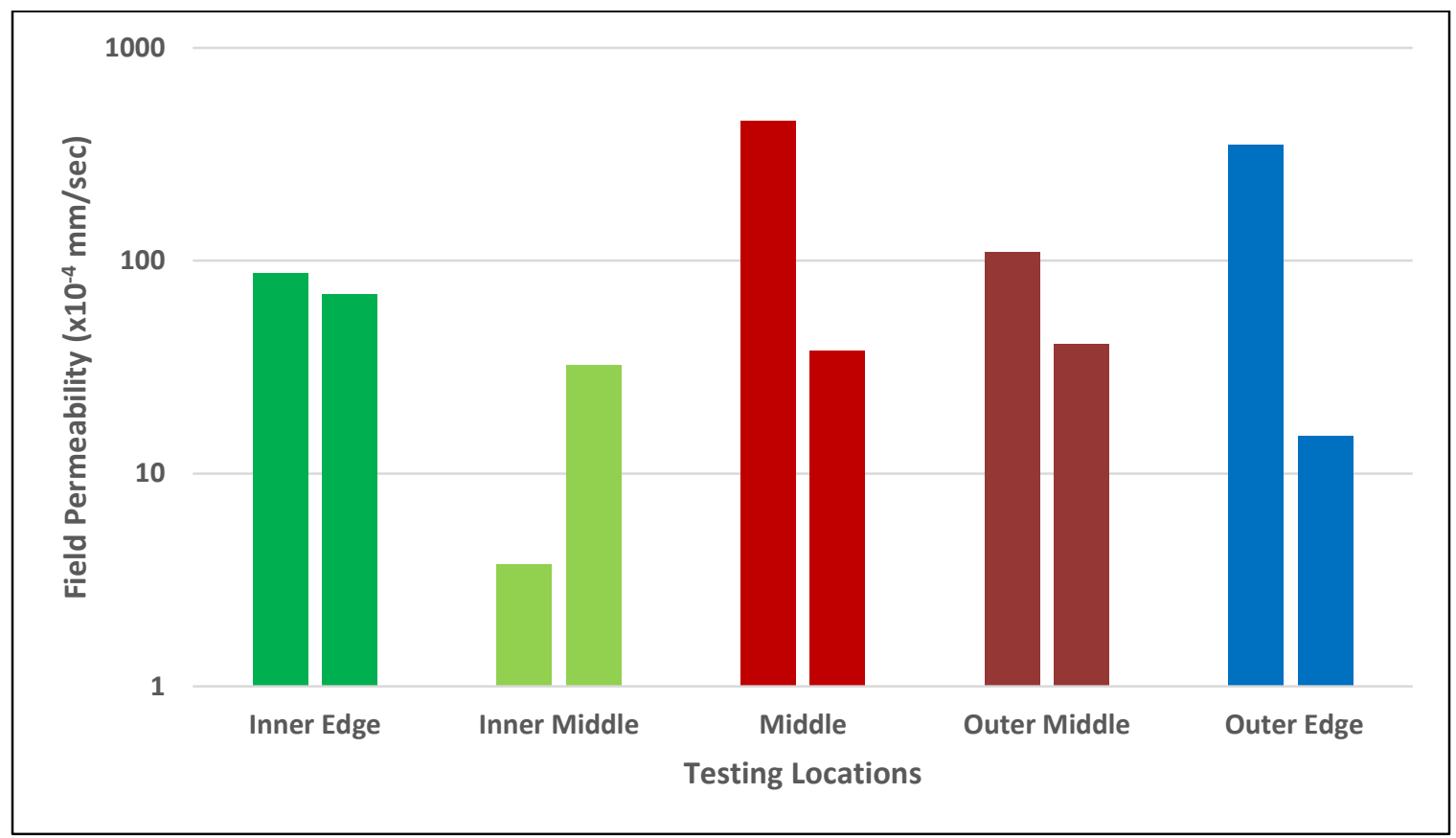

Figure 4.10: Field Permeability Result of Highway 15 before Microsurfacing (2013)

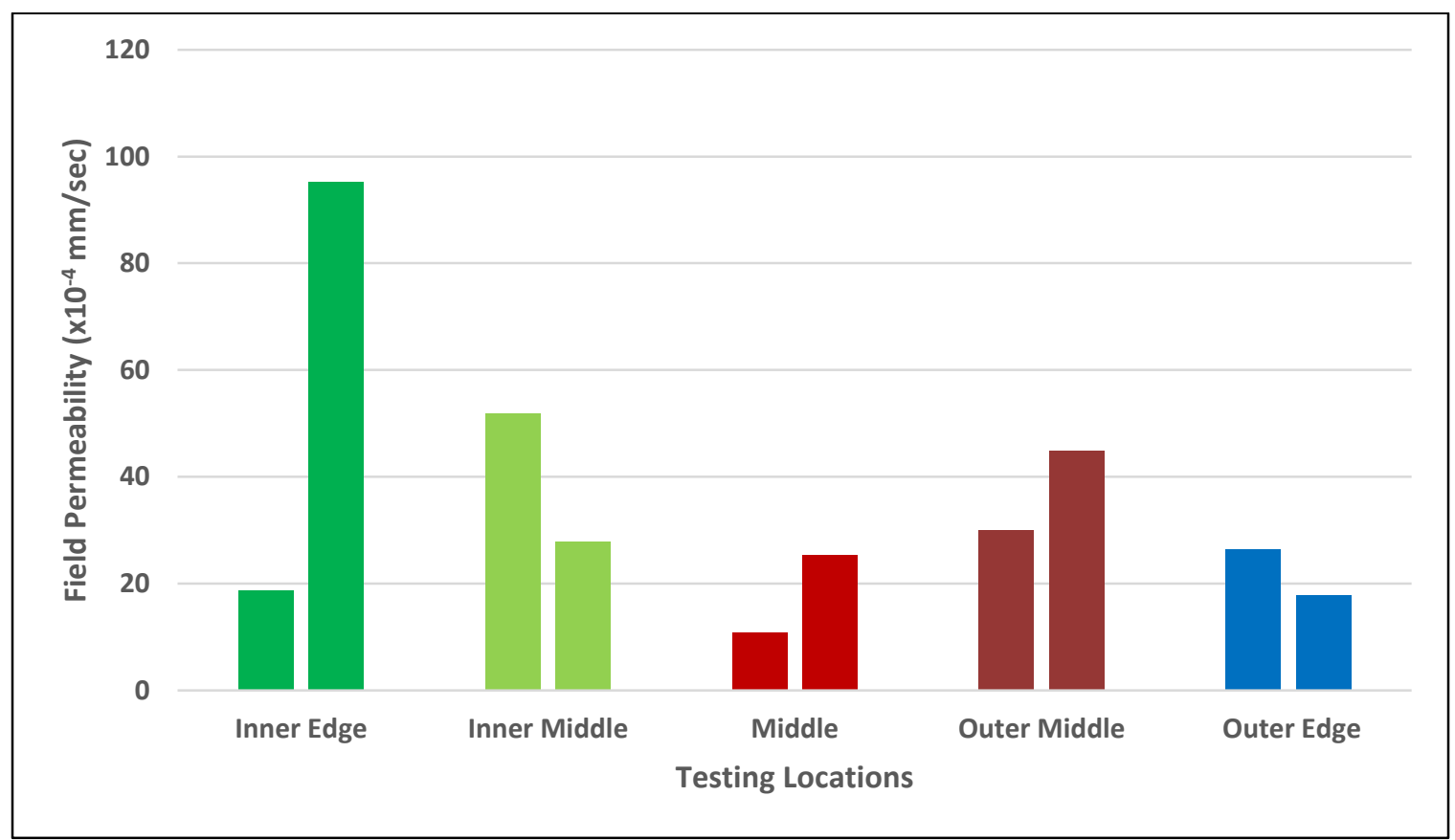

Figure 4.11: Field Permeability Result of Highway 15 after Microsurfacing (2013) 


\subsubsection{Field Results of Year 2014}

An in-house field trial took place at Greenbelt site in 2014 as part of another research contract with the MTO for evaluating the AMIR compaction method and comparing it to the conventional compaction. After the field compaction, the in-situ permeability test was conducted on the paved asphalt mat. Three test measurements were taken at different locations as shown in Figure 4.12.

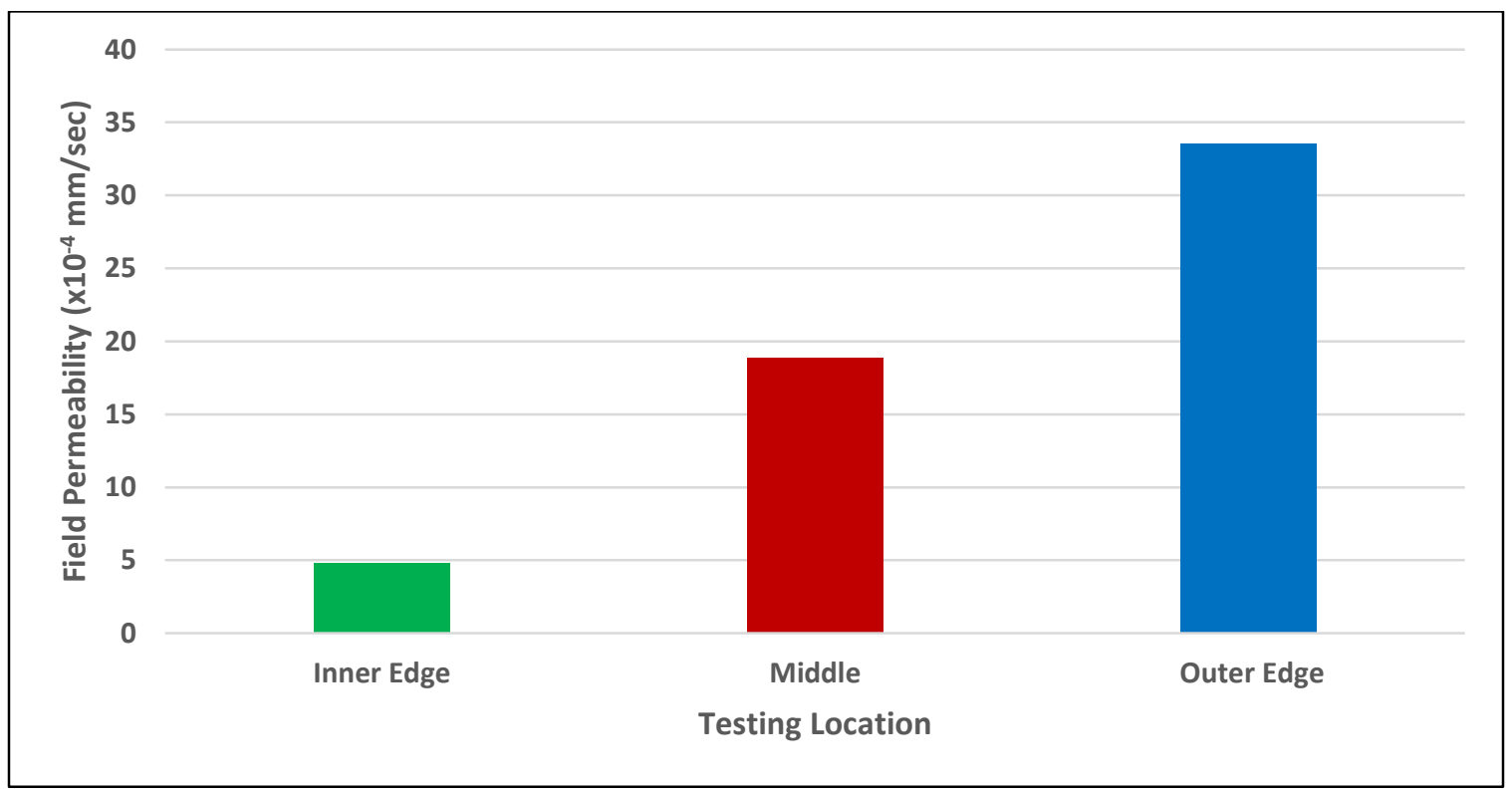

Figure 4.12: Field Permeability Result of Greenbelt Trial One (2014)

The last field permeability test in 2014 was conducted at a Highway 34 bridge overpassing Highway 417. In this site, seven field permeability measurements were taken along one lane of the two-lane bridge deck. All testing locations were taken at the inner edge since the lane closure performed by the traffic control technicians covered only one lane (compacted by AMIR roller) in addition to small portion $(300 \mathrm{~mm})$ of the opposing lane which is compacted by the conventional method. The overall permeability values were relatively high (average $=486 \times 10^{-4} \mathrm{~mm} / \mathrm{sec}$ ) on the bridge deck compared to 
permeability measurements performed on regular road sections. The field permeability results are shown in Figure 4.13.

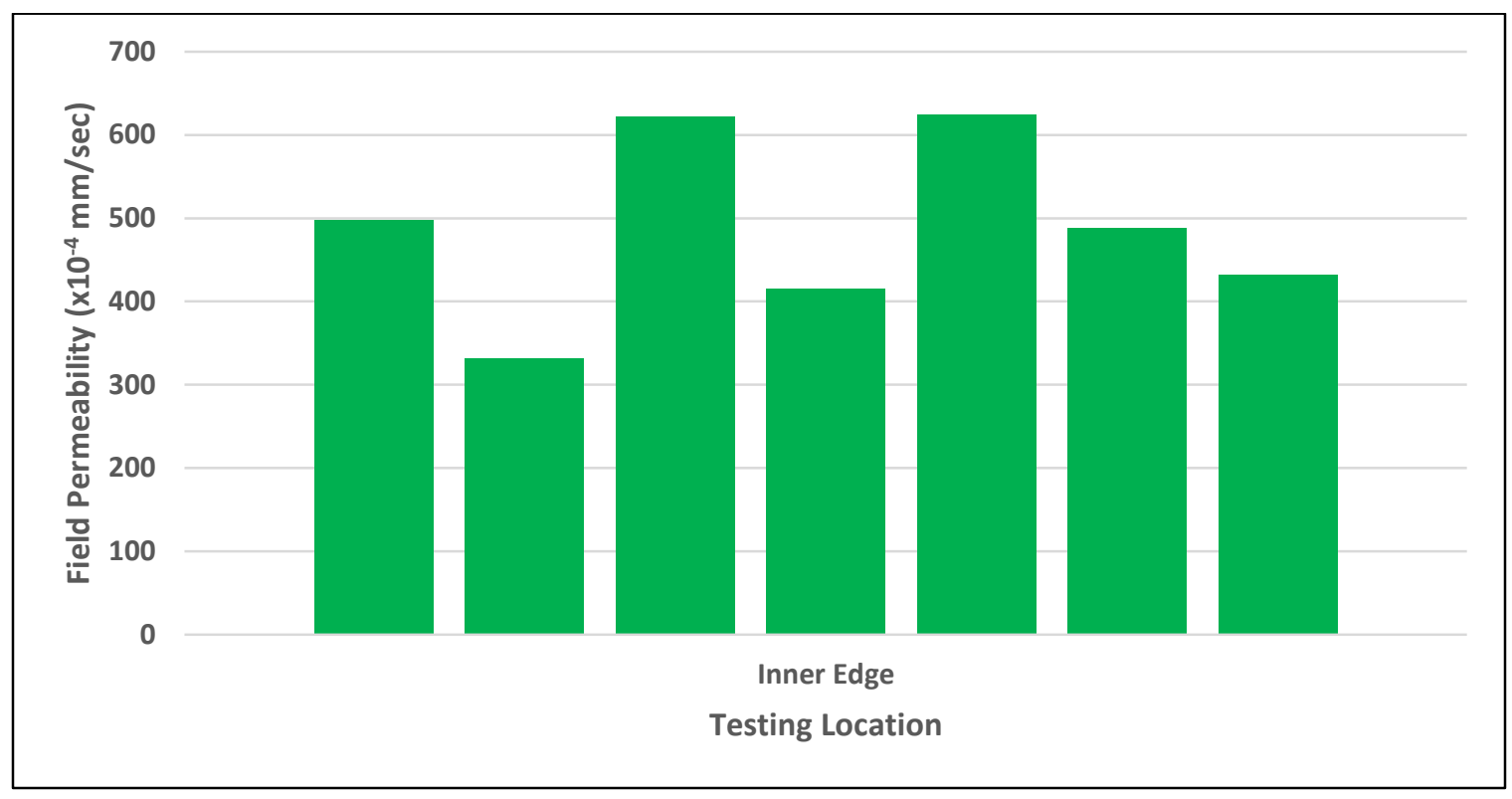

Figure 4.13: Field Permeability Result of Highway 34 Bridge (2014)

\subsubsection{Summary of the Field Results by the Conventional Compaction Method}

The results of the field measured permeability presented herein show that the conventional compaction method produced field permeability values ranging from $4 \times$ $10^{-4} \mathrm{~mm} / \mathrm{sec}$ to $1501 \times 10^{-4} \mathrm{~mm} / \mathrm{sec}$. Figure 4.14 summarizes the average permeability measurement for all tested sites that were compacted using the conventional compaction method. The overall average permeability of all sites is $176 \times 10^{-4} \mathrm{~mm} / \mathrm{sec}$ which is $41 \%$ higher than the overall average laboratory permeability of SGC.

The effect of age on permeability can be observed for the three inspected sites where the as-built and in-service permeability measurements are available. For Thousand Islands Parkway, the average initial and in-service permeability values are 202 and $144 \times 10^{-4}$ $\mathrm{mm} / \mathrm{sec}$ respectively. This means that there was a $29 \%$ drop in average permeability after 
the first year of service. For Highway 28, there was also a drop of $70 \%$ while the average permeability at Tomlinson dropped by $29 \%$ from year 2012 to 2013 . Therefore, on average, there was a $50 \%$ drop in average permeability after one year of opening the road. This drop in permeability can be attributed to two main reasons, first the traffic loads contribute in compacting the newly asphalt section which in turn reduces the air voids content. Also, the surface open textures (gaps or voids located at the newly finished surface immediately after road paving and compaction were likely clogged by various partials (e.g. such as dust).

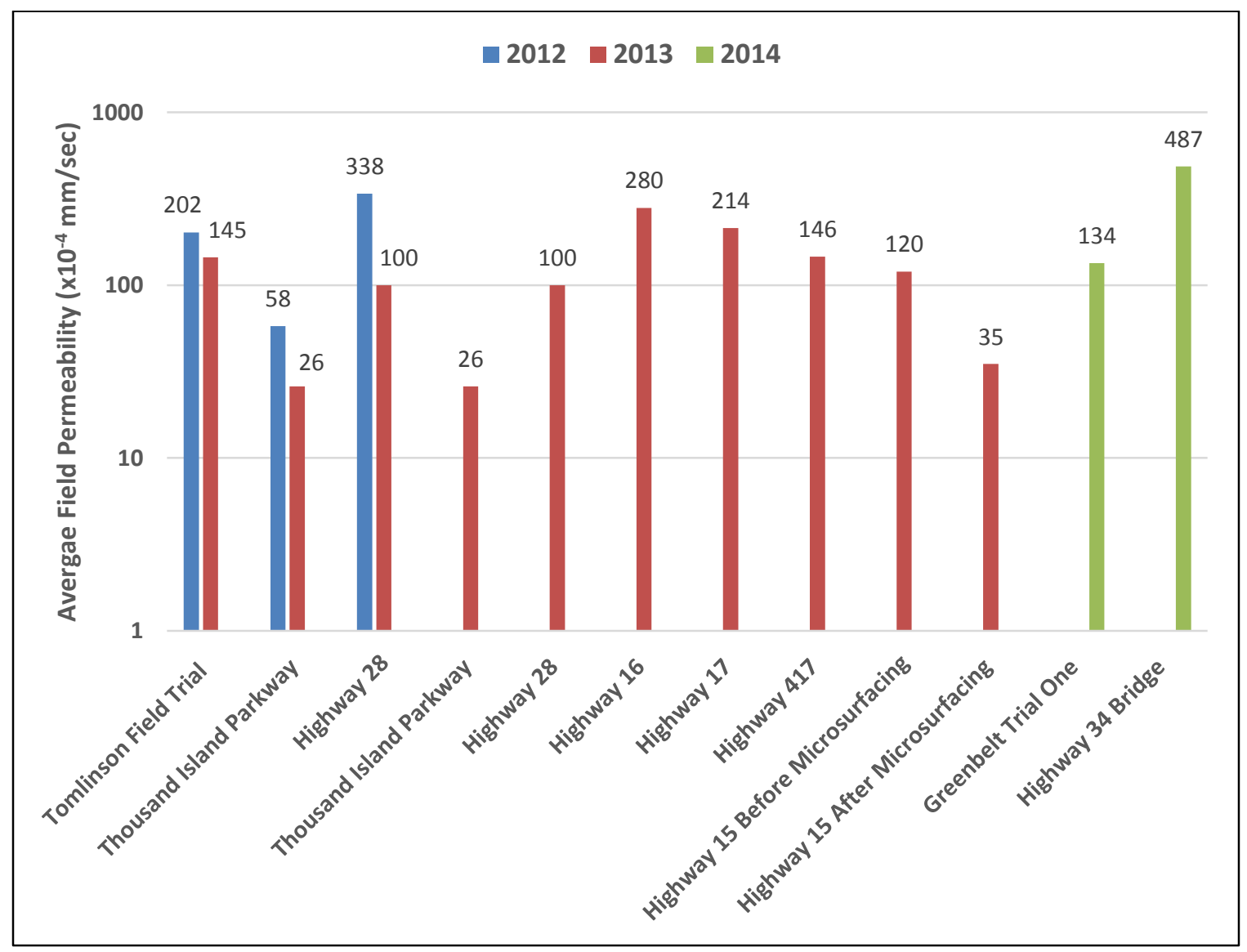

Figure 4.14: Summary of all 12 Investigated Projects Finished by the Conventional Method 


\subsubsection{Advanced Compaction Method}

As mentioned previously, this report includes seven common sites between the conventional compaction technique and the new compaction technique (AMIR-II) where the two technologies were used side-by-side under the same compaction conditions (e.g. weather and the roller operator). Similarly, the results of field investigations will be presented in chronological order starting from the summer of year 2012 to the fall of 2014.

\subsubsection{A Field Results of Year 2012}

As mentioned earlier, three of the seven mutual sites were newly constructed in 2012 including two highway projects, which are Highway 28, Thousand Islands Parkway, and an in-house field trial at Tomlinson. The sample size for both Thousand Islands Parkway and Tomlinson project is seven while ten measurements were taken on Highway 28. The field permeability results and their corresponding testing locations for each site are graphically shown in Figure 4.15 through Figure 4.17.

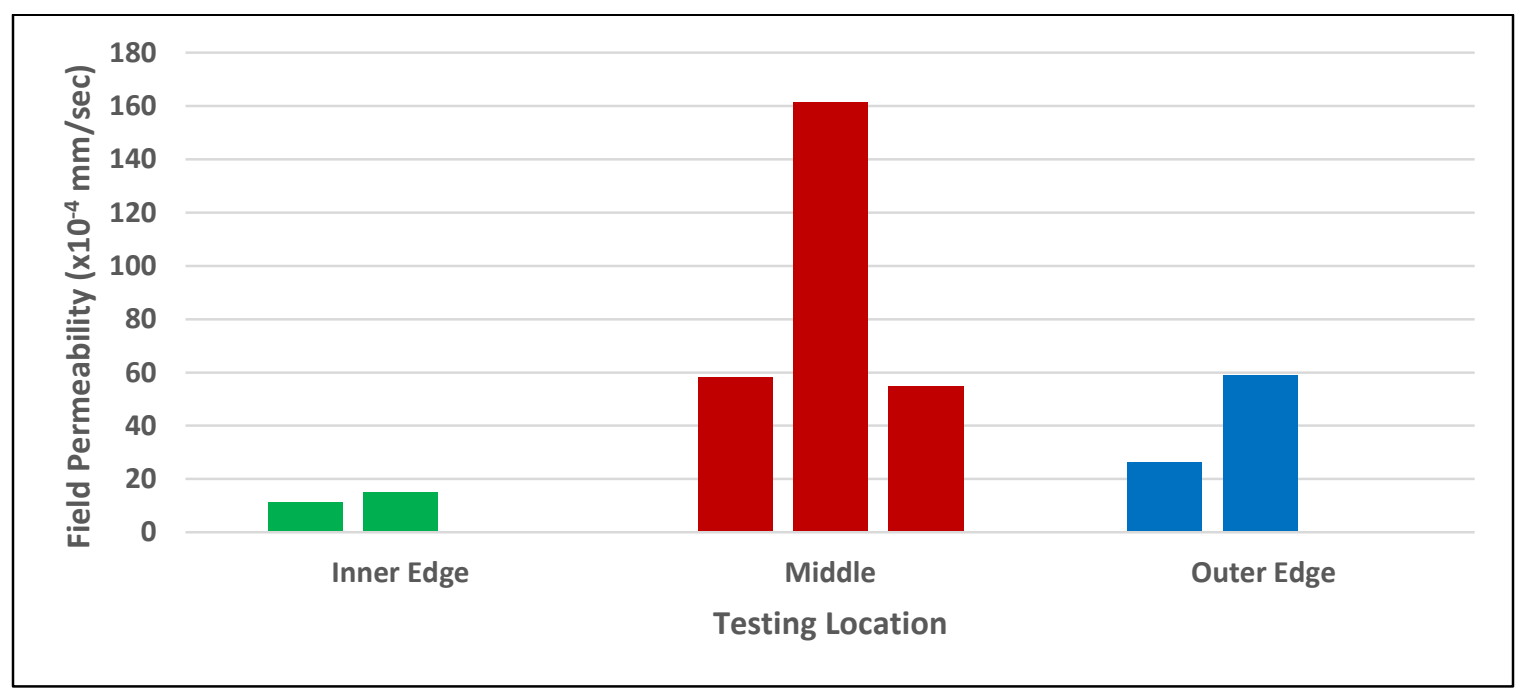

Figure 4.15: Field Permeability Result of Thousand Islands Parkway (2012) 


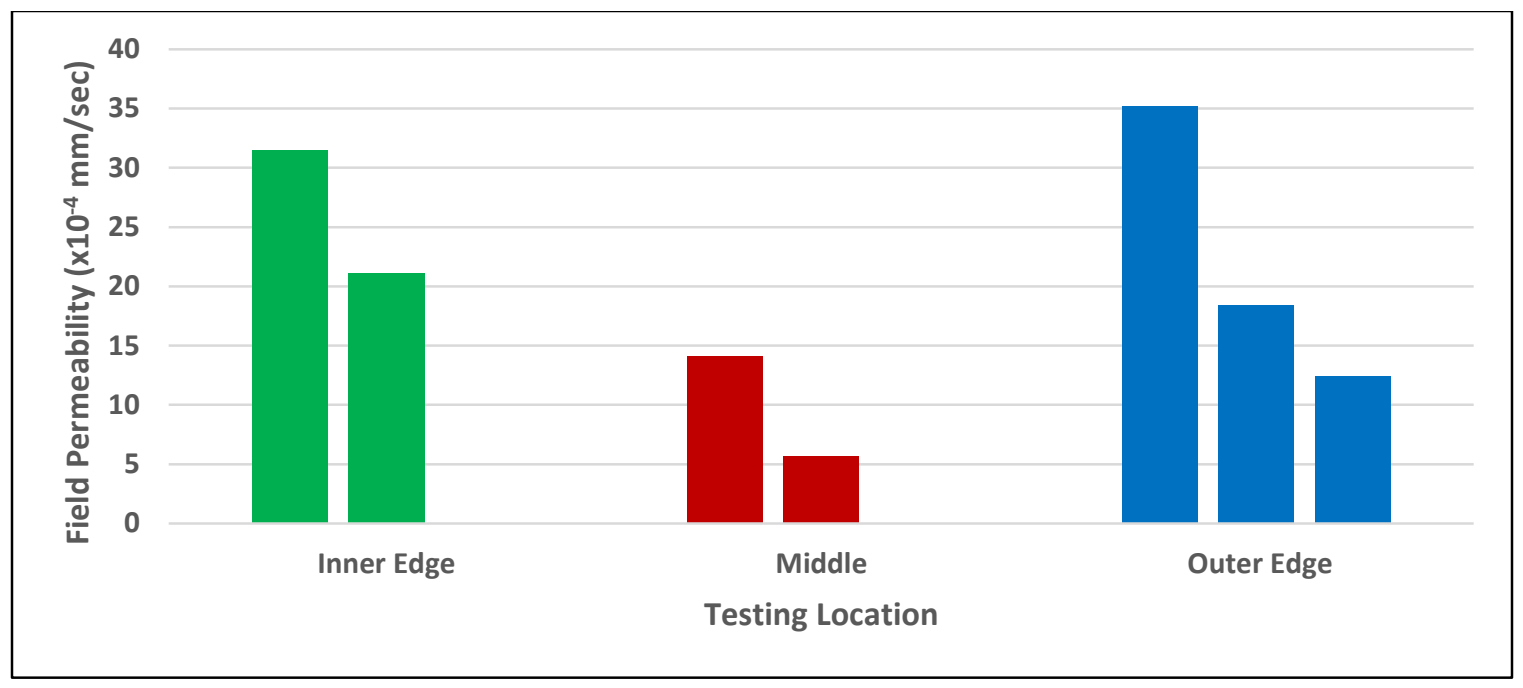

Figure 4.16: Field Permeability Result of Tomlinson In-house Field Trial (2012)

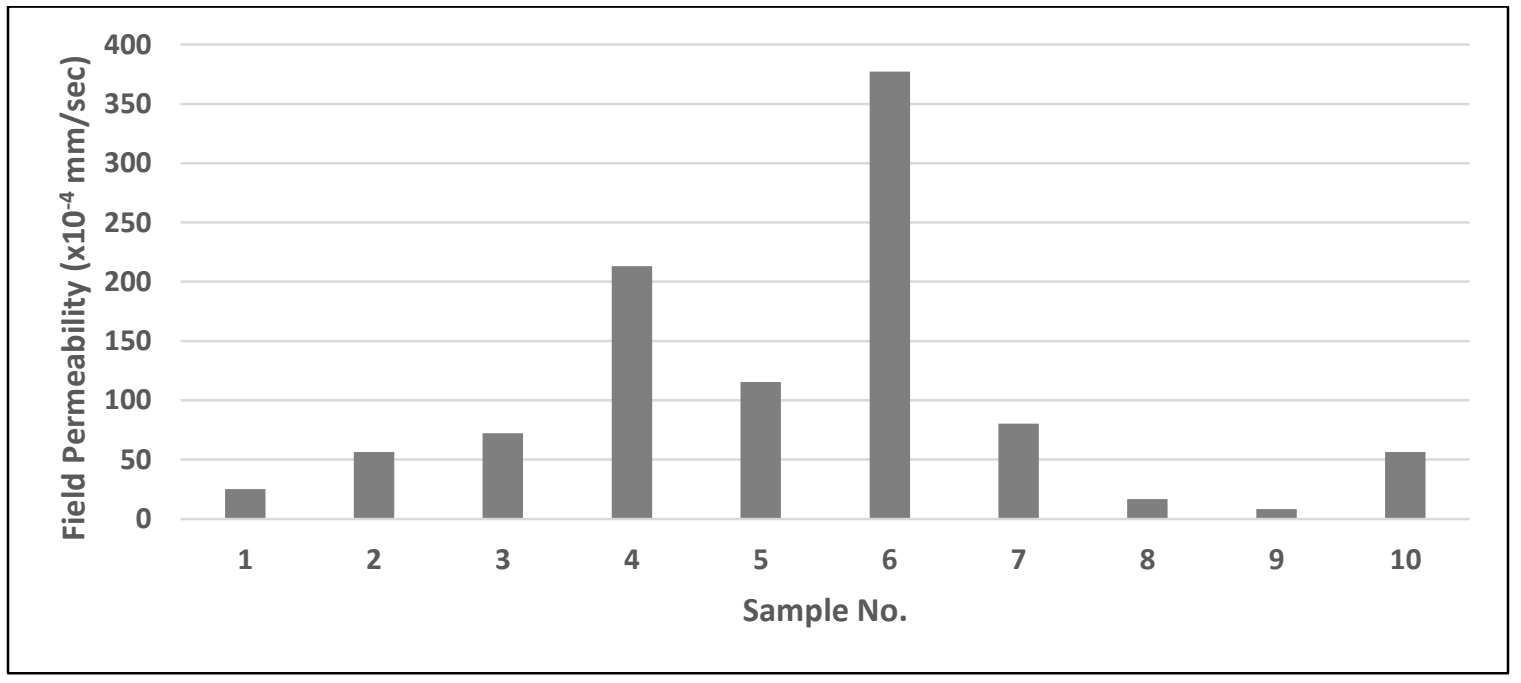

Figure 4.17: Field Permeability Result of Highway 28 (2012)

\subsubsection{B Field Results of Year 2013}

For the same three above-mentioned sites compacted by AMIR-II in 2012, further field permeability investigations were undertaken one year after the road opening date. Thus, the as-built and in-service investigations in terms of in-situ permeability measurements were available for two consecutive years for these three sites (Highway 28, Thousand Islands Parkway, and the in-house field trial at Tomlinson). The testing locations along 
with the field permeability measurements (represented by bar charts) are shown in Figure 4.18 through Figure 4.20.

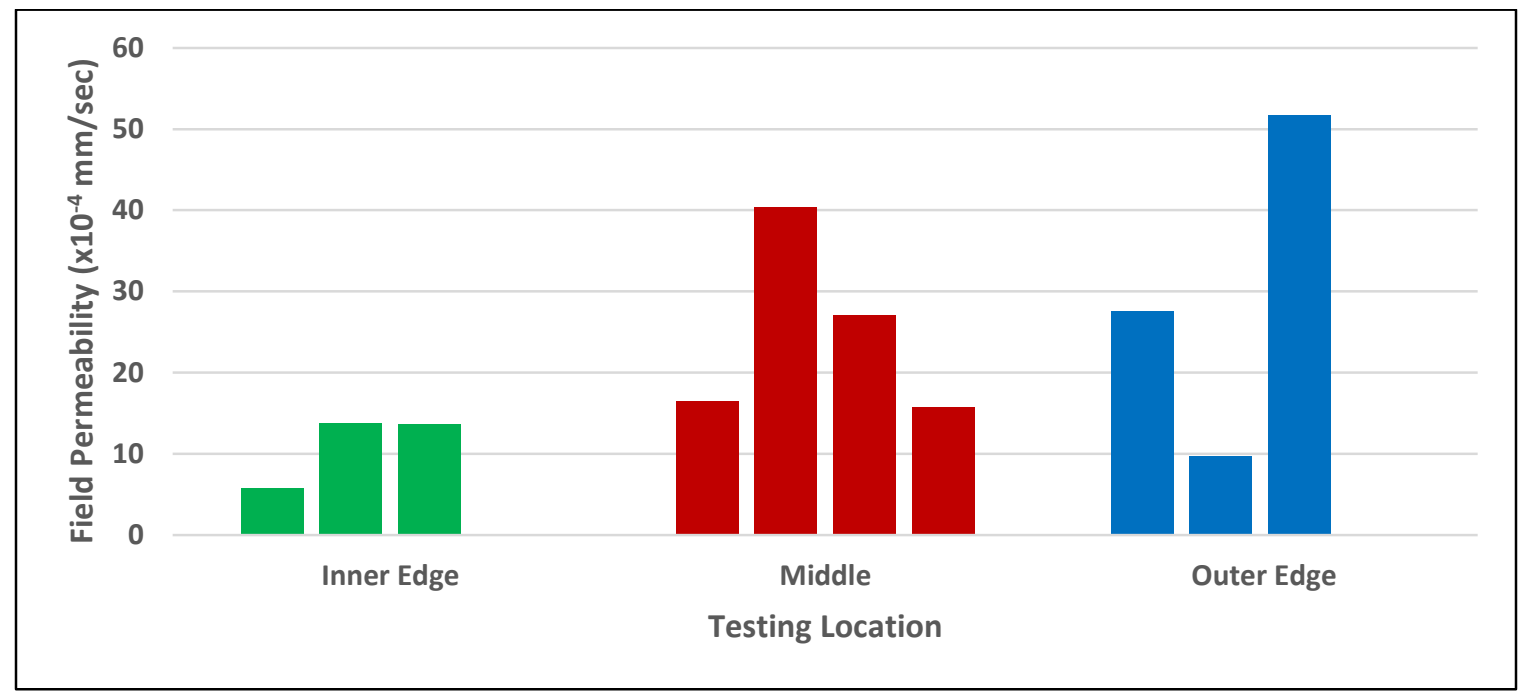

Figure 4.18: Field Permeability Result of Thousand Islands Parkway (2013)

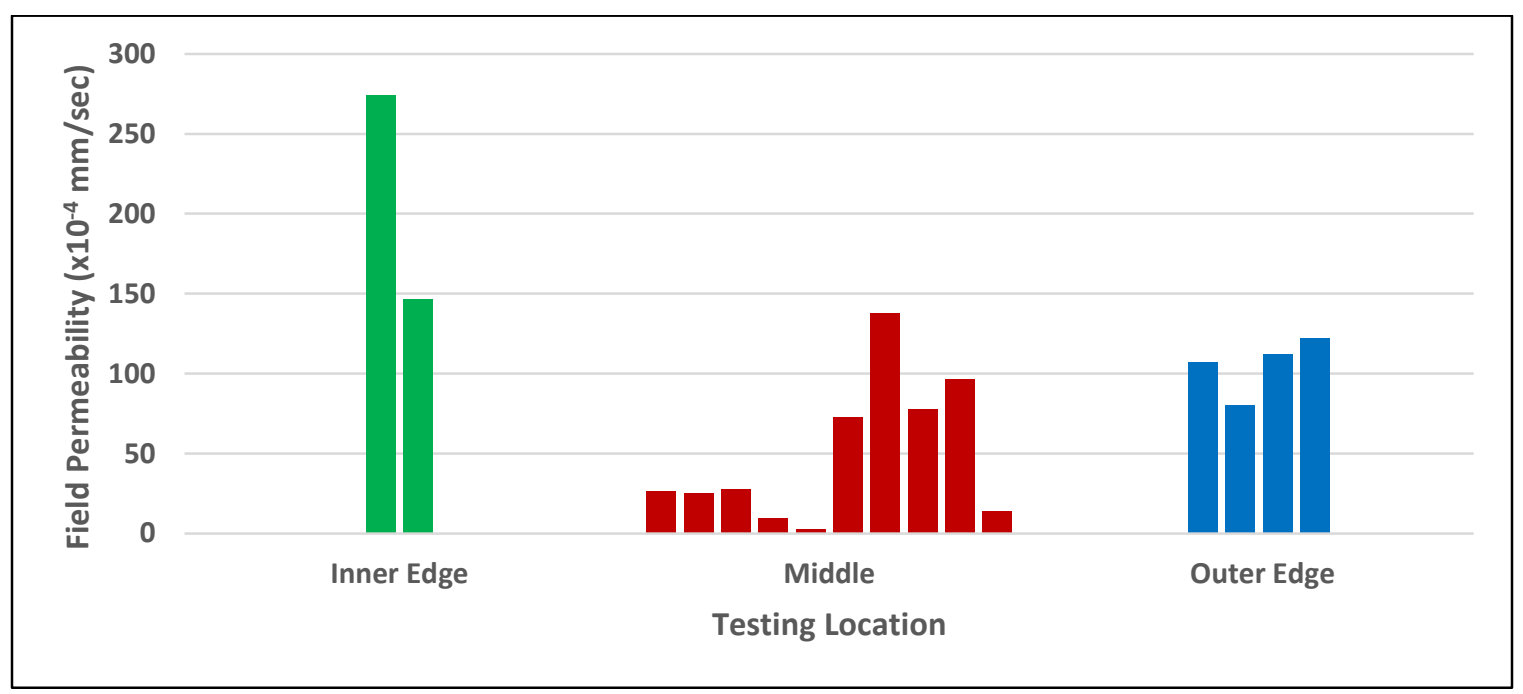

Figure 4.19: Field Permeability Result of Highway 28 (2013) 


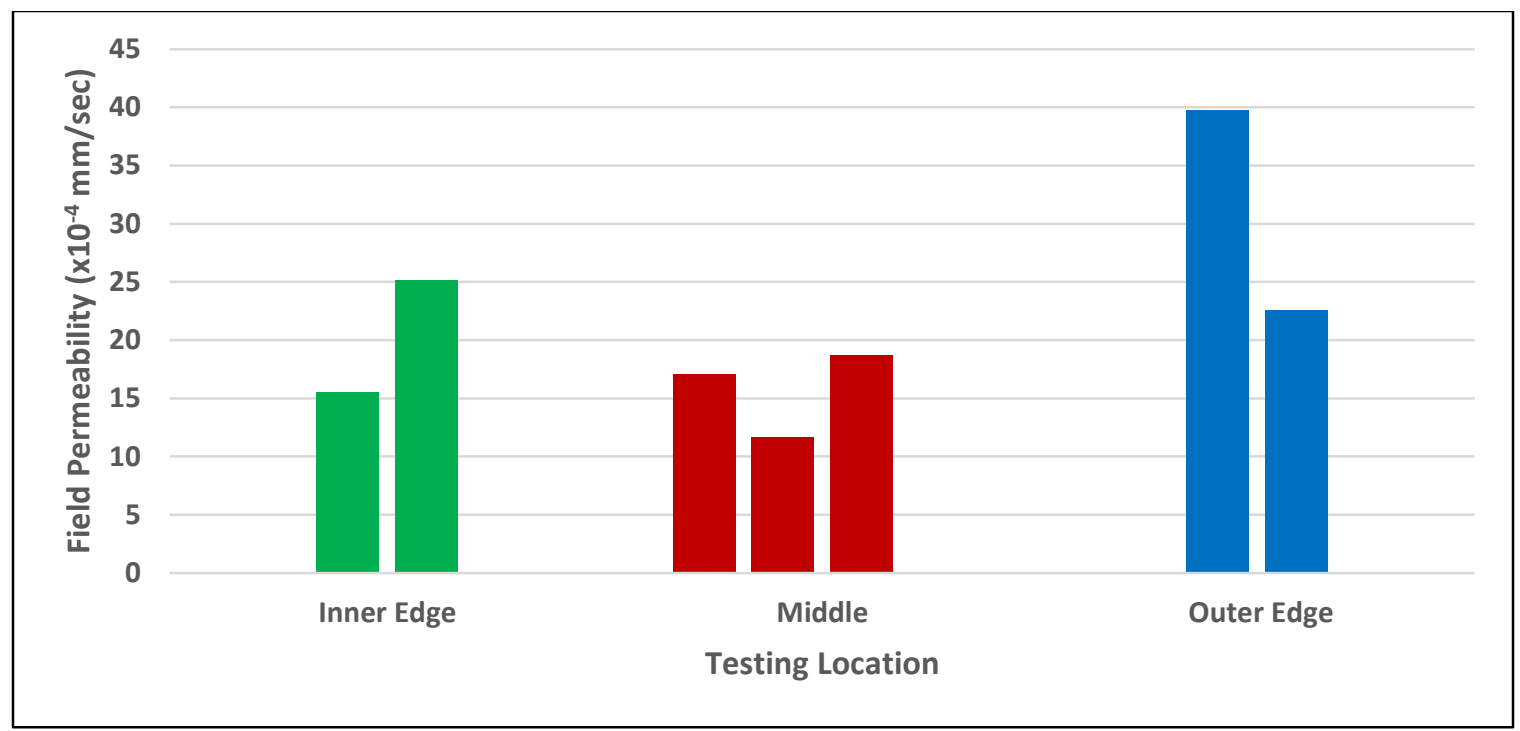

Figure 4.20: Field Permeability Result of Tomlinson In-house Field Trial (2013)

\subsubsection{Field Results of Year 2014}

The AMIR-II compactor was used to pave a $200 \mathrm{~m}$ long bridge on Highway 34 overpassing Highway 417. It is important to mention that unlike any other inspected site, this one was performed in late November where the air temperature is $-2^{\circ} \mathrm{C}$. Two testing locations were selected for this project, which are the inner (two measurements) and middle lane (four measurements). The outer lane was avoided as it was re-compacted by a steel drum roller. Figure 4.21 summarizes the results of the field permeability investigation. 


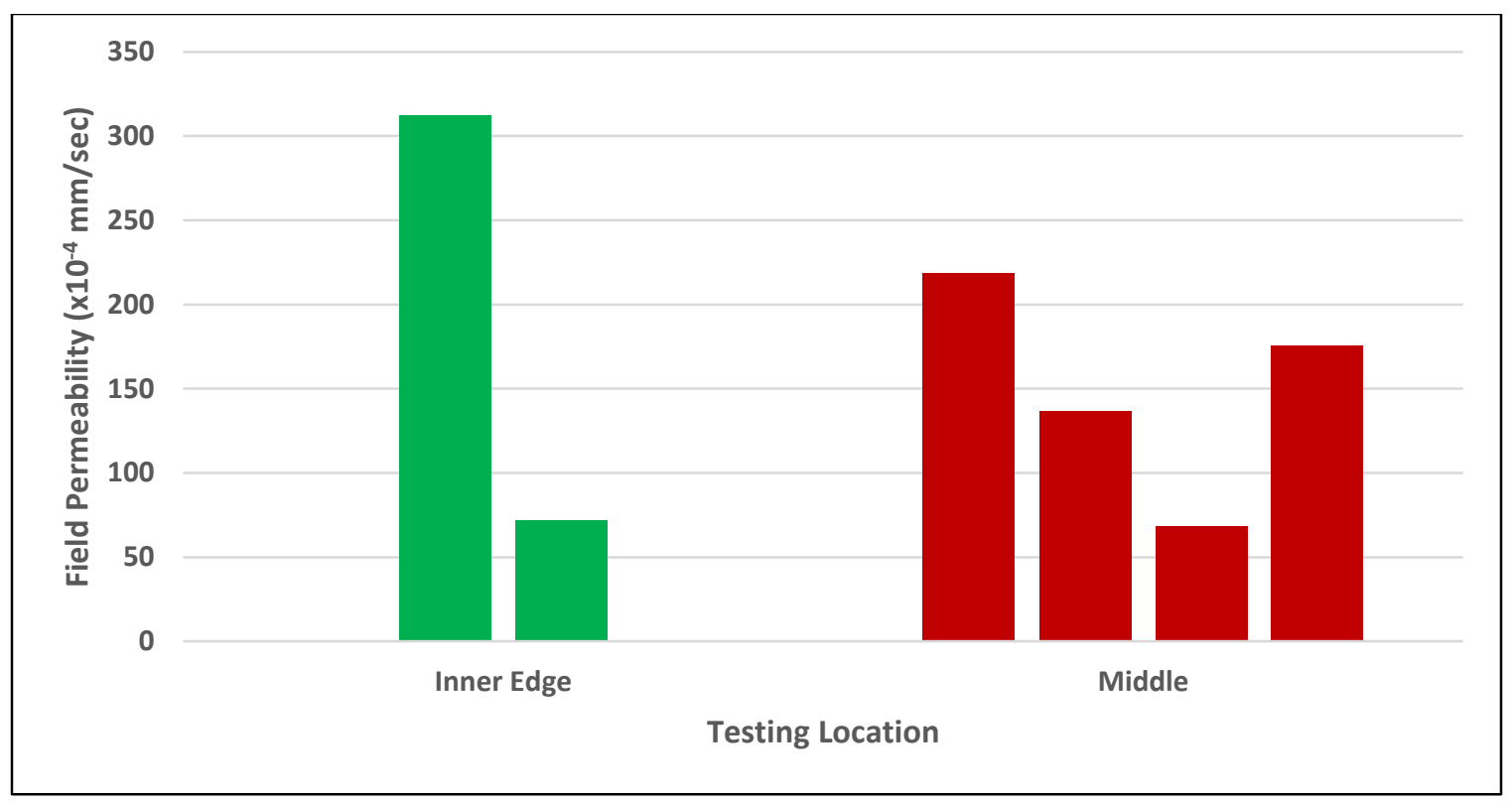

Figure 4.21: Field Permeability Result of Highway 34 Bridge (2014)

The AMIR-II compactor was also deployed in the in-house trial located at Greenbelt site. The roller compacted three adjacent lanes and the permeability test was conducted two days later. Four field measurements were taken at three different locations as summarized in Figure 4.22.

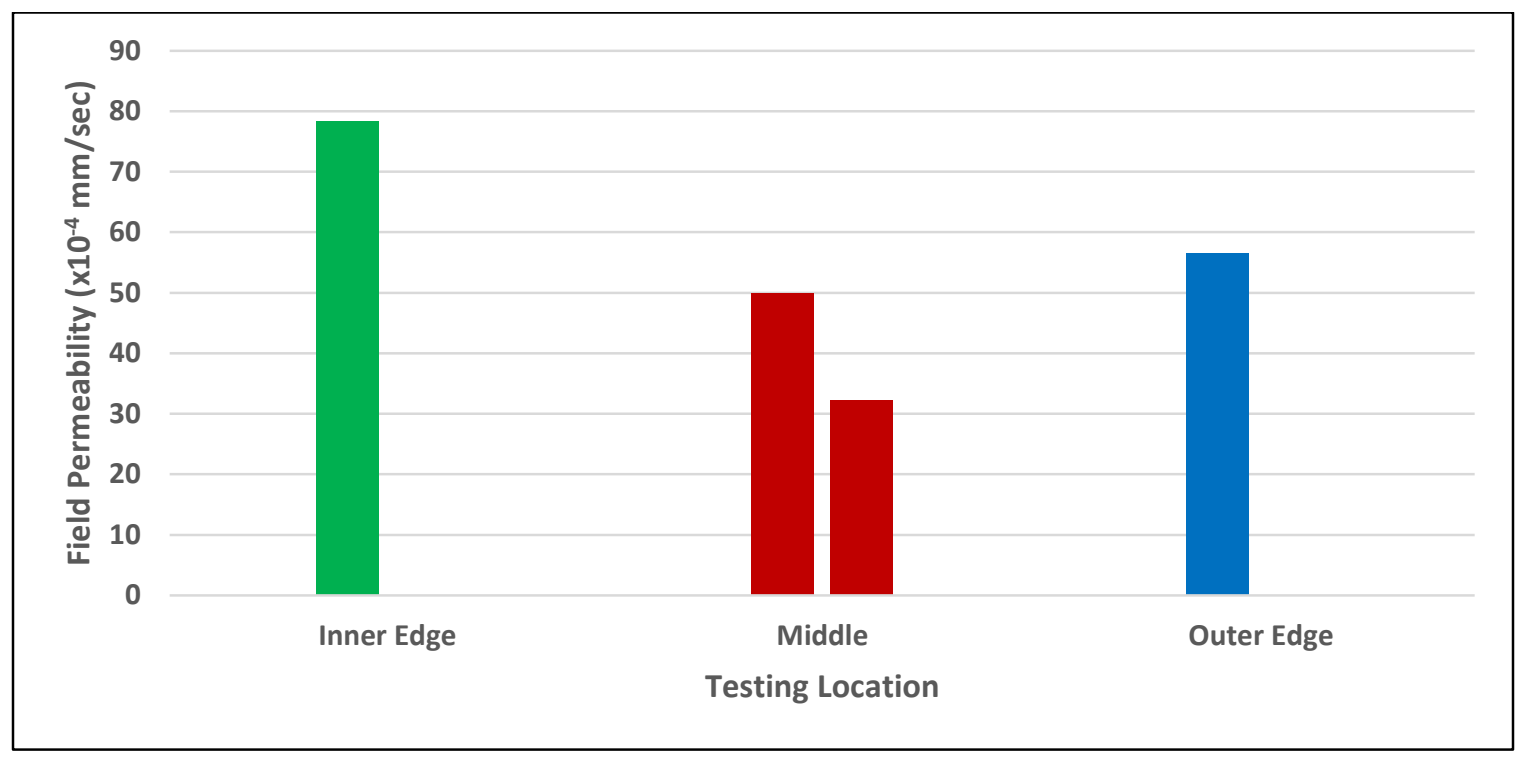

Figure 4.22: Field Permeability Result of Greenbelt Trial One (2014) 


\subsubsection{Summary of the Field Results by the Advanced Compaction Method}

The results of the in-situ permeability presented previously show that the advanced compaction method produced field permeability values ranging from $2 \times 10^{-4} \mathrm{~mm} / \mathrm{sec}$ to $377 \times 10^{-4} \mathrm{~mm} / \mathrm{sec}$. Figure 4.23 summarizes the average permeability measurements for considered sites. The overall average permeability of all sites is $69 \times 10^{-4} \mathrm{~mm} / \mathrm{sec}$ which is $22 \%$ less than the overall average laboratory permeability of SGC.

For Highway 28, the average initial and in-service permeability values are 134 and $83 \times$ $10^{-4} \mathrm{~mm} / \mathrm{sec}$ respectively. Consequently, there was a $62 \%$ drop in average permeability after one year of service. At Tomlinson project, no significant change in the average permeability was observed since the as-built and in-service permeability values are 20 and $21 \times 10^{-4} \mathrm{~mm} / \mathrm{sec}$ respectively. There was a $40 \%$ drop in average permeability at Thousand Islands Parkway site since the initial and in-service permeability values are 134 and $83 \times 10^{-4} \mathrm{~mm} / \mathrm{sec}$ respectively.

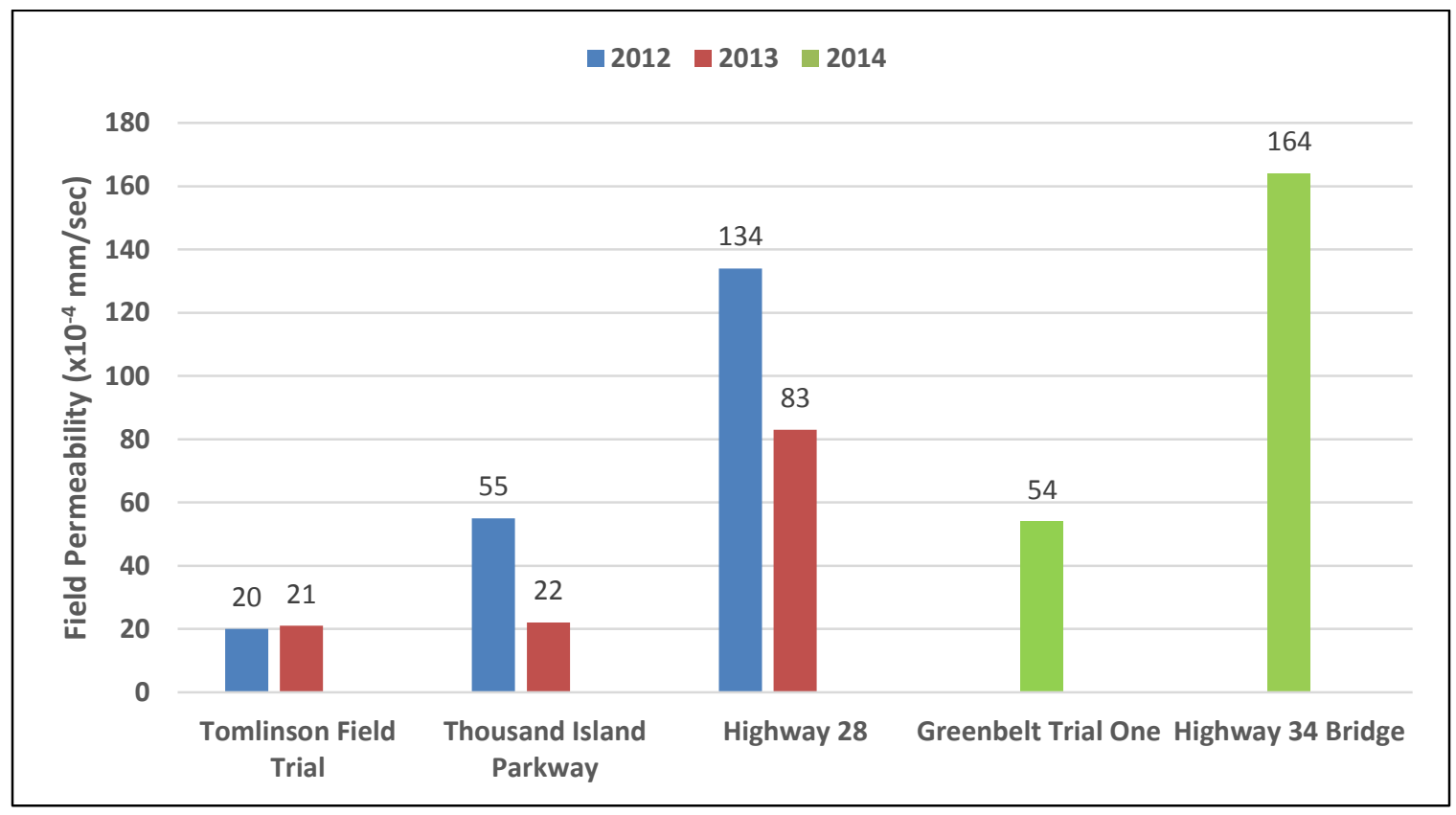

Figure 4.23: Summary of Projects Compacted by the Advanced Method 


\subsection{Laboratory Investigations}

The second section of this chapter presents the laboratory results of both the SGC specimens and field cores. The laboratory phase incorporated cores recovered from eight sites; six highway projects and two in-house field trials. The total number of common sites between the two compaction methods is four. This section presents first the results produced by the SGC specimens followed by the field-recovered cores.

\subsubsection{Results of Superpave Gyratory Compactor Specimens}

In total, the gyratory compactor was used to prepare 33 specimens of different engineering properties. Table 4.2 presents the test results for each mix under the four compaction levels introduced in the previous chapter. In order to illustrate the laboratory results graphically, the average bulk specific gravity, IDT, and permeability of each compaction level are plotted in Figure 4.24 through Figure 4.26. In general, the results show that as the achieved relative density increases, the IDT increases while the permeability. These results are observed for all four highway asphalt mixtures. 
Table 4.2: The Laboratory Results on SGC Specimens for the Four Considered Mixtures

\begin{tabular}{|c|c|c|c|c|}
\hline Specimen ID & $\begin{array}{c}\text { Bulk Specific } \\
\text { Gravity }\end{array}$ & $\begin{array}{c}\text { Relative Density } \\
\text { (\%) }\end{array}$ & $\begin{array}{l}\text { IDT } \\
\text { (kPa) }\end{array}$ & $\begin{array}{l}\text { Lab Permeability } \\
\left(\times 10^{-4} \mathrm{~mm} / \mathrm{sec}\right)\end{array}$ \\
\hline \multicolumn{5}{|c|}{ Highway 417 Mixture } \\
\hline A1 & 2.425 & 97.0 & 1575.9 & 1.01 \\
\hline A2 & 2.452 & 98.1 & 1639.8 & 0.66 \\
\hline $\mathrm{A} 3$ & 2.436 & 97.4 & 1454.42 & 1.29 \\
\hline B1 & 2.386 & 95.4 & 1412.75 & 11.04 \\
\hline B2 & 2.355 & 94.2 & 1120.04 & 0.73 \\
\hline B3 & 2.365 & 94.6 & 937.6 & 29.71 \\
\hline $\mathrm{C} 1$ & 2.241 & 89.6 & 591.25 & 35.12 \\
\hline $\mathrm{C} 2$ & 2.247 & 89.9 & 608.95 & 66.26 \\
\hline $\mathrm{C} 3$ & 2.266 & 90.6 & 697.27 & 33.56 \\
\hline D1 & 2.174 & 87.0 & 322.26 & 209.1 \\
\hline D2 & 2.195 & 87.8 & 358.88 & 683.27 \\
\hline D3 & 2.188 & 87.5 & 366.25 & 746.34 \\
\hline \multicolumn{5}{|c|}{ Highway 16 Mixture } \\
\hline A1 & 2.424 & 97.1 & 1137.92 & 2.08 \\
\hline B1 & 2.388 & 95.6 & 1124.64 & 0.98 \\
\hline B2 & 2.373 & 95.0 & 846.78 & 7.43 \\
\hline $\mathrm{C} 1$ & 2.304 & 92.3 & 675.6 & 27.18 \\
\hline $\mathrm{C} 2$ & 2.256 & 90.4 & 430.55 & 36.48 \\
\hline D1 & 2.176 & 87.1 & 340.48 & 331.14 \\
\hline D2 & 2.138 & 85.6 & 259.62 & 219.02 \\
\hline \multicolumn{5}{|c|}{ Highway 17 Mixture } \\
\hline A1 & 2.496 & 99.9 & 1156.92 & 0.67 \\
\hline B1 & 2.343 & 93.9 & 667.39 & 9.95 \\
\hline B2 & 2.401 & 96.1 & 859.1 & 1.52 \\
\hline $\mathrm{C} 1$ & 2.280 & 91.3 & 479.19 & 70.71 \\
\hline $\mathrm{C} 2$ & 2.267 & 90.8 & 440.56 & 28.09 \\
\hline D1 & 2.167 & 86.8 & 282.58 & 416.41 \\
\hline D2 & 2.157 & 86.4 & 250.65 & 603.64 \\
\hline \multicolumn{5}{|c|}{ Highway 15 Mixture } \\
\hline $\mathrm{A} 1$ & 2.514 & 99.9 & 1535.08 & 2.07 \\
\hline B1 & 2.403 & 96.3 & 1168.82 & 32.04 \\
\hline B2 & 2.407 & 96.4 & 1064.62 & 17.69 \\
\hline $\mathrm{C} 1$ & 2.278 & 91.2 & 738.88 & 38.85 \\
\hline $\mathrm{C} 2$ & 2.333 & 93.4 & 841.69 & 7.35 \\
\hline D1 & 2.203 & 88.2 & 431.82 & 246.25 \\
\hline D2 & 2.187 & 87.6 & 445.69 & 306.07 \\
\hline
\end{tabular}




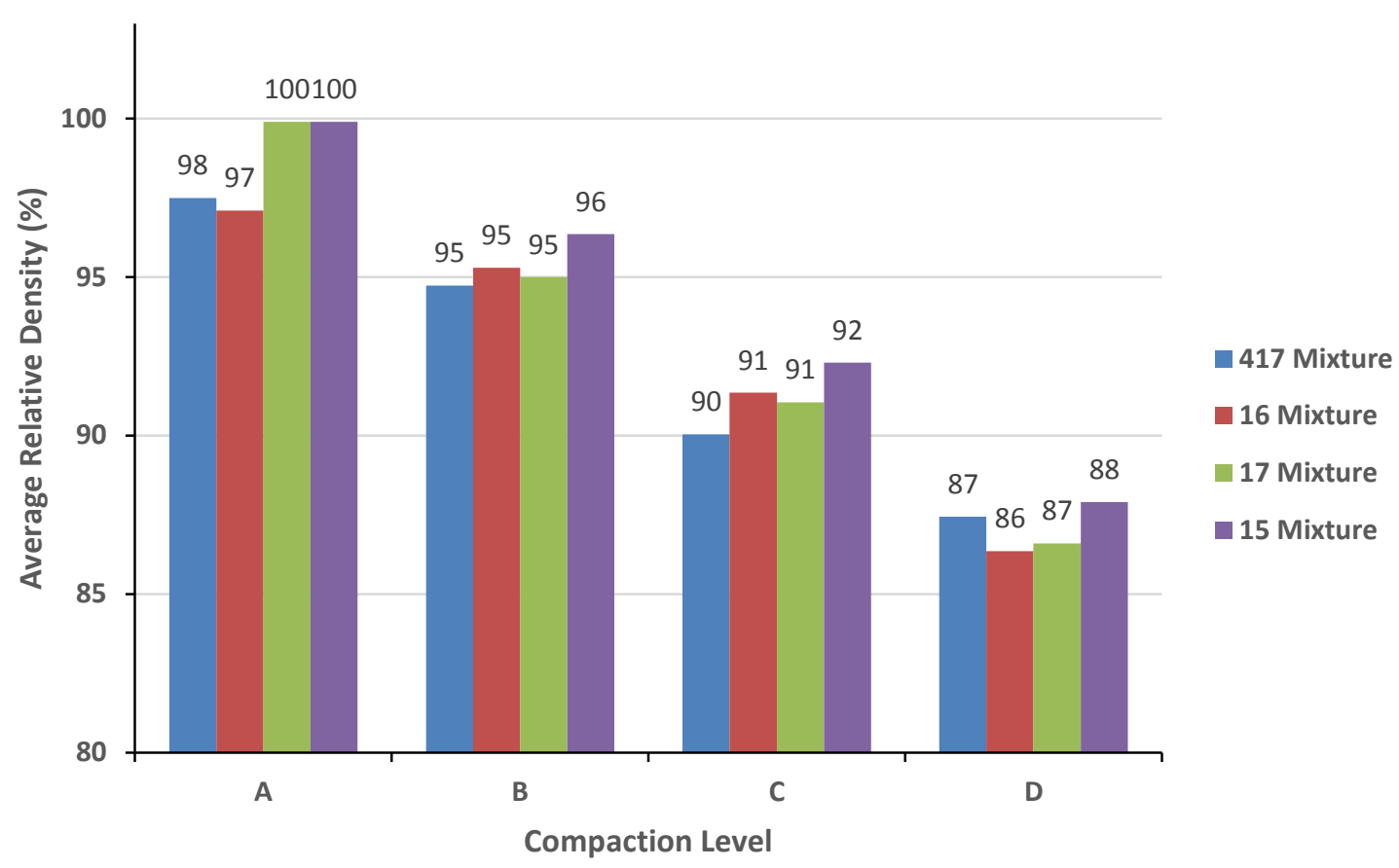

Figure 4.24: The Average Relative Density Values corresponding to the Four Compaction Levels

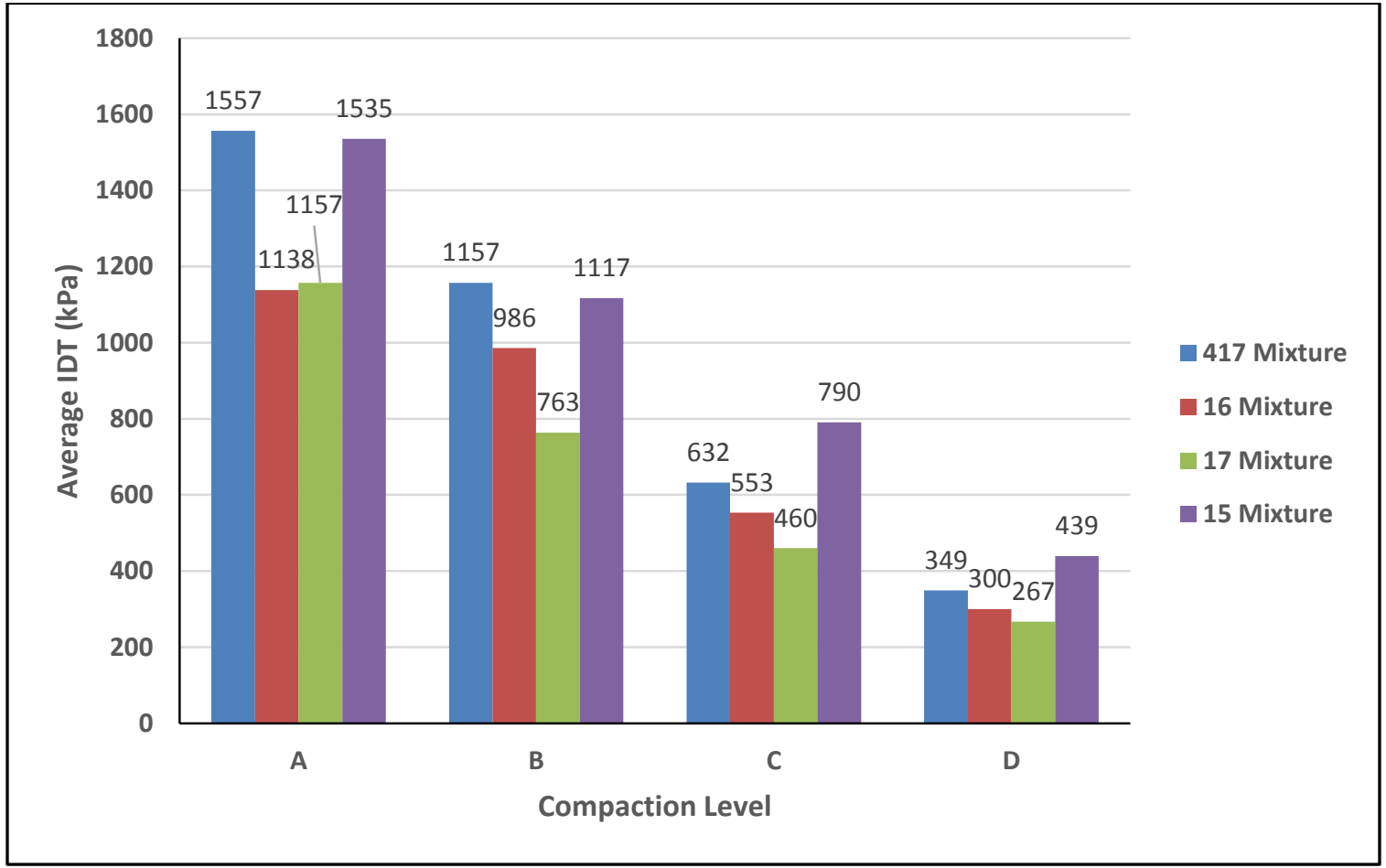

Figure 4.25: The Average IDT Values corresponding to the Four Compaction Levels 


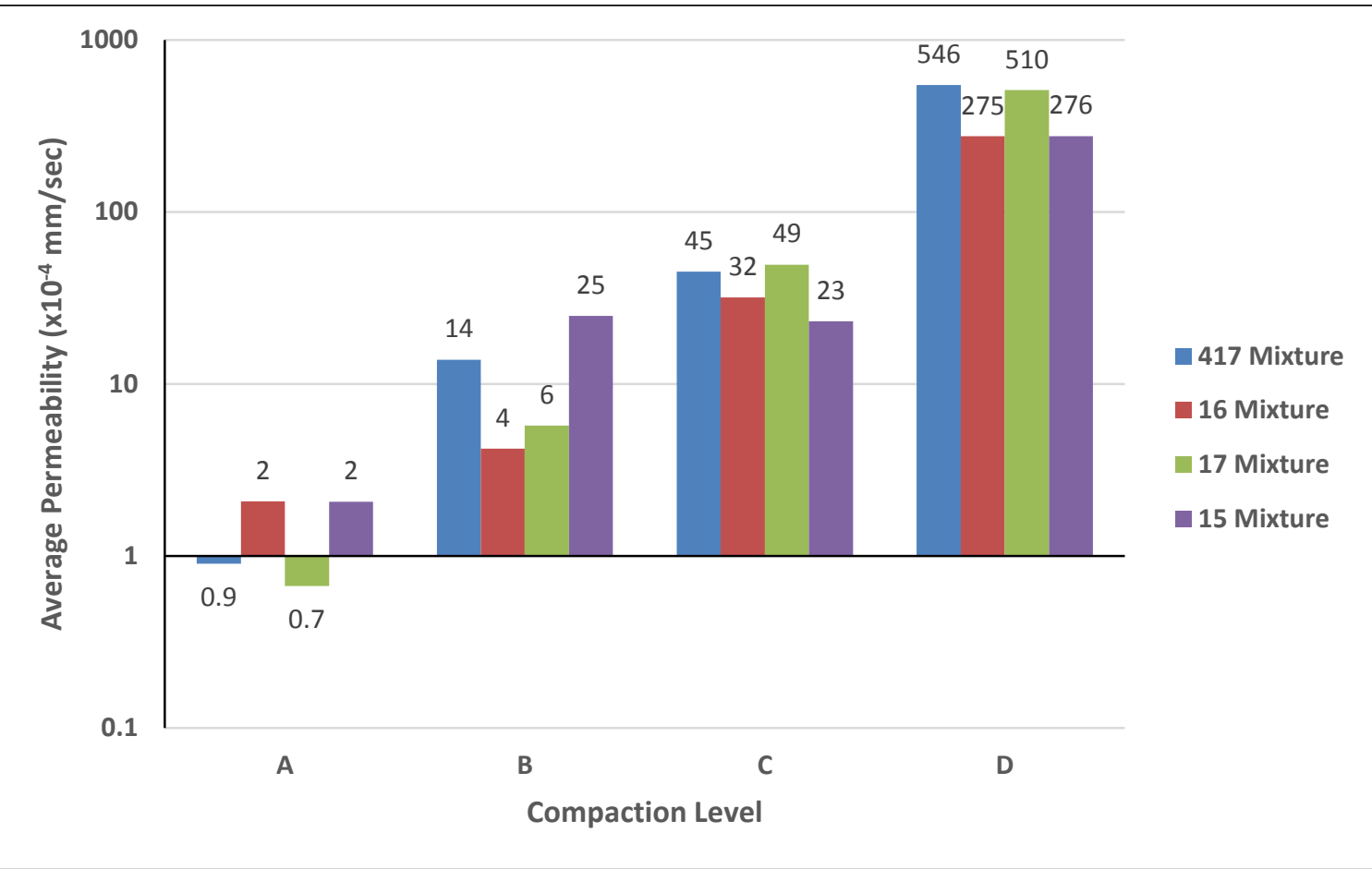

Figure 4.26: The Average Permeability Values corresponding to the Four Compaction Levels

\subsubsection{Results of Field-Recovered Cores}

This section deals with presenting the results of laboratory tests conducted on the fieldrecovered cores of different sites constructed between the year 2012 and 2014. The section is divided into two main subsections; the first one shows the laboratory test results of field-recovered cores collected from sites compacted by the conventional steel roller, while the other subsection illustrates the laboratory results of cores from finished surfaces compacted by AMIR-II roller. In total, 78 field-recovered cores were collected from sites paved by the conventional method and 59 field-recovered cores were collected from sites finished by the advanced compaction method. Figure 4.27 demonstrates the procedure for cutting the field-recovered cores using the pavement core drilling machine. In step one shown in Figure 4.27 (a), the operator uses the drilling machine to extract 
field sample from the roadbed. The operator then uses a shovel to gently lift the field sample from its sides as seen in Figure 4.27 (b). Figure 4.27 (c) displays the road after extracting the field-recovered core. Finally, the drilled location is filled with loose asphalt mixture and compacted by a manual vibratory compactor as Figure 4.27 (d) shows.

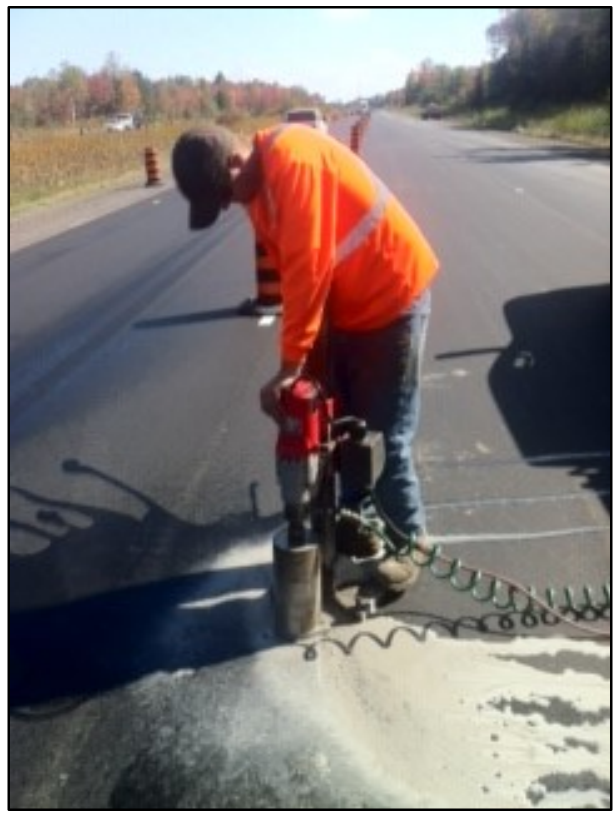

(a) Step One

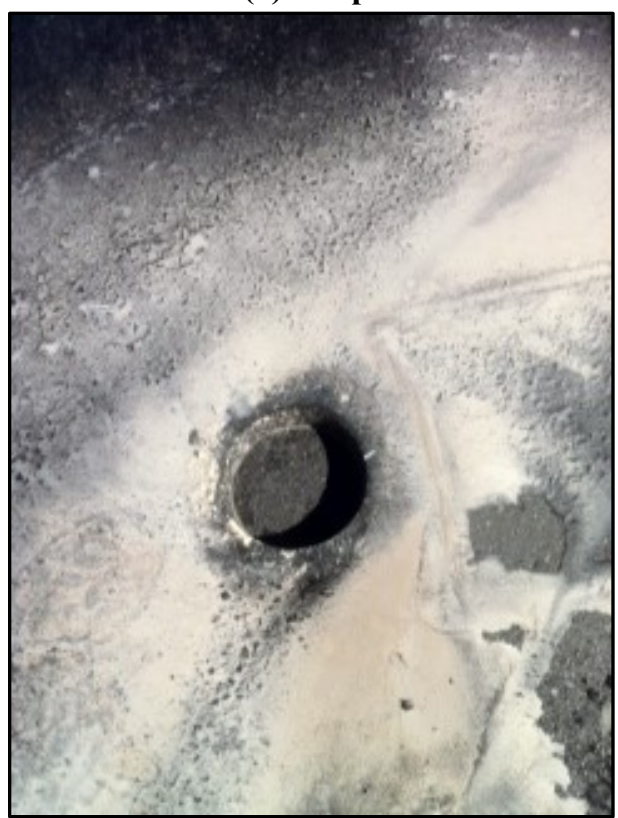

(c) Step Three

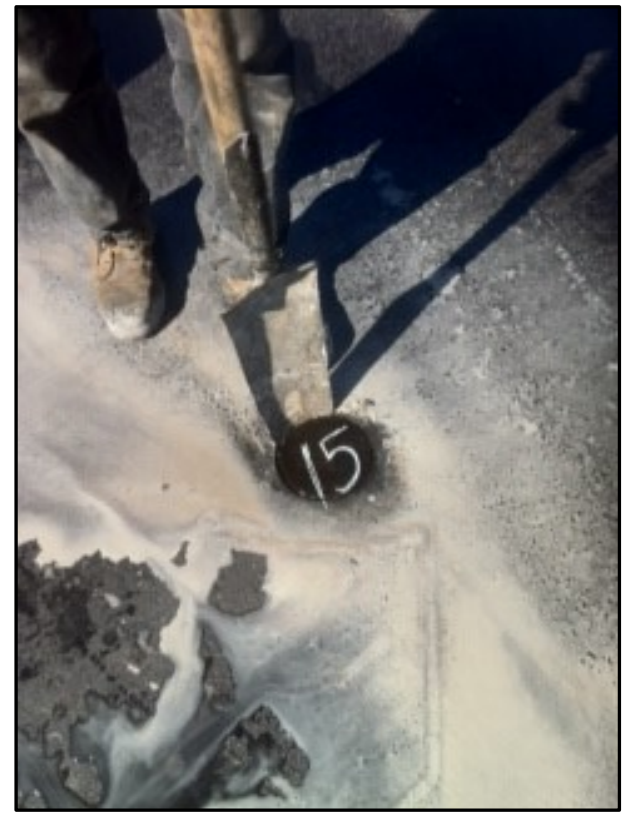

(b) Step Two

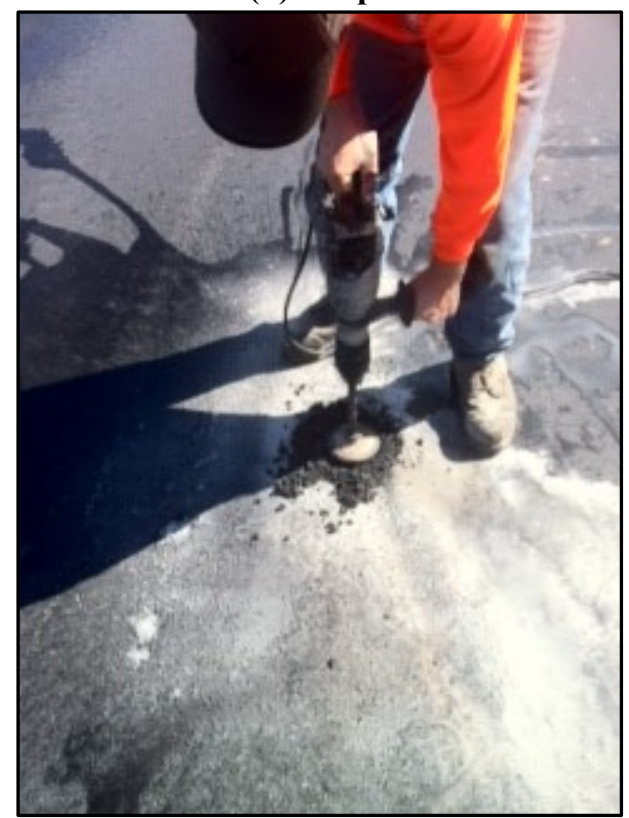

(d) Step Four

Figure 4.27: Field Coring For the Inner Edge Location at Highway 417 Project 


\subsubsection{A Conventional Compaction Method}

As discussed in the experimental investigation, core samples were recovered from each testing site considered by MTO in this research. In total, field cores were recovered from seven testing sites compacted by conventional method (five highway projects and two inhouse controlled sections). These two in-house sites were field trials were performed under the supervision of the construction firm R.W.Tomlinson Limited and observed by MTO personal. The laboratory testing program included the determination of bulk relative densities, laboratory permeability measurements, and IDT values. The results of laboratory tests are presented in chronological order below.

\section{A.1 Lab Results of Year 2012}

Three newly constructed sites were inspected in 2012 including two highway projects, which are Highway 28 and Thousand Islands Parkway, and one in-house trial at Power Road Tomlinson site. A total of 10 cores were recovered from each of Highway 28 and Tomlinson site, while only 5 cores were extracted from Thousand Islands Parkway site. The bulk specific gravity and IDT test were performed on all collected cores. The results of the bulk specific gravity are shown in Figure 4.28 while Figure 4.29 presents the results of the IDT test. It is important to mention that no laboratory permeability tests were conducted on any of the collected cores in 2012 as the Karol-Warner Asphalt permeameter (the lab permeability device) was not available at Carleton University's J.A. Civil Engineering lab. 


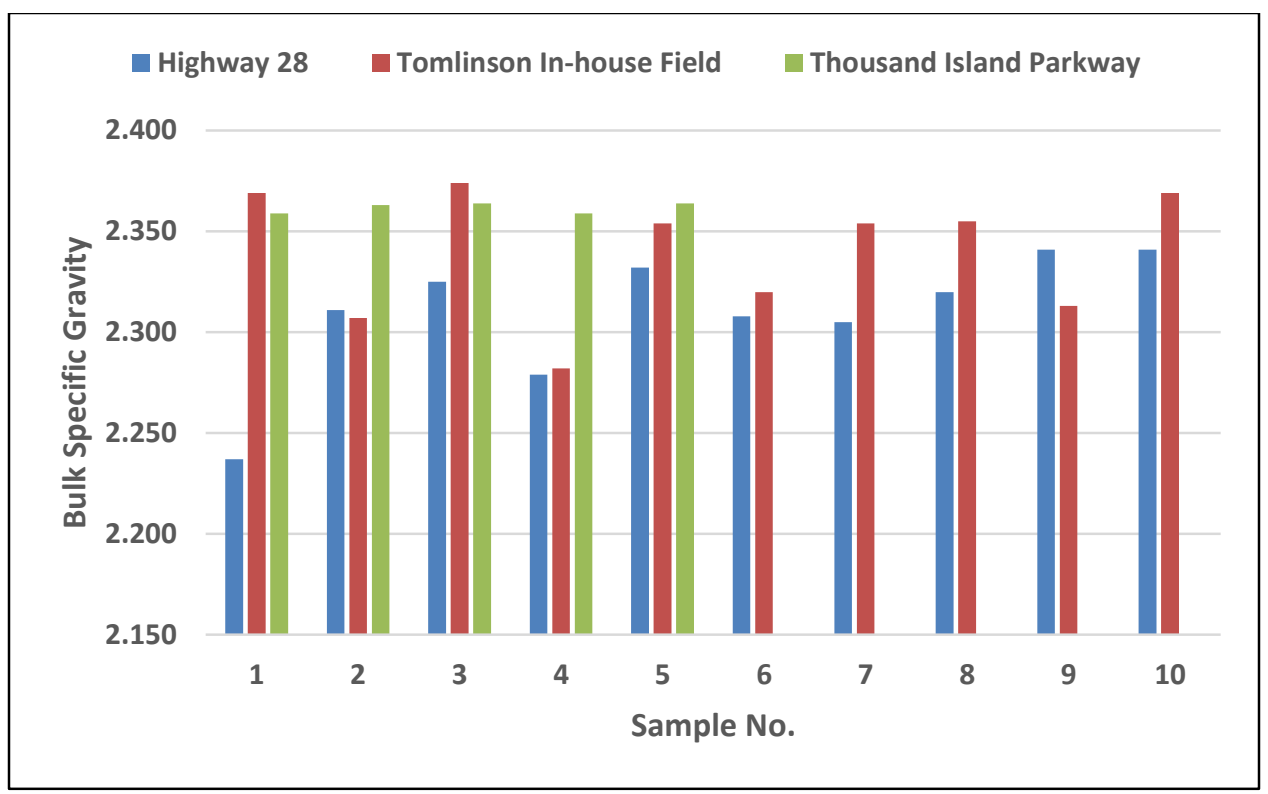

Figure 4.28: The Bulk Specific Gravity Results for year 2012 Projects

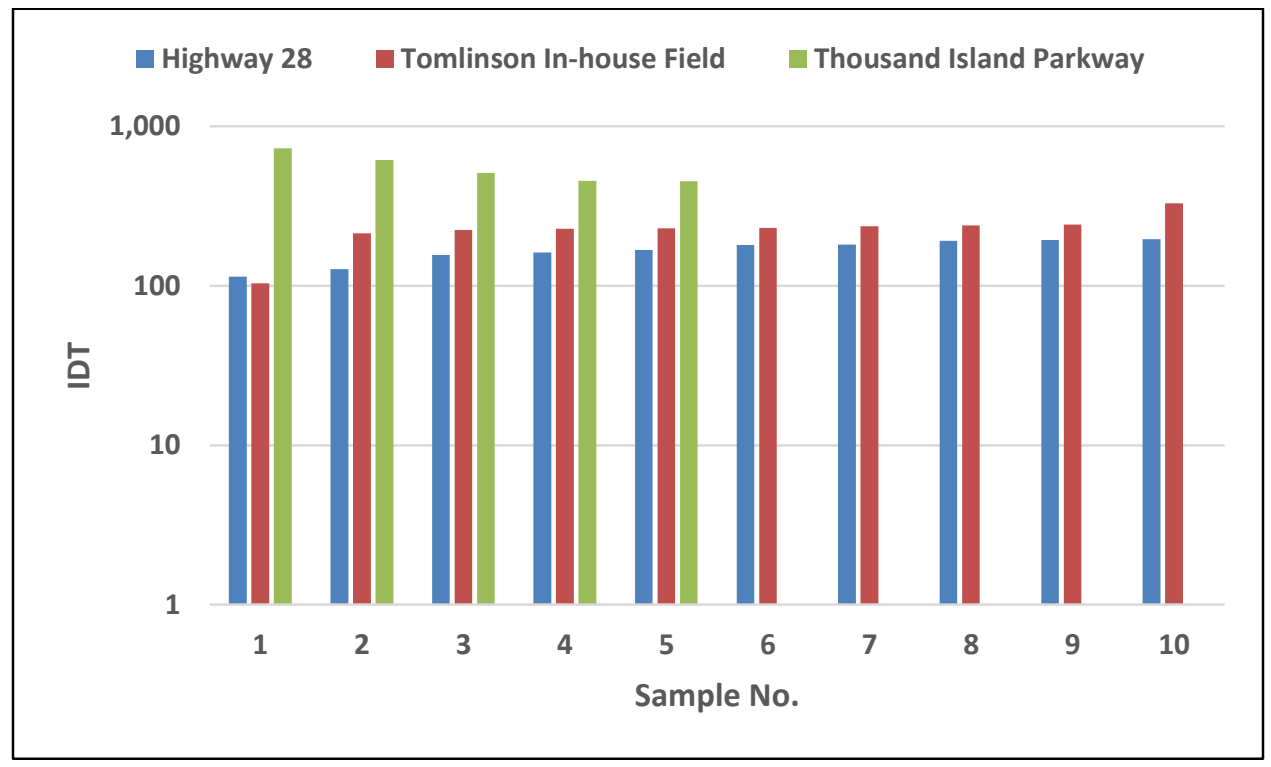

Figure 4.29: The IDT Results for year 2012 Projects

\section{A.2 Lab Results of Year 2013}

In 2013, the laboratory investigations consisted of collecting field cores from three newly constructed sites which are Highways 16, 17 and 417. In total, 15 cores were extracted to cover 5 different populations in terms of their location across the $3.6 \mathrm{~m}$ highway lane as 
stated earlier in this Chapter 3; each population had three cores $(3$ cores per population $\times$ 5 population $=15$ cores). The laboratory permeability test was performed on field cores collected in 2013 onward to explore the potential correlation between field and laboratory permeability. Graphical representation of the results is shown in Figure 4.30 through Figure 4.32. According to these results, Highway 417 had the lowest average lab permeability $\left(31.26 \times 10^{-4} \mathrm{~mm} / \mathrm{sec}\right)$, the highest average bulk specific gravity (2.341), and the highest average IDT $(652.52 \mathrm{kPa})$ compared to the two other sites finished in the same year.

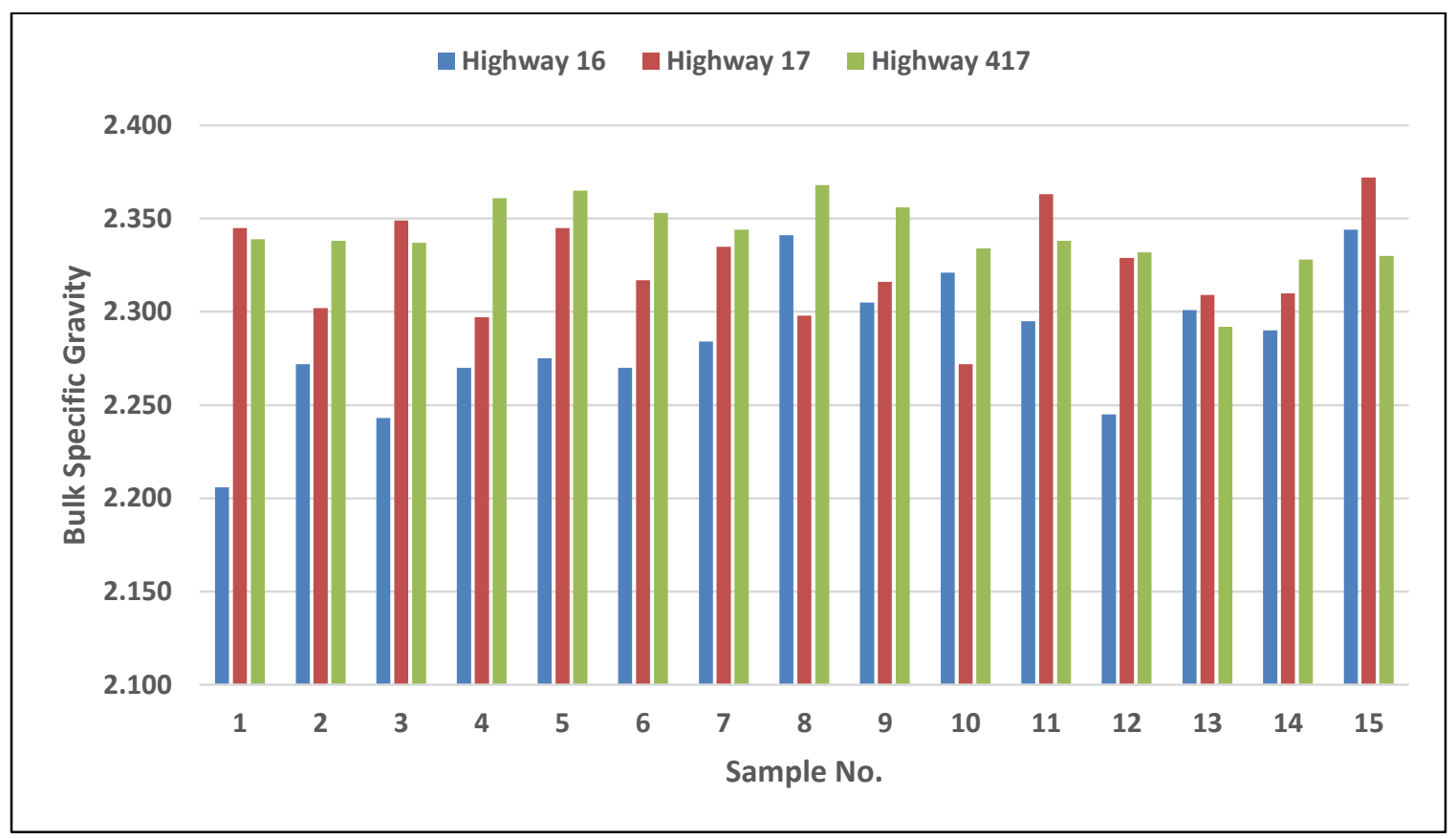

Figure 4.30: The Bulk Specific Gravity Results for year 2013 Projects 


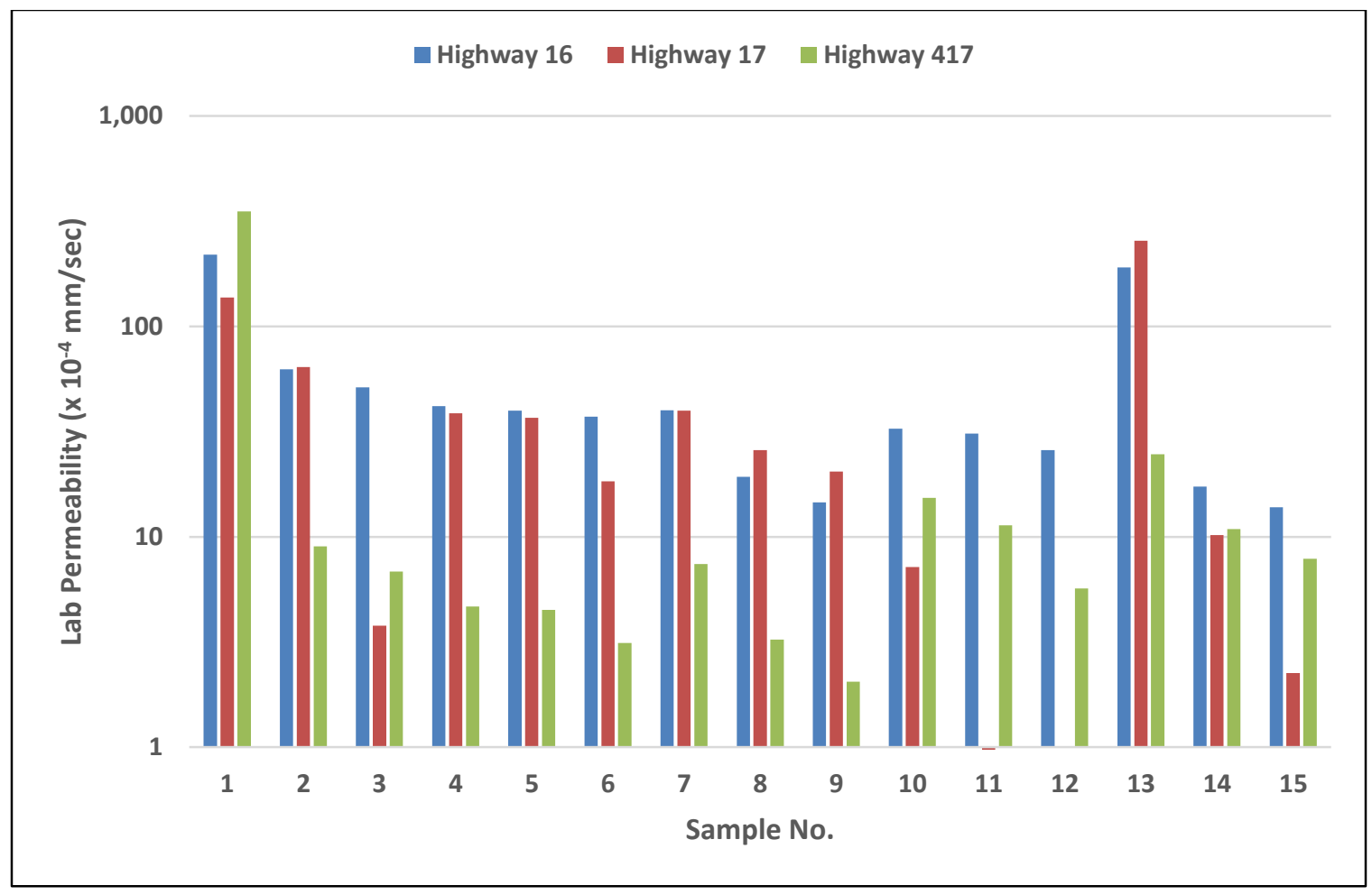

Figure 4.31: The Lab Permeability Results for year 2013 Projects

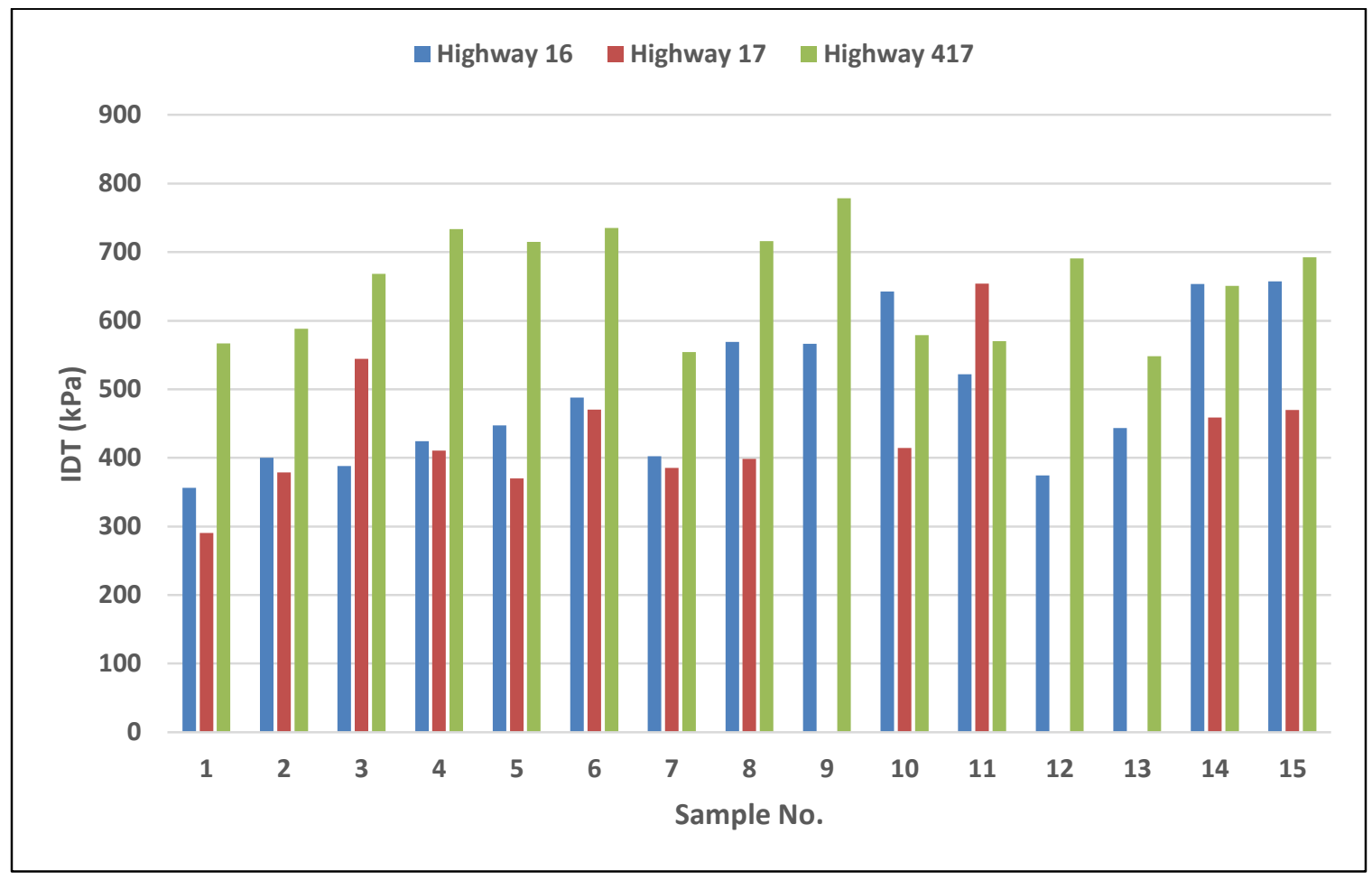

Figure 4.32: The IDT Results for year 2013 Projects 


\section{A.3 Lab Results of Year 2014}

Sampling cores was also performed in 2014 at an in-house project at Greenbelt site. In total, 8 cores were extracted from the paved section. The same three aforementioned laboratory tests were also conducted on each recovered core. According to the results presented in Figure 4.33 (a) through Figure 4.33 (c), high laboratory permeability values $\left(\right.$ mean $\left.=733 \times 10^{-4} \mathrm{~mm} / \mathrm{sec}\right)$ were exhibited coupled with poor bulk relative density $($ mean $=2.208)$ and low IDT strength values $($ mean $=236 \mathrm{kPa})$.

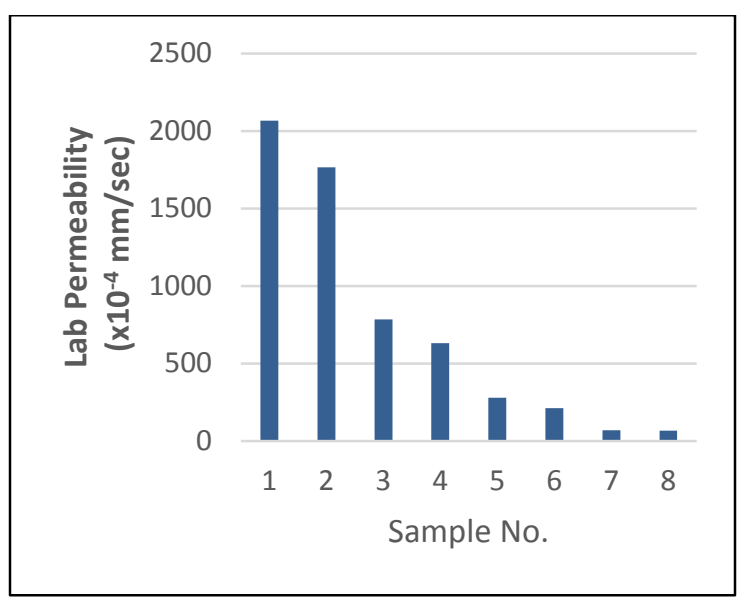

(a) Lab Permeability

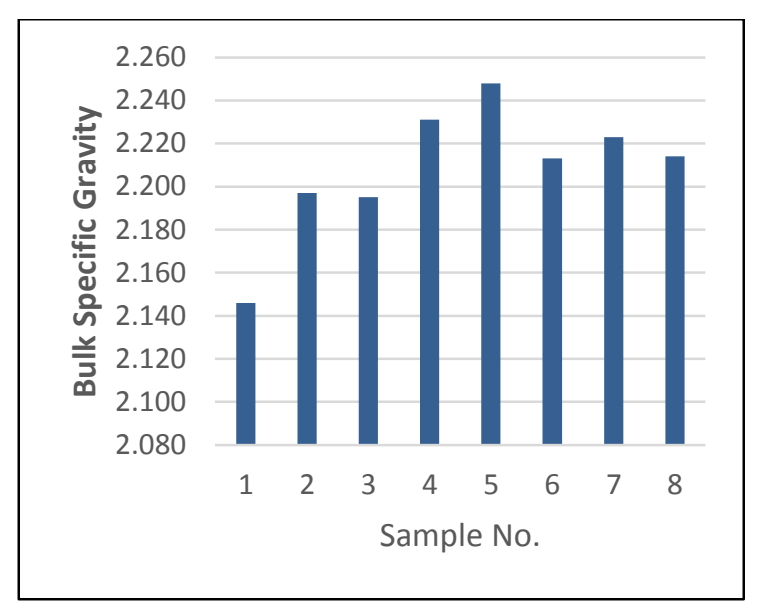

(b) Bulk Relative Density

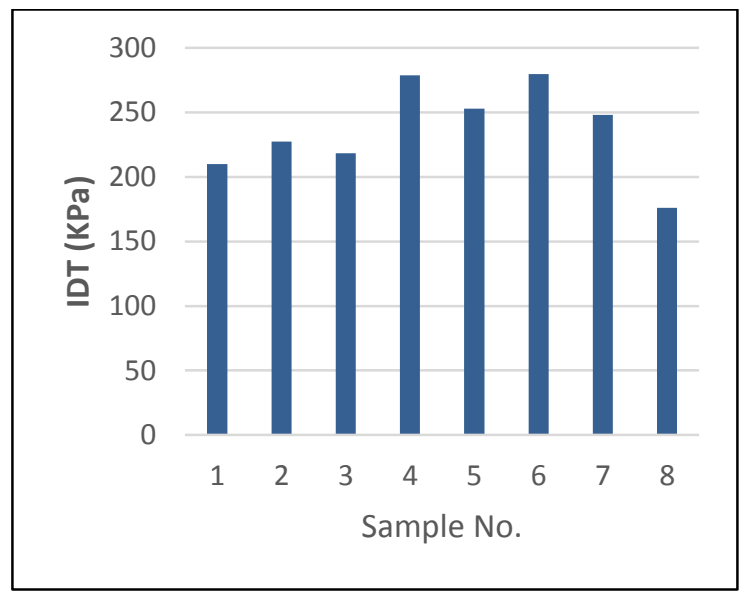

(c) IDT

Figure 4.33: The Laboratory Results of The in-house Field Trial at Greenbelt 


\subsubsection{B Advanced Compaction Method}

\section{B.1 Lab Results of Year 2012}

The AMIR-II compactor was utilized to pave several sites inside and outside Ontario. In 2012, AMIR-II compacted the same aforementioned projects side-by-side with the Steel roller. These projects are Highway 28, Highway Thousand Islands Parkway, and the inhouse trial located at Tomlinson site. In total 25 cores were collected; ten from Highway 28, ten from Tomlinson site trial, and five from Thousand Islands Parkway. As previously stated, only the bulk relative density and IDT tests were conducted on the field-recovered cores by that time. The results for the bulk specific gravity and the IDT tests are presented in bar charts in Figure 4.34 and Figure 4.35 respectively.

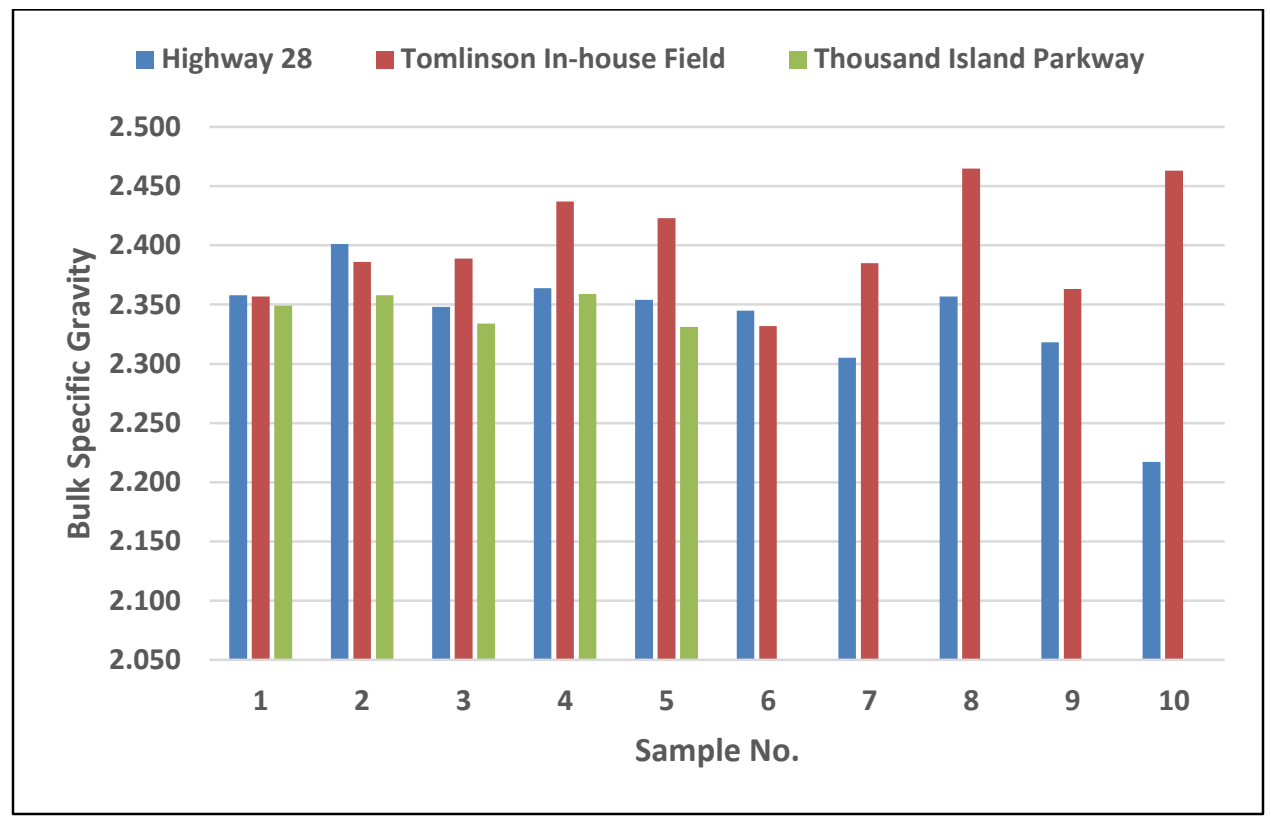

Figure 4.34: The Bulk Specific Gravity Results for year 2012 Projects 


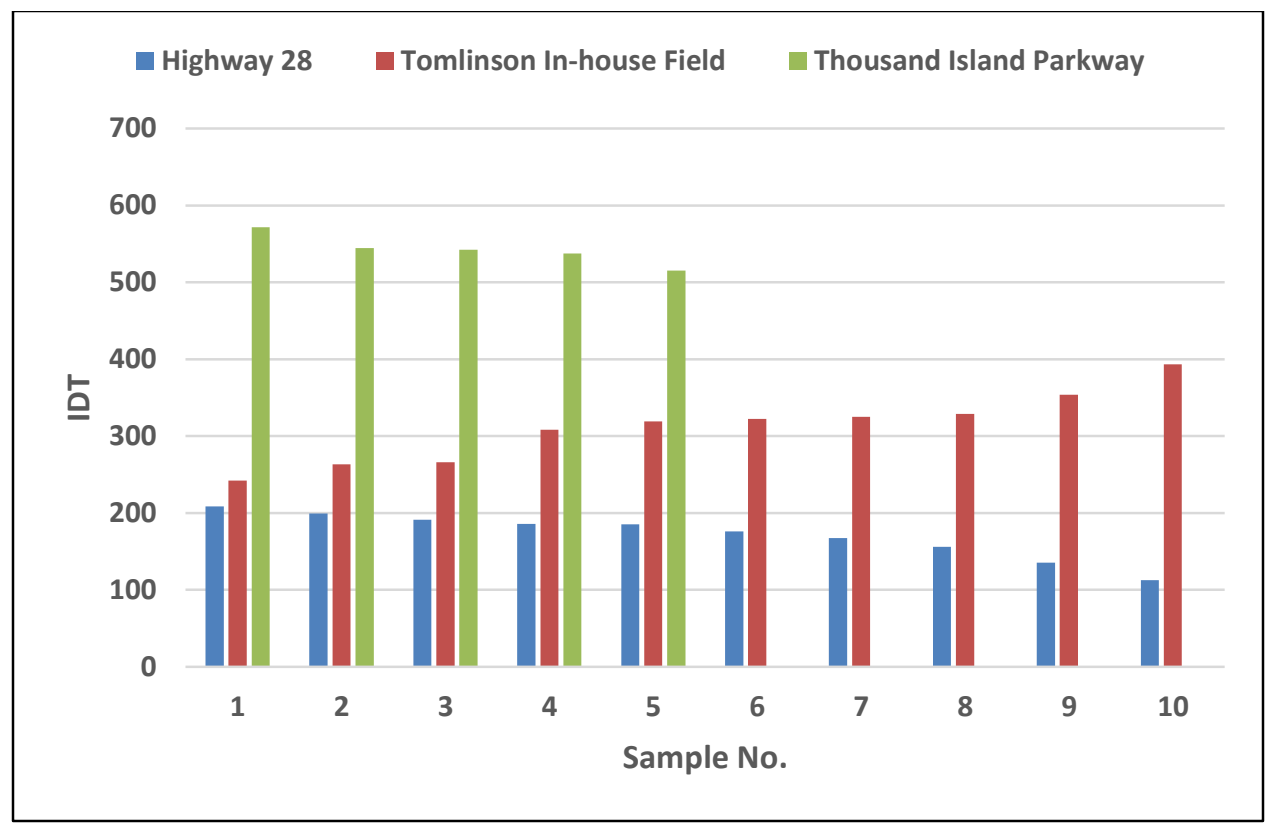

Figure 4.35: The IDT Results for year 2012 Projects

\section{B.2 Lab Results of Year 2014}

Three paving projects were implemented in 2014 using the AMIR-II compactor side-byside with the conventional steel roller. As stated earlier, two of these projects are in-house trials which took place at the Greenbelt site. The third project was the compaction of a $200 \mathrm{~m}$ long bridge located at Highway 34. Both compaction techniques were used in this project, the Steel roller and the AMIR-II roller. The results of the bulk specific gravity test, lab permeability, and IDT are presented in Figure 4.36, Figure 4.37, and Figure 4.38 respectively. 


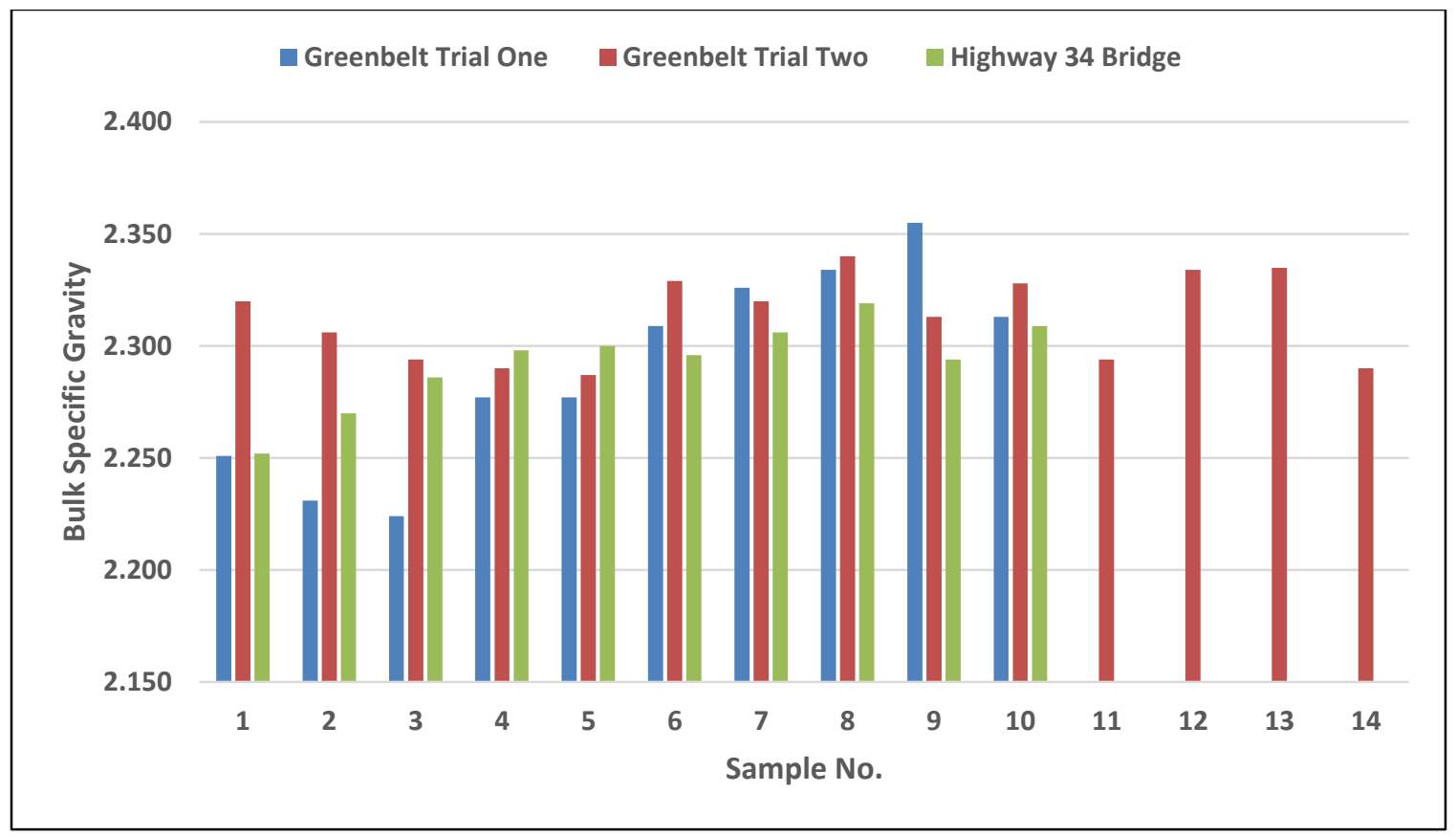

Figure 4.36: The Bulk Specific Gravity Results for year 2014 Projects

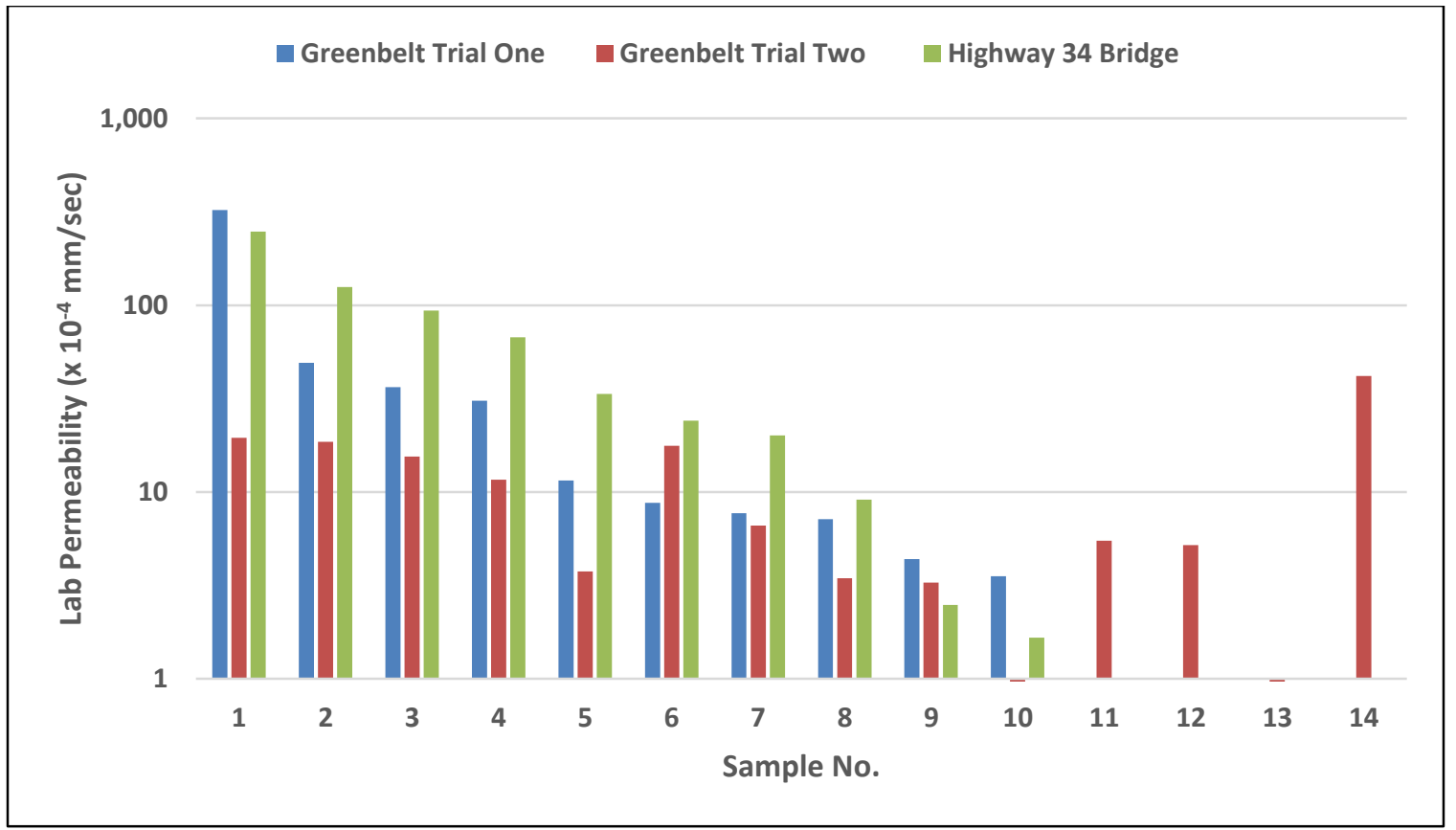

Figure 4.37: The Lab Permeability Results for year 2013 Projects 


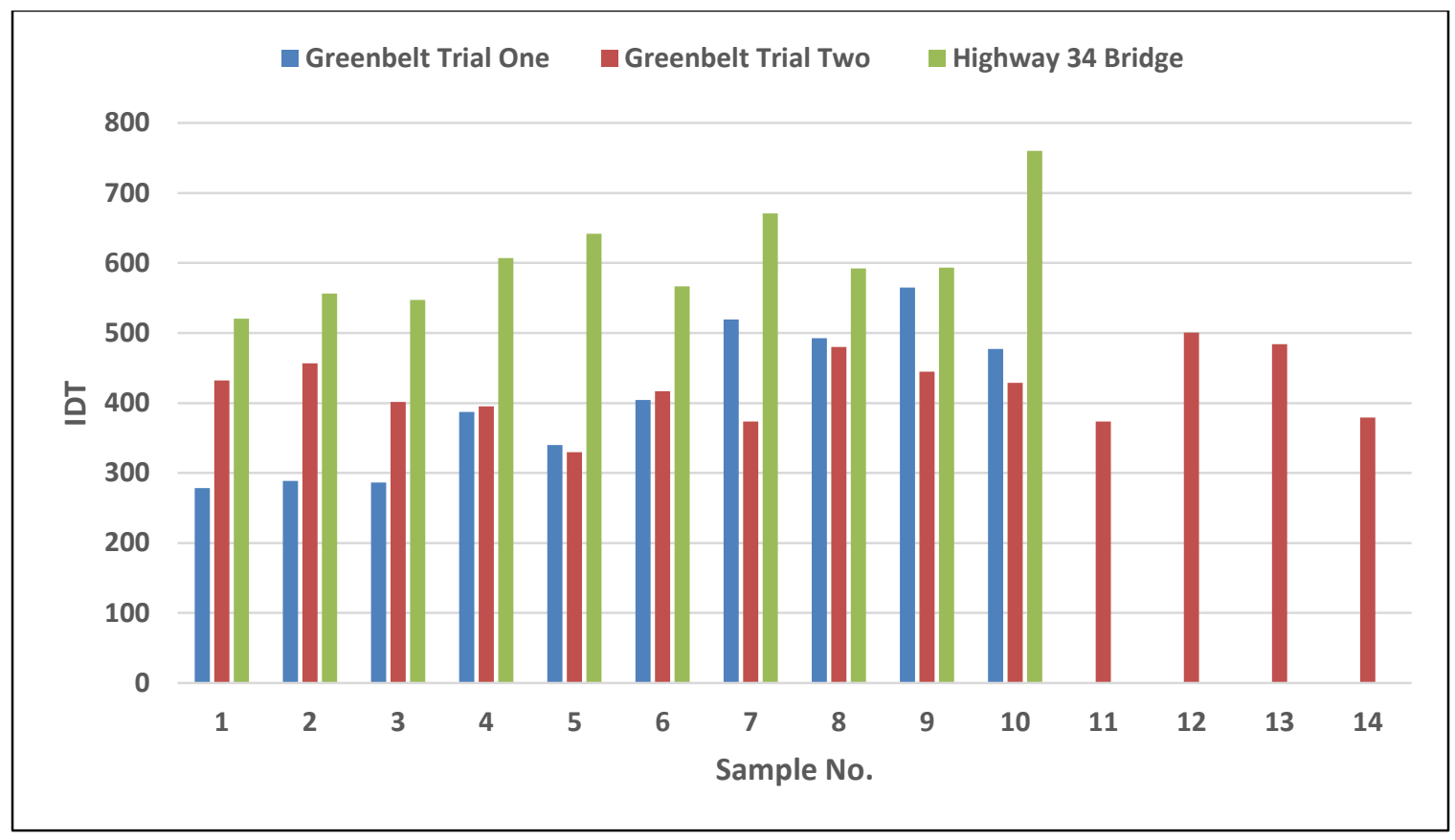

Figure 4.38: The IDT Results for year 2014 Projects

\subsection{Summary}

This chapter of the thesis presented the data and results obtained through implementing the laboratory and field testing programs. The field investigations consisted of performing in-situ permeability tests in addition to recovering core samples from each test section. The laboratory investigations incorporated measuring the bulk specific gravity, lab permeability, and IDT values of the field-recovered cores. In this study, some testing sites were compacted by both compaction techniques while others were constructed and finished by only the conventional techniques.

The next chapter deals with the quantitative analysis required to investigate the possible correlations between physical and mechanical properties of asphalt pavement, and to examine the effect of testing location, compaction method and project level on different engineering properties (density, permeability, strength) of asphalt pavement. An attempt to model and relate the physical properties (permeability) and mechanical properties 
(strength) of field-recovered cores using the Gyratory compactor is carried out. Also, the chapter studies, compares, and analyzes field and laboratory results obtained by two different compaction methods. 


\section{CHAPTER 5: DATA ANALYSIS}

This chapter presents the general trends and relationships of the different pavement properties examined in this study as well as results of statistical analysis conducted on the results obtained from both the field and laboratory investigations. The chapter consists of five main sections. The first section illustrates and studies each asphalt pavement property considered in this research. The second section examines the possible correlations between the considered asphalt properties. The last three sections present the relationship of each property to the other in two different settings; the field and laboratory.

\subsection{Physical and Mechanical Properties of Asphalt Pavement}

This section is devoted to present the analysis of different physical and mechanical properties as well as comparing the performance of the two compaction techniques in terms of these properties. Particularly, the obtained field and laboratory results at the five testing locations introduced earlier in Chapter 3 were used to construct the comparison. In this research, the impact of three different independent factors including the testing location, compaction method, and project level on each pavement property (response variable) was examined. Subsequently, a three-way ANOVA test at 5\% level of significance was used in Section 5.1.1 through Section 5.1.4 to examine the possible three-way and two-way interaction effects between the three considered factors. For further investigation purposes, the three-way ANOVA was followed in some cases by one-way ANOVA test at 5\% level of significance to determine if the compaction method has a statistically significant effect on the quality of the each pavement property. Before conducting any of the statistical tests in this chapter, the test of homogeneity of variances 
was performed by Levene's test to check whether any of the examined sets have equal variance or not. In case of not meeting the homogeneity of variances assumption, the results assuming not equal variance were considered.

\subsubsection{Relative Density of Field-Recovered Cores}

The first pavement property used to examine the effect of the three aforementioned factors is the relative density. In total, 117 field cores were recovered from different sites finished by the two compaction methods; 68 conventional and 49 advanced. The number of field cores for each testing location as well as compaction method is summarized in Table 5.1.

Table 5.1: Summary of the Relative Density Dataset

\begin{tabular}{ccc}
\hline \multirow{2}{*}{ Testing Location } & \multicolumn{2}{c}{ Compaction Method } \\
\cline { 2 - 3 } & Advanced & Conventional \\
\hline Inner Edge & 9 & 14 \\
\hline Inner Middle & 5 & 11 \\
\hline Middle & 18 & 17 \\
\hline Outer Middle & 7 & 11 \\
\hline Outer Edge & 10 & 15 \\
\hline Total & 49 & 68 \\
\hline
\end{tabular}

All density measurements along with the average value for each testing location are shown in Figure 5.1 and Figure 5.2 for the conventional and advanced method respectively. 


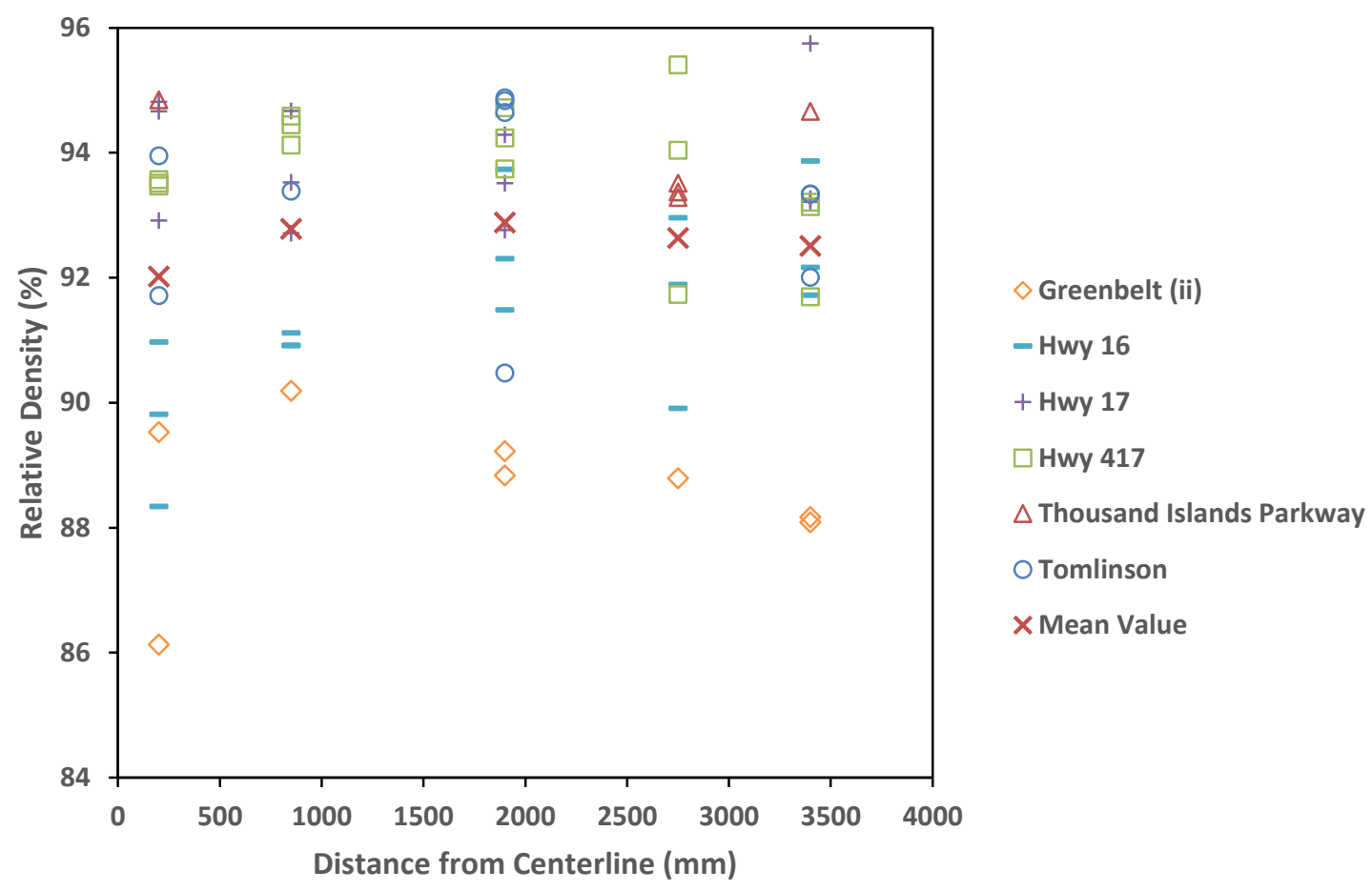

Figure 5.1: Relative Density vs. Testing Locations (Conventional Method)

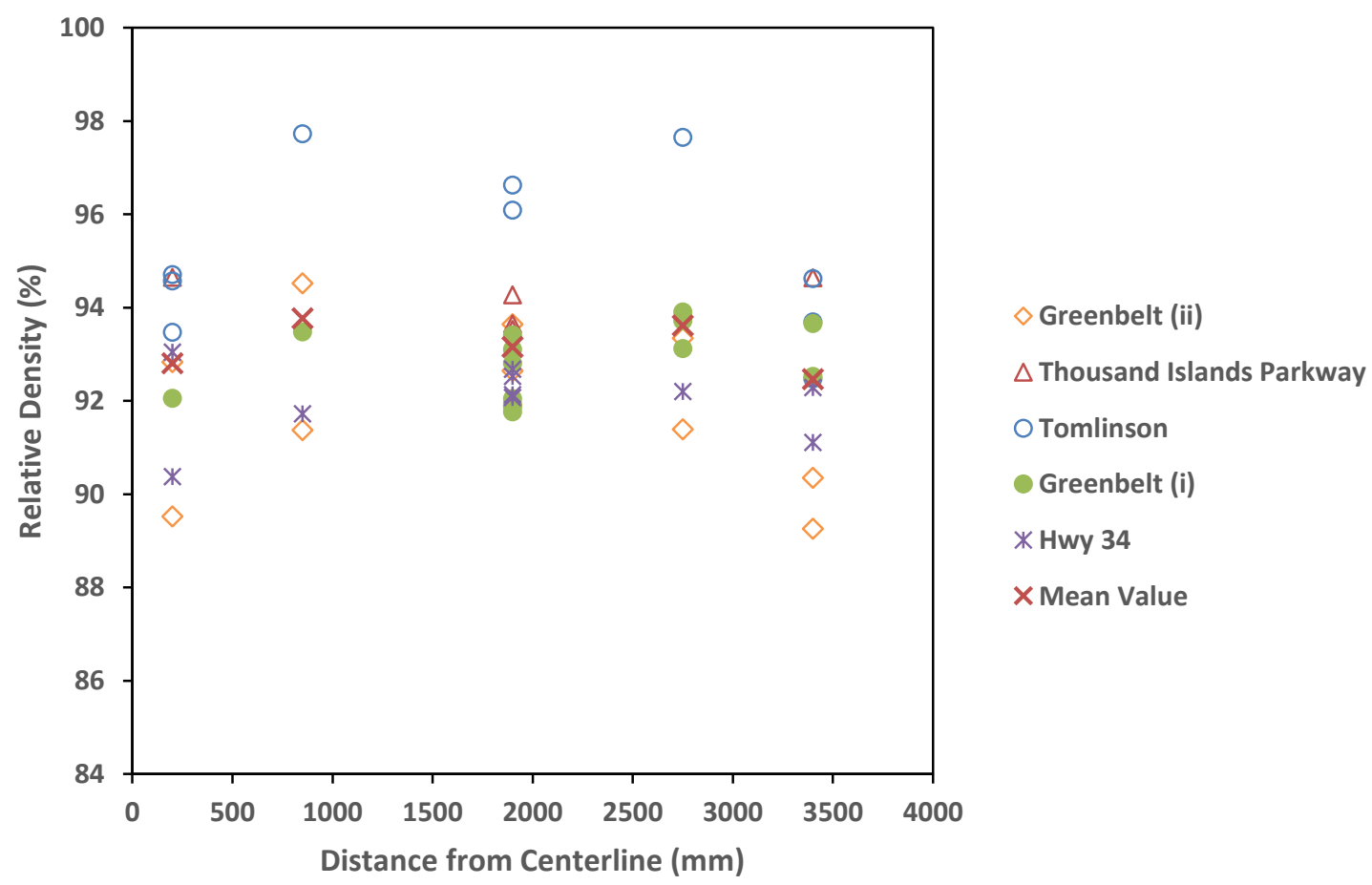

Figure 5.2: Relative Density vs. Testing Locations (Advanced Method) 
The null and alternative hypotheses for the three-way ANOVA test are summarized in Table 5.2. These hypotheses will be the same throughout this chapter, expect for changing the response variable in each subsection (e.g. relative density, permeability...etc.).

Table 5.2: Summary of the Three-Way ANOVA Test Hypotheses

\begin{tabular}{ccc}
\hline Factor & Null Hypothesis & Alternative Hypothesis \\
\hline $\mathrm{TL}$ & $\mu_{1}=\mu_{2}=\mu_{3}=\mu_{4}=\mu_{5}$ & Not all $\mu_{i}$ are equal \\
$\mathrm{CM}$ & $\mu_{\text {conventional }}=\mu_{\text {advanced }}$ & $\mu_{\text {conventional }} \neq \mu_{\text {advanced }}$ \\
\hline $\mathrm{PL}$ & $\mu_{p r j 1}=\mu_{p r j 2}=\cdots=\mu_{\text {prj } n}$ & Not all $\mu_{\text {prj }}$ are equal
\end{tabular}

$\mathrm{TL} * \mathrm{CM}$

TL*PL No interaction between the There is an interaction between

$\mathrm{CM}^{*} \mathrm{PL} \quad$ considered factors the considered factors

\section{$\mathrm{TL} * \mathrm{CM} * \mathrm{PL}$}

where $\quad \frac{\mu_{p r j 1} \text { to } \mu_{\operatorname{prj} n} \text { indicates mean value at each examined project }}{\text { TL: testing location, CM: compaction method, and PL: project level }}$

The three-way ANOVA test was carried out to examine the significance of the differences and determine if there is an interaction between the three considered factors in this study when examining the relative density as the response variable. The summarized results in Table 5.3 suggest that all three factors (raw 1 to 3 ) were statistically significant at 5\% level of significance. The results of the two-way interaction effect (raw 4 to 6) imply that only the interaction between the compaction method and project level was statistically significant at 5\% level of significance, while other interactions were not statistically significant. 
Table 5.3: Summary of the Three-Way ANOVA Results for Relative Density

\begin{tabular}{ccc}
\hline Factor & $\boldsymbol{F}$ & $\boldsymbol{p}$-value \\
\hline $\mathrm{TL}$ & 3.672 & 0.009 \\
\hline $\mathrm{CM}$ & 30.828 & $<0.001$ \\
\hline $\mathrm{PL}$ & 32.985 & $<0.001$ \\
\hline $\mathrm{TL} * \mathrm{CM}$ & 1.377 & 0.252 \\
\hline $\mathrm{TL} * \mathrm{PL}$ & 1.545 & 0.080 \\
\hline $\mathrm{CM}{ }^{*} \mathrm{PL}$ & 6.112 & 0.004 \\
\hline $\mathrm{TL} \mathrm{CM}^{*} \mathrm{PL}$ & 1.245 & 0.295 \\
\hline
\end{tabular}

This implies that the impact of compaction method on relative density depends on the project level and vice versa. The three-way interaction effect presented in last raw suggests that there was no statistically significant interaction between the three factors.

\subsubsection{IDT of Field-Recovered Cores}

The second pavement property used to study the influence of the three considered factors on the overall pavement performance is the IDT. The IDT test is incorporated in this research to explore the effect of physical properties (permeability and relative density) on pavement mechanical properties represented by the strength. The same set of data used in the relative density testing was used as well for the IDT test except for three cores of Highway 17. Due to transporting the cores from one testing set up to another, these three cores were accidently broken before the IDT test. It is worth noting that these cores were tested for both the permeability and density test since they were in good condition at that time. A summary of the set of data used in this test is presented in Table 5.4. 
Table 5.4: Summary of the IDT Dataset

\begin{tabular}{ccc}
\hline \multirow{2}{*}{ Testing Location } & \multicolumn{2}{c}{ Compaction Method } \\
\cline { 2 - 3 } & Advanced & Conventional \\
\hline Inner Edge & 9 & 14 \\
\hline Inner Middle & 5 & 11 \\
\hline Middle & 18 & 16 \\
\hline Outer Middle & 7 & 10 \\
\hline Outer Edge & 10 & 14 \\
\hline Total & 49 & 65 \\
\hline
\end{tabular}

The IDT results at the five testing locations for the conventional and advanced methods are shown in Figure 5.3 and

Figure 5.4 respectively.

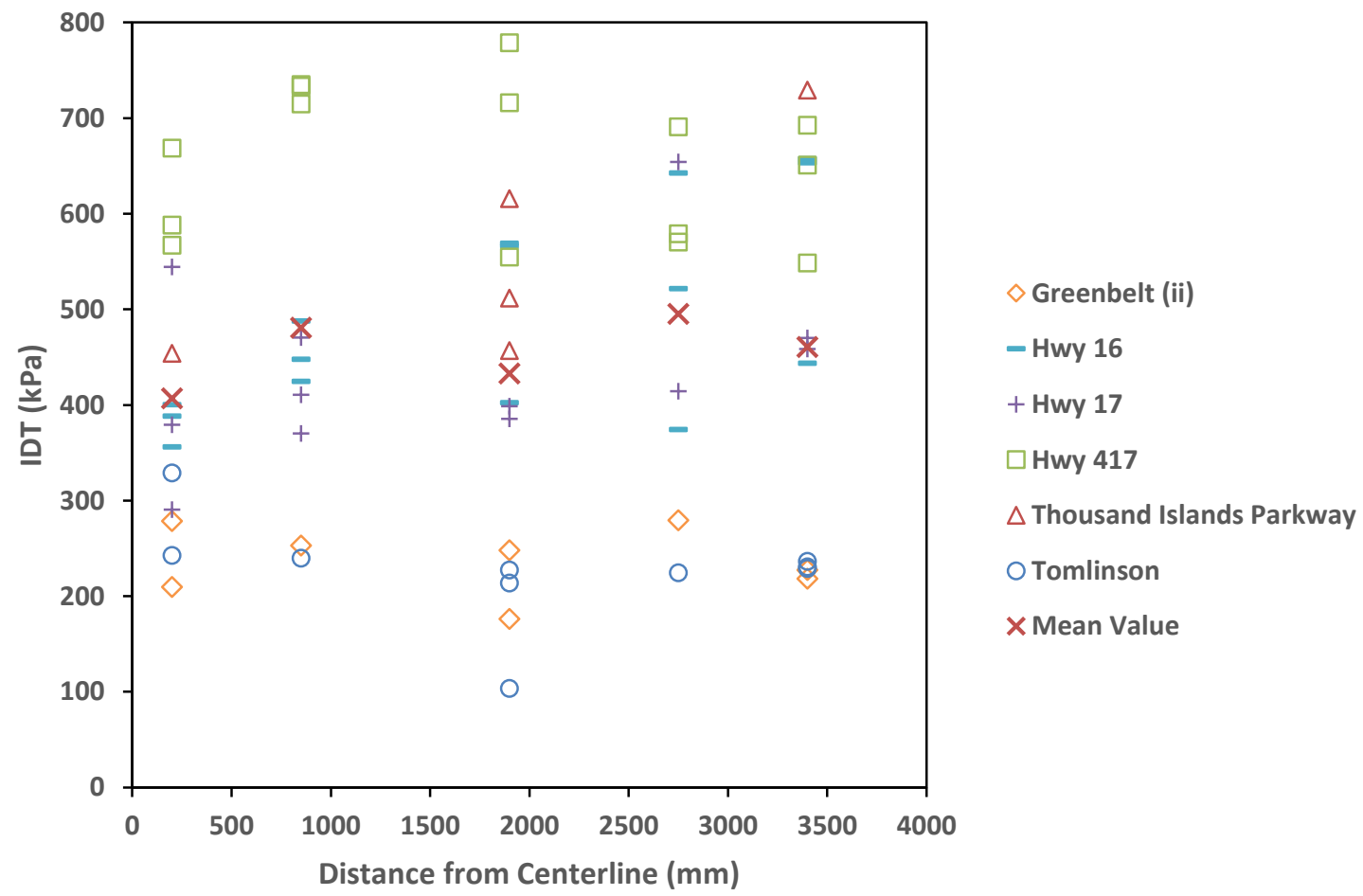

Figure 5.3: IDT vs. Testing Locations (Conventional Method) 


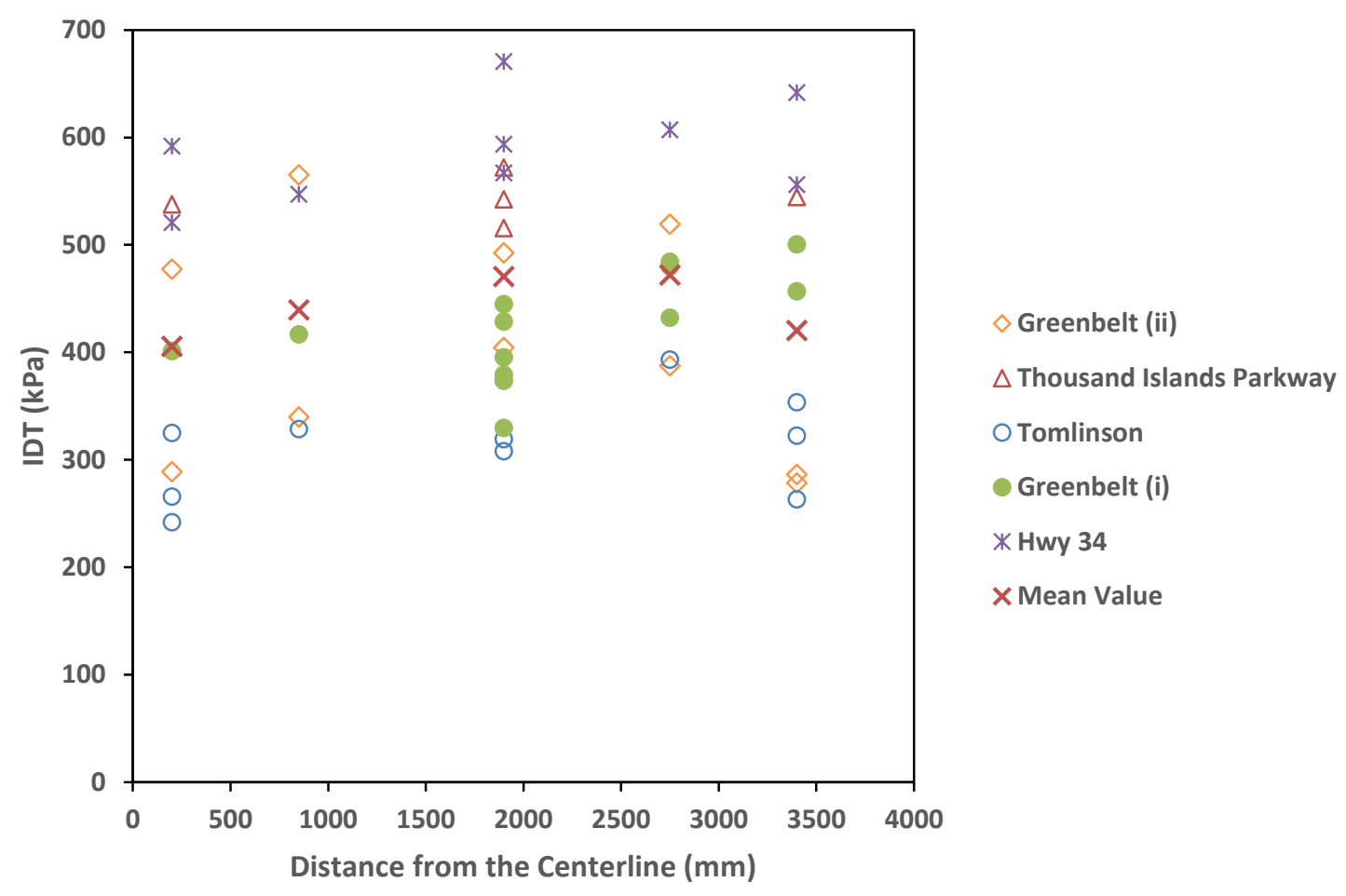

Figure 5.4: IDT vs. Testing Locations (Advanced Method)

The three-way ANOVA test was carried out and the results are summarized in Table 5.5. It can be seen that all factors, except for testing location, were statistically significant at $5 \%$ level of significance. In addition, the results imply that the only significant two-way interaction effect was found between the compaction method and the project level. There was no statistically significant three-way interaction effect $(p$-value $=0.524)$ between the three factors. Note that the findings related to the two-way and three-way interaction effects were similar to the previously found results based on relative density. 
Table 5.5: Summary of the Three-Way ANOVA Results for IDT

\begin{tabular}{ccc}
\hline Factor & $\boldsymbol{F}$ & $\boldsymbol{p}$-value \\
\hline $\mathrm{TL}$ & 2.110 & 0.090 \\
\hline $\mathrm{CM}$ & 10.716 & 0.002 \\
\hline $\mathrm{PL}$ & 42.929 & $<0.001$ \\
\hline $\mathrm{TL} * \mathrm{CM}$ & 1.598 & 0.186 \\
\hline $\mathrm{TL} * \mathrm{PL}$ & 1.323 & 0.183 \\
\hline $\mathrm{CM}{ }^{*} \mathrm{PL}$ & 3.287 & 0.044 \\
\hline $\mathrm{TL}{ }^{*} \mathrm{CM} \mathrm{M}^{*} \mathrm{PL}$ & 0.867 & 0.524 \\
\hline
\end{tabular}

Further analysis was carried out to examine if there is a significant difference in terms of IDT between the two compaction methods for the same project level. Note that this analysis was performed regardless of the testing location since this factor did not have a statistically significant effect on IDT. The summarized results in Table 5.6 suggest that two out of the four common projects were statistically significant. This also confirms the interaction between the two variables where it was found that the effect of compaction method depends on the project level.

Table 5.6: Summary of One-Way ANOVA Results for Effect of Compaction Method on IDT

\begin{tabular}{ccc}
\hline Project & $\boldsymbol{F}$ & $\boldsymbol{p}$-value \\
\hline Greenbelt (ii) & 18.436 & 0.001 \\
\hline Highway 28 & 0.125 & 0.728 \\
\hline Thousand Islands Parkway & 0.041 & 0.844 \\
\hline Tomlinson & 14.439 & 0.001 \\
\hline
\end{tabular}

\subsubsection{Field Permeability}

The in-situ permeability measurements were available for the two compaction methods. In total, there are 197 field measurements; 67 for the advanced method and 130 for the conventional. Since the exact locations of permeability measurement were not available 
for one common site (Highway 28) for the two compaction method, 20 field measurements were excluded in this analysis; 10 for each compaction method. This results in having 57 field permeability measurements for the advanced method and 120 for the conventional. Table 5.7 summarizes the numbers of field permeability measurements for each compaction technique and their corresponding testing locations. Note that no field permeability measurements were taken at the inner middle or outer inner locations for the advanced method.

Table 5.7: Summary of the Field Permeability Dataset

\begin{tabular}{ccc}
\hline \multirow{2}{*}{ Testing Location } & \multicolumn{2}{c}{ Compaction Method } \\
\cline { 2 - 3 } & Advanced & Conventional \\
\hline Inner Edge & 14 & 33 \\
\hline Inner Middle & - & 13 \\
\hline Middle & 28 & 34 \\
\hline Outer Middle & - & 13 \\
\hline Outer Edge & 15 & 27 \\
\hline Total & 57 & 120 \\
\hline
\end{tabular}

Figure 5.5 and Figure 5.6 show all permeability measurements at the five test locations for the conventional and advanced method respectively. According to the presented results, on average the inner edge location of the conventional method experiences relatively higher permeability compared to the other testing locations of the same compaction method. In general, the field permeability trend of the conventional method showed that the middle locations, except for the outer middle location, have less permeability compared to the three other locations. Note that the outer middle is higher than the outer edge due to the influence of one single measurement. For the advanced 
method, there was an observed trend suggesting that the outer location had on average less permeability followed by the middle then the inner edge location.

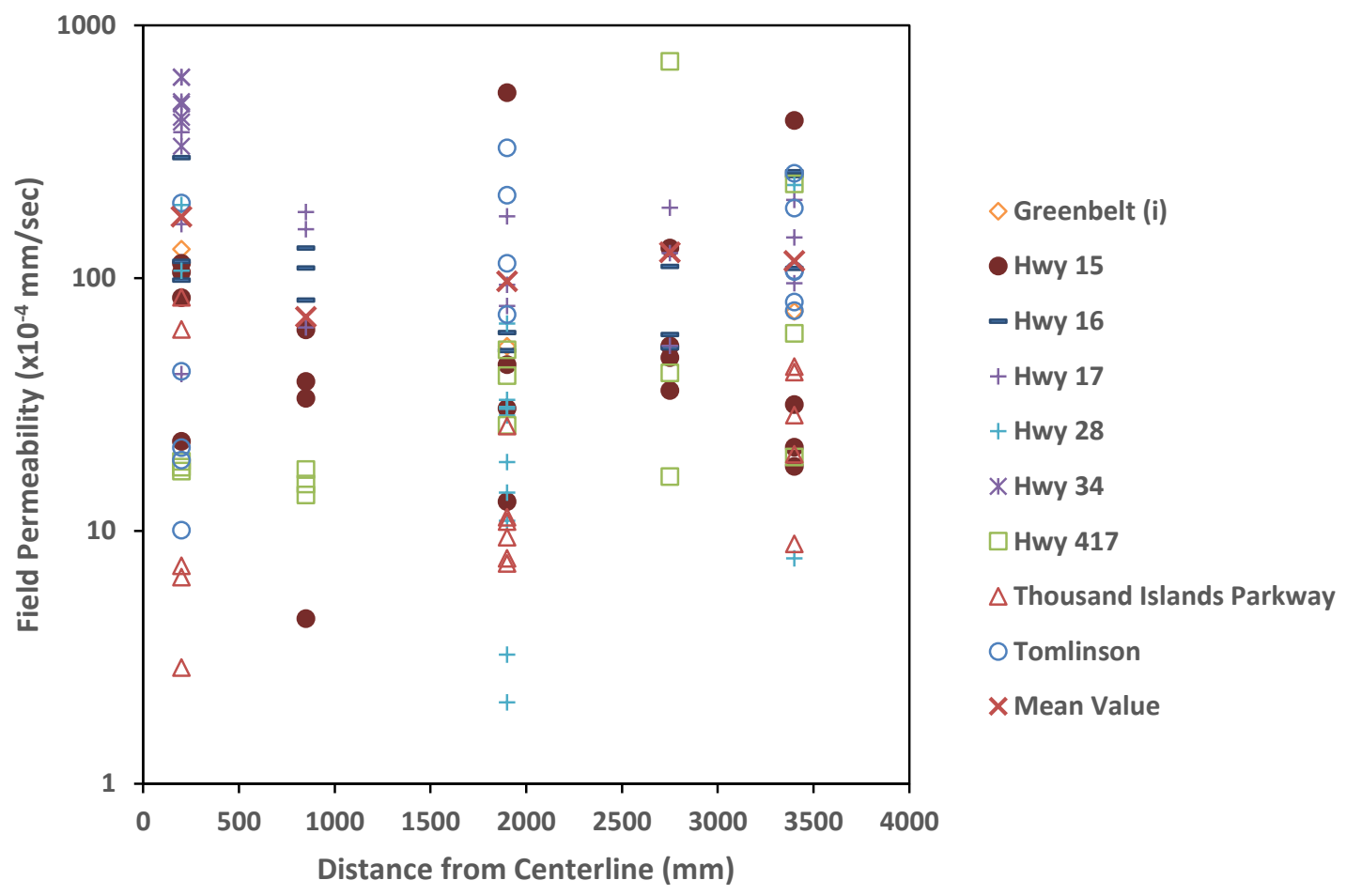

Figure 5.5: Field Permeability vs. Testing Locations (Conventional Method) 


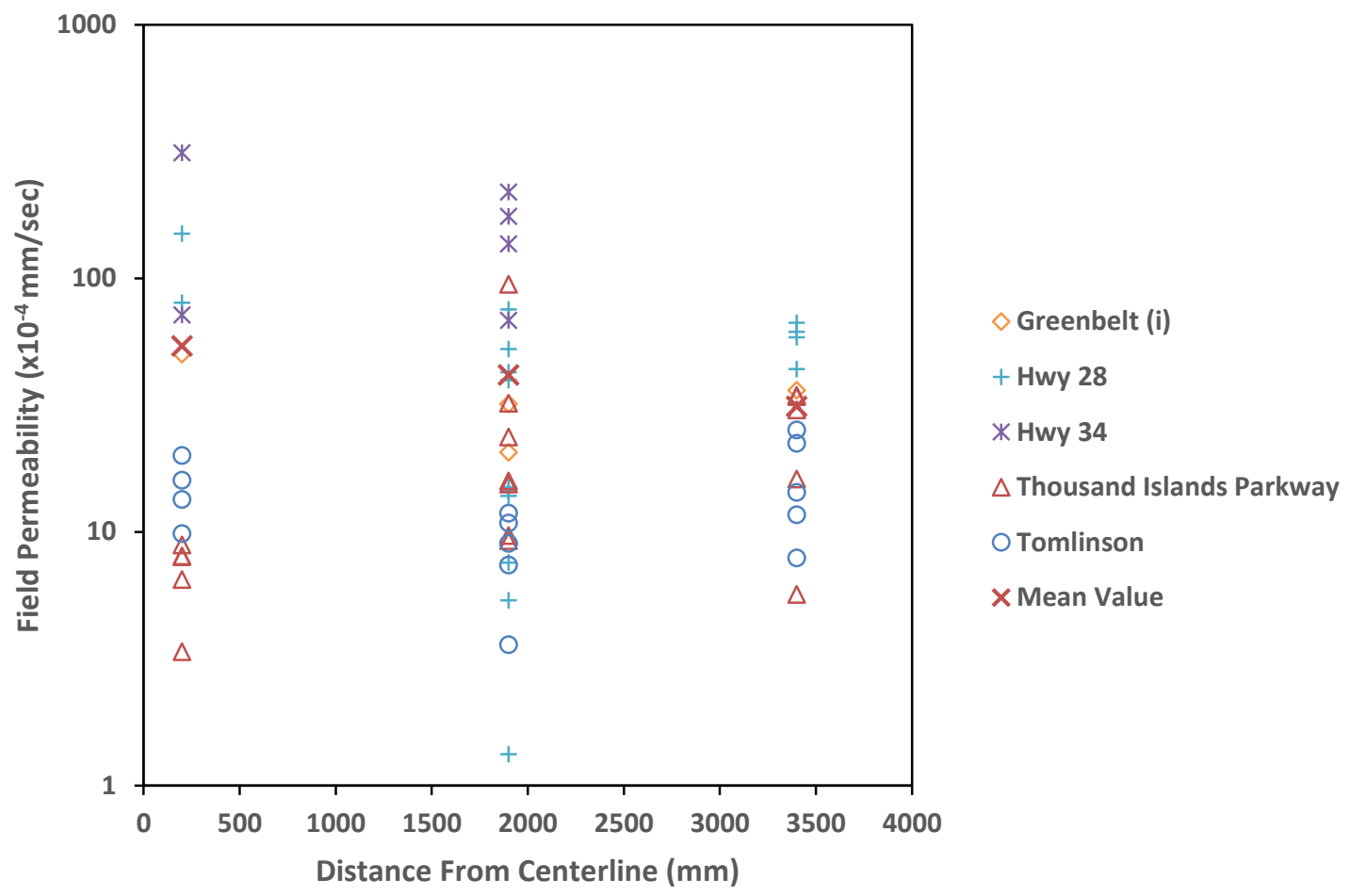

Figure 5.6: Field Permeability vs. Testing Locations (Advanced Method)

Similar to the previous two properties, the three-way ANOVA was performed to examine the interaction effect between the three factors when considering the field permeability as the response variable. Table 5.8 suggests that all factors, except for the testing location, were statistically significant at 5\% level of significance. The two-way and three-way interaction effects were found to be similar to findings reached earlier when examining the relative density and IDT. This implies that the effect of compaction method on these three variables depends on the project level and vice versa. 
Table 5.8: Summary of the Three-Way ANOVA Results for Field Permeability

\begin{tabular}{ccc}
\hline Factor & $\boldsymbol{F}$ & $\boldsymbol{p}$-value \\
\hline $\mathrm{TL}$ & 1.051 & 0.384 \\
\hline $\mathrm{CM}$ & 12.572 & 0.001 \\
\hline $\mathrm{PL}$ & 6.708 & $<0.001$ \\
\hline $\mathrm{TL}{ }^{*} \mathrm{CM}$ & 0.101 & 0.904 \\
\hline $\mathrm{TL} * \mathrm{PL}$ & 1.204 & 0.244 \\
\hline $\mathrm{CM}^{*} \mathrm{PL}$ & 3.347 & 0.021 \\
\hline $\mathrm{TL} \mathrm{CM}^{*} \mathrm{PL}$ & 0.384 & 0.820 \\
\hline
\end{tabular}

A one-way ANOVA test was conducted at the project level to determine if there is a statistically significant difference between the two compaction methods in terms of field permeability for the same project. This analysis ignores the effect testing location since this factor was not statistically significant. According to the ANOVA results shown in Table 5.9, the two compaction methods differ significantly in terms of field permeability in three out of four projects constructed in the as-built year (2012 and 2014). This confirms the general finding of the significant effect of compaction method and the significance of the interaction between project level and compaction method. For the subsequent year, the difference was significant at one project only. It is evident that the difference between the two compaction methods in terms of the field permeability for Highway 28 was significant $(p$-value $=0.016)$ at the first year; however, this difference was no longer significant after one year $(p$-value $=0.628)$. As mentioned earlier in Chapter 4, this could be attributed to the effect of traffic loads over one year of service. The difference for Tomlinson site remained significant even after one year which could be explained by the fact that this paved section was not exposed to significant traffic loads since it was in-house field trial. 
Table 5.9: Summary of One-Way ANOVA Results for Effect Compaction Method on Field Permeability

\begin{tabular}{cccc}
\hline Year & Site & $\boldsymbol{F}$ & $\boldsymbol{p}$-value \\
\hline \multirow{2}{*}{2012} & Highway 28 & 7.140 & 0.016 \\
\cline { 2 - 4 } & Thousand Islands Parkway & 0.020 & 0.890 \\
\cline { 2 - 4 } & Tomlinson & 8.145 & 0.015 \\
\hline \multirow{2}{*}{2013} & Highway 28 & 0.240 & 0.628 \\
\cline { 2 - 4 } & Thousand Islands Parkway & 0.223 & 0.643 \\
\cline { 2 - 4 } & Tomlinson & 12.398 & 0.004 \\
\hline 2014 & Highway 34 & 32.872 & $<0.001$ \\
\hline
\end{tabular}

The effect of age and traffic on field permeability was studied in this research. The field permeability measurements were available for two consecutive years (the as-built and one year later) for three sites finished and compacted by the two different compaction methods; conventional and advanced. In order to evaluate such effect, a one-way ANOVA test at $5 \%$ level of significance was carried out with the following null and alternative hypotheses:

$$
\begin{aligned}
& H_{0}=\mu_{\text {field permability of year } 2012}=\mu_{\text {field permability of year } 2013} \\
& H_{1}=\mu_{\text {field permability of year } 2012} \neq \mu_{\text {field permability of year } 2013}
\end{aligned}
$$

Table 5.10 summarizes the results of the ANOVA test for each site and compaction method. According to the test results, the null hypothesis was accepted for all sites expect for Highway 28 finished by the conventional method. In other words, the mean permeability for 5 out of 6 sites was not statistically different after one year of road opening. 
Table 5.10: Summary of the $t$-test Results for Effect of Age and Traffic on Field Permeability

\begin{tabular}{ccrcr}
\hline \multirow{2}{*}{ Site Name } & \multicolumn{2}{c}{ Conventional } & \multicolumn{2}{c}{ Advanced } \\
\cline { 2 - 5 } & $F$ & $p$-value & $F$ & $p$-value \\
\hline Highway 28 & 8.838 & 0.007 & 0.277 & 0.603 \\
\hline Thousand Islands Parkway & 2.988 & 0.106 & 3.822 & 0.069 \\
\hline Tomlinson & 0.667 & 0.429 & 0.103 & 0.753 \\
\hline
\end{tabular}

\subsubsection{Laboratory Permeability of Field-Recovered Cores}

The results obtained by performing the laboratory tests on a total of 86 field-recovered cores (34 advanced and 52 conventional) were used for the purpose of comparison between the two compaction techniques. It is worth noting that out of the 117 cores tested for relative density, 31 cores were not tested for lab permeability test since the testing device was not available in Carleton lab by that time. Table 5.11 summarizes the numbers of field cores per testing location for the two compaction methods.

Table 5.11: Summary of the Lab Permeability Dataset

\begin{tabular}{ccc}
\hline \multirow{2}{*}{ Testing Location } & \multicolumn{2}{c}{ Compaction Method } \\
\cline { 2 - 3 } & Advanced & Conventional \\
\hline Inner Edge & 5 & 11 \\
\hline Inner Middle & 4 & 10 \\
\hline Middle & 13 & 11 \\
\hline Outer Middle & 6 & 9 \\
\hline Outer Edge & 6 & 11 \\
\hline Total & 34 & 52 \\
\hline
\end{tabular}

All lab permeability measurements for the conventional and advanced methods at the five testing locations are presented graphically in Figure 5.7 and Figure 5.8 respectively According to the presented bar chart, there is an obvious decrease in mean permeability values in the three middle locations compared to the lane edges. On the other hand, outer and inner edges experienced relatively high permeability compared to the middle 
locations. This observations holds true for the two compaction methods. In addition, the presented results suggest that the field cores recovered from road sections finished by the advanced method are, on average, less permeable in all considered locations compared to the conventional method. 


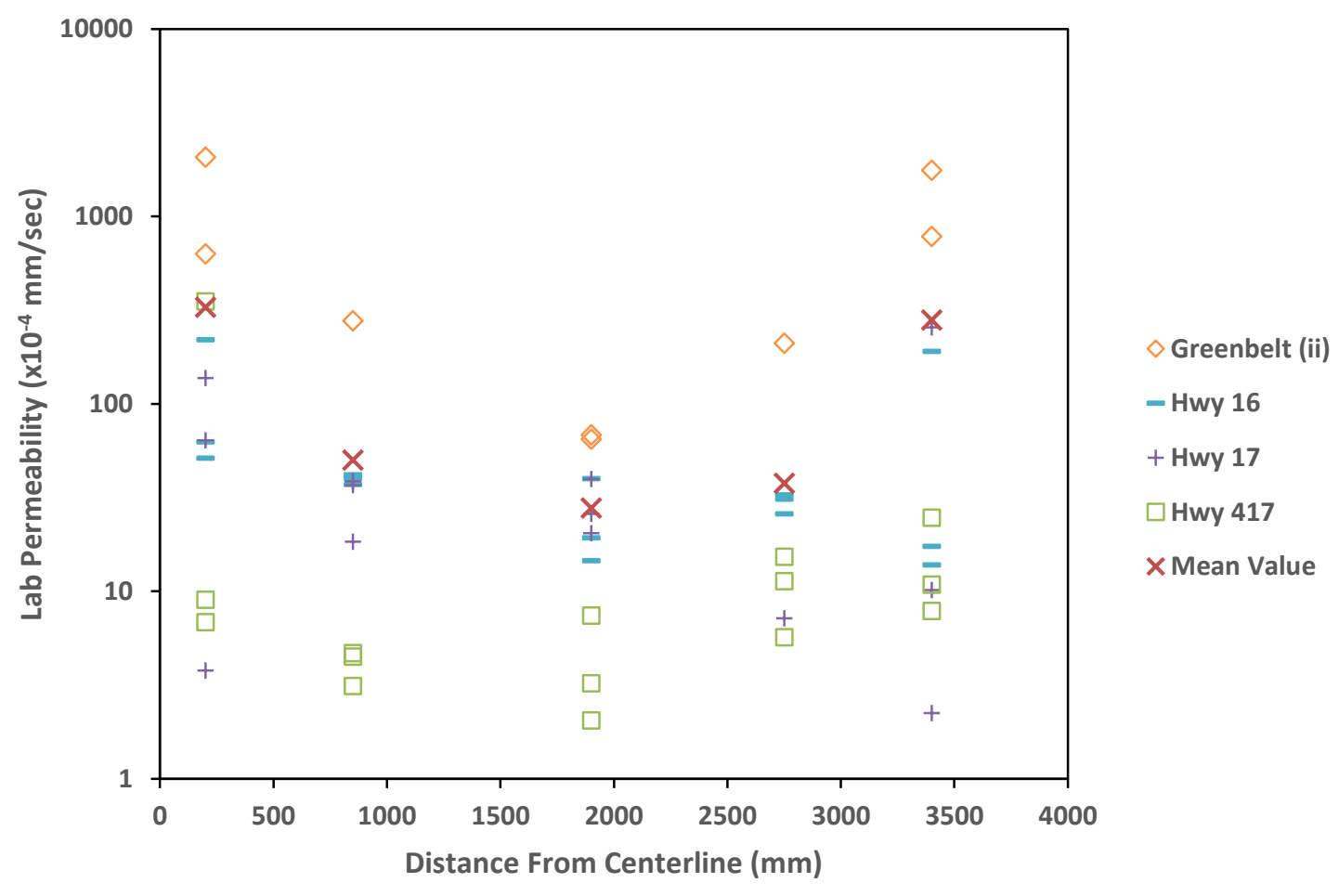

Figure 5.7: Lab Permeability vs. Testing Locations (Conventional Method)

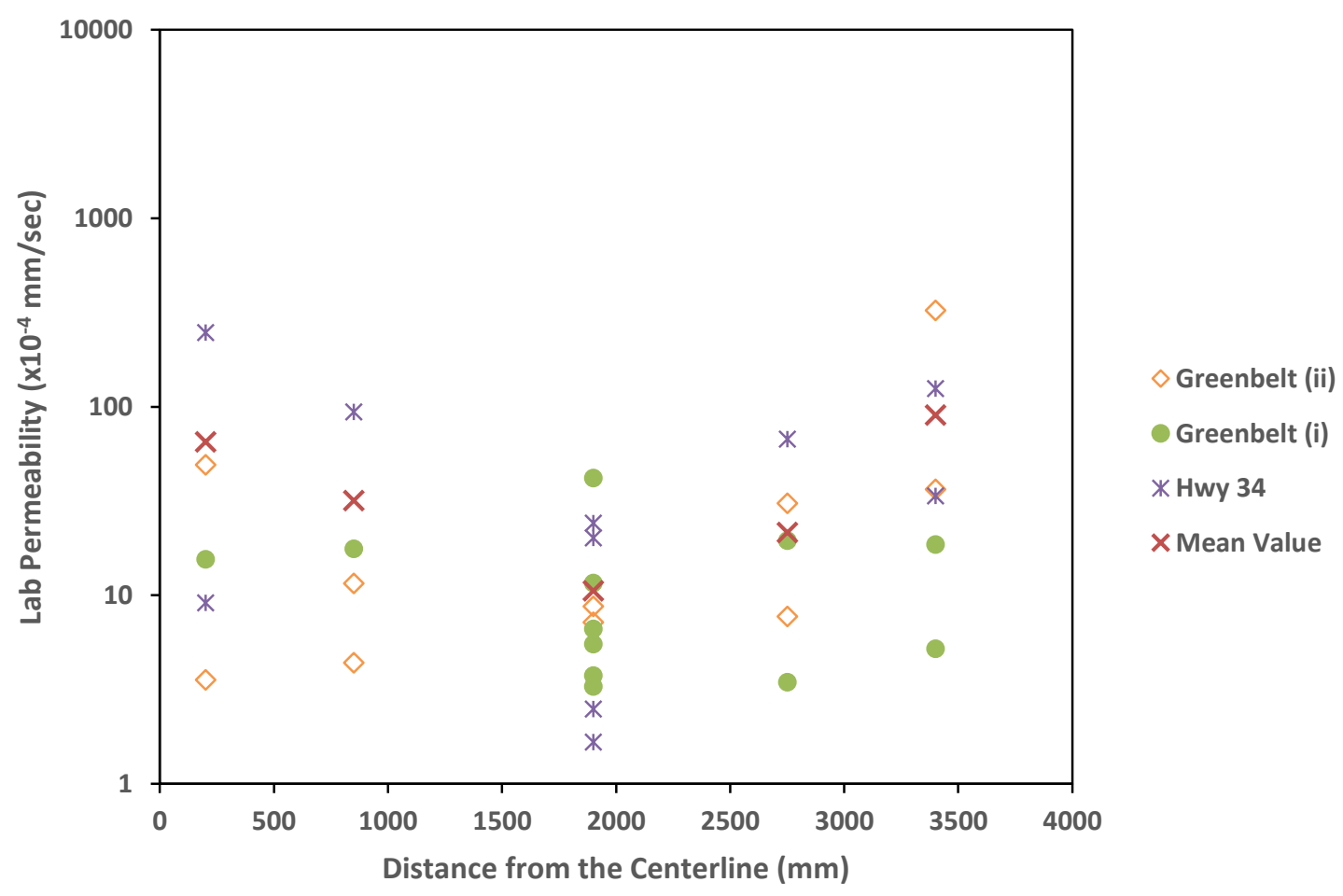

Figure 5.8: Lab Permeability vs. Testing Locations (Advanced Method) 
Note also that the average laboratory permeability (Figure 5.7 and Figure 5.8) for the two edges is relatively higher than those of the field permeability (Figure 5.5 and Figure 5.6), especially for the conventional method. This is mainly caused by the influence of one or two extreme measurements located on the inner or outer locations.

The three-way ANOVA test was also carried out for the laboratory permeability as response variable and the results are summarized in Table 5.12. It can be seen that all three factors were statistically significant at $5 \%$ level of confidence. Note that the twoway interaction between the compaction method and project level as well as the threeway interaction were not applicable because the dataset had only one common project between the two compaction methods in terms of lab permeability which contributed to have zero degree of freedom for these kind of interactions. The two-way interaction effect between the testing location and both the compaction method and project level was statistically significant at $5 \%$ level of significance. This means that the effect of testing location on lab permeability depends on both the project level and compaction method and vice versa.

Table 5.12: Summary of the Three-Way ANOVA Results for Lab Permeability

\begin{tabular}{cccc}
\hline Factor & $\boldsymbol{d} \boldsymbol{f}$ & $\boldsymbol{F}$ & $\boldsymbol{p}$-value \\
\hline $\mathrm{TL}$ & 4 & 2.679 & 0.042 \\
\hline $\mathrm{CM}$ & 1 & 41.697 & $<0.001$ \\
\hline $\mathrm{PL}$ & 5 & 12.597 & $<0.001$ \\
\hline $\mathrm{TL} * \mathrm{CM}$ & 4 & 8.963 & $<0.001$ \\
\hline $\mathrm{TL} * \mathrm{PL}$ & 20 & 3.015 & 0.001 \\
\hline $\mathrm{CM} * \mathrm{PL}$ & 0 & $\mathrm{~N} / \mathrm{A}$ & $\mathrm{N} / \mathrm{A}$ \\
\hline $\mathrm{TL} * \mathrm{CM} * \mathrm{PL}$ & 0 & $\mathrm{~N} / \mathrm{A}$ & $\mathrm{N} / \mathrm{A}$ \\
\hline N/A: Not Applicable & & \\
\hline
\end{tabular}




\subsubsection{Comparison between the Two Compaction Methods}

Further investigations were carried out to evaluate the performance of the two compaction methods based on results obtained from common sites only where the two compaction methods were used side-by-side. These sites were Thousand Islands Parkway, Highway 34, Tomlinson, and Greenbelt II. The dataset used for this comparison is presented in Table 5.13. It worth noting that due to lack of common sites between the two compaction methods in terms of lab permeability, the same dataset presented previously in Table 5.11 which has only one common site was used. That was necessary since the main goal of this comparison is to understand the overall trend relating all four pavement properties with the change of the compaction method and the testing location. For each property, the average value per testing location was computed and was categorized by the compaction method as shown in Figure 5.9.

Table 5.13: Summary of the Dataset for Common Sites

\begin{tabular}{ccccccc}
\hline \multirow{2}{*}{$\begin{array}{c}\text { Testing } \\
\text { Location }\end{array}$} & \multicolumn{2}{c}{ IDT and Relative Density } & \multicolumn{2}{c}{ Lab Permeability } & \multicolumn{2}{c}{ Field Permeability } \\
\cline { 2 - 7 } & Advanced & Conventional & Advanced & Conventional & Advanced & Conventional \\
\hline Inner Edge & 6 & 5 & 5 & 11 & 8 & 13 \\
\hline Inner Middle & 3 & 2 & 4 & 10 & - & - \\
\hline Middle & 7 & 8 & 13 & 11 & 19 & 14 \\
\hline Outer Middle & 3 & 2 & 6 & 9 & - & - \\
\hline Outer Edge & 6 & 6 & 6 & 11 & 9 & 9 \\
\hline Total & 25 & 23 & 34 & 52 & 36 & 36 \\
\hline
\end{tabular}




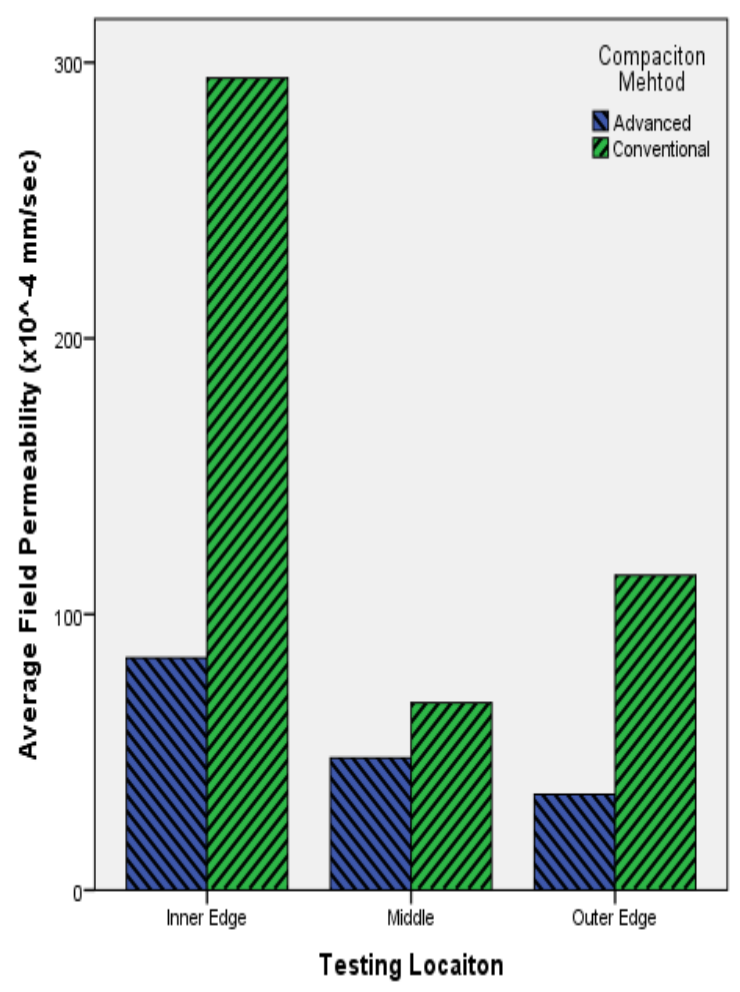

(a) Field Permeability

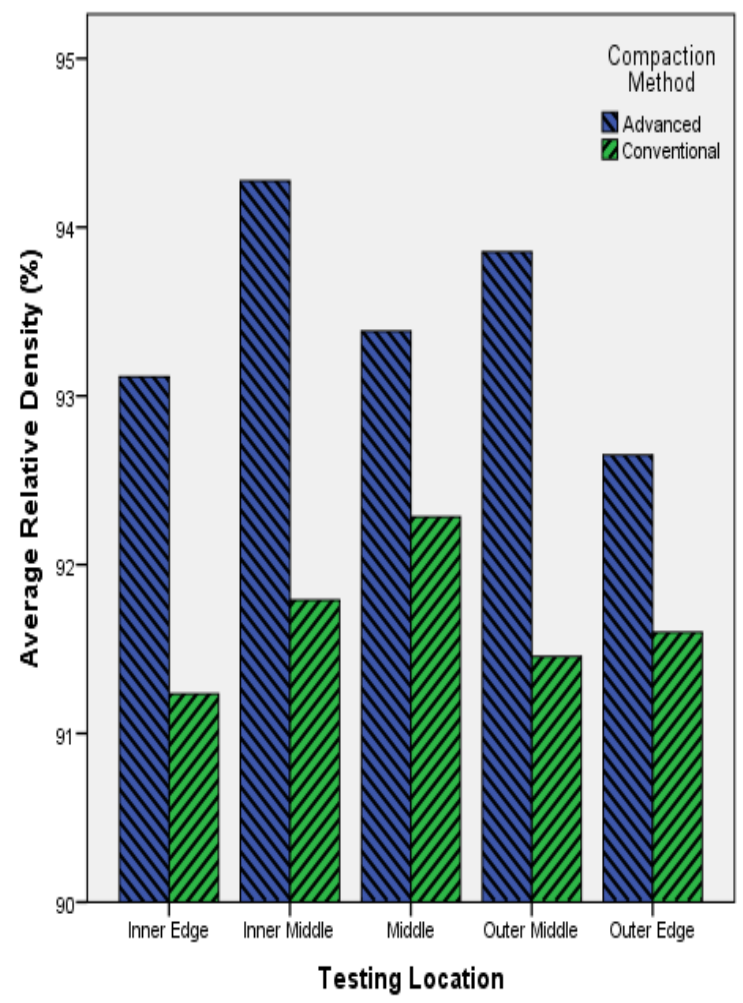

(c) Relative Density

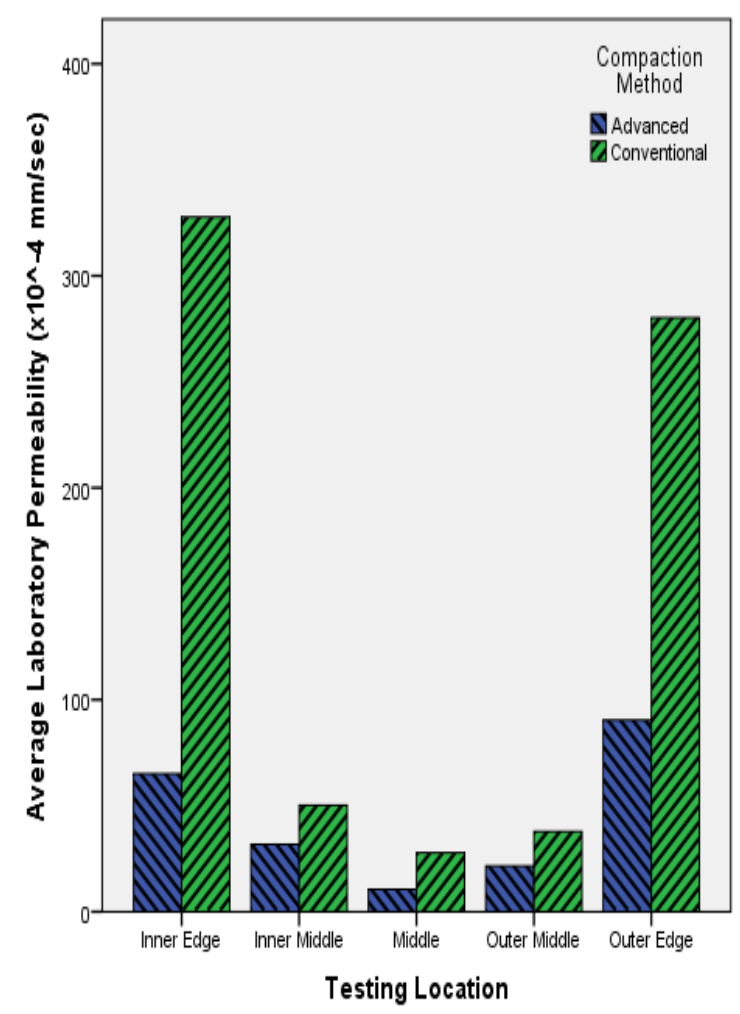

(b) Lab Permeability

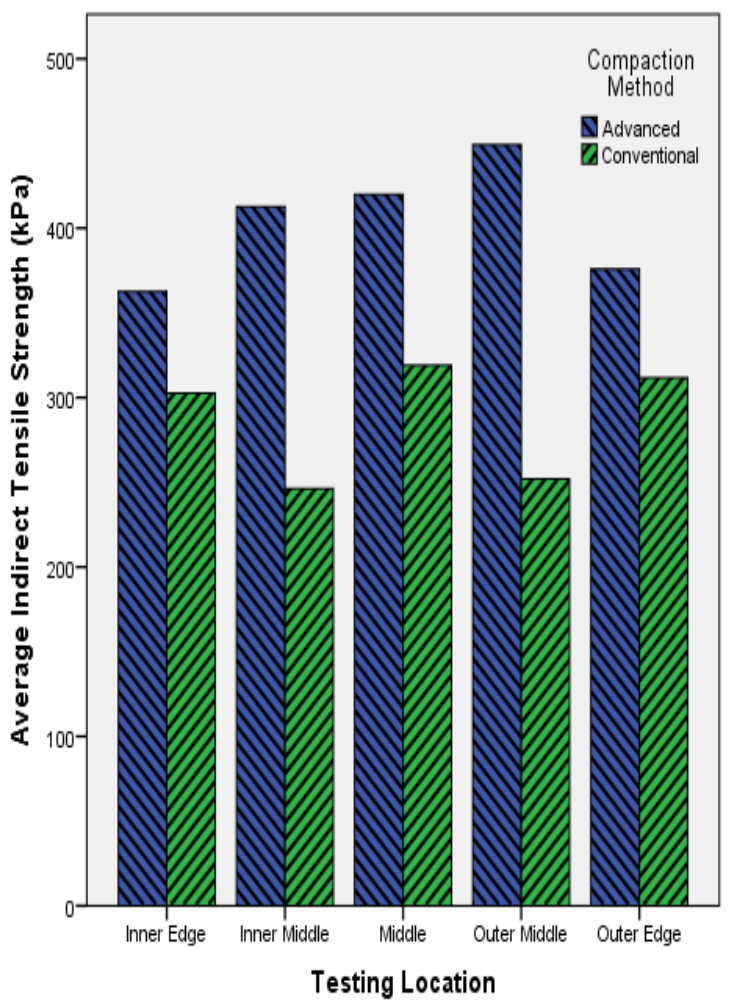

(d) IDT

Figure 5.9: Comparison Between The Compaction Methods In Terms The Four Pavement Properties 
For the field permeability Figure 5.9 (a), the observed trend for the conventional method suggests that the two edges had higher average permeability than the middle location. The advanced method showed that there was a gradual reduction in average permeability as moving from the inner edge to the outer. In all cases, it is quite evident that the field permeability values for the conventional method were higher than those of the advanced method. Figure 5.9 (b) suggests that there was an obvious decrease in average lab permeability values where the outer and inner edges experienced relatively high permeability compared to the middle locations. This observation holds true for the two compaction methods. In addition, the presented results imply that the field-recovered cores obtained from road sections finished by the advanced method are, on average, less permeable in all considered locations compared to the conventional method. The bar chart presented in Figure 5.9 (c) shows that the observed trend of the conventional method indicates that the relative density was higher at the middle and it decreases gradually at the two lane edges. For the advanced method, it was found that the inner middle and outer middle have on average the highest relative density followed by the middle location and the two edge locations. According to the IDT results shown in Figure 5.9 (d), the conventional method showed less strength in the inner and outer middle locations while the other three locations were almost equal. The advanced technique exhibited a gradual trend where the IDT values are higher in the three middle locations compared to the two edges. 
A one-way ANOVA test was also conducted to investigate if there is a significant difference between the mean values for each property of the two compaction methods. The null and alternative hypotheses for each property are shown in Table 5.14.

Table 5.14: Summary of the Null and Alternative Hypotheses for Common Sites

\begin{tabular}{ccc}
\hline \multirow{2}{*}{ Property } & Null & Test Hypotheses \\
\cline { 3 - 3 }$\frac{}{\text { Field Permeability }}$ & & Alternative \\
\hline$\frac{\text { Lab Permeability }}{\text { Relative Density }}$ & $\mu_{\text {conventional }}=\mu_{\text {advanced }}$ & $\mu_{\text {conventional }} \neq \mu_{\text {advanced }}$ \\
\hline IDT &
\end{tabular}

According to the ANOVA results summarized in Table 5.15, it can be seen that all $p$ values were less than $5 \%$ and the null hypothesis was rejected. This indicates that there was a significant difference between the two compaction methods in terms of the four considered properties in this study when examining the common sites between them only.

Table 5.15: Summary of the One-way ANOVA Results for the common sites

\begin{tabular}{ccc}
\hline Response Factor & $\boldsymbol{F}$ & $\boldsymbol{p}$-value \\
\hline Field Permeability & 17.752 & $<0.001$ \\
\hline Lab Permeability & 4.253 & 0.044 \\
\hline Relative Density & 8.675 & 0.004 \\
\hline IDT & 4.311 & 0.042 \\
\hline
\end{tabular}

\subsection{Correlations between the Physical and Mechanical Properties}

The correlations between the four asphalt pavement properties considered in this research were investigated using Pearson product-moment correlation or Pearson's correlation, denoted as “ $r$ ”. In general, the Pearson's correlation coefficient ranges between -1 and 1 and it represents the association between two variables. The Pearson's correlation 
coefficient can also be tested for significance with the null and alternative hypothesis formulated as follow:

$H_{0}: r=0$; the correlation between the two variables is not statistically significant

$H_{1}: r \neq 0$; the correlation between the two variables is statistically significant

The correlations between the different properties were examined for each compaction method separately. First, the results produced by the Gyratory compactor was analyzed, followed by the two field compaction methods, the conventional and advanced compactor.

\subsubsection{SGC Samples}

The correlation matrix for the SGC specimens is presented in Table 5.16. The lab permeability had strong negative correlation with both the IDT and relative density. These two correlations were statistically significant at 5\% level of significance. There was also very strong positive correlation $(r=0.913)$ between the relative density and IDT; this relationship was also statistically significant.

Table 5.16: Summary of the Correlation Coefficients and $p$-values for SGC Samples

\begin{tabular}{cccc}
\hline & Lab Permeability & IDT & Relative Density \\
\hline Lab Permeability & 1 & $-0.651(<0.001)$ & $-0.743(<0.001)$ \\
\hline IDT & $-0.651(<0.001)$ & 1 & $0.913(<0.001)$ \\
\hline Relative Density & $-0.743(<0.001)$ & $0.913(<0.001)$ & 1 \\
\hline
\end{tabular}

\subsubsection{Field-Recovered Cores}

Table 5.17 shows the correlation matrix for the field-recovered cores of the conventional method. It can be seen that the field permeability had moderate positive correlation with the lab permeability. In addition, the field permeability correlated negatively with both 
the relative density and IDT as the $r$ value was -0.45 and -0.48 , respectively. The lab permeability on field cores had a fair negative correlation with both the IDT and relative density. Finally, there was a fair correlation between the relative density and IDT. It is important to mention that all presented correlations were statistically significant at $5 \%$ level of significance.

Table 5.17: Summary of the Correlation Coefficients and $p$-values for Conventional Method

\begin{tabular}{ccccc}
\hline & Field Permeability & Lab Permeability & IDT & Relative Density \\
\hline Field Permeability & 1 & $0.630(<0.001)$ & $-0.484(<0.001)$ & $-0.450(<0.001)$ \\
\hline Lab Permeability & $0.630(<0.001)$ & 1 & $-0.532(<0.001)$ & $-0.617(<0.001)$ \\
\hline IDT & $-0.484(<0.001)$ & $-0.532(<0.001)$ & 1 & $0.609(<0.001)$ \\
\hline Relative Density & $-0.450(<0.001)$ & $-0.617(<0.001)$ & $0.609(<0.001)$ & 1 \\
\hline
\end{tabular}

The correlation matrix for the field-recovered cores of the advanced method is shown in Table 5.18. The field permeability had strong positive correlation with the lab permeability and the relationship was statistically significant at 5\% level of significance. Poor, statistically insignificant negative correlation was found between the field permeability and IDT. The field permeability had fair negative correlation with the relative density. Fair negative correlation was also found between the lab permeability and relative density. It can be seen that the IDT correlated poorly with all other three properties. All correlations not involving the IDT property were statistically significant at $5 \%$ significance. More details and clarifications of the resulting poor correlations are presented in this research later on. 
Table 5.18: Summary of the Correlation Coefficients and $p$-values for Advanced Method

\begin{tabular}{ccccc}
\hline & Field Permeability & Lab Permeability & IDT & Relative Density \\
\hline Field Permeability & 1 & $0.704(0.023)$ & $-0.276(0.172)$ & $-0.613(<0.001)$ \\
\hline Lab Permeability & $0.704(0.023)$ & 1 & $-0.208(0.288)$ & $-0.668(<0.001)$ \\
\hline IDT & $-0.276(0.172)$ & $-0.208(0.288)$ & 1 & $0.184(0.171)$ \\
\hline Relative Density & $-0.613(<0.001)$ & $-0.668(<0.001)$ & $0.184(0.171)$ & 1 \\
\hline
\end{tabular}

\subsubsection{Relationship between Laboratory and Field Permeability}

Before studying the relationship between the field and lab permeability, a $t$-test at $5 \%$ level of significance was carried out to examine if there is any significant difference between the two test settings, the field and laboratory, in terms of permeability. For each site, the null $\left(H_{0}\right)$ and alternative $\left(H_{1}\right)$ hypotheses were as follows:

$$
\begin{aligned}
& H_{0}=\mu_{\text {field permability }}=\mu_{\text {lab permeability }} \\
& H_{1}=\mu_{\text {field permability }} \neq \mu_{\text {lab permeability }}
\end{aligned}
$$

Table 5.19 shows the $t$-test results for five different sites where the field and lab measurements were available as well as for all data points of different sites aggregated together. As can be seen, the $p$-values of each site and all sites was less than $5 \%$ indicating that there is a statistically significant difference between the field and lab measurements regardless of the compaction method. 
Table 5.19: $t$-test Results for Examining the Difference between the Field and Lab Permeability

\begin{tabular}{cccc}
\hline Site & Compaction Method & $\boldsymbol{t}$ & $\boldsymbol{p}$-value \\
\hline Highway 16 & Conventional & 2.692 & 0.012 \\
\hline Highway 17 & Conventional & 5.254 & $<0.001$ \\
\hline Highway 417 & Conventional & 2.205 & 0.046 \\
\hline Greenbelt (i) & Advanced & 2.680 & 0.037 \\
\hline Highway 34 & Advanced & 2.693 & 0.023 \\
\hline All Sites & - & 5.863 & $<0.001$ \\
\hline
\end{tabular}

The relationship between field and laboratory permeability of field cores was therefore examined using results obtained from five different projects. In total, 54 points were plotted in a scatter diagram, and a linear relationship was developed. The coefficient of determination denoted as $R^{2}$ was used to examine the goodness of the developed relationships. In general, low $R^{2}$ values indicate poor relationship between two variables where knowing one variable does not help in predicting the other variable and vice versa According to Figure 5.10, a moderate linear relationship $\left(R^{2}=0.41\right)$ exists between the field and laboratory measurements. In addition, majority of field permeability measurements were below the 1:1 line which indicates that the field permeability was higher than the laboratory permeability in most cases. Linear regression analysis was performed using the field and lab permeability data as follows:

Lab Permeability $=a_{0}+a_{1}$ Field Permeability

Equation 5.1 


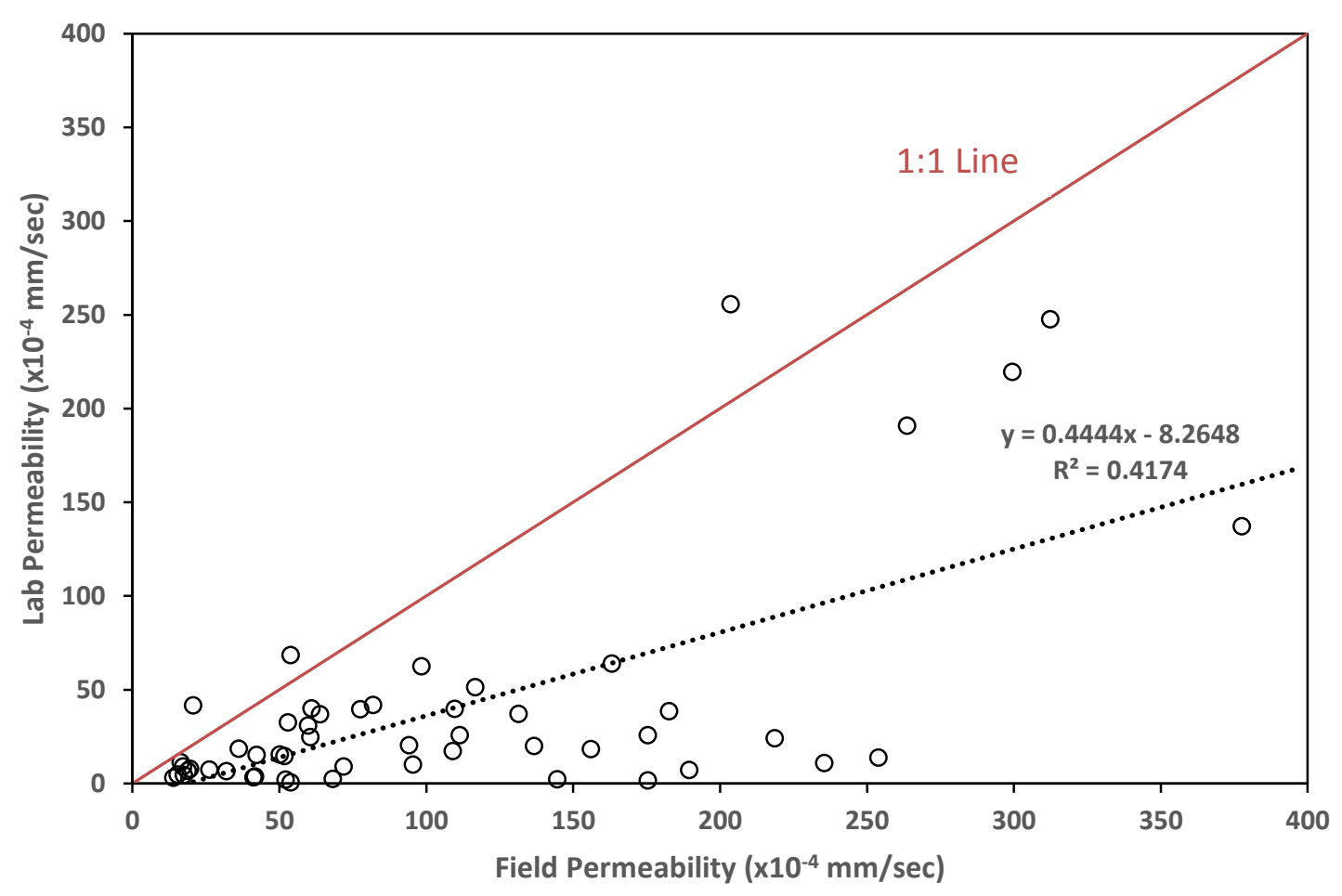

Figure 5.10: Field and Laboratory Correlation

The detailed regression results are presented in Appendix A . Table 5.20 summarizes the regression coefficients and the corresponding significance value donated as $p$-value. As can be seen, The $R^{2}$ coefficient of 0.417 indicates that the presented model fits the data points fairly. However, the lab permeability was statistically significant at $5 \%$ level of significance. This implies that the change in the independent variable (lab) is related with the change in the dependent variable (field).

Table 5.20: Summary of Linear Regression Model between Field and Lab Permeability

\begin{tabular}{ccccc}
\hline $\boldsymbol{a}_{\boldsymbol{o}}$ & $\boldsymbol{a}_{\mathbf{1}}$ & $\boldsymbol{F}$ & $\boldsymbol{p}$-value & $\boldsymbol{R}^{\mathbf{2}}$ \\
\hline-8.266 & 0.444 & 35.829 & $<0.001$ & 0.417 \\
\hline
\end{tabular}

Having the field permeability to be significantly higher than the lab permeability could be explained by several reasons. First, each device (field and lab) has its own measurement 
mechanism to estimate the permeability coefficient despite the fact that both of them are based on the falling head principle. More specifically, in the NCAT field device the water has the flexibility to diffuse in vertical and lateral directions within the pavement structure. The water infiltration rate is associated with the drop in water pressure head within the NCAT standpipes. However, the NCAT device assumes that the water will flow in one dimension (vertically down) through the $150 \mathrm{~mm}$ diameter test area which might not be a very accurate assumption. Giving those aforementioned dilemmas, to some extent, the reading from the NCAT device might not be the best representation of the true pavement permeability status. On the other hand, the measurement mechanism of the Karol-Warner Asphalt permeameter forces the water to move only through the pavement thickness by applying a confining pressure of $68.9 \pm 3.4 \mathrm{kPa}$ to the attached rubber membrane. This setup is more consistent with the theoretical basis for calculating the permeability coefficient according to Darcy's law. In particular, the steady state flow condition as well as the saturation can be easily met. In fact, one can control the specimen saturation condition in the laboratory to reach a specific level in order not to violate Darcy's law; this is not possible during the field permeability test.

\subsection{Relative Density-IDT Relationship}

\subsubsection{Gyratory Specimens}

The relationship between the relative density and the IDT was explored for the 33 SGC specimens prepared in the laboratory using the four asphalt mixtures mentioned in Section 4.2.1. Figure 5.11 shows the relationship between the relative density and the IDT values for the four mixes. A very strong relationship is observed in each of the four 
mixes where the coefficient of determination $\left(R^{2}\right)$ varies between 0.96 and 0.99 . These strong relationships confirm the earlier findings shown in the correlation matrix (Table 5.16) The relationship for all data points aggregated together (Figure 5.12) indicates that there is an overall strong relationship $\left(R^{2}=0.88\right)$ between the relative density and the IDT. In general, the presented relationship suggests that as the relative density increases, the IDT values increase and vice versa.

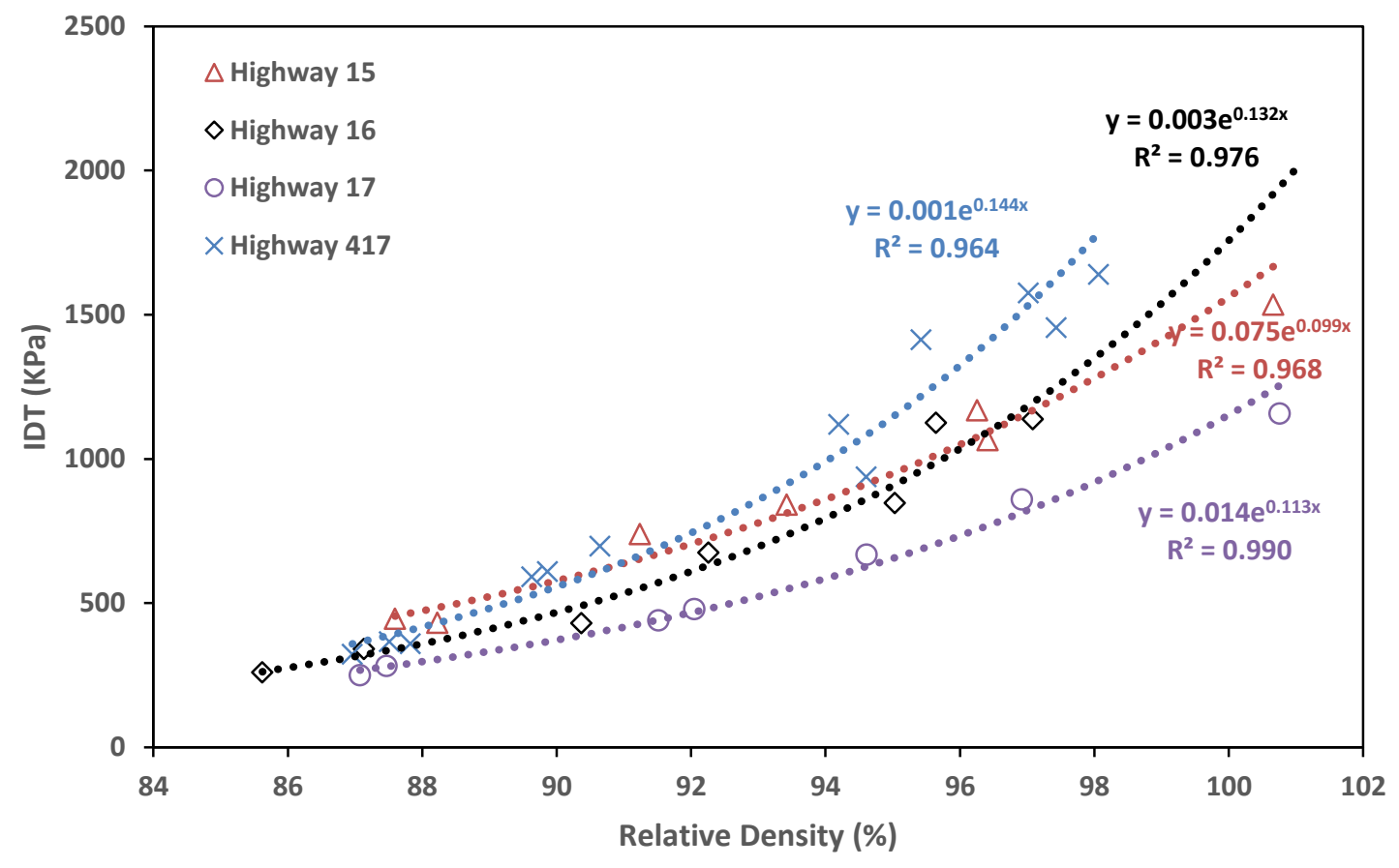

Figure 5.11: The Relative Density-IDT Relationship for SGC Specimens 


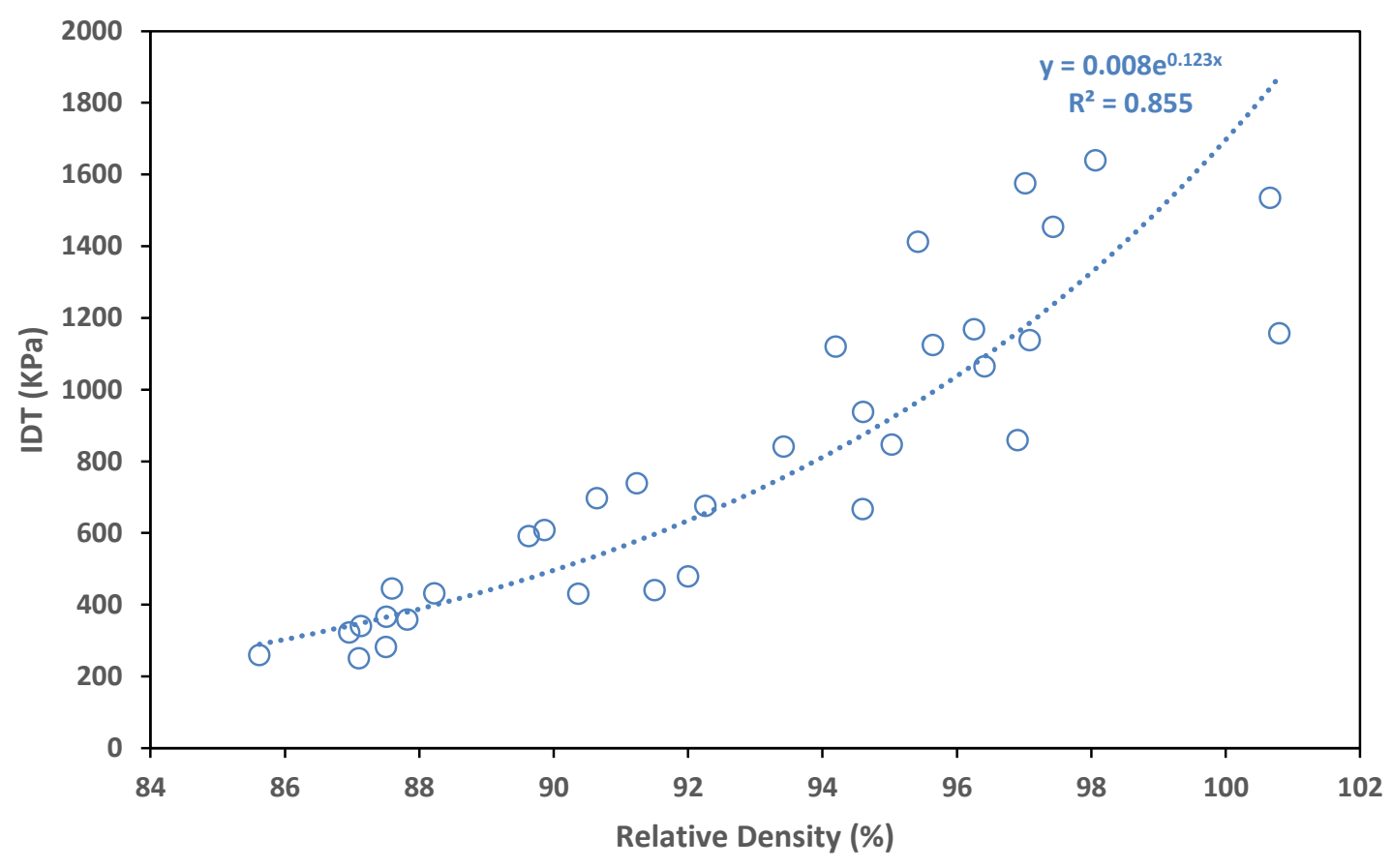

Figure 5.12: The General Trend of the Relative Density-IDT Relationship for SGC

Non-linear regression models relating the IDT to relative density were developed for each highway separately and for all data combined together using IBM SPSS Statistics 20.0 software package. The general regression form is as follows:

$I D T=E X P\left(a_{0}+a_{1} *\right.$ Relative Density $)$

Equation 5.2

As can be seen in Table 5.21, all developed exponential models were statistically significant at $5 \%$ level of significance and had high $R^{2}$ value. 
Table 5.21: Summary of the Regression Models between IDT and Relative Density (SCG Specimens)

\begin{tabular}{cccccc}
\hline Site & $\boldsymbol{a}_{\boldsymbol{o}}$ & $\boldsymbol{a}_{\mathbf{1}}$ & $\boldsymbol{F}$ & $\boldsymbol{p}$-value & $\boldsymbol{R}^{\mathbf{2}}$ \\
\hline Highway 15 & 0.075 & 0.099 & 150.886 & $<0.001$ & 0.968 \\
\hline Highway 16 & 0.003 & 0.132 & 199.239 & $<0.001$ & 0.976 \\
\hline Highway 17 & 0.014 & 0.113 & 465.135 & $<0.001$ & 0.989 \\
\hline Highway 417 & 0.001 & 0.144 & 269.709 & $<0.001$ & 0.964 \\
\hline All & 0.008 & 0.123 & 182.290 & $<0.001$ & 0.855
\end{tabular}

$\boldsymbol{a}_{\boldsymbol{o}}$ and $\boldsymbol{a}_{\mathbf{1}}$ are regression coefficients

\subsubsection{Field-Recovered Cores}

The relationship that relates the IDT with the relative density of the field-recovered cores extracted from nine projects is shown in Figure 5.13. Although it is obvious that a poor $\left(R^{2}=0.21\right)$ relationship between the density and IDT is observed, it can be seen that when the relative density increases, the IDT increases as well. As a result of this weak relationship, more investigations were carried out. More specifically, it was suspected that this poor relationship is possibly attributed to the fact that all sites were aggregated together. Consequently, the same relationship was examined at three different levels: all sites aggregated together, compaction method and project level. 


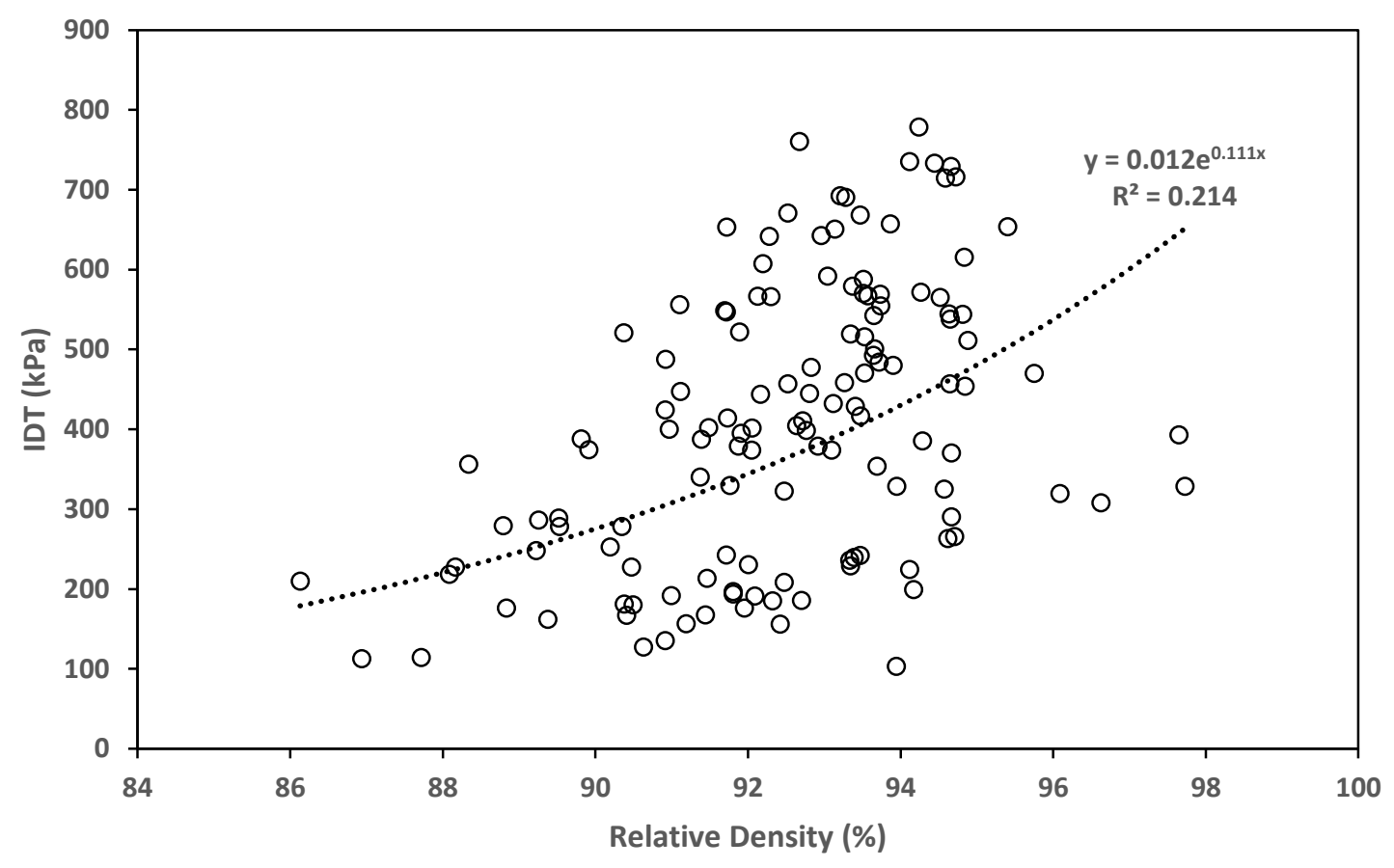

Figure 5.13: The Relative Density-IDT Relationship for Field Cores

The relationship between relative-density and IDT was examined for each compaction method separately as presented in Figure 5.14. According to the results, the advanced method did not show clear pattern as the conventional method did. These findings are in agreement with the results presented earlier in the correlation matrix. Therefore, there was a need to conduct further analysis on a project level, especially for the advanced method. Figure 5.15 shows the developed relationship for projects finished by the conventional method. Better $R^{2}$ values were observed after disaggregating the data points. As can be seen, each site had a unique relationship or curve that differs from other sites. As an example, cores recovered from Highway 28 project had less IDT values compared to those from Greenbelt site. This result confirms the statistical findings concluded in Section 5.1.2 where the IDT value depends significantly on the project level. In fact, it is common to observe differences in road construction and paving projects in terms the 
quality of the finished sections. This in turn results in making each project unique by itself. As an example, a project could differ from other projects depending on various factors including, but not limited to, the environmental conditions where the project was implemented, the road classification (e.g. freeways, collectors, local), the attained level of compaction, and so forth. In addition to the aforementioned reasons, the differences in IDT-relative density trends could be mainly caused by the differences in asphalt mix type used at each project including the aggregate properties, the job mix formula, and the design percentage of asphalt content $(\% \mathrm{AC})$.

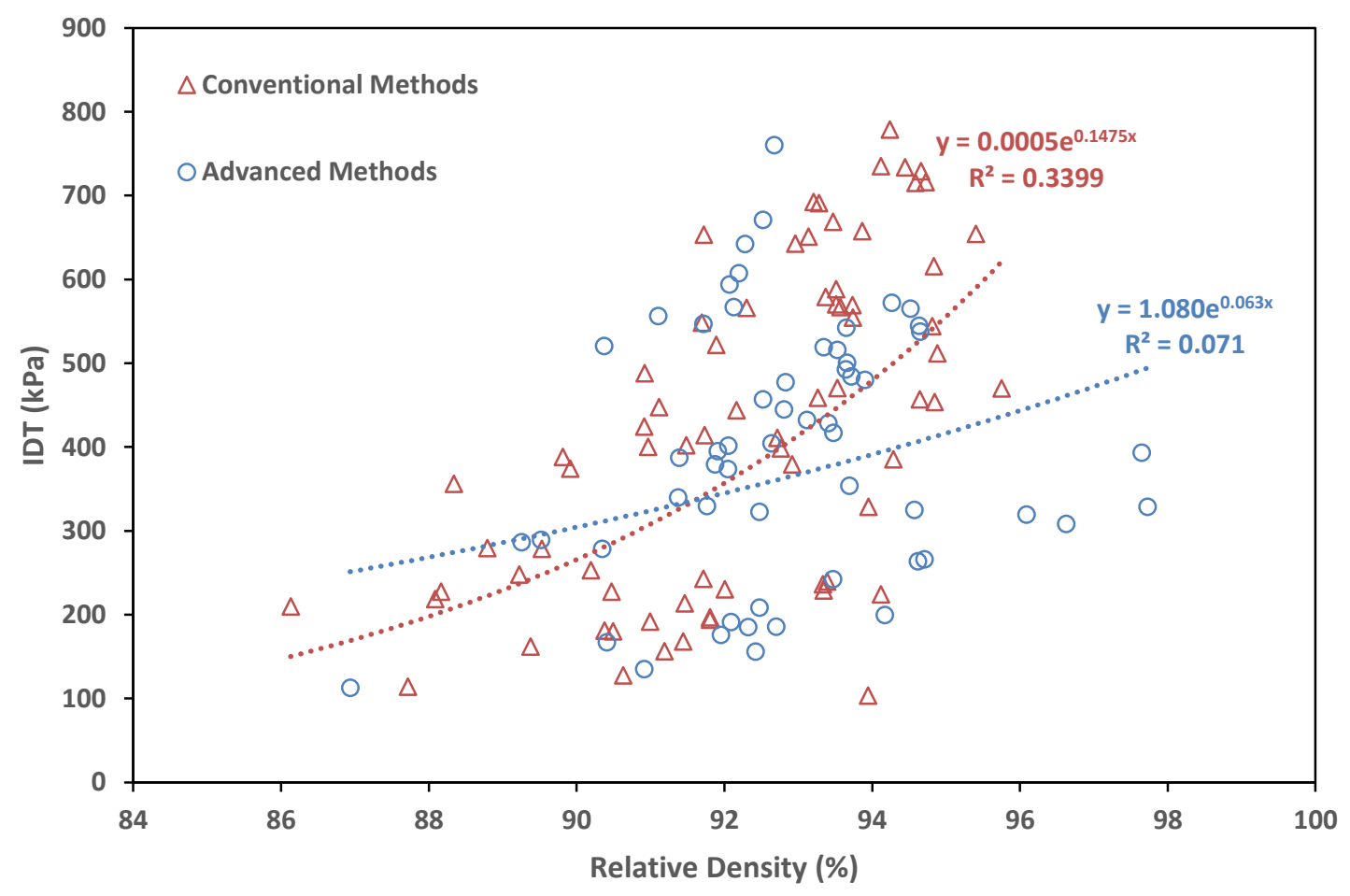

Figure 5.14: The Relative Density-IDT Relationship Categorized by Compaction Method 


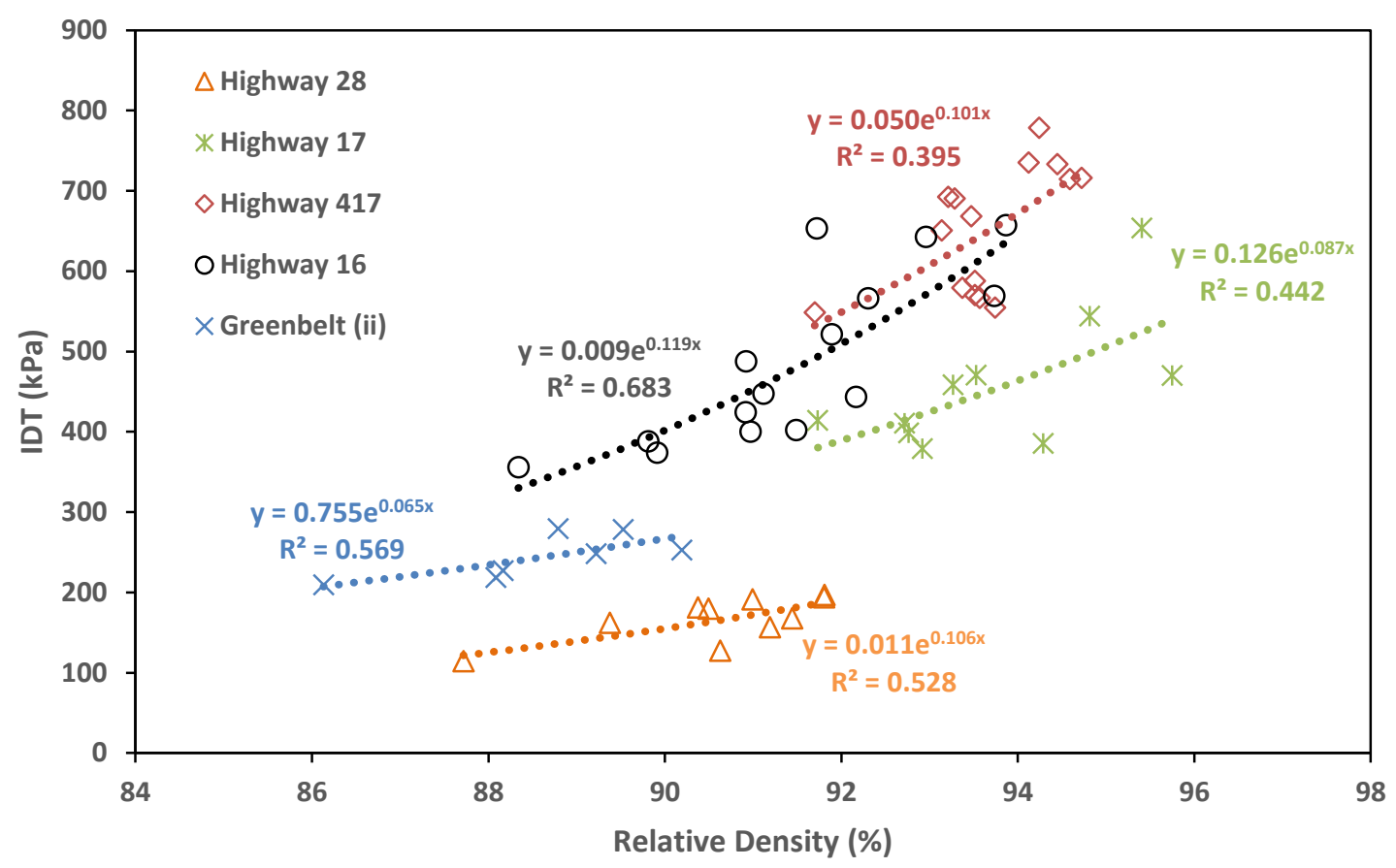

Figure 5.15: The Relative Density-IDT Relationship for Field Cores (Conventional Method)

The same observation holds true for sites compacted by advanced method as well. Figure 5.16 shows the IDT-density relationship for four different sites. As can be seen, each site had a unique trend that differs from other projects. These individual trends at project level contributed to have an overall poor correlation coefficient which presented earlier in Table 5.18. Fair to strong relationship between the two examined properties was found since the $R^{2}$ value ranges between 0.66 and 0.93 . Note that both Greenbelt site (i) and (ii) had a very similar trend while the other two sites were different. The main reasons of having such similarity are that those two projects were constructed within the same period (one week difference), under similar environmental condition, same site specifications (e.g. soil condition), same road contractor and most importantly the same asphalt mix design. 


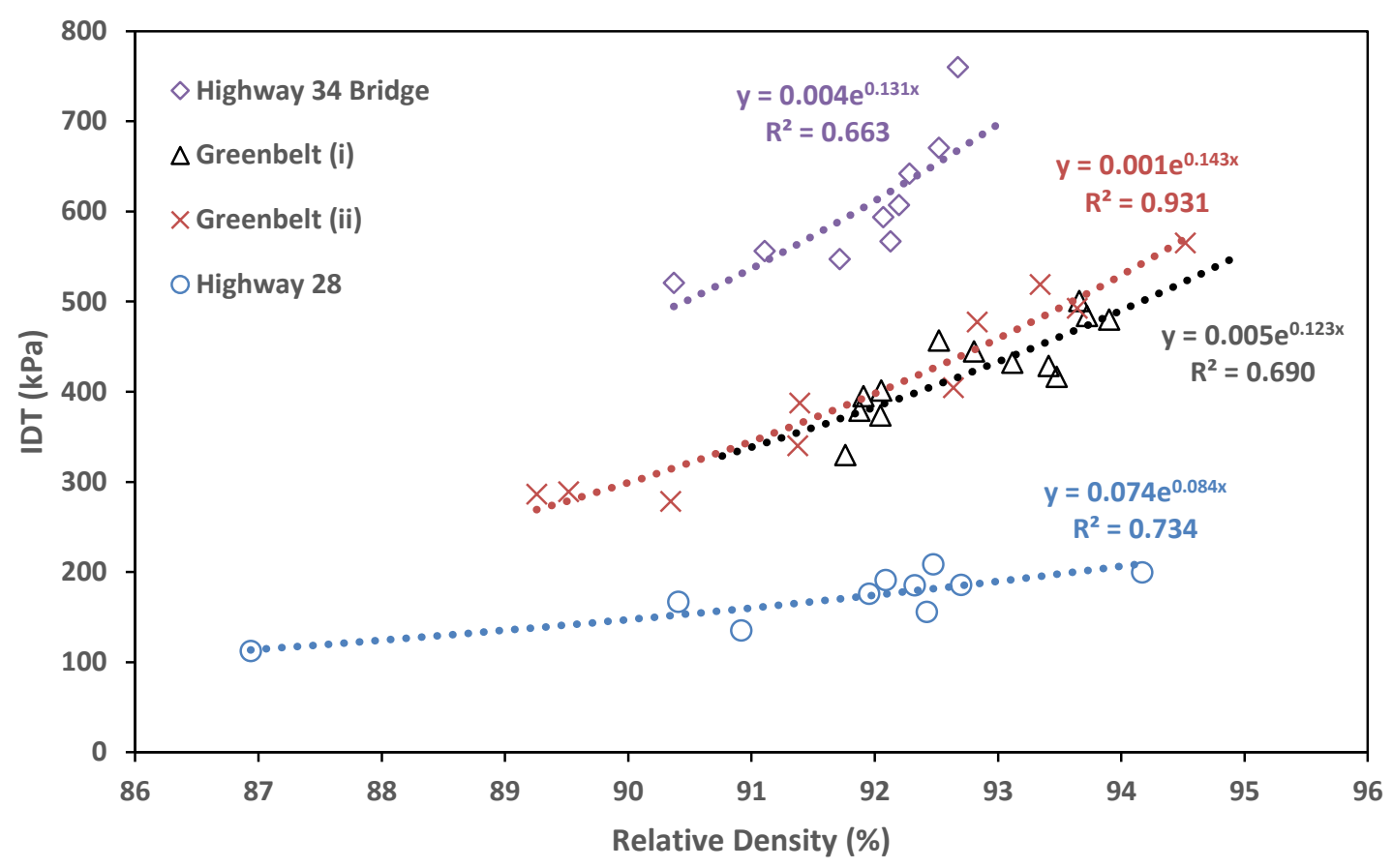

Figure 5.16: The Relative Density- IDT Relationship for Field Cores (Advanced Method)

Non-linear regression analysis was also carried out using the field-recovered cores data to relate the IDT to relative density. According to the results presented in Table 5.22, it can be seen that combining all sites produced low $R^{2}$ value but the model was significant. For both compaction methods, disaggregating the data based on project level produced higher $R^{2}$ value as opposed to aggregating all sites based on compaction method. It is also quite evident that at the project level, the advanced method had higher $R^{2}$ compared to the conventional method. It should be noted that all models were statistically significant at $5 \%$ level of significance. 
Table 5.22: Summary of the Regression Models between IDT and Relative Density (Field-Recovered Cores)

\begin{tabular}{ccccccc}
\hline Site & Compaction Method & $\boldsymbol{a}_{\boldsymbol{o}}$ & $\boldsymbol{a}_{\mathbf{1}}$ & $\boldsymbol{F}$ & $\boldsymbol{p}$-value & $\boldsymbol{R}^{\mathbf{2}}$ \\
\hline All & Combined & 0.013 & 0.111 & 33.410 & $<0.001$ & 0.214 \\
\hline All & Conventional & 0.0005 & 0.147 & 36.055 & $<0.001$ & 0.340 \\
\hline All & Advanced & 1.079 & 0.063 & 4.199 & 0.045 & 0.071 \\
\hline Highway 28 & Conventional & 0.011 & 0.106 & 8.959 & 0.017 & 0.528 \\
\hline Highway 16 & Conventional & 0.009 & 0.119 & 27.957 & $<0.001$ & 0.683 \\
\hline Highway 17 & Conventional & 0.126 & 0.087 & 6.341 & 0.036 & 0.442 \\
\hline Highway 417 & Conventional & 0.050 & 0.101 & 8.481 & 0.012 & 0.395 \\
\hline Greenbelt (ii) & Conventional & 0.755 & 0.065 & 6.587 & 0.050 & 0.568 \\
\hline Highway 28 & Advanced & 0.074 & 0.084 & 22.096 & 0.002 & 0.734 \\
\hline Greenbelt (ii) & Advanced & 0.001 & 0.143 & 108.298 & $<0.001$ & 0.931 \\
\hline Highway 34 & Advanced & 0.004 & 0.131 & 13.748 & 0.008 & 0.663 \\
\hline Greenbelt (i) & Advanced & 0.005 & 0.123 & 24.481 & $<0.001$ & 0.690 \\
\hline $\boldsymbol{a}_{\boldsymbol{o}}$ and $\boldsymbol{a}_{\mathbf{1}}$ are regression coefficients & & & & & \\
\hline
\end{tabular}

\subsection{Relative Density-Permeability Relationship}

\subsubsection{Gyratory Specimens}

The relationship between relative density and laboratory permeability was examined for the 33 laboratory prepared specimens. First, the relationship is examined and plotted for each mixture independently as shown in Figure 5.17, and then all data points were aggregated together and fitted by one curve to explore the overall trend as shown in Figure 5.18. As can be seen, the relationships suggest that the plotted curves follow an exponential relationship for the four incorporated mixtures in this research. 


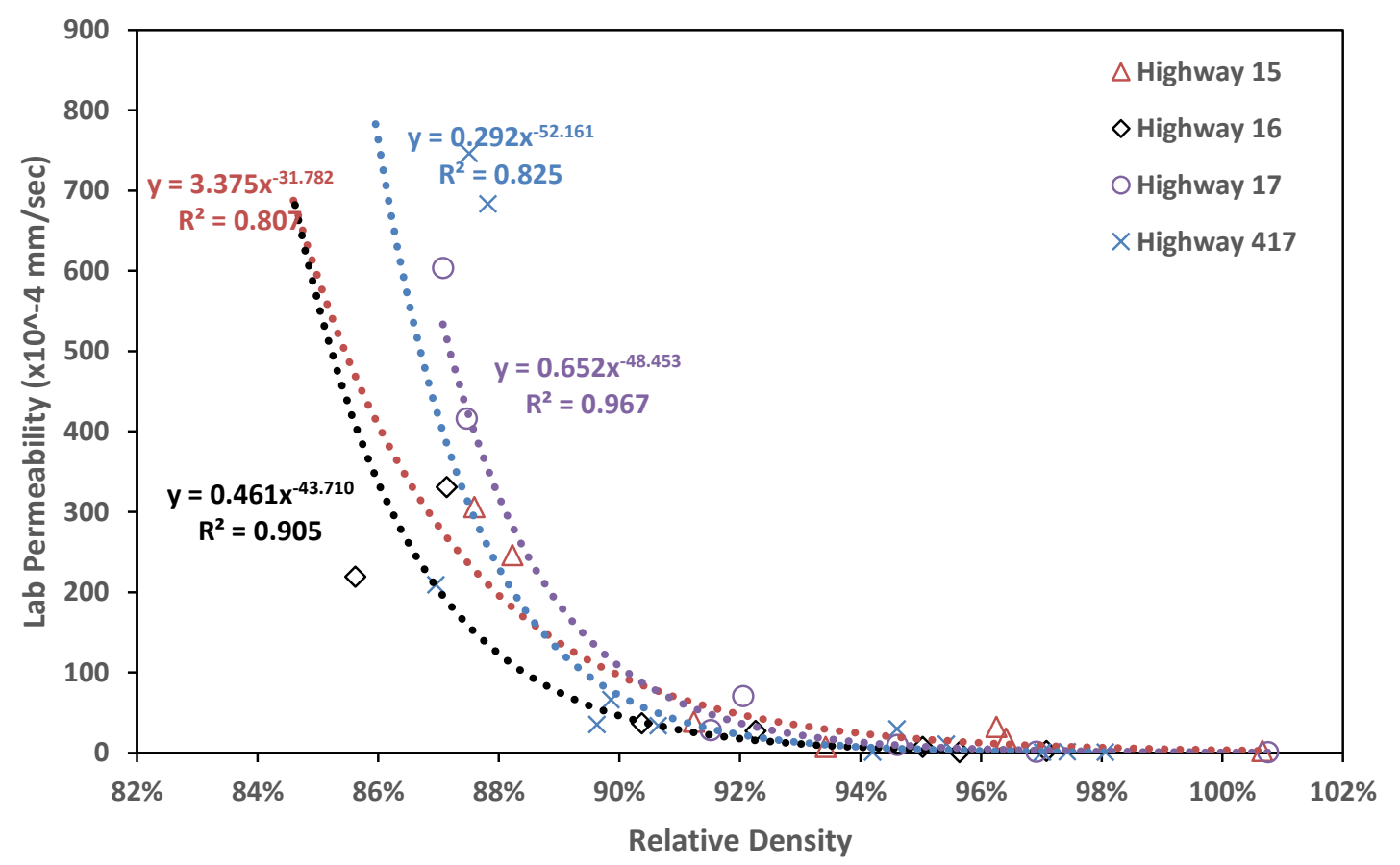

Figure 5.17: The Relative Density-Permeability Relationship for SGC Specimens

As expected, a strong relationship between permeability and relative density was observed in all mixtures as $R^{2}$ ranged from 0.76 to 0.97 . The overall observed trend in all examined mixtures shows that as the achieved relative density level decreases, the permeability coefficient increases. In particular, the permeability coefficient increases at a slow rate with decreasing the relative density until a certain value (from $92 \%$ to $90 \%$ ) where the permeability values increase exponentially with further decreases in the relative density. This suggests that after a specific relative compaction level, the asphalt pavement will likely become excessively permeable. 


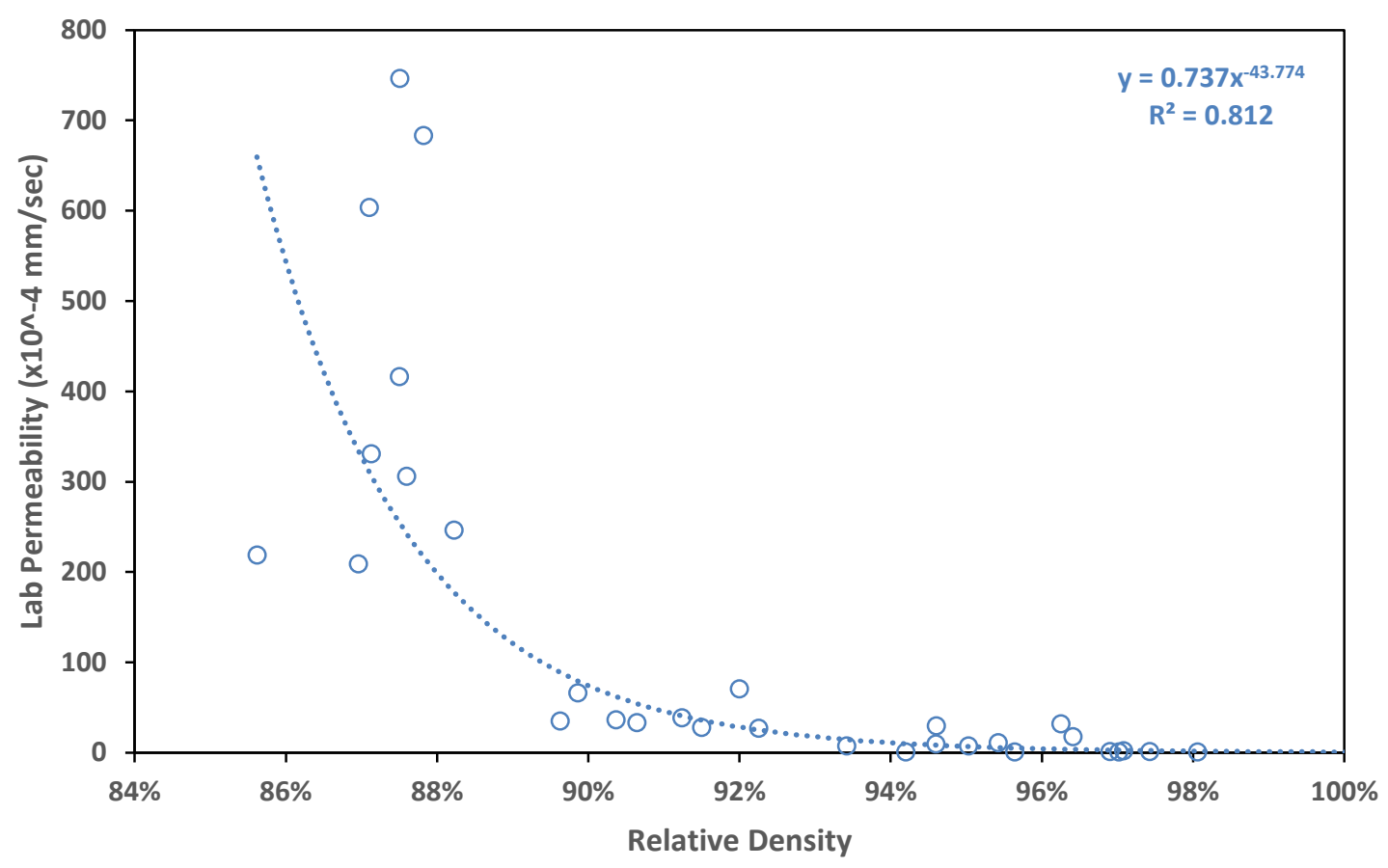

Figure 5.18: The General Trend of the Relative Density-Permeability Relationship for SGC

The previously developed relationship between density and permeability in Figure 5.17 and Figure 5.18 could be explained by two facts. First, having higher relative density values means lower air void content and thus less chances of having interconnected paths for water to go through. Second, even if the higher relative density did not eliminate the interconnected air voids, it would likely create narrower channels where water can flow, thereby reducing permeability. Therefore, it is expected to have low permeability coefficients at high relative density values.

Non-linear regression analysis was conducted to develop statistical models using the laboratory permeability and relative density data. Each mix was modeled separately, and then all data points were combined and modeled together. The general power model relating the two variables is as follows: 
Lab Permeability $=a_{0} *(\text { Relative Density })^{a_{1}}$

Equation 5.3

As can be seen in Table 5.23, all developed power models were statistically significant at $5 \%$ level of significance and had high $R^{2}$ value.

Table 5.23: Summary of the Regression Models between Lab Permeability and Relative Density (SCG Specimens)

\begin{tabular}{cccccc}
\hline Site & $\boldsymbol{a}_{\mathbf{0}}$ & $\boldsymbol{a}_{\mathbf{1}}$ & $\boldsymbol{F}$ & $\boldsymbol{p}$-value & $\boldsymbol{R}^{\mathbf{2}}$ \\
\hline Highway 15 & 3.371 & -31.798 & 20.945 & 0.006 & 0.807 \\
\hline Highway 16 & 0.461 & -43.710 & 47.489 & 0.001 & 0.905 \\
\hline Highway 17 & 0.651 & -48.479 & 145.175 & $<0.001$ & 0.967 \\
\hline Highway 417 & 0.292 & -52.163 & 47.156 & $<0.001$ & 0.825 \\
\hline All & 0.737 & -43.781 & 133.607 & $<0.001$ & 0.812 \\
\hline $\boldsymbol{a}_{\boldsymbol{o}}$ and $\boldsymbol{a}_{\mathbf{1}}$ are regression coefficients & & & \\
\hline
\end{tabular}

\subsubsection{Field-Recovered Cores}

The relationship between laboratory permeability and relative density is explored and presented in Figure 5.19. The results revealed that there is an exponential fair relationship with $\left(R^{2}=0.50\right)$ between the laboratory permeability of the field-recovered cores and relative density. This finding confirms the earlier results developed for the SGC specimens. 


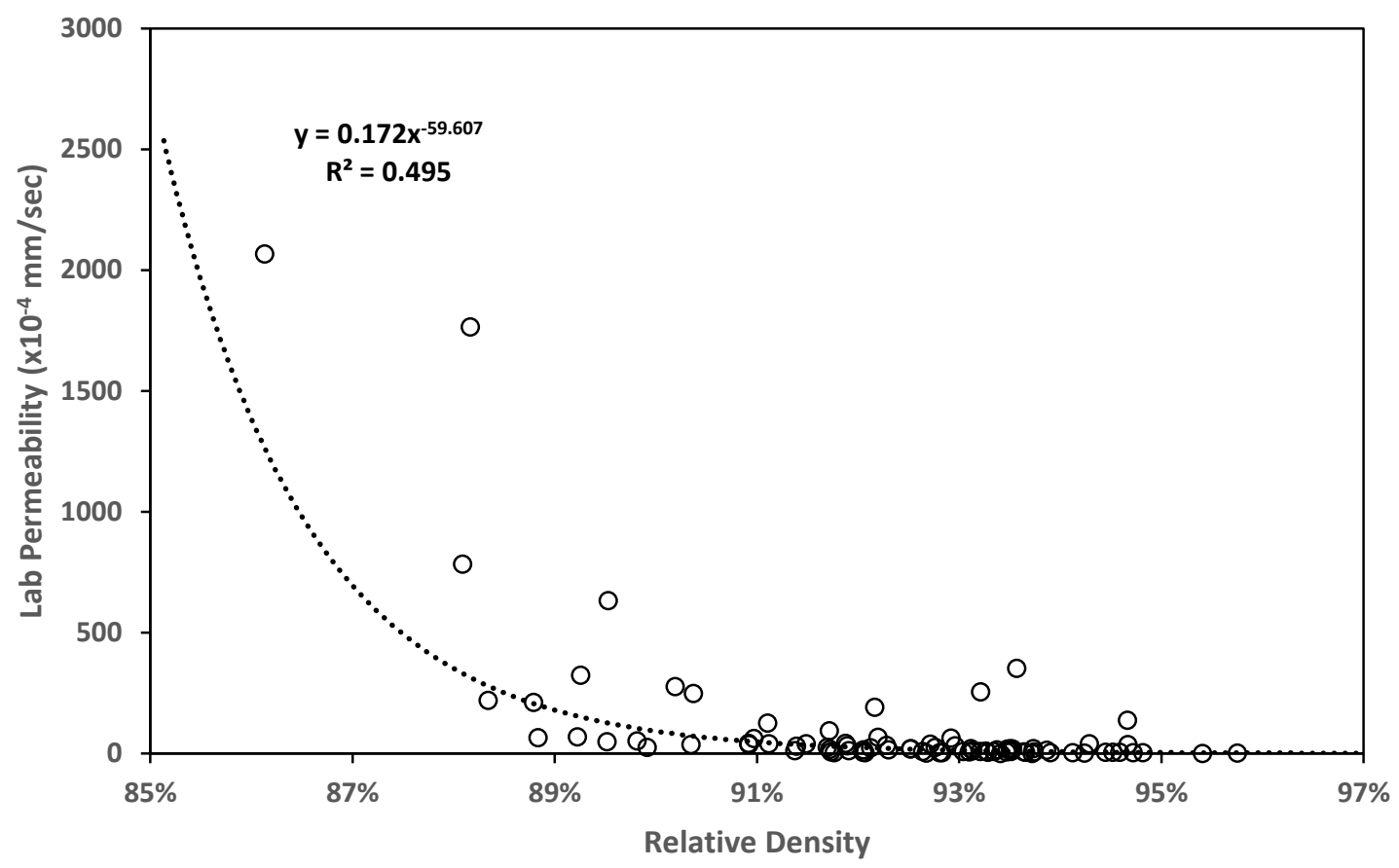

Figure 5.19: The Relative Density-Permeability Relationship for Field Cores

Similarly, the regression analysis was also performed on the field-recovered cores for the two compaction methods. The results of Table 5.24 suggest that the examined model for each compaction method was significant as well as the aggregated model combining both of them together. At the project level, the conventional method had only one site (Highway 16) that was statistically significant while the others were not significant. On the other hand, 2 out of 3 models for the advanced compaction method were statistically significant with moderate $R^{2}$ value. 
Table 5.24: Summary of the Regression Models between Lab Permeability and Relative Density (Field-Recovered Cores)

\begin{tabular}{ccccccc}
\hline Site & Compaction Method & $\boldsymbol{a}_{\boldsymbol{o}}$ & $\boldsymbol{a}_{\mathbf{1}}$ & $\boldsymbol{F}$ & $\boldsymbol{p}$-value & $\boldsymbol{R}^{\mathbf{2}}$ \\
\hline All & Combined & 0.173 & -59.574 & 82.423 & $<0.001$ & 0.495 \\
\hline All & Conventional & 0.351 & -54.930 & 64.773 & $<0.001$ & 0.564 \\
\hline All & Advanced & 0.017 & -82.042 & 30.682 & $<0.001$ & 0.489 \\
\hline Highway 16 & Conventional & 2.745 & -29.571 & 6.853 & 0.021 & 0.345 \\
\hline Highway 17 & Conventional & 0.544 & -54.788 & 2.461 & 0.143 & 0.170 \\
\hline Highway 417 & Conventional & 0.084 & -70.715 & 3.645 & 0.079 & 0.219 \\
\hline Greenbelt (ii) & Conventional & 0.352 & -57.854 & 3.359 & 0.117 & 0.359 \\
\hline Greenbelt (ii) & Advanced & 0.082 & -62.668 & 31.030 & 0.001 & 0.795 \\
\hline Greenbelt (i) & Advanced & 0.018 & -77.921 & 3.571 & 0.083 & 0.229 \\
\hline Highway 34 & Advanced & 0.0002 & -140.953 & 8.998 & 0.017 & 0.529 \\
\hline $\boldsymbol{a}_{\boldsymbol{o}}$ and $\boldsymbol{a}_{\mathbf{1}}$ are regression coefficients & & & & & \\
\hline
\end{tabular}

\subsubsection{Field Permeability}

A total of 98 field permeability measurements were plotted to their corresponding relative density values and the resulting relationship is depicted in Figure 5.21. As can be seen, the data points were fitted using a power model and the resulting relationship is weak with an $R^{2}$ value of 0.29 . In general, it can be observed that many data points have high permeability values (scattered above the fitted curve) which do not correspond to the achieved relative density. 


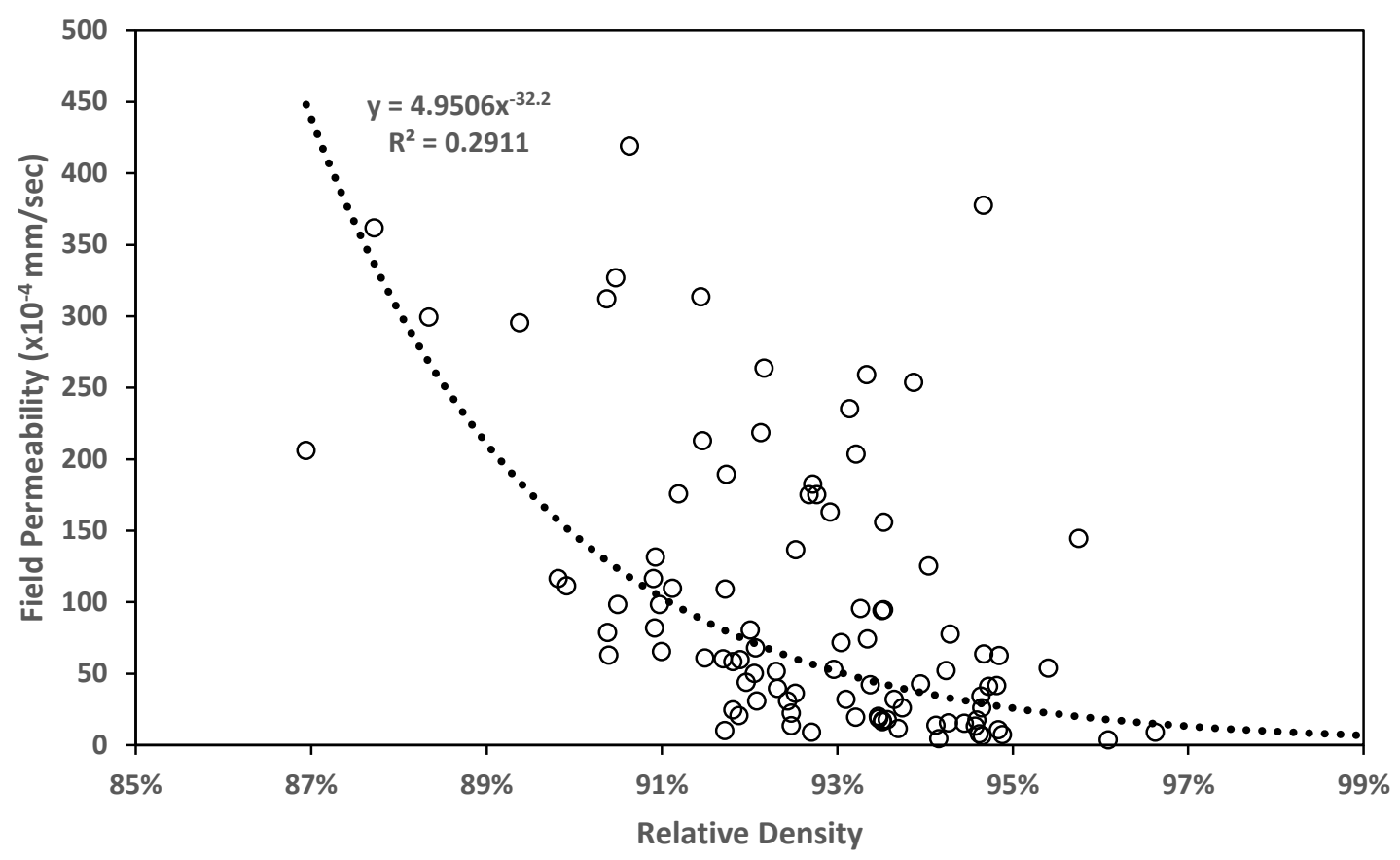

Figure 5.20: The Correlation between Relative Density and Field Permeability

More analysis was carried out to explain the observed trend. Specifically, the data points were disaggregated based on the compaction method as seen in Figure 5.21. It can be observed that the overall poor trend was caused by the field permeability measurements belonging to the conventional method. It is possible that there was/were other factor(s) affecting the expected trend. Higher permeability rates could be attributed to and explained by the fact that the water had possibly infiltrated rapidly in those locations due to the existence of surface cracks caused by improper finishing of the road surface. The relative density alone does not necessarily reflect the effect of these cracks. Consequently, it is possible to have two different samples with slight differences in relative density but with considerable differences in permeability as depicted in the previous figure. 


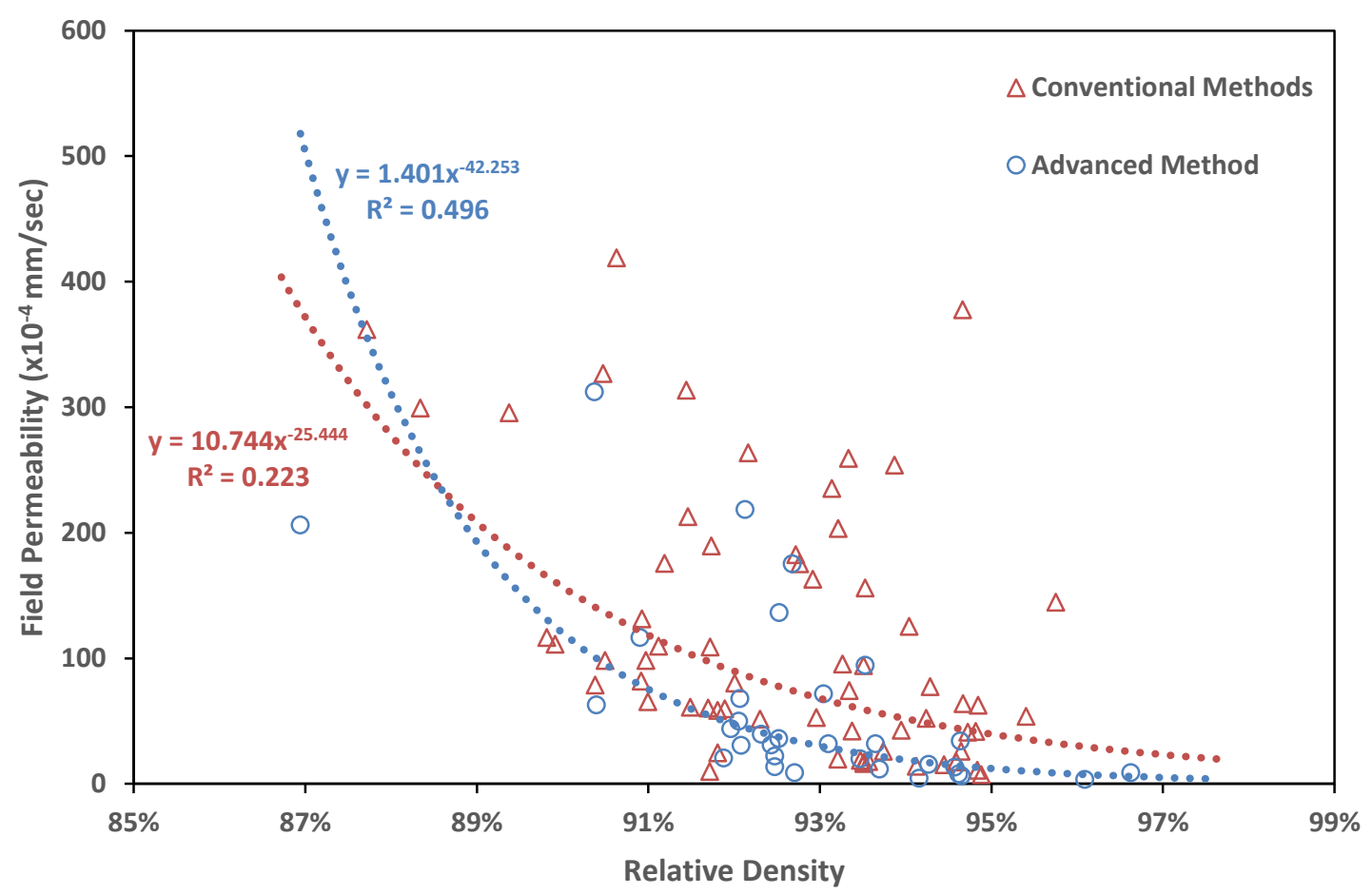

Figure 5.21: Field Permeability-Density Relationship Categorized by Compaction Method

The relationship of the relative density to both field and lab permeability of field cores are presented in Figure 5.22. Although, the two relationships have negative exponential trend, the permeability of field cores has less variability compared to the field measurements. Also, the field measurements overestimate the pavement permeability compared to the lab measurements. 


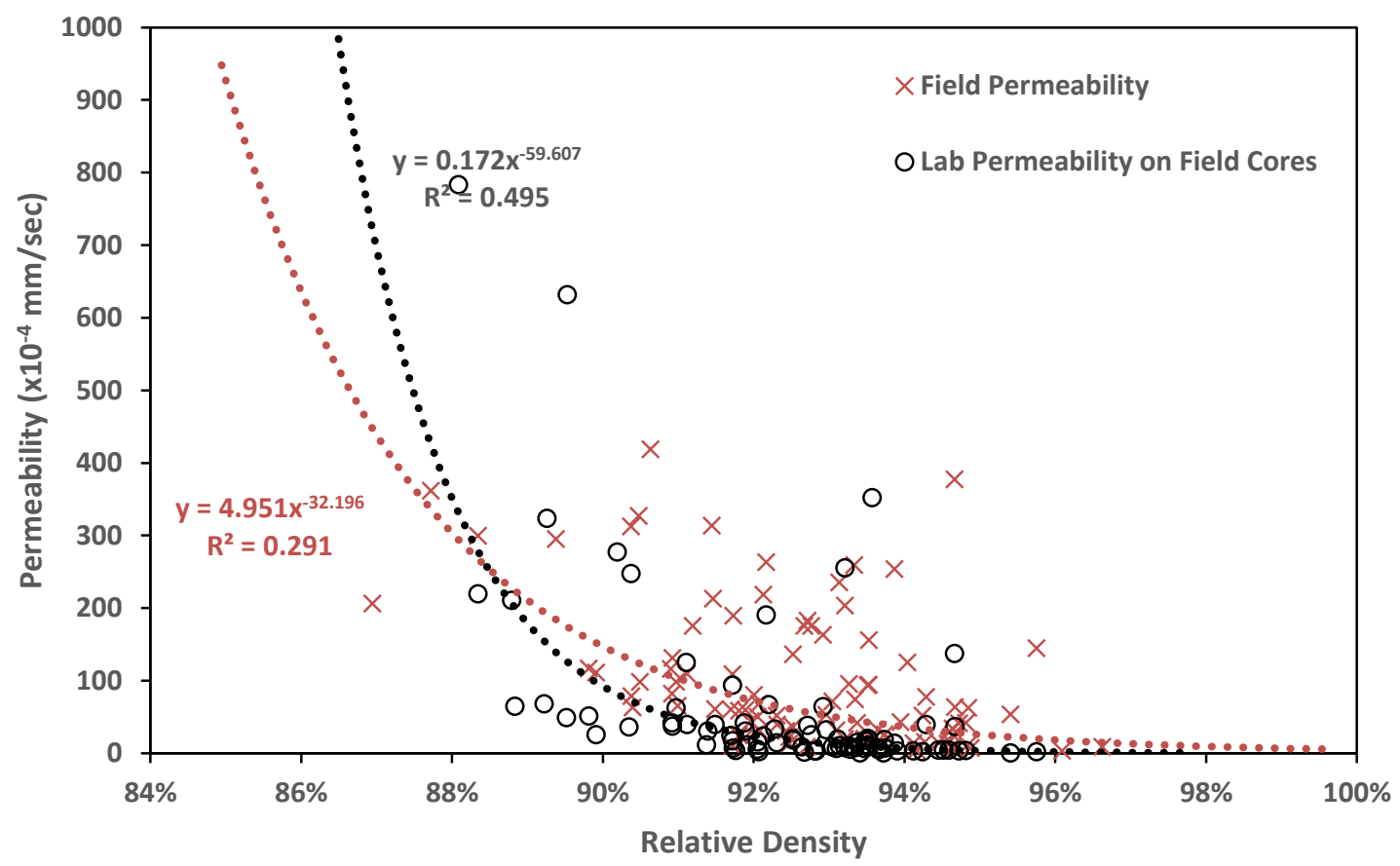

Figure 5.22: The Relative Density-Permeability Trend for Field Cores and Field Measurements

The relative density was used as independent variable while the field permeability was used as the dependent variable in the regression analysis. The following equation describes the general form of the power model:

Field Permeability $=a_{0} *(\text { Relative Density })^{a_{1}}$ Equation 5.4

The models summarized in Table 5.25 suggest that aggregating the data points based on compaction method as well as combining the two compaction methods produced significant models. In general, building individual models at the project level was not statistically significant for the two compaction methods. 
Table 5.25: Summary of the Regression Models between Field Permeability and Relative Density

\begin{tabular}{ccccccc}
\hline Site & Compaction Method & $\boldsymbol{a}_{\boldsymbol{o}}$ & $\boldsymbol{a}_{\mathbf{1}}$ & $\boldsymbol{F}$ & $\boldsymbol{p}$-value & $\boldsymbol{R}^{\mathbf{2}}$ \\
\hline All & Combined & 4.950 & -32.197 & 38.619 & $<0.001$ & 0.291 \\
\hline All & Conventional & 10.745 & -25.443 & 17.843 & $<0.001$ & 0.223 \\
\hline All & Advanced & 1.402 & -42.249 & 29.518 & $<0.001$ & 0.496 \\
\hline Tomlinson & Conventional & 16.690 & -21.028 & 0.288 & 0.615 & 0.054 \\
\hline Thousand Islands Parkway & Conventional & $1.965 \times 10^{-5}$ & -258.017 & 0.209 & 0.693 & 0.095 \\
\hline Highway 28 & Conventional & 2.790 & -39.087 & 3.848 & 0.085 & 0.325 \\
\hline Highway 16 & Conventional & 46.088 & -9.446 & 0.776 & 0.396 & 0.061 \\
\hline Highway 17 & Conventional & 30.519 & -21.789 & 3.165 & 0.099 & 0.196 \\
\hline Highway 417 & Conventional & 3.083 & -33.981 & 1.765 & 0.209 & 0.128 \\
\hline Tomlinson & Advanced & 1.794 & -31.835 & 8.652 & 0.032 & 0.634 \\
\hline Thousand Islands Parkway & Advanced & 0.011 & -127.734 & 3.287 & 0.167 & 0.523 \\
\hline Highway 28 & Advanced & 0.573 & -46.188 & 22.929 & 0.001 & 0.741 \\
\hline Greenbelt (i) & Advanced & 67.731 & 9.049 & 0.043 & 0.855 & 0.021 \\
\hline Highway 34 & Advanced & 5.755 & -39.058 & 2.994 & 0.159 & 0.428 \\
\hline
\end{tabular}

$\boldsymbol{a}_{\boldsymbol{o}}$ and $\boldsymbol{a}_{1}$ are regression coefficients

\subsection{Permeability- IDT Relationship}

\subsubsection{Gyratory Specimens}

Since the previous two subsections (5.35.4.2and 5.4) showed that relative density correlates well with both the IDT as well as permeability, it is therefore expected to observe a strong relationship between IDT and permeability. Figure 5.23 depicts the relationship between the permeability and IDT for four asphalt mixes. In addition, Figure 5.24 shows the overall relationship by plotting all SGC data points into one graph and fitting them using one curve. In all mixtures, it is obvious that a strong relationship 
exists between the permeability and IDT as $R^{2}$ ranges between 0.77 and 0.93 . This could be attributed to the fact that stronger bonds between the aggregate and asphalt binder (cohesion) as well as stronger bonds within the binder itself (adhesion) exist in any given specimen of high IDT value. In general, higher relative density values (or less air voids content) will likely contribute to have such solid and strong internal structure. This reduction in air voids content is compensated by having the asphalt binder content filling the air void content. In addition, this reduction reduces the possible gaps between the sample's aggregate. These structural changes caused by increasing the relative density will likely reduce the possibility of having interconnected paths and increase the isolated voids content. Consequently, lower permeability is expected since it is highly dependent upon the interconnected air voids.

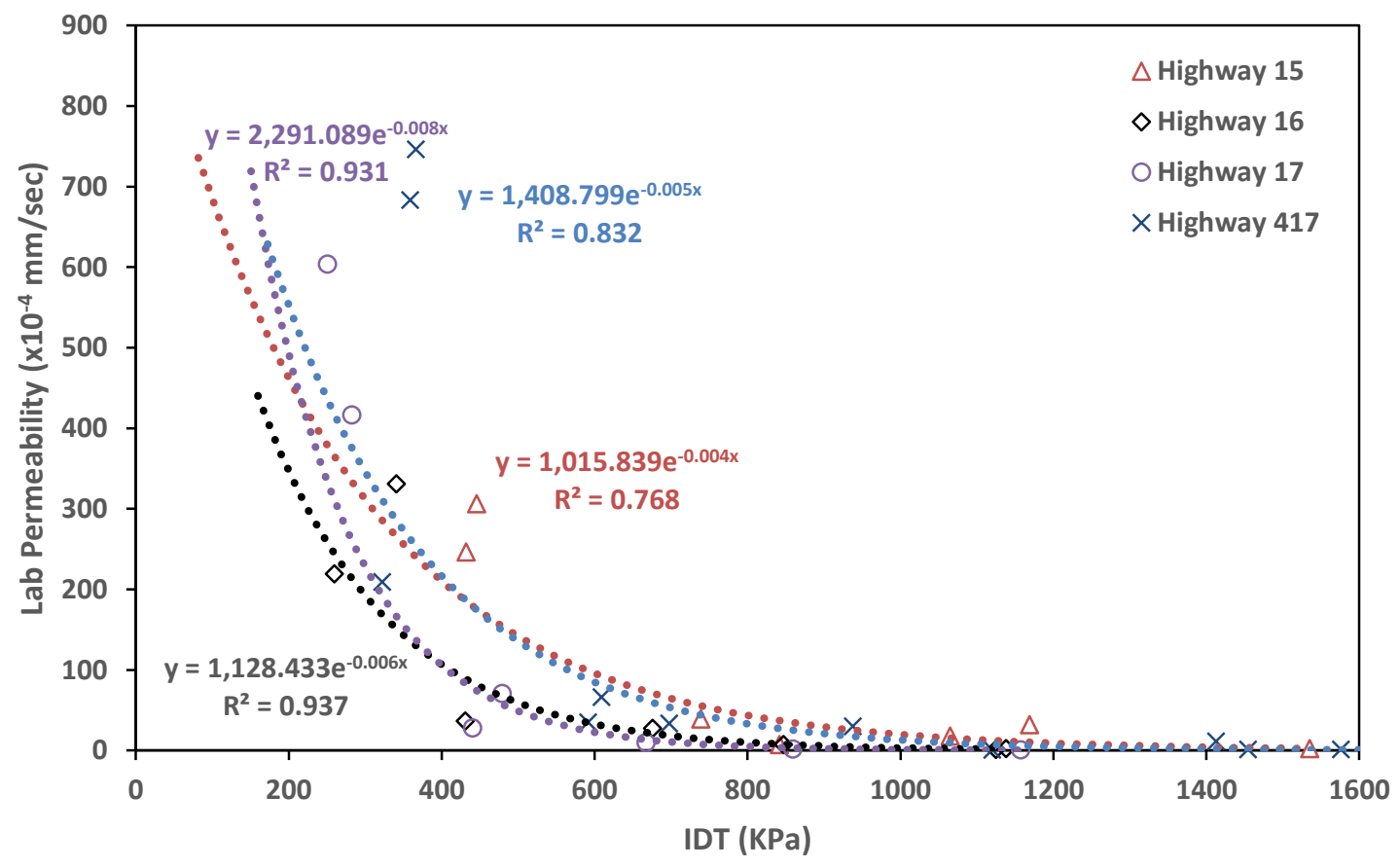

Figure 5.23: The Permeability- IDT Relationship for SGC Specimens 


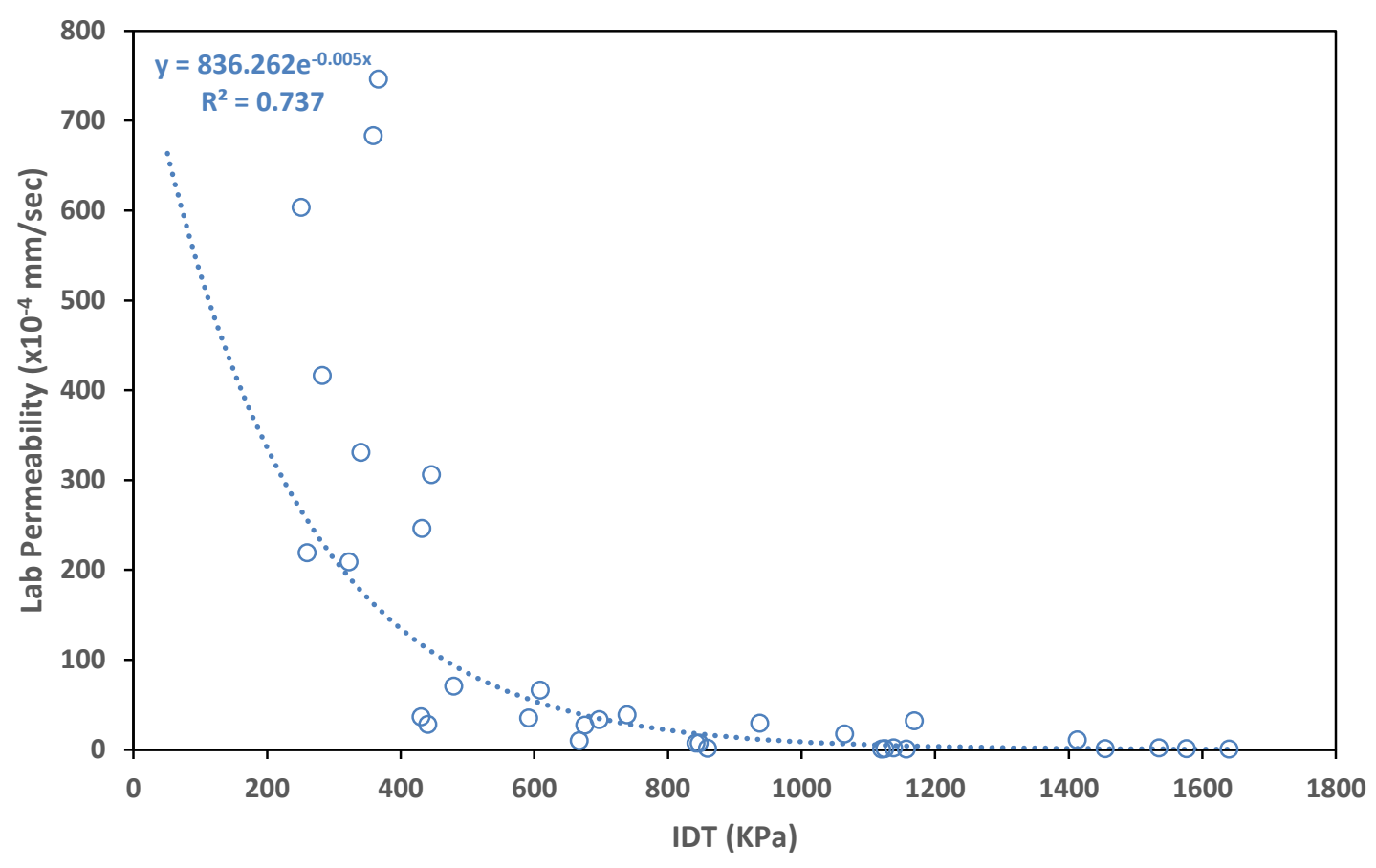

Figure 5.24: The General Trend of the Strength-Permeability Relationship for SGC

Non-linear regression models were also developed to model the relationship between the laboratory permeability and IDT. The general exponential regression function is as follows:

Lab Permeability $=\operatorname{EXP}\left(a_{0}+a_{1} * I D T\right)$ Equation 5.5

According to Table 5.26, it can be seen that all models based on SGC specimens were statistically significant at $5 \%$ level of significance with high $R^{2}$ value. 
Table 5.26: Summary of the Regression Models between Lab Permeability and IDT (SCG Specimens)

\begin{tabular}{cccccc}
\hline Site & $\boldsymbol{a}_{\boldsymbol{o}}$ & $\boldsymbol{a}_{\mathbf{1}}$ & $\boldsymbol{F}$ & $\boldsymbol{p}$-value & $\boldsymbol{R}^{\mathbf{2}}$ \\
\hline Highway 15 & 1015.851 & -0.004 & 16.558 & 0.010 & 0.768 \\
\hline Highway 16 & 1128.440 & -0.006 & 74.724 & $<0.001$ & 0.937 \\
\hline Highway 17 & 2291.183 & -0.008 & 67.582 & $<0.001$ & 0.931 \\
\hline Highway 417 & 1408.806 & -0.005 & 49.537 & $<0.001$ & 0.832 \\
\hline \multicolumn{7}{c}{ All } & 836.270 & -0.005 & 86.679 & $<0.001$ & 0.737 \\
\hline $\boldsymbol{a}_{\boldsymbol{o}}$ and $\boldsymbol{a}_{\mathbf{1}}$ are regression coefficients & & & \\
\hline
\end{tabular}

\subsubsection{Field-Recovered Cores}

Similar to Section 5.3.2, the relationship between IDT and lab permeability was investigated at the same three different levels introduced earlier. Figure 5.25 shows the overall trend when aggregating all data points. A moderate relationship $\left(R^{2}=0.43\right)$ was observed at this level of classification. The next level of analysis categorized by compaction method was then performed and the results are presented in Figure 5.26. A fair relationship was observed for results obtained and finished by the conventional method while the advanced method showed variability in the data with low coefficient of determination.

The relationship between permeability and IDT was also inspected site-by-site which is the third level of analysis. Figure 5.27 presents the results of conventional compaction method. A logarithmic scale was used to represent the lab permeability due to the existence of some high permeability values. In general, fair to strong relationship $(0.33<$ $R^{2}<0.83$ ) exists between the IDT and laboratory permeability and it is best fitted by an exponential curve. This confirms the finding obtained by the SGC specimens when 
establishing the same relationship. The results of three sites obtained from sections finished by the advanced method are presented in Figure 5.28. The results of these sites followed an exponential relationship with $R^{2}$ value ranging between 0.52 and 0.71 . It can then be understood that the poor relationship of the advanced method (presented in Figure 5.26) was caused by having one site (Highway 34) deviating from the overall trend produced by the other sites.

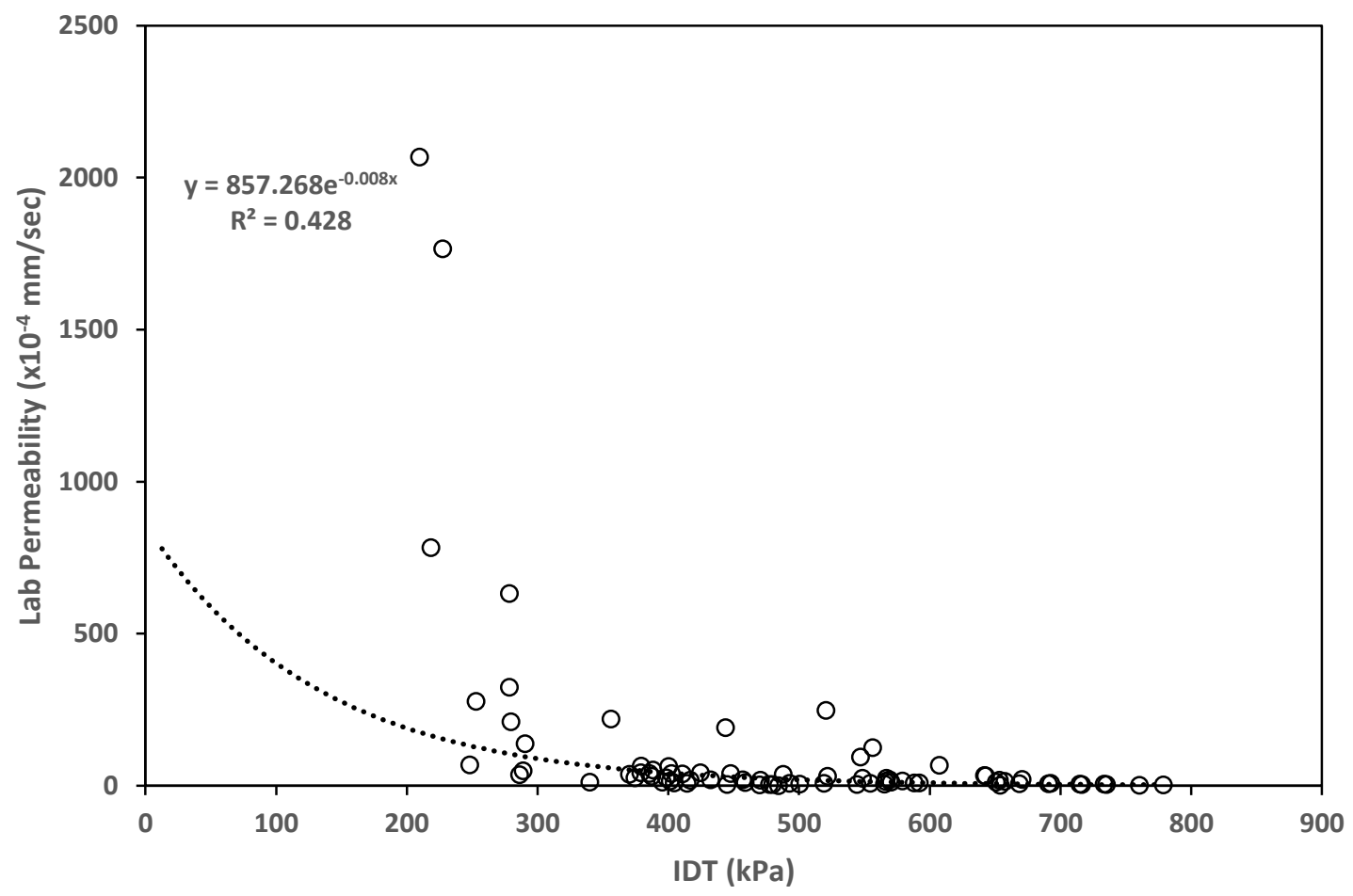

Figure 5.25: The Permeability- IDT Relationship for All Data Points 


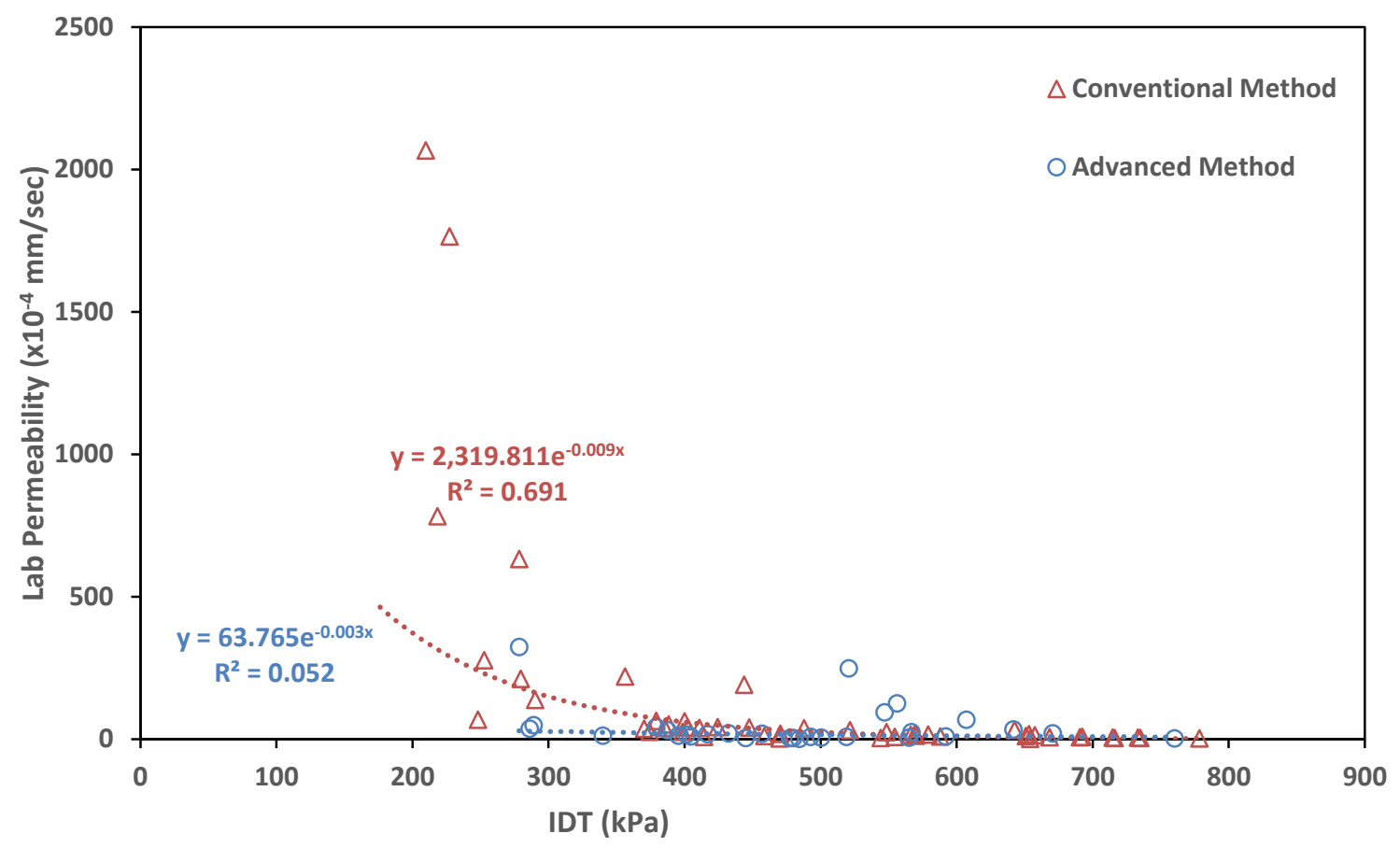

Figure 5.26: The Permeability- IDT Relationship based on Compaction Method

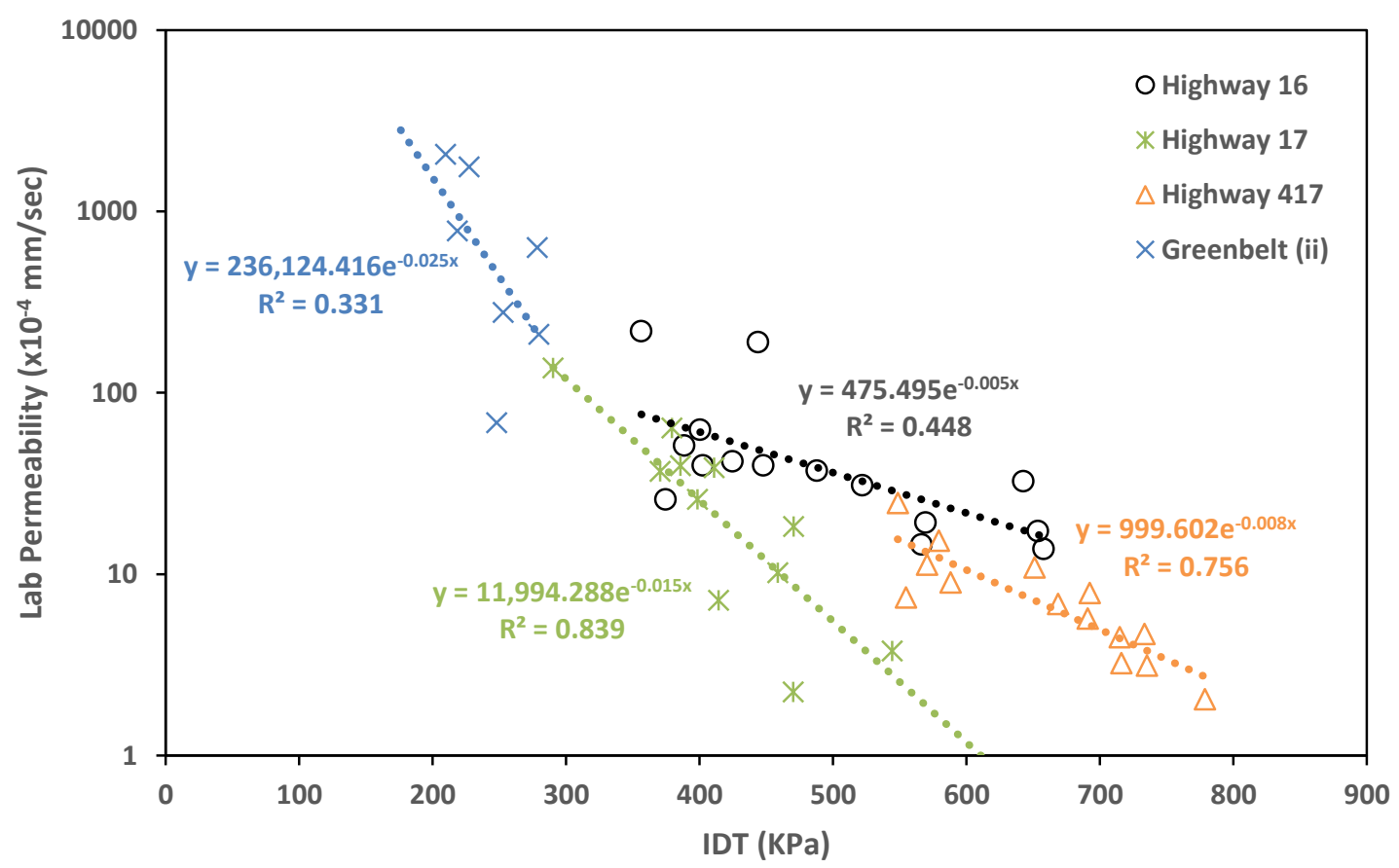

Figure 5.27: The Permeability- IDT Relationship for Field Cores (Conventional Method) 


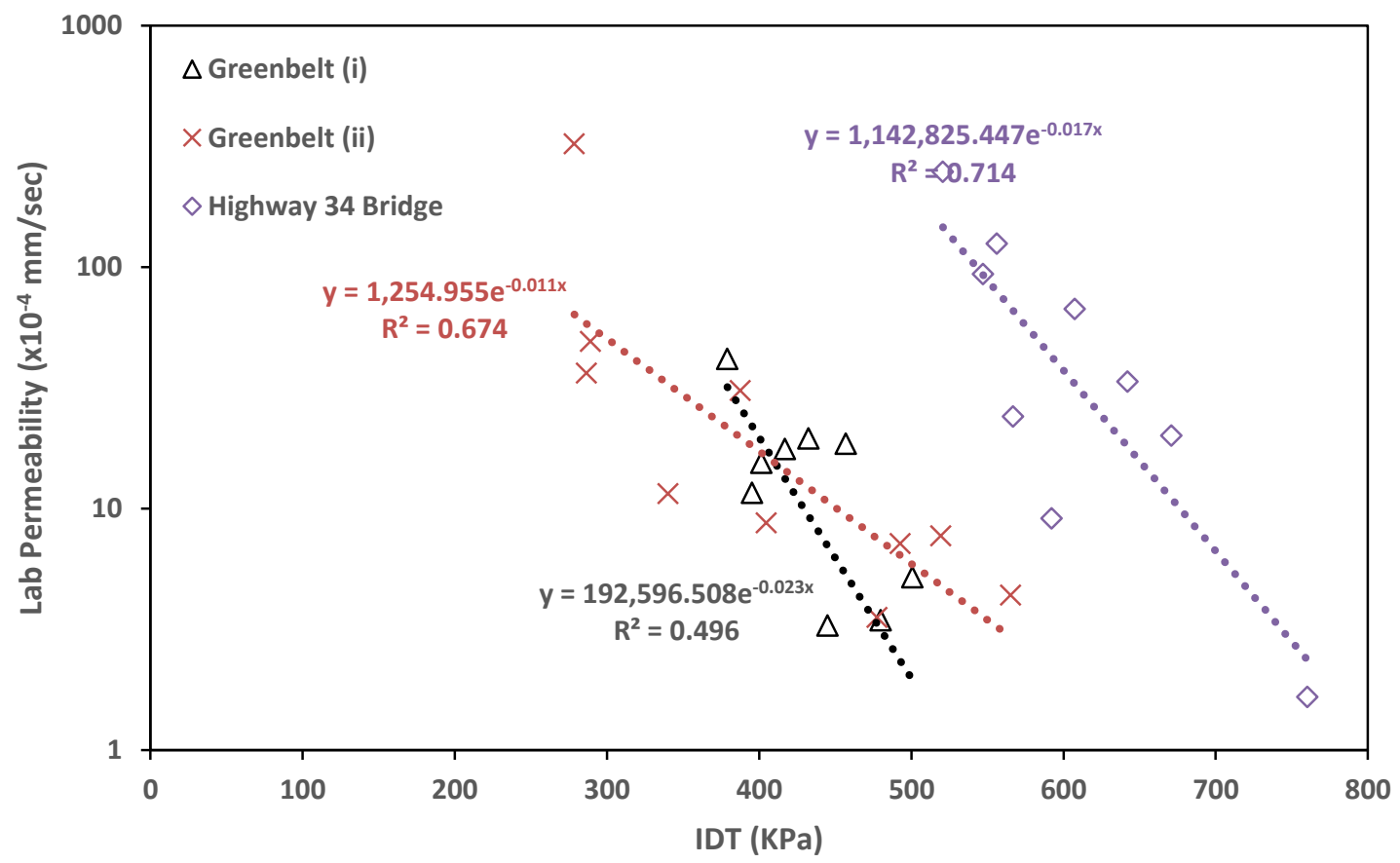

Figure 5.28: The Permeability- IDT Relationship for Field Cores (Advanced Method)

It was concluded in the literature review (Chapter 2) of this thesis that the permeability of HMA is highly affected by the NMAS when examining the permeability-density relationship. In other words, the permeability-density trend of road sections having 12.5 mm NMAS is different from roads with $19 \mathrm{~mm}$ NMAS. It is important to mention that all incorporated sites in this study have a NMAS of $12.5 \mathrm{~mm}$. The previously developed relationships (Figure 5.15, Figure 5.16, Figure 5.27 and Figure 5.28) suggest that, unlike the permeability-density relationship, unique strength-density or strength-permeability relationships could exist for the same NMAS. This is possibly attributed to the differences in asphalt mixtures used in each project.

The regression analysis presented in Table 5.27 implies that the developed model for the conventional method was statistically significant while the advanced was not. It is important to mention that there are slight differences in the regression coefficients 
presented in the previous figures and the ones shown in Table 5.27. This is due to the fact that those regression models shown in the figures were produced by Excel, while the regression models in the table were developed using SPSS. At the individual project scale, it can be seen that all sites had significant model (except for Greenbelt (ii) of conventional method) with moderate to strong $R^{2}$ coefficient. It is worth noting that these models based on IDT had an overall better significance in modeling the lab permeability compared to relative density.

Table 5.27: Summary of the Regression Models between Lab Permeability and IDT (Field-Recovered Cores)

\begin{tabular}{ccccccc}
\hline Site & Compaction Method & $\boldsymbol{a}_{\boldsymbol{o}}$ & $\boldsymbol{a}_{\mathbf{1}}$ & $\boldsymbol{F}$ & $\boldsymbol{p}$-value & $\boldsymbol{R}^{\mathbf{2}}$ \\
\hline All & Combined & 857.151 & -0.008 & 56.074 & $<0.001$ & 0.428 \\
\hline All & Conventional & 2319.067 & -0.009 & 102.762 & $<0.001$ & 0.691 \\
\hline All & Advanced & 63.793 & -0.003 & 1.471 & 0.236 & 0.052 \\
\hline Highway 16 & Conventional & 475.514 & -0.005 & 10.554 & 0.006 & 0.448 \\
\hline Highway 17 & Conventional & 11899.198 & -0.015 & 51.957 & $<0.001$ & 0.839 \\
\hline Highway 417 & Conventional & 1000.213 & -0.008 & 37.266 & $<0.001$ & 0.756 \\
\hline Greenbelt (ii) & Conventional & 236159.218 & -0.025 & 2.469 & 0.177 & 0.331 \\
\hline Greenbelt (ii) & Advanced & 1255.387 & -0.011 & 16.512 & 0.004 & 0.674 \\
\hline Highway 34 & Advanced & 1145174.321 & -0.017 & 17.444 & 0.004 & 0.714 \\
\hline Greenbelt (i) & Advanced & 191370.070 & -0.023 & 7.898 & 0.023 & 0.497 \\
\hline
\end{tabular}

$\boldsymbol{a}_{\boldsymbol{o}}$ and $\boldsymbol{a}_{1}$ are regression coefficients

\subsubsection{Field Permeability}

Finally, the IDT values were plotted against the field permeability measurements. The developed trend presented in Figure 5.29 suggests that poor relationship $\left(R^{2}=0.05\right)$ exists 
between the two variables. This indicates that the field permeability test using the NCAT device does not correlate well with the IDT test.

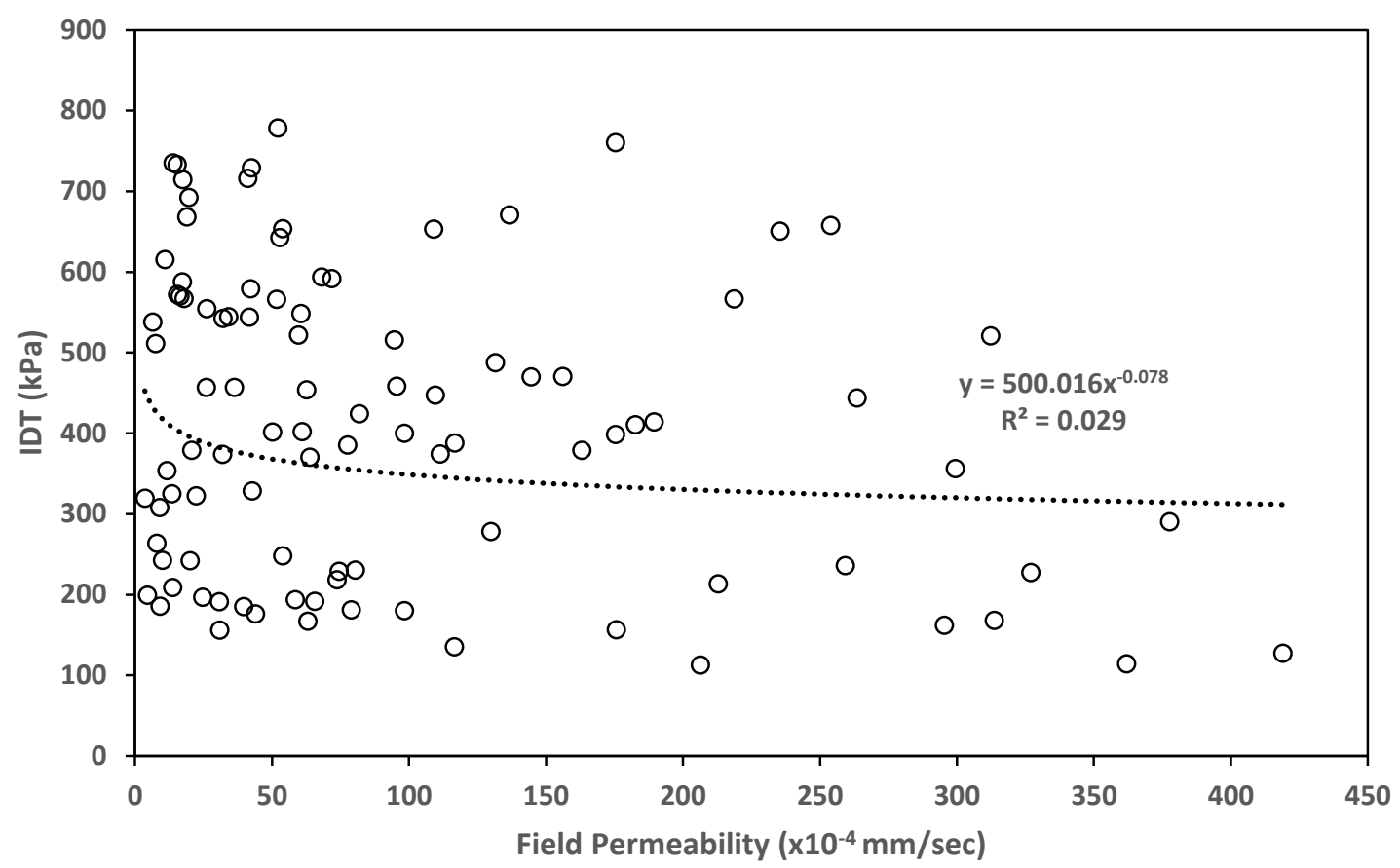

Figure 5.29: The Correlation between IDT and Field Permeability

Non-linear regression analysis was also carried out in an attempt to model the relationship between the field permeability and IDT as shown in Equation 5.6. $I D T=a_{0} *(\text { Field Permeability })^{a_{1}}$ Equation 5.6 According to the presented results in Table 5.28, the general model regardless of the compaction method was not statistically significant with poor $R^{2}$. The model developed for the conventional method was statistically significant, while the advanced method had an insignificant model. In general, majority of individual models at the project level produced insignificant models. 
Table 5.28: Summary of the Regression Models between Field Permeability and IDT

\begin{tabular}{ccccccc}
\hline Site & Compaction Method & $\boldsymbol{a}_{\boldsymbol{o}}$ & $\boldsymbol{a}_{\mathbf{1}}$ & $\boldsymbol{F}$ & $\boldsymbol{p}$-value & $\boldsymbol{R}^{\mathbf{2}}$ \\
\hline All & Combined & 500.003 & -0.078 & 2.862 & 0.094 & 0.029 \\
\hline All & Conventional & 1095.373 & -0.243 & 19.969 & 0.000 & 0.241 \\
\hline All & Advanced & 241.991 & 0.086 & 1.114 & 0.300 & 0.036 \\
\hline Tomlinson & Conventional & 300.492 & -0.048 & 1.060 & 0.350 & 0.175 \\
\hline Thousand Islands Parkway & Conventional & 569.017 & -0.015 & 0.012 & 0.919 & 0.004 \\
\hline Highway 28 & Conventional & 356.886 & -0.158 & 16.784 & 0.003 & 0.677 \\
\hline Highway 16 & Conventional & 684.913 & -0.079 & 0.583 & 0.460 & 0.046 \\
\hline Highway 17 & Conventional & 1221.614 & -0.219 & 8.412 & 0.016 & 0.457 \\
\hline Highway 417 & Conventional & 664.754 & -0.009 & 0.038 & 0.849 & 0.003 \\
\hline Tomlinson & Advanced & 329.576 & -0.036 & 0.143 & 0.721 & 0.028 \\
\hline Thousand Islands Parkway & Advanced & 578.617 & -0.020 & 1.255 & 0.344 & 0.295 \\
\hline Highway 28 & Advanced & 338.599 & -0.128 & 1.061 & 0.323 & 0.081 \\
\hline Highway 34 & Advanced & 744.921 & -0.039 & 0.134 & 0.733 & 0.032 \\
\hline $\boldsymbol{a}_{\boldsymbol{o}}$ and $\boldsymbol{a}_{\mathbf{1}}$ are regression coefficients & & & & & & \\
\hline & & & & & &
\end{tabular}

\subsection{Summary}

In summary, this chapter presented different asphalt pavement properties and their variability with respect to the testing location, compaction method, and project level. Also, the chapter presented a comparison between the conventional and advanced compaction methods on the same project level. In general, there were significant differences between the two compaction techniques in terms of the considered physical and mechanical properties for some of the common projects. According to the thee-way ANOVA test results summarized in Table 5.29, it was concluded also that the testing 
location had significant effect on both relative density and lab permeability, and insignificant effect on field permeability and IDT. The only significant two-way interaction effect was between the compaction method and project level. Such significant interaction implies that the effect of project level on all considered pavement properties depends significantly on the project level and vice versa. None of the three-way interactions were significant.

Table 5.29: Summary of the Three-way ANOVA Results

\begin{tabular}{ccccc}
\hline Factor & Relative Density & Lab Permeability & IDT & Field Permeability \\
\hline $\mathrm{TL}$ & Significant & Significant & Not Significant & Not Significant \\
\hline $\mathrm{CM}$ & Significant & Significant & Significant & Significant \\
\hline $\mathrm{PL}$ & Significant & Significant & Significant & Significant \\
\hline $\mathrm{TL}$ CM & Not Significant & Significant & Not Significant & Not Significant \\
\hline $\mathrm{TL} * \mathrm{PL}$ & Not Significant & Significant & Not Significant & Not Significant \\
\hline $\mathrm{CM}{ }^{*} \mathrm{PL}$ & Significant & N/A & Significant & Significant \\
\hline $\mathrm{TL} \mathrm{CM}^{*} \mathrm{PL}$ & Not Significant & N/A & Not Significant & Not Significant \\
\hline
\end{tabular}

The effect of age and traffic on field permeability was examined and found to be statistically insignificant after one year of road opening date. According to Pearson's correlation test, fair and significant correlations were observed between the considered properties in this study. In particular, the examined associations between relative density, permeability, and IDT developed for the SGC specimens had higher correlation coefficients compared to those of field cores. Also, the general trend indicates that less permeability is associated with higher relative density and higher IDT. The permeameters used in this study to estimate the field and lab permeability correlate fairly with each other $\left(R^{2}=0.417\right)$, however there was significant difference between them. The chapter explored as well the possible relationships between different asphalt pavement properties 
in two different settings; the field and lab. The relationships between field permeability and any of the three laboratory tests (permeability, density, and IDT) were generally moderate to poor. The chapter also presented the results of non-linear regression analysis between the different dependent and independent variables. In general, all models based on SGC specimens were statistically significant with high $R^{2}$ coefficient. For the fieldrecovered cores, it was found that modeling the lab permeability based on IDT is better than modeling it using the relative density at project level. Neither the relative density nor the IDT were able to show significance in modeling the field permeability at the project level. In most cases, aggregating the data points based on the compaction method showed significant model, but poor $R^{2}$ coefficient. 


\section{CHAPTER 6: CONCLUSIONS AND RECOMMENDATIONS}

\subsection{Summary}

Ensuring the highest possible qualities of the finished asphalt roads is essential to minimize various types of damage in the short and long terms of the service life of the pavement. This research was designed and carried out to examine a more reliable pavement characteristic or test method based on permeability to evaluate the as-built quality of the newly HMA road pavements. This is because permeability is closely related to moisture-induced damages more than relative density, the currently adopted pavement characteristic by road authorities.

The first step towards achieving the research objectives was to carry out a comprehensive review of the state of the art concerning the methods and techniques used to estimate both the in-situ and laboratory permeability. Based on this review, the NCAT and the KarolWarner permeameters were selected for performing the field and laboratory permeability test respectively.

The research scope was limited to particular sites in Eastern Ontario, most of which were selected in consultation with engineers from MTO whilst other sections were built as inhouse field trials intended to evaluate asphalt mixtures compacted using the AMIR-II compactor. In addition, different asphalt mixture types corresponding to the same mixtures studied in the field were provided by the MTO for the purpose of performing the required laboratory experiments. The field and laboratory investigations were performed on newly constructed sites as well as other one year in-service sections. The 
field experimental program entailed performing the in-situ permeability testing in addition to recovering field cores from the exact testing location where the field permeability was conducted. The laboratory testing program consisted of various laboratory tests including relative density, lab permeability, and IDT. The aforementioned laboratory tests were carried out on both the field-recovered cores as well as the laboratory prepared specimens by the SGC.

The variability of the mechanical and physical properties was examined against three different factors. Those variability were described in terms of the relative density, IDT, field and lab permeability. The first factor was the testing location which was determined by performing the field permeability as well as core sampling at five different locations in the asphalt mat. The effect of the compaction technique on HMA properties was addressed and included in this research as the second factor. Particularly, the current compaction method including the conventional vibratory steel drum and pneumatic train rollers were compared to the advanced method. The last factor was termed as the project level in which the effect of project type on the HMA properties was examined. The threeway ANOVA test was select to examine the possible effects of all these three factors on each pavement property separately.

In addition to examining the permeability characteristic of HMA for the purpose of utilizing it as reliable test method, a comprehensive analysis was performed on the data and results to understand the interactions between the physical and mechanical properties of HMA asphalt pavements. More specifically, the relationship between the permeability of HMA and other important asphalt pavement properties (relative density and IDT) was 
studied in this research to examine the validity of proposing the permeability in addition to the density to improve the reliability of the current $\mathrm{QA} / \mathrm{QC}$ techniques adopted by road authorities. Several conclusions, findings, and recommendations were drawn on the basis of the carried analysis.

\subsection{Conclusions}

According to the conducted research, the following can be concluded:

1) The current quality criteria which depend only on the measurement of the relative densities of finished pavements in the field may not be sufficient to decide on the quality of the finished pavement. The results of this research provided evidence based on laboratory and field measurements pointing to the fact that measurements of lab permeability along with the relative density must be considered and added to the mix design specifications.

2) Based on the results of measuring the IDT of field-recovered cores and SGC specimens, it is quite evident that considering both the permeability and relative density of the designed mix provide a better indication of the actual physical condition of newly constructed HMA road pavements which in turn reflects the expected long-term performance. This result is further validated and supported through several field and laboratory observations of the selected test roads.

3) Laboratory investigations based on SGC specimens showed that there is a strong exponential relationship between the laboratory permeability and the relative density. This finding was further supported and confirmed when the relationship between lab permeability and IDT was constructed. In general, the relationship 
suggests that higher permeability is highly related to both less relative density and less IDT.

4) The relationship between lab permeability and relative density based on the fieldrecovered cores had fair relationship. When relating the lab permeability to IDT, strong relationship was also found.

5) The field permeability exhibited poor relationship to both the relative density. This finding was confirmed when the relationship between the field permeability and IDT was examined since the resulting trend was poor as well. Therefore, it was concluded that other factor(s) might have affected the trend as the variability in field permeability could not be explained by neither the relative density nor the IDT. Since majority of the used data were collected from newly constructed roads, it means that effect of ageing or traffic did not contribute to this poor trend and these factors could be eliminated. The reason might be attributed to the construction method used to build these new road pavements, the existence of construction induced-cracks (hairline cracks perpendicular to the rolling direction of field compactors), the non-uniform or heterogeneous distribution of air voids in the field, the anisotropic nature of water flow in field, or combination of any of these factors. Having some field measurements incorporating these shortages can significantly contribute to produce inconsistency in the overall trend.

6) The field permeability estimated using the NCAT field permeameter exhibited generally fair relationship to the lab permeability using Karol-Warner permeameter. It was concluded also that the field permeability has higher inconsistency and overestimates pavement permeability. This was attributed 
mainly to the multiple flow directions of water in the field, compared to the one dimensional flow of water in the lab.

7) The regression models relating permeability to both relative density and IDT based on SGC specimens were statistically significant with strong $R^{2}$ coefficient. For the field-recovered cores, it was found that majority of the regression models developed to model the lab permeability based on the IDT values were statistically significant compared to models based on relative density. The regression analysis revealed that it is not possible to model the field permeability based laboratory measurements represented by the relative density and IDT.

8) According to the three-way ANOVA test results, it was concluded that in all pavement properties (except for lab permeability due to inapplicability and dataset limitations) there was insignificant three-way interaction effect between the three considered factors. The only statistically significant two-way interaction was between the compaction method and project level. This implies that the effect of the compaction method on field permeability, relative density, or IDT depends significantly on the project level and vice versa. The effect of testing location was significant for the relative density and lab permeability only, while it was insignificant when examining the IDT and the field permeability.

9) There was a significant difference between the two compaction techniques when studying and comparing some of the selected sites where the two compactors were used side-by-side under the same conditions. In terms of both field and lab permeability values, the advanced method provided less permeable sections of HMA asphalt pavement. Also, the advanced method showed higher IDT and 
relative density values as opposed to the current compaction method. All these differences in terms of the four considered pavement properties in this study were statistically significant.

\subsection{Recommendations for Future Studies}

The research scope had several constrains including the type of asphalt mixture as 12.5 $\mathrm{mm}$, pavement mix type as dense-graded HMA, age of the selected site to be as-built and one year old sections, and the incorporated laboratory experiments. It is recommended that further laboratory and field investigations to be planned and performed in order to verify and validate the main findings of this research especially on highway pavements of different design and/or asphalt mixtures. There is a need also to monitor the performance of the selected sites of this study over time. This would provide much more understanding of the effect of age and traffic loads on pavement properties. Subsequently, the main variables contributing to affect the pavement performance negatively can be identified and addressed for further investigations. This research also considered only estimating the permeability using the falling-head test in both field and laboratory. Using different techniques to measure the asphalt permeability (e.g. based on constant-head test) and examining the effect of testing method on the overall mechanical and physical properties can be added to expand the research scope.

Since the permeability of the field-recovered cores had closer trend to the SGC compared to the field permeability measurements, it is therefore suggested that the road authorities could use the SGC specimens to establish the permeability criteria and add them to the mix design specifications, while relaying on the field-recovered cores to test the quality 
of the newly constructed roads against those established criteria. In reality, the accumulated water on HMA surfaces caused by rainfalls will likely flow in one direction. Thereby, the HMA permeability based on laboratory measurements will likely reflect and simulate the actual field condition as opposed to the field permeability measurements using the NCAT. 


\section{List of References}

Abd El Halim, Abd El Halim O., Said Dalia and, Mostafa Abdelzaher. "A Protection of the Environment Through the Prevention of Surface Cracking", The Open Civil Engineering Journal, Vol. 3, 2009, pp. 7-15.

Abd El Halim, Abd El Halim O. and Mostafa Abdelzaher. "Asphalt Multi-Integrated Rollers and Steel Drum Compactors: Evaluating Effect of Compaction on Permeability of Asphalt Pavements", Transportation Research Record: Journal of the Transportation Research Board, Vol. 1967, 2006, pp. 173-180.

Abd El Halim, Abd El Halim O. and G. E. Bauer. "Premature Failure of Asphalt Overlays at Time of Construction", Road Transportation Association of Canada Annual Conference Proceedings, Ottawa, Ontario, 1985, pp. 221-262.

Abd El Halim, Abd El Halim O., Kassim Aly, Hassan Yasser, Goodman Steve, and Lee Warren. "Cold In-Place Recycled Mix: Field and Laboratory Monitoring", Canadian Technical Asphalt Association Conference, Quebec City, November 2012.

Abd El Halim, Abd El Halim O., Pinder F., Chelliah A. Abdelalim O. "Reducing Maintenance and Rehabilitation Costs through the Use of AMIR Compaction", Horizon Research, Vol. 1, No. 3, 2013, pp. 51-60.

Abd El Halim, Abd El Halim O., Haas R. and Svec O. J. "Improved Asphalt Pavement Performance through a New Method of Compaction", ARRB Conference Part 3, Melbourne: Australian Road Research Board, 1994, pp. 175-191.

Abd El-Halim, Abd El-Halim O. and Herman Scott C. "Influence of Relative Rigidity on the Problem on Reflection Cracking", Transportation Research Record, Vol. 1007, 1985, pp. 53-58.

Allen, David L., Schultz David B., and Fleckenstein L. John. "Development and Proposed Implementation of a Field Permeability Test for Asphalt Concrete. Kentucky", Kentucky Transportation Center, 2003.

ASTM. ASTM D2726 / D2726M-14. "Standard Test Method for Bulk Specific Gravity and Density of Non-Absorptive Compacted Bituminous Mixtures", West Conshohocken, PA: ASTM International, 2014, www.astm.org.

ASTM D6931-12 (2012). "Standard Test Method for Indirect Tensile (IDT) Strength of Bituminous Mixtures", American Society for Testing and Materials Standards, West Conshohocken, Pennsylvania, USA, 2012.

Bhasin, Amit, Masad Eyad, Lytton Robert, and Little Dallas. "Development of a Database for Surface Energy of Aggregates and Asphalt Binders", Texas Transportation Institute, Austin, Texas: Texas Department of Transportation, 2009. 
BOMAG Fayat Group. "Basic Principles of Asphalt Compaction: Compaction Methods Compaction Equipment Rolling Technique", Germany: BOMAG GmbH, Hellerwald, D56154 Boppard, 2009, http:/www.bomag.com/world/media/pdf/PRE109016_0901.pdf

Brandon, James M., Jared David M., Wu Peter Y., and Geary Georgene M. "Field and Laboratory Investigation of Permeable Asphalt Mixes on Georgia Highways", Transportation Research Record: Journal of the Transportation Research Board, Vol. 1891, 2004, pp. 32-39.

Brown, Ray, Hainin M., Cooley Allen, Hurley Garham. "Relationship of Air Voids, Lift Thickness, and Permeability in Hot Mix Asphalt Pavements", Washington, DC: Transportation Research Board, 2004.

Crouch, L. K., Badoe Daniel A., Cates Mark, Borden T. Adam, Copeland Audrey R., C. Todd walker, Dunn Tim, Maxwell Richard A., Goodwin W. A. "Bulk Specific Gravity of Compacted Bituminous Mixtures: Finding A More Widely Applicable Method", Tennessee Technological University, 2003.

Caro, Silvia, Masad Eyad, Bhasin Amit, and Little Dallas. "Coupled Micromechanical Model of Moisture-Induced Damage in Asphalt Mixtures", Journal of Materials in Civil Engineering, Vol. 22, No. 4, 2010, pp. 380-388.

Çelik, ON. "Air Permeability of Asphalt Concrete Made with Shredded-Tire RubberModified Binders and its Relationship with Porosity", Journal of Testing and Evaluation Vol. 33, No. 4, 2005 pp. 217-221.

Chen, Can, Williams R. C., Ahmed Taha, and Schram Scott. "Quality control/quality assurance testing for longitudinal joint density and segregation of asphalt mixtures", Construction and Building Materials, Vol. 47, 2013, pp. 80-85.

Chen, Jian-Shiuh, Lin Kuei-Yi and Young Sian-Yun. "Effects of Crack Width and Permeability on Moisture-Induced Damage of Pavements", Journal of Materials in Civil Engineering, Vol. 16, No. 3, 2004, pp. 276-282.

Choubane, Bouzid, Page Gale and Musselman James. "Investigation of Water Permeability of Coarse Graded Superpave Pavements", Journal of the Association of Asphalt Paving Technologists, Vol. 67, 1998, pp. 254-276.

Christison, T. J. "The Response of Asphalt Concrete Pavements to Low Temperature", PhD Dissertation, University of Alberta, Edmonton, Canada, 1972.

Cooley, Allen and Brown Ray. "Selection and Evaluation of Field Permeability Device for Asphalt", Transportation Research Record: Journal of the Transportation Research Board, Vol. 1723, 2007, pp. 73-82.

Cooley, Allen. "Permeability of Superpave Mixtures: Evaluation of Field Permeameters", Auburn University, Alabama: National Center for Asphalt Technology, 1999. 
Cooley, Allen, Prowell Brian and Brown Ray. "Issues Pertaining to the Permeability Characteristics of Coarse-Graded Superpave Mixes", Report No. 02-06, National Center for Asphalt Technology (NCAT), 2002.

Cooley, Allen, Prowell Brian, Hainin Mohd and Buchanan M. "Bulk Specific Gravity Round-Robin Using the Corelok Vacuum Sealing Device", Report No. 02-11, National Center for Asphalt Technology (NCAT), 2002.

Cooley, Allen, Brown Ray and Saeed Maghsoodloo. "Developing Critical Field Permeability and Pavement Density Values for Coarse-Graded Superpave Pavements", Transportation Research Record, Vol. 1761, No. 1, 2001, pp. 41-49.

Cross, Stephen A. and Bhusal Sushanta. "Longitudinal Joint Density and Permeability in Asphalt Concrete", Oklahoma State University, Oklahoma City, 2009.

Darcy, Henry. "Les Fontaines Publiques De La Ville De Dijon", Paris: Ghent University, 1856.

Florida Department of Transportation. "Bulk Specific Gravity of Compacted Hot Mix Asphalt (HMA) Specimens", 2014.

Florida Test Method. "Florida Method of Test for Measurement of Water Permeability of Compacted Asphalt Paving Mixtures", Tallahassee: Florida Department of Transportation, 1997.

Garber, Nicholas J. and Hoel Lester A. "Traffic and Highway Engineering", Fifth Edition, Stamford: Cengage Learning, 2014.

Geller, Myron. "Compaction equipment for asphalt mixtures: Placement and Compaction of Asphalt Mixtures", Edited by F. T. Wagner, ASTM STP, 1984, pp. 28-47.

Government of Canada. "Road Transportation: Overview of Road Transportation", 2012, retrieved on March, 15 ${ }^{\text {th }}$ 2015, http://www.tc.gc.ca/eng/policy/anre-menu-3021.htm

Hall, Kevin. "Comparison of Falling-Head and Constant-Head Techniques: Estimating Field Permeability of Hot-Mix Asphalt Pavements", Transportation Research Record: Journal of the Transportation Research Board, Vol. 1891, No. 1, 2004, pp. 23-31.

Hammoud, Adnan M. "Top-Down Cracking of Asphalt Pavements: Causes, Mechanisms, and Remedies", M.A.Sc. Thesis, Carleton University. Ottawa, March, 2010a.

Hammoud, Adnan M. and Abd El Halim, Abd El Halim O. "Influence of top-down cracks of asphalt layer on environmental performance of roads", ISAP Conference, Japan, 2010b.

Harris, Christopher. "Hot Mix Asphalt Permeability: Tester Size Effects and Anisotropy”, M.A.Sc. Virginia Polytechnic Institute and State University, Blacksburg, Virginia, 2007. 
Huerne, Hendrikus Lodewikus ter. "Compaction of asphalt road pavements: using finite elements and critical state theory", $\mathrm{PhD}$ Thesis, University of Twente, Enschede, Netherlands, 2004.

Instrotek ${ }^{\circledR}$. “Inc. CoreLok ${ }^{\circledR}$ Operator’s Guid”, Raleigh, North Carolina, 2011.

Kentucky Method 64-449-05. "Determining the Permeability of In-Place Hot-Mix Asphalt (HMA)", 2004.

Kim, Yong-Rak, Little Dallas and Lytton Robert. "Effect of Moisture Damage on Material Properties and Fatigue Resistance of Asphalt Mixtures", Transportation Research Record: Journal of the Transportation Research Board, Vol. 1891, 2004, pp. 4854.

Lancellotta, Renato. "Geotechnical Engineering", Second Edition, CRC Press, 2008.

Li, Hui, Kayhanian Masoud and Harvey John. "Comparative field permeability measurement of permeable pavements using ASTM C1701 and NCAT permeameter methods", Journal of Environmental Management, Vol. 118, 2013, pp. 144-152.

Mallick, Rajib B., Cooley Allen L., Teto Matthew R., Bradbury Richard L., and Peabody Dale. "An Evaluation of Factors Affecting Permeability of Superpave Designed Pavements", Report No. Report 03-02, Auburn: National Center for Asphalt Technology (NCAT), 2003.

Maupin, G. W. "Asphalt Permeability Testing in Virginia", Transportation Research Record: Journal of the Transportation Research Board, Vol. 1723, No. 1, 2000a, pp. 8391.

Maupin, G. W. "Investigation of Test Methods, Pavements, and Laboratory Design Related To Asphalt Permeability", Charlottesville, Virginia: Virginia Transportation Research Council, 2000b.

McLaughlin, J. F., and Goetz H. W. "Permeability, Void Content, and Durability of Bituminous Concrete", Highway Research Board Proceedings, 1955, pp. 274-286.

Mogawer, Walaa S., Mallick Rajib B., Teto Matthew R., and Crockford W. C. "Evaluation of Permeability of Superpave Mixes", The New England Transportation Consortium, 2002.

Mohammad, Louay, Ananda Herath and Huang Baoshan. "Evaluation of Permeability of Superpave ${ }^{\circledR}$ Asphalt Mixtures", Transportation Research Record: Journal of the Transportation Research Board, Vol. 1832, 2003, pp. 50-58.

Mostafa, Abdelzaher. "The Stripping Susceptibility of Airfield Asphalt Mixes: The Development of Guidelines for a Laboratory Test Method", PhD. Thesis, Carleton University, Ottawa, February, 2005. 
MTO. "Ontario Provincial Standards for Roads and Public Works", 2002, Ministry of Transportation Ontario, retrieved on October, $13^{\text {th }} 2014$.

MTO. "Ontario's Transportation Technology Transfer Digest - Road Talk", 2004, retrieved on January, $15^{\text {th }} 2015$, http://www.mto.gov.on.ca/english/transtek/roadtalk/rt103/rt10-3.pdf

Neal, Brett. "13 Pavement Defects and Failures You Should Know!", 2014, retrieved on October, $9^{\text {th }} 2014$.

http://www.pavemanpro.com/article/identifying asphalt pavement defects

OHMPA Asphalt Fact Sheet. "Why asphalt is the better way to pave", Mississauga, Ontario, Hot Mix Producers Association, 2012, retrieved on March, $17^{\text {th }}$ 2015, http://www.ohmpa.org/files/Publications/OHMPA\%20Asphalt\%20Fact\%20Sheet.pdf

Owusu-Ababio, Sam and Robert Schmitt. "A Framework for Performance-Based Permeability and Density Acceptance Criteria for HMA Pavements in Wisconsin", MidContinent Transportation Research Symposium, 2009.

Pang, Chuan Qin. "Research on the Moisture Damage Occurred on the Asphalt Pavement", Applied Mechanics and Materials, Vols. 178-181, 2012, pp. 1117-1124.

Pavement Interactive. "HMA Mix Design Fundamentals", 2009, retrieved on October, $10^{\text {th }} 2014$, http://www.pavementinteractive.org/article/hma-mix-design-fundamentals

Pavement Interactive. "HMA Mix Types", 2010, retrieved on March, 17 $7^{\text {th }} 2015$, http://www.pavementinteractive.org/article/pavement-typesmix-types

Pavement Interactive. "Bulk Specific Gravity", 2011, retrieved on October, $12^{\text {th }} 2014$, http://www.pavementinteractive.org/article/bulk-specific-gravity

Retzer, Neal. "Permeability Research with the ROMUS Air Permeameter", Report No. CDOT-2008-5, Colorado Department of Transportation, 2008.

Roberts, Freddy L., Kandhal Prithvi S., Brown Ray E., Lee Dah-Yinn, and Kennedy Thomas W. "Hot Mix Asphalt Materials, Mixture Design, and Construction", Second Edition, Lanham: NAPA Educational Foundation, 1996.

Rollings, Raymoud, and Rollings Marian. "Pavement Failures: Oversights, Omissions and Wishful Thinking", Journal of Performance of Constructed Facilities, Vol. 5 No. 4, 1991Russell, Jeffrey, Bahia Hussain and Kanitpong Kunnawee. "Effect of Pavement Thickness on Superpave Mix Permeability and Density", Report No. WHRP 05-05, University of Wisconsin-Platteville, 2005. 
Tarefder, Rafiqul and Ahmad Mohiuddin. "Evaluating the Relationship between Permeability and Moisture Damage of Asphalt Concrete Pavements", Journal of Materials in Civil Engineering, Vol. 27 No. 5, 2014.

Umiliaco, Andrea and Benedetto Andrea. "Aggregate Size Distribution and Hydraulic Permeability of HMA: A Full Simulation Study", Airfield and Highway Pavement Sustainable and Efficient Pavements (C) ASCE, 2013, pp. 1134-1144.

Vardanega, P. J. "State of the Art: Permeability of Asphalt Concrete", Journal of Materials in Civil Engineering, Vol. 26 No. 1, 2014, pp. 54-64.

Vivar, Eliana del Pilar and Haddock John. "HMA Pavement Performance and Durability", Report No. FHWA/IN/JTRP-2005/14, Indiana Department of Transportation and the Federal Highway Administration, 2006.

Williams, R. "Early Permeability Test for Asphalt Acceptance", Report No.: OR09-017, Missouri Department of Transportation, 2009.

Williams, Stacy G. A. "Comprehensive Study of Field Permeability Using the Vacuum Permeameter", University of Arkansas, Fayetteville, 2006.

Woodbury, George. "Introduction to Statistics", First Edition, Cengage Learning, 2001.

Zaniewski, John and Yu Yan. "Hot Mix Asphalt Concrete Density, Bulk Specific Gravity, and Permeability", Morgantown, West Virginia: Department of Civil and Environmental Engineering, 2013.

Zube, Ernest. "Compaction Studies of Asphalt Concrete Pavement as Related to the Water Permeability Test", 41st Annual Meeting of the Highway Research Board. Washington, DC, 1962, pp. 12-37. 


\section{Appendices}

\section{Appendix A : ANOVA and $t$-test Results}

\section{A.1 Relative Density}

Tests of Between-Subjects Effects [ Three-Way ANOVA ]

Dependent Variable: Relative Density

\begin{tabular}{|l|r|r|r|r|r|}
\hline Source & $\begin{array}{c}\text { Type III Sum of } \\
\text { Squares }\end{array}$ & df & Mean Square & F & Sig. \\
\hline Corrected Model & $370.598^{\mathrm{a}}$ & 50 & 7.412 & 6.676 & .000 \\
Intercept & 743780.116 & 1 & 743780.116 & 669926.310 & .000 \\
Loc_L & 16.305 & 4 & 4.076 & 3.672 & .009 \\
Roller & 34.227 & 1 & 34.227 & 30.828 & .000 \\
Prj & 256.348 & 7 & 36.621 & 32.985 & .000 \\
Loc_L* Roller & 6.115 & 4 & 1.529 & 1.377 & .252 \\
Loc_L*Pj & 44.606 & 26 & 1.716 & 1.545 & .080 \\
Roller * Prj & 13.572 & 2 & 6.786 & 6.112 & .004 \\
Loc_L * Roller * Prj & 8.296 & 6 & 1.383 & 1.245 & .295 \\
Error & 73.276 & 66 & 1.110 & & \\
Total & 1007593.041 & 117 & & & \\
Corrected Total & 443.874 & 116 & & & \\
\hline
\end{tabular}

a. $\mathrm{R}$ Squared $=.835$ (Adjusted R Squared $=.710$ )

\section{A.2 IDT}

Tests of Between-Subjects Effects [ Three-Way ANOVA ]

Dependent Variable: Strength

\begin{tabular}{|l|r|r|r|r|r|}
\hline Source & $\begin{array}{r}\text { Type III Sum of } \\
\text { Squares }\end{array}$ & df & Mean Square & F & Sig. \\
\hline Corrected Model & $2341120.912^{a}$ & 50 & 46822.418 & 8.582 & .000 \\
Intercept & 18060752.913 & 1 & 18060752.913 & 3310.299 & .000 \\
Loc_L & 46040.320 & 4 & 11510.080 & 2.110 & .090 \\
Roller & 58468.195 & 1 & 58468.195 & 10.716 & .002 \\
Prj & 1639539.641 & 7 & 234219.949 & 42.929 & .000 \\
Loc_L * Roller & 34879.006 & 4 & 8719.752 & 1.598 & .186 \\
Loc_L * Prj & 187681.492 & 26 & 7218.519 & 1.323 & .183 \\
Roller *Prj & 35866.084 & 2 & 17933.042 & 3.287 & .044 \\
Loc_L * Roller *Prj & 28372.220 & 6 & 4728.703 & .867 & .524 \\
Error & 343723.412 & 63 & 5455.927 & & \\
Total & 25615052.678 & 114 & & & \\
Corrected Total & 2684844.324 & 113 & & & \\
\hline
\end{tabular}

a. $\mathrm{R}$ Squared $=.872$ (Adjusted R Squared $=.770)$ 
Strength

One-Way ANOVA

\begin{tabular}{|c|c|c|c|c|c|c|}
\hline Project & & Sum of Squares & df & Mean Square & $\mathrm{F}$ & Sig. \\
\hline \multirow{4}{*}{ Greenbelt (ii) } & Between Groups & 125046.443 & 1 & 125046.443 & 18.436 & .001 \\
\hline & Within Groups & 108523.169 & 16 & 6782.698 & & \\
\hline & Total & 233569.611 & 17 & & & \\
\hline & Between Groups & 104.150 & 1 & 104.150 & .125 & .728 \\
\hline \multirow[t]{3}{*}{ Hwy 28} & Within Groups & 15052.357 & 18 & 836.242 & & \\
\hline & Total & 15156.507 & 19 & & & \\
\hline & Between Groups & 296.045 & 1 & 296.045 & .041 & .844 \\
\hline \multirow[t]{3}{*}{ Thousand Islands Parkway } & Within Groups & 57372.795 & 8 & 7171.599 & & \\
\hline & Total & 57668.840 & 9 & & & \\
\hline & Between Groups & 35823.034 & 1 & 35823.034 & 14.439 & .001 \\
\hline \multirow[t]{2}{*}{ Tomlinson } & Within Groups & 44658.855 & 18 & 2481.048 & & \\
\hline & Total & 80481.889 & 19 & & & \\
\hline
\end{tabular}

\section{A.3 Field Permeability}

Tests of Between-Subjects Effects [ Three-Way ANOVA ]

Dependent Variable: Field Permeability

\begin{tabular}{|l|r|r|r|r|r|}
\hline Source & $\begin{array}{c}\text { Type III Sum of } \\
\text { Squares }\end{array}$ & df & Mean Square & F & Sig. \\
\hline Corrected Model & $2156402.275^{a}$ & 51 & 42282.398 & 3.422 & .000 \\
Intercept & 710148.521 & 1 & 710148.521 & 57.477 & .000 \\
Loc_f & 51939.185 & 4 & 12984.796 & 1.051 & .384 \\
Roller & 155328.724 & 1 & 155328.724 & 12.572 & .001 \\
Prj & 828761.637 & 10 & 82876.164 & 6.708 & .000 \\
Loc_f* Roller & 2499.439 & 2 & 1249.719 & .101 & .904 \\
Loc_f Prj & 401814.454 & 27 & 14882.017 & 1.204 & .244 \\
Roller * Prj & 124060.008 & 3 & 41353.336 & 3.347 & .021 \\
Loc_f * Roller * Prj & 18973.066 & 4 & 4743.266 & .384 & .820 \\
Error & 1544428.296 & 125 & 12355.426 & & \\
Total & 5365876.330 & 177 & & & \\
Corrected Total & 3700830.572 & 176 & & & \\
\hline
\end{tabular}

a. $\mathrm{R}$ Squared $=.583$ (Adjusted R Squared $=.412$ ) 
Field Permeability

ANOVA

\begin{tabular}{|c|c|c|c|c|c|c|c|}
\hline Project & Time & & Sum of Squares & $\mathrm{df}$ & Mean Square & $\mathrm{F}$ & Sig. \\
\hline \multirow[t]{6}{*}{ Hwy 28} & \multirow[t]{3}{*}{ New } & Between Groups & 88872.872 & 1 & 88872.872 & \multirow[t]{3}{*}{7.140} & \multirow[t]{3}{*}{.016} \\
\hline & & Within Groups & 224047.558 & 18 & 12447.087 & & \\
\hline & & Total & 312920.430 & 19 & & & \\
\hline & \multirow[t]{3}{*}{ Old } & Between Groups & 779.200 & 1 & 779.200 & \multirow[t]{3}{*}{.240} & \multirow[t]{3}{*}{.628} \\
\hline & & Within Groups & 90881.102 & 28 & 3245.754 & & \\
\hline & & Total & 91660.302 & 29 & & & \\
\hline \multirow[t]{3}{*}{ Hwy 34} & \multirow[t]{3}{*}{ New } & Between Groups & 337420.803 & 1 & 337420.803 & \multirow[t]{3}{*}{32.872} & \multirow[t]{3}{*}{.000} \\
\hline & & Within Groups & 112912.345 & 11 & 10264.759 & & \\
\hline & & Total & 450333.148 & 12 & & & \\
\hline \multirow[t]{6}{*}{ Thousand Islands Parkway } & \multirow[t]{3}{*}{ New } & Between Groups & 17.719 & 1 & 17.719 & \multirow[t]{3}{*}{.020} & \multirow[t]{3}{*}{.890} \\
\hline & & Within Groups & 10716.727 & 12 & 893.061 & & \\
\hline & & Total & 10734.446 & 13 & & & \\
\hline & \multirow[t]{3}{*}{ Old } & Between Groups & 27.817 & 1 & 27.817 & \multirow[t]{3}{*}{.223} & \multirow[t]{3}{*}{.643} \\
\hline & & Within Groups & 2118.086 & 17 & 124.593 & & \\
\hline & & Total & 2145.904 & 18 & & & \\
\hline \multirow[t]{6}{*}{ Tomlinson } & \multirow[t]{3}{*}{ New } & Between Groups & 60282.469 & 1 & 60282.469 & \multirow[t]{3}{*}{8.145} & \multirow[t]{3}{*}{.015} \\
\hline & & Within Groups & 88812.782 & 12 & 7401.065 & & \\
\hline & & Total & 149095.251 & 13 & & & \\
\hline & \multirow[t]{3}{*}{ Old } & Between Groups & 29972.275 & 1 & 29972.275 & \multirow[t]{3}{*}{12.398} & \multirow[t]{3}{*}{.004} \\
\hline & & Within Groups & 31426.835 & 13 & 2417.449 & & \\
\hline & & Total & 61399.111 & 14 & & & \\
\hline
\end{tabular}

Field Permeability (effect of time)

\begin{tabular}{|c|c|c|c|c|c|c|c|}
\hline \multirow{2}{*}{$\frac{\text { Project }}{\text { Hwy } 28}$} & \multicolumn{2}{|c|}{ Compaction Method } & \multirow{2}{*}{$\begin{array}{r}\text { Sum of Squares } \\
652.386\end{array}$} & $\mathrm{df}$ & Mean Square & $\mathrm{F}$ & \multirow{2}{*}{$\frac{\text { Sig. }}{.603}$} \\
\hline & Advanced & Between Groups & & 1 & 652.386 & .277 & \\
\hline & & Within Groups & 56511.699 & 24 & 2354.654 & & \\
\hline & & Total & 57164.085 & 25 & & & \\
\hline & Conventional & Between Groups & 103810.599 & 1 & 103810.599 & 8.838 & .007 \\
\hline & & Within Groups & 258416.962 & 22 & 11746.226 & & \\
\hline & & Total & 362227.561 & 23 & & & \\
\hline \multirow{6}{*}{$\begin{array}{l}\text { Thousand } \\
\text { Islands } \\
\text { Parkway }\end{array}$} & Advanced & Between Groups & 1541.740 & 1 & 1541.740 & 3.822 & .069 \\
\hline & & Within Groups & 6051.075 & 15 & 403.405 & & \\
\hline & & Total & 7592.815 & 16 & & & \\
\hline & Conventional & Between Groups & 1447.994 & 1 & 1447.994 & 2.988 & .106 \\
\hline & & Within Groups & 6783.738 & 14 & 484.553 & & \\
\hline & & Total & 8231.733 & 15 & & & \\
\hline \multirow[t]{6}{*}{ Tomlinson } & Advanced & Between Groups & 4.082 & 1 & 4.082 & .103 & .753 \\
\hline & & Within Groups & 473.408 & 12 & 39.451 & & \\
\hline & & Total & 477.491 & 13 & & & \\
\hline & Conventional & Between Groups & 6141.108 & 1 & 6141.108 & .667 & .429 \\
\hline & & Within Groups & 119766.209 & 13 & 9212.785 & & \\
\hline & & Total & 125907.318 & 14 & & & \\
\hline
\end{tabular}




\section{A.4 Lab Permeability}

Tests of Between-Subjects Effects [ Three-Way ANOVA ]

Dependent Variable: Lab Permeability

\begin{tabular}{|l|r|r|r|r|r|}
\hline Source & $\begin{array}{r}\text { Type III Sum of } \\
\text { Squares }\end{array}$ & df & Mean Square & \multicolumn{1}{|c|}{ F } & Sig. \\
\hline Corrected Model & $6337181.841^{a}$ & 34 & 186387.701 & 5.407 & .000 \\
Intercept & 596407.613 & 1 & 596407.613 & 17.300 & .000 \\
Loc_L & 369478.160 & 4 & 92369.540 & 2.679 & .042 \\
Roller & 1437485.285 & 1 & 1437485.285 & 41.697 & .000 \\
Prj & 2171355.105 & 5 & 434271.021 & 12.597 & .000 \\
Loc_L* Roller & 1235980.587 & 4 & 308995.147 & 8.963 & .000 \\
Loc_L Prj & 2078717.226 & 20 & 103935.861 & 3.015 & .001 \\
Roller * Prj & .000 & 0 & &. &. \\
Loc_L* Roller * Prj & 1758206.534 & 0 & &. &. \\
Error & 9057694.422 & 86 & 34474.638 & &. \\
Total & 8095388.375 & 85 & & & \\
Corrected Total & & & & \\
\hline
\end{tabular}

a. $\mathrm{R}$ Squared $=.783$ (Adjusted $\mathrm{R}$ Squared $=.638$ ) 


\section{A.5 Lab vs. Field Permeability}

\begin{tabular}{|c|c|c|c|c|c|c|c|c|c|}
\hline & \multirow{2}{*}{\multicolumn{2}{|c|}{$\begin{array}{l}\text { Levene's Test for } \\
\text { Equality of Variances }\end{array}$}} & & & & & & & \\
\hline \multirow[t]{3}{*}{ All Sites } & & & \multicolumn{7}{|c|}{ t-test for Equality of Means } \\
\hline & \multirow[t]{2}{*}{$\mathrm{F}$} & \multirow[t]{2}{*}{ Sig. } & \multirow[t]{2}{*}{$t$} & \multirow[t]{2}{*}{$\mathrm{df}$} & \multirow[t]{2}{*}{ Sig. (2-tailed) } & \multirow[t]{2}{*}{$\begin{array}{c}\text { Mean } \\
\text { Difference }\end{array}$} & \multirow[t]{2}{*}{$\begin{array}{l}\text { Std. Error } \\
\text { Difference }\end{array}$} & \multicolumn{2}{|c|}{$\begin{array}{l}95 \% \text { Confidence Interval } \\
\text { of the Difference }\end{array}$} \\
\hline & & & & & & & & Lower & Upper \\
\hline Equal variances assumed & 19.766 & .000 & 5.781 & 105 & .000 & 71.31651 & 12.33626 & 46.85599 & 95.77703 \\
\hline Equal variances not assumed & & & 5.863 & 87.276 & .000 & 71.31651 & 12.16279 & 47.14272 & 95.49030 \\
\hline
\end{tabular}

\begin{tabular}{|c|c|c|c|c|c|c|c|c|c|}
\hline & & & epende & it Samp & es Test & & & & \\
\hline \multirow[t]{3}{*}{ Highway 16} & \multicolumn{2}{|c|}{$\begin{array}{c}\text { Levene's Test for } \\
\text { Equality of Variances }\end{array}$} & \multicolumn{7}{|c|}{ t-test for Equality of Means } \\
\hline & \multirow[t]{2}{*}{$\mathrm{F}$} & \multirow[t]{2}{*}{ Sig. } & \multirow[t]{2}{*}{$\mathrm{t}$} & \multirow[t]{2}{*}{ df } & \multirow[t]{2}{*}{ Sig. (2-tailed) } & \multirow[t]{2}{*}{$\begin{array}{c}\text { Mean } \\
\text { Difference }\end{array}$} & \multirow[t]{2}{*}{$\begin{array}{l}\text { Std. Error } \\
\text { Difference }\end{array}$} & \multicolumn{2}{|c|}{$\begin{array}{l}\text { 95\% Confidence Interval of } \\
\text { the Difference }\end{array}$} \\
\hline & & & & & & & & Lower & Upper \\
\hline Equal variances assumed & 1.379 & .251 & 2.692 & 27 & .012 & 72.76738 & 27.02829 & 17.30991 & 128.22485 \\
\hline Equal variances not assumed & & & 2.666 & 24.190 & .013 & 72.76738 & 27.29251 & 16.46178 & 129.07298 \\
\hline
\end{tabular}

\begin{tabular}{|c|c|c|c|c|c|c|c|c|c|}
\hline \multirow{2}{*}{ Highway 17} & \multicolumn{7}{|c|}{ Independent Samples Test } & & \\
\hline & $\mathrm{F}$ & Sig. & $t$ & df & Sig. (2-tailed) & $\begin{array}{c}\text { Mean } \\
\text { Difference }\end{array}$ & $\begin{array}{l}\text { Std. Error } \\
\text { Difference }\end{array}$ & \multicolumn{2}{|c|}{$\begin{array}{c}\text { 95\% Confidence Interval of } \\
\text { the Difference }\end{array}$} \\
\hline Equal variances assumed & 5.457 & .028 & 5.254 & 25 & .000 & 95.02615 & 18.08803 & 57.77315 & 132.27915 \\
\hline Equal variances not assumed & & & 5.329 & 22.927 & .000 & 95.02615 & 17.83028 & 58.13491 & 131.91740 \\
\hline
\end{tabular}


Independent Samples Test

\begin{tabular}{|c|c|c|c|c|c|c|c|c|c|}
\hline \multirow[t]{3}{*}{ Highway 417} & \multicolumn{2}{|c|}{$\begin{array}{l}\text { Levene's Test for } \\
\text { Equality of Variances }\end{array}$} & \multicolumn{7}{|c|}{ t-test for Equality of Means } \\
\hline & \multirow[t]{2}{*}{$\mathrm{F}$} & \multirow[t]{2}{*}{ Sig. } & \multirow[t]{2}{*}{$\mathrm{t}$} & \multirow[t]{2}{*}{ df } & \multirow[t]{2}{*}{ Sig. (2-tailed) } & \multirow[t]{2}{*}{$\begin{array}{c}\text { Mean } \\
\text { Difference }\end{array}$} & \multirow[t]{2}{*}{$\begin{array}{l}\text { Std. Error } \\
\text { Difference }\end{array}$} & \multicolumn{2}{|c|}{$\begin{array}{l}95 \% \text { Confidence Interval of } \\
\text { the Difference }\end{array}$} \\
\hline & & & & & & & & Lower & Upper \\
\hline Equal variances not assumed & & & 2.205 & 13.279 & .046 & 34.11643 & 15.47025 & .76611 & 67.46675 \\
\hline
\end{tabular}

Independent Samples Test

\begin{tabular}{|c|c|c|c|c|c|c|c|c|c|}
\hline \multirow[t]{2}{*}{ Greenbelt (i) } & \multicolumn{2}{|c|}{$\begin{array}{l}\text { Levene's Test for } \\
\text { Equality of Variances }\end{array}$} & \multicolumn{7}{|c|}{ t-test for Equality of Means } \\
\hline & $\mathrm{F}$ & Sig. & $\mathrm{t}$ & df & Sig. (2-tailed) & $\begin{array}{c}\text { Mean } \\
\text { Difference }\end{array}$ & $\begin{array}{l}\text { Std. Error } \\
\text { Difference }\end{array}$ & Lower & Upper \\
\hline
\end{tabular}

Independent Samples Test

\begin{tabular}{|c|c|c|c|c|c|c|c|c|c|}
\hline Highway 34 & \multicolumn{2}{|c|}{$\begin{array}{l}\text { Levene's Test for } \\
\text { Equality of Variances }\end{array}$} & \multicolumn{7}{|c|}{ t-test for Equality of Means } \\
\hline$K$ Equal variances assumed & 1.819 & .207 & 2.693 & 10 & .023 & 116.48500 & 43.25590 & 20.10485 & 212.86515 \\
\hline${ }^{\mathrm{K}}$ Equal variances not assumed & & & 2.693 & 7.668 & .028 & 116.48500 & 43.25590 & 15.98033 & 216.98967 \\
\hline
\end{tabular}




\section{A.6 Comparison between the Two Compaction Methods}

ANOVA

Field Permeability

\begin{tabular}{|l|r|r|r|r|r|}
\hline & Sum of Squares & \multicolumn{1}{|c|}{ df } & Mean Square & F & Sig. \\
\hline Between Groups & 305228.161 & 1 & 305228.161 & 17.752 & .000 \\
Within Groups & 1599059.463 & 93 & 17194.188 & & \\
Total & 1904287.624 & 94 & & & \\
\hline
\end{tabular}

ANOVA

\begin{tabular}{|ll|r|r|r|r|r|}
\hline & & Sum of Squares & df & Mean Square & F & Sig. \\
\hline Relative Density & Between Groups & 47.295 & 1 & 47.295 & 8.675 & .004 \\
& Within Groups & 359.814 & 66 & 5.452 & & \\
Strength & Total & 407.109 & 67 & & \\
& Between Groups & 84326.362 & 1 & 84326.362 & 4.311 & .042 \\
& Within Groups & 1291086.615 & 66 & 19561.918 & & \\
& Total & 1375412.977 & 67 & & & \\
\hline
\end{tabular}

Test of Homogeneity of Variances

\begin{tabular}{|c|c|c|c|}
\hline Levene Statistic & $\mathrm{df1}$ & $\mathrm{df} 2$ & Sig. \\
\hline 7.941 & 1 & 84 & .006 \\
\hline
\end{tabular}

\section{ANOVA}

Lab Permeability

\begin{tabular}{|l|r|r|r|r|r|}
\hline & Sum of Squares & df & Mean Square & \multicolumn{1}{|c|}{ F } & Sig. \\
\hline Between Groups & 265299.009 & 1 & 265299.009 & 2.846 & .095 \\
Within Groups & 7830089.365 & 84 & 93215.350 & & \\
Total & 8095388.375 & 85 & & & \\
\hline
\end{tabular}

\section{Robust Tests of Equality of Means}

Lab Permeability

\begin{tabular}{|l|r|r|r|r|}
\hline & Statistic $^{a}$ & df1 & df2 & Sig. \\
\hline Welch & 4.253 & & 55.907 & .044 \\
\hline
\end{tabular}

a. Asymptotically F distributed. 


\section{Appendix B : Regression Analysis}

\section{B.1 Field vs. Lab}

Model Summary and Parameter Estimates

Dependent Variable: Lab Permeability

\begin{tabular}{|l|r|r|r|r|r|r|r|}
\hline \multirow{2}{*}{ Equation } & \multicolumn{4}{|c|}{ Model Summary } & \multicolumn{2}{c|}{ Parameter Estimates } \\
\cline { 2 - 8 } & R Square & F & df1 & \multicolumn{1}{c|}{ df2 } & Sig. & Constant & b1 \\
\hline Linear & .417 & 35.829 & 1 & 50 & .000 & -8.266 & .444 \\
\hline
\end{tabular}

The independent variable is Field Permeability .

\section{B.2 Relative Density-IDT}

\section{SGC Specimens}

Model Summary and Parameter Estimates

Dependent Variable: Strength

\begin{tabular}{|c|c|c|c|c|c|c|c|c|}
\hline \multirow[t]{2}{*}{ Site } & \multirow[t]{2}{*}{ Equation } & \multicolumn{5}{|c|}{ Model Summary } & \multicolumn{2}{|c|}{$\begin{array}{l}\text { Parameter } \\
\text { Estimates }\end{array}$} \\
\hline & & R Square & $\mathrm{F}$ & df1 & $\mathrm{df} 2$ & Sig. & Constant & b1 \\
\hline Hwy 15 Mix & Exponential & .968 & 150.886 & 1 & 5 & .000 & .075 & .099 \\
\hline Hwy 16 Mix & Exponential & .976 & 199.239 & 1 & 5 & .000 & .003 & .132 \\
\hline Highway 17 Mix & Exponential & .989 & 465.135 & 1 & 5 & .000 & .014 & .113 \\
\hline Hwy 417 Mix & Exponential & .964 & 269.709 & 1 & 10 & .000 & .001 & .144 \\
\hline
\end{tabular}

The independent variable is Relative Density.

Model Summary and Parameter Estimates

Dependent Variable: Strength

\begin{tabular}{|l|r|r|r|r|r|r|r|}
\hline \multirow{2}{*}{ Equation } & \multicolumn{4}{|c|}{ Model Summary } & \multicolumn{2}{c|}{ Parameter Estimates } \\
\cline { 2 - 8 } & R Square & F & df1 & df2 & Sig. & Constant & b1 \\
\hline Exponential & .855 & 182.290 & 1 & 31 & .000 & .008 & .123 \\
\hline
\end{tabular}

The independent variable is Relative Density. 


\section{Field-Recovered Cores}

Model Summary and Parameter Estimates

Dependent Variable: Strength

\begin{tabular}{|c|c|c|c|c|c|c|c|c|c|}
\hline \multirow[t]{2}{*}{$\begin{array}{l}\text { Compaciton } \\
\text { Method }\end{array}$} & \multirow[t]{2}{*}{ Site } & \multirow[t]{2}{*}{ Equation } & \multicolumn{5}{|c|}{ Model Summary } & \multicolumn{2}{|c|}{$\begin{array}{l}\text { Parameter } \\
\text { Estimates }\end{array}$} \\
\hline & & & $\begin{array}{c}\mathrm{R} \\
\text { Square } \\
\end{array}$ & $\mathrm{F}$ & df1 & $\mathrm{df} 2$ & Sig. & Constant & b1 \\
\hline \multicolumn{10}{|l|}{ Advanced } \\
\hline & Hwy 28 & Exponential & .734 & 22.096 & 1 & 8 & .002 & .074 & .084 \\
\hline & Greenbelt (ii) & Exponential & .931 & 108.298 & 1 & 8 & .000 & .001 & .143 \\
\hline & Hwy 34 & Exponential & .663 & 13.748 & 1 & 7 & .008 & .004 & .131 \\
\hline & Greenbelt (i) & Exponential & .690 & 24.481 & 1 & 11 & .000 & .005 & .123 \\
\hline \multicolumn{10}{|l|}{ Conventional } \\
\hline & Hwy 28 & Exponential & .528 & 8.959 & 1 & 8 & .017 & .011 & .106 \\
\hline & Hwy 16 & Exponential & .683 & 27.957 & 1 & 13 & .000 & .009 & .119 \\
\hline & Hwy 17 & Exponential & .442 & 6.341 & 1 & 8 & .036 & .126 & .087 \\
\hline & Hwy 417 & Exponential & .395 & 8.481 & 1 & 13 & .012 & .050 & .101 \\
\hline & Greenbelt (ii) & Exponential & .568 & 6.587 & 1 & 5 & .050 & .755 & .065 \\
\hline
\end{tabular}

The independent variable is Relative Density.

Model Summary and Parameter Estimates

Dependent Variable: Strength

\begin{tabular}{|ll|r|r|r|r|r|r|r|}
\hline \multirow{2}{*}{$\begin{array}{l}\text { Mompaciton } \\
\text { Method }\end{array}$} & \multicolumn{6}{|c|}{ Equation } & \multicolumn{2}{c|}{$\begin{array}{c}\text { Parameter } \\
\text { Estimates }\end{array}$} \\
\cline { 3 - 9 } & & $\begin{array}{c}\text { R } \\
\text { Square }\end{array}$ & F & df1 & df2 & Sig. & $\begin{array}{c}\text { Constan } \\
\mathrm{t}\end{array}$ & $\mathrm{b} 1$ \\
\hline Advanced & Exponential & .071 & 4.199 & 1 & 55 & .045 & 1.079 & .063 \\
Conventional & Exponential & .340 & 36.055 & 1 & 70 & .000 & .000 & .147 \\
\hline
\end{tabular}

The independent variable is Relative Density. 
Model Summary and Parameter Estimates

Dependent Variable: Strength

\begin{tabular}{|l|r|r|r|r|r|r|r|}
\hline \multirow{2}{*}{ Equation } & \multicolumn{4}{|c|}{ Model Summary } & \multicolumn{2}{c|}{ Parameter Estimates } \\
\cline { 2 - 8 } & R Square & F & df1 & \multicolumn{1}{c|}{ df2 } & Sig. & Constant & b1 \\
\hline Exponential & .208 & 33.410 & 1 & 127 & .000 & .013 & .111 \\
\hline
\end{tabular}

The independent variable is Relative Density.

\section{B.3 Relative Density-Permeability}

\section{SGC Specimens}

Model Summary and Parameter Estimates

Dependent Variable: Per

\begin{tabular}{|c|c|c|c|c|c|c|c|c|}
\hline \multirow[t]{2}{*}{ Site } & \multirow[t]{2}{*}{ Equation } & \multicolumn{5}{|c|}{ Model Summary } & \multicolumn{2}{|c|}{$\begin{array}{l}\text { Parameter } \\
\text { Estimates }\end{array}$} \\
\hline & & R Square & $\mathrm{F}$ & df1 & $\mathrm{df2}$ & Sig. & Constant & b1 \\
\hline Hwy 15 Mix & Power & .807 & 20.945 & 1 & 5 & .006 & 3.371 & -31.798 \\
\hline Hwy 16 Mix & Power & .905 & 47.489 & 1 & 5 & .001 & .461 & -43.710 \\
\hline Highway 17 Mix & Power & .967 & 145.175 & 1 & 5 & .000 & .651 & -48.479 \\
\hline Hwy 417 Mix & Power & .825 & 47.156 & 1 & 10 & .000 & .292 & -52.163 \\
\hline
\end{tabular}

The independent variable is Density_Percentage.

Model Summary and Parameter Estimates

Dependent Variable: Per

\begin{tabular}{|l|r|r|r|r|r|r|r|}
\hline \multirow{2}{*}{ Equation } & \multicolumn{4}{|c|}{ Model Summary } & \multicolumn{2}{c|}{ Parameter Estimates } \\
\cline { 2 - 9 } & R Square & F & df1 & df2 & Sig. & Constant & b1 \\
\hline Power & .812 & 133.607 & 1 & 31 & .000 & .737 & -43.781 \\
\hline
\end{tabular}

The independent variable is Density_Percentage. 


\section{Field-Recovered Cores}

Model Summary and Parameter Estimates

Dependent Variable: Lab_Permeability

\begin{tabular}{|c|c|c|c|c|c|c|c|c|c|}
\hline \multirow[t]{2}{*}{ Compaction_Method } & \multirow[t]{2}{*}{ Site } & \multirow[t]{2}{*}{ Equation } & \multicolumn{5}{|c|}{ Model Summary } & \multicolumn{2}{|c|}{ Parameter Estimates } \\
\hline & & & $\begin{array}{c}\mathrm{R} \\
\text { Square }\end{array}$ & $\mathrm{F}$ & df1 & df2 & Sig. & $\begin{array}{c}\text { Constan } \\
\mathrm{t}\end{array}$ & b1 \\
\hline \multirow[t]{3}{*}{ Advanced } & Greenbelt (ii) & Power & .795 & 31.030 & 1 & 8 & .001 & .082 & -62.668 \\
\hline & Greenbelt (i) & Power & .229 & 3.571 & 1 & 12 & .083 & .018 & -77.921 \\
\hline & Hwy 34 & Power & .529 & 8.998 & 1 & 8 & .017 & .000 & -140.953 \\
\hline \multirow[t]{4}{*}{ Conventional } & Hwy 16 & Power & .345 & 6.853 & 1 & 13 & .021 & 2.745 & -29.571 \\
\hline & hwy 17 & Power & .170 & 2.461 & 1 & 12 & .143 & .544 & -54.788 \\
\hline & Hwy 417 & Power & .219 & 3.645 & 1 & 13 & .079 & .084 & -70.715 \\
\hline & Greenbelt (ii) & Power & .359 & 3.359 & 1 & 6 & .117 & .352 & -57.854 \\
\hline
\end{tabular}

The independent variable is Relative_Density.

\section{Model Summary and Parameter Estimates}

Dependent Variable: Lab_Permeability

\begin{tabular}{|c|c|c|c|c|c|c|c|c|}
\hline \multirow[t]{2}{*}{$\begin{array}{l}\text { Compaction_Meth } \\
\text { od }\end{array}$} & \multirow[t]{2}{*}{ Equation } & \multicolumn{5}{|c|}{ Model Summary } & \multicolumn{2}{|c|}{$\begin{array}{l}\text { Parameter } \\
\text { Estimates }\end{array}$} \\
\hline & & $\begin{array}{c}\mathrm{R} \\
\text { Square }\end{array}$ & $\mathrm{F}$ & df1 & df2 & Sig. & Constant & b1 \\
\hline Advanced & Power & .489 & 30.682 & 1 & 32 & .000 & .017 & -82.042 \\
\hline Conventional & Power & .564 & 64.773 & 1 & 50 & .000 & .351 & -54.930 \\
\hline
\end{tabular}

The independent variable is Relative_Density.

\section{Model Summary and Parameter Estimates}

Dependent Variable: Lab_Permeability

\begin{tabular}{|c|c|c|c|c|c|c|c|}
\hline \multirow[t]{2}{*}{ Equation } & \multicolumn{5}{|c|}{ Model Summary } & \multicolumn{2}{|c|}{ Parameter Estimates } \\
\hline & R Square & $\mathrm{F}$ & $\mathrm{df1}$ & df2 & Sig. & Constant & b1 \\
\hline Power & .495 & 82.423 & 1 & 84 & .000 & .173 & -59.574 \\
\hline
\end{tabular}

The independent variable is Relative_Density. 


\section{Field Measurements}

Model Summary and Parameter Estimates

Dependent Variable: Field Permeability

\begin{tabular}{|c|c|c|c|c|c|c|c|c|c|}
\hline \multirow{2}{*}{$\begin{array}{l}\text { Compaction } \\
\text { Method }\end{array}$} & \multirow[t]{2}{*}{ Site } & \multirow{2}{*}{$\begin{array}{l}\text { Equati } \\
\text { on }\end{array}$} & \multicolumn{5}{|c|}{ Model Summary } & \multicolumn{2}{|c|}{ Parameter Estimates } \\
\hline & & & $\begin{array}{c}\mathrm{R} \\
\text { Square }\end{array}$ & $\mathrm{F}$ & df1 & $\mathrm{df} 2$ & Sig. & Constant & b1 \\
\hline \multirow[t]{6}{*}{ Conventional } & Tomlinson & Power & .054 & .288 & 1 & 5 & .615 & 16.690 & -21.028 \\
\hline & Thousand Islands Parkway & Power & .095 & .209 & 1 & 2 & .693 & $1.965 \mathrm{E}-005$ & -258.017 \\
\hline & Highway 28 & Power & .325 & 3.848 & 1 & 8 & .085 & 2.790 & -39.087 \\
\hline & Highway 16 & Power & .061 & .776 & 1 & 12 & .396 & 46.088 & -9.446 \\
\hline & Highway 17 & Power & .196 & 3.165 & 1 & 13 & .099 & 30.519 & -21.789 \\
\hline & Highway 417 & Power & .128 & 1.765 & 1 & 12 & .209 & 3.083 & -33.981 \\
\hline \multirow[t]{5}{*}{ Advanced } & Tomlinson & Power & .634 & 8.652 & 1 & 5 & .032 & 1.794 & -31.835 \\
\hline & Thousand Islands Parkway & Power & .523 & 3.287 & 1 & 3 & .167 & .011 & -127.734 \\
\hline & Highway 28 & Power & .741 & 22.929 & 1 & 8 & .001 & .573 & -46.188 \\
\hline & Greenbelt (i) & Power & .021 & .043 & 1 & 2 & .855 & 67.731 & 9.049 \\
\hline & Highway 34 Bridge & Power & .428 & 2.994 & 1 & 4 & .159 & 5.755 & -39.058 \\
\hline
\end{tabular}

The independent variable is Density_Percentage.

\section{Model Summary and Parameter Estimates}

Dependent Variable: Field Permeability

\begin{tabular}{|c|c|c|c|c|c|c|c|c|}
\hline \multirow[t]{2}{*}{$\begin{array}{l}\text { Compaction } \\
\text { Method }\end{array}$} & \multirow[t]{2}{*}{ Equation } & \multicolumn{5}{|c|}{ Model Summary } & \multicolumn{2}{|c|}{$\begin{array}{l}\text { Parameter } \\
\text { Estimates }\end{array}$} \\
\hline & & $\begin{array}{c}\mathrm{R} \\
\text { Square }\end{array}$ & $\mathrm{F}$ & df1 & df2 & Sig. & Constant & b1 \\
\hline Conventional & Power & .223 & 17.843 & 1 & 62 & .000 & 10.745 & -25.443 \\
\hline Advanced & Power & .496 & 29.518 & 1 & 30 & .000 & 1.402 & -42.249 \\
\hline
\end{tabular}

The independent variable is Density_Percentage.

\section{Model Summary and Parameter Estimates}

Dependent Variable: Field Permeability

\begin{tabular}{|c|c|c|c|c|c|c|c|}
\hline \multirow[t]{2}{*}{ Equation } & \multicolumn{5}{|c|}{ Model Summary } & \multicolumn{2}{|c|}{ Parameter Estimates } \\
\hline & R Square & $\mathrm{F}$ & df1 & $\mathrm{df} 2$ & Sig. & Constant & b1 \\
\hline Power & .291 & 38.619 & 1 & 94 & .000 & 4.950 & -32.197 \\
\hline
\end{tabular}

The independent variable is Density_Percentage. 


\section{B.4 IDT-Permeability}

\section{SGC Specimens}

Model Summary and Parameter Estimates

Dependent Variable: Per

\begin{tabular}{|ll|r|r|r|r|r|r|r|}
\hline \multirow{2}{*}{ Site } & \multirow{4}{*}{ Equation } & \multicolumn{4}{|c|}{ Model Summary } & \multicolumn{3}{|c|}{$\begin{array}{c}\text { Parameter } \\
\text { Estimates }\end{array}$} \\
\cline { 3 - 9 } & & R Square & \multicolumn{1}{|c|}{ F } & \multicolumn{1}{c|}{ df1 } & df2 & Sig. & Constant & b1 \\
\hline Hwy 15 Mix & Exponential & .768 & 16.558 & 1 & 5 & .010 & 1015.851 & -.004 \\
Hwy 16 Mix & Exponential & .937 & 74.724 & 1 & 5 & .000 & 1128.440 & -.006 \\
Highway 17 Mix & Exponential & .931 & 67.582 & 1 & 5 & .000 & 2291.183 & -.008 \\
Hwy 417 Mix & Exponential & .832 & 49.537 & 1 & 10 & .000 & 1408.806 & -.005 \\
\hline
\end{tabular}

The independent variable is Strength .

Model Summary and Parameter Estimates

Dependent Variable: Per

\begin{tabular}{|l|r|r|r|r|r|r|r|}
\hline \multirow{2}{*}{ Equation } & \multicolumn{4}{|c|}{ Model Summary } & \multicolumn{2}{c|}{ Parameter Estimates } \\
\cline { 2 - 8 } & R Square & $\mathrm{F}$ & $\mathrm{df1}$ & $\mathrm{df2}$ & \multicolumn{1}{c|}{ Sig. } & Constant & b1 \\
\hline Exponential & .737 & 86.679 & 1 & 31 & .000 & 836.270 & -.005 \\
\hline
\end{tabular}

The independent variable is Strength . 


\section{Field-Recovered Cores}

Model Summary and Parameter Estimates

Dependent Variable: Lab Permeability

\begin{tabular}{|c|c|c|c|c|c|c|c|c|c|}
\hline \multirow{2}{*}{$\begin{array}{l}\text { Compaction } \\
\text { Method }\end{array}$} & \multirow[t]{2}{*}{ Site } & \multirow[t]{2}{*}{ Equation } & \multicolumn{5}{|c|}{ Model Summary } & \multicolumn{2}{|c|}{ Parameter Estimates } \\
\hline & & & $\begin{array}{c}\mathrm{R} \\
\text { Square } \\
\end{array}$ & $\mathrm{F}$ & df1 & df2 & Sig. & Constant & b1 \\
\hline \multirow[t]{4}{*}{ Conventional } & Hwy 16 & Exponential & .448 & 10.554 & 1 & 13 & .006 & 475.514 & -.005 \\
\hline & Hwy 17 & Exponential & .839 & 51.957 & 1 & 10 & .000 & 11899.198 & -.015 \\
\hline & Hwy 17 & Exponential & .756 & 37.266 & 1 & 12 & .000 & 1000.213 & -.008 \\
\hline & Greenbelt (ii) & Exponential & .331 & 2.469 & 1 & 5 & .177 & 236159.218 & -.025 \\
\hline \multirow[t]{3}{*}{ Advanced } & Greenbelt (ii) & Exponential & .674 & 16.512 & 1 & 8 & .004 & 1255.387 & -.011 \\
\hline & Hwy 34 & Exponential & .714 & 17.444 & 1 & 7 & .004 & 1145174.321 & -.017 \\
\hline & Greenbelt (i) & Exponential & .497 & 7.898 & 1 & 8 & .023 & 191370.070 & -.023 \\
\hline
\end{tabular}

The independent variable is IDT.

\section{Model Summary and Parameter Estimates}

Dependent Variable: Lab Permeability

\begin{tabular}{|lr|r|r|r|r|r|r|r|}
\hline \multirow{2}{*}{ Compaction Method Equation } & \multicolumn{4}{|c|}{ Model Summary } & \multicolumn{2}{c|}{ Parameter Estimates } \\
\cline { 3 - 9 } & & R Square & \multicolumn{1}{c|}{$\mathrm{F}$} & $\mathrm{df1}$ & $\mathrm{df2}$ & \multicolumn{1}{c|}{ Sig. } & Constant & $\mathrm{b} 1$ \\
\hline Conventional & Exponential & .691 & 102.762 & 1 & 46 & .000 & 2319.067 & -.009 \\
Advanced & Exponential & .052 & 1.471 & 1 & 27 & .236 & 63.793 & -.003 \\
\hline
\end{tabular}

The independent variable is IDT.

\section{Model Summary and Parameter Estimates}

Dependent Variable: Lab Permeability

\begin{tabular}{|l|r|r|r|r|r|r|r|}
\hline \multirow{2}{*}{ Equation } & \multicolumn{9}{|c|}{ Model Summary } & \multicolumn{2}{c|}{ Parameter Estimates } \\
\cline { 2 - 9 } & R Square & F & df1 & df2 & Sig. & Constant & b1 \\
\hline Exponential & .428 & 56.074 & 1 & 75 & .000 & 857.151 & -.008 \\
\hline
\end{tabular}

The independent variable is IDT. 


\section{Field Measurements}

Model Summary and Parameter Estimates

Dependent Variable: IDT

\begin{tabular}{|c|c|c|c|c|c|c|c|c|c|}
\hline \multirow[t]{2}{*}{$\begin{array}{l}\text { Compaction } \\
\text { Method }\end{array}$} & \multirow[t]{2}{*}{ Site } & \multirow[t]{2}{*}{ Equation } & \multicolumn{5}{|c|}{ Model Summary } & \multicolumn{2}{|c|}{$\begin{array}{l}\text { Parameter } \\
\text { Estimates }\end{array}$} \\
\hline & & & $\begin{array}{c}\mathrm{R} \\
\text { Square } \\
\end{array}$ & $\mathrm{F}$ & df1 & df2 & Sig. & Constant & b1 \\
\hline \multirow[t]{6}{*}{ Conventional } & Tomlinson & Power & .175 & 1.060 & 1 & 5 & .350 & 300.492 & -.048 \\
\hline & Thousand Islands Parkway & Power & .004 & .012 & 1 & 3 & .919 & 569.017 & -.015 \\
\hline & Hwy 28 & Power & .677 & 16.784 & 1 & 8 & .003 & 356.886 & -.158 \\
\hline & Hwy 16 & Power & .046 & .583 & 1 & 12 & .460 & 684.913 & -.079 \\
\hline & Hwy 17 & Power & .457 & 8.412 & 1 & 10 & .016 & 1221.614 & -.219 \\
\hline & Hwy 417 & Power & .003 & .038 & 1 & 12 & .849 & 664.754 & -.009 \\
\hline \multirow[t]{4}{*}{ Advanced } & Tomlinson & Power & .028 & .143 & 1 & 5 & .721 & 329.576 & -.036 \\
\hline & Thousand Islands Parkway & Power & .295 & 1.255 & 1 & 3 & .344 & 578.617 & -.020 \\
\hline & Hwy 28 & Power & .081 & 1.061 & 1 & 12 & .323 & 338.599 & -.128 \\
\hline & Hwy 34 & Power & .032 & .134 & 1 & 4 & .733 & 744.921 & -.039 \\
\hline
\end{tabular}

The independent variable is Field Permeability.

Dependent Variable: IDT

\section{Model Summary and Parameter Estimates}

\begin{tabular}{|c|c|c|c|c|c|c|c|c|}
\hline \multirow[t]{2}{*}{$\begin{array}{l}\text { Compaction } \\
\text { Method }\end{array}$} & \multirow[t]{2}{*}{ Equation } & \multicolumn{5}{|c|}{ Model Summary } & \multicolumn{2}{|c|}{$\begin{array}{l}\text { Parameter } \\
\text { Estimates }\end{array}$} \\
\hline & & $\begin{array}{c}\mathrm{R} \\
\text { Square }\end{array}$ & $F$ & df1 & df2 & Sig. & Constant & $\mathrm{b} 1$ \\
\hline $\begin{array}{l}\text { Conventional } \\
\text { Advanced }\end{array}$ & $\begin{array}{l}\text { Power } \\
\text { Power }\end{array}$ & $\begin{array}{l}.241 \\
.036\end{array}$ & $\begin{array}{r}19.969 \\
1.114\end{array}$ & $\begin{array}{l}1 \\
1\end{array}$ & $\begin{array}{l}63 \\
30\end{array}$ & $\begin{array}{l}.000 \\
.300\end{array}$ & $\begin{array}{r}1095.373 \\
241.991\end{array}$ & $\begin{array}{r}-.243 \\
.086\end{array}$ \\
\hline
\end{tabular}

The independent variable is Field Permeability.

Model Summary and Parameter Estimates

Dependent Variable: IDT

\begin{tabular}{|l|r|r|r|r|r|r|r|}
\hline \multirow{2}{*}{ Equation } & \multicolumn{5}{|c|}{ Model Summary } & \multicolumn{2}{c|}{ Parameter Estimates } \\
\cline { 2 - 9 } & R Square & F & df1 & \multicolumn{1}{c|}{ df2 } & Sig. & Constant & b1 \\
\hline Power & .029 & 2.862 & 1 & 95 & .094 & 500.003 & -.078 \\
\hline
\end{tabular}

The independent variable is Field Permeability. 
